University of Warwick institutional repository: http://go.warwick.ac.uk/wrap

A Thesis Submitted for the Degree of PhD at the University of Warwick

http://go.warwick.ac.uk/wrap/45389

This thesis is made available online and is protected by original copyright.

Please scroll down to view the document itself.

Please refer to the repository record for this item for information to help you to cite it. Our policy information is available from the repository home page. 


\title{
Shakespeare and the Idea of Apocrypha:
}

Negotiating the Boundaries of the

\author{
Dramatic Canon
}

\author{
by \\ Peter Philip Kirwan
}

A thesis submitted in partial fulfilment of the requirements for the degree of Doctor of Philosophy in English Literature

University of Warwick, Department of English and Comparative Literary Studies

August 2011 
For my grandparents, Kathleen and Meynell Marshall

The leaning of sophists towards the bypaths of apocrypha is a constant quantity, John Eglinton detected. The highroads are dreary but they lead to the town.

- James Joyce, Ulysses 250.

All held Apocrypha, not worth survey.

- Antonio's Revenge 4.1.22. 


\section{Contents}

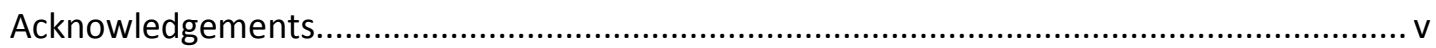

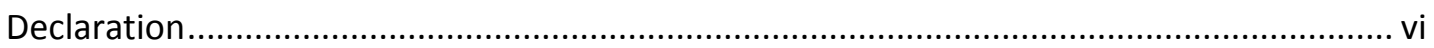

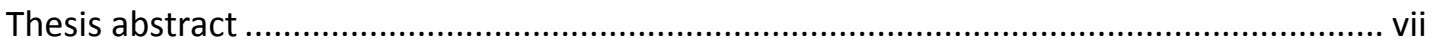

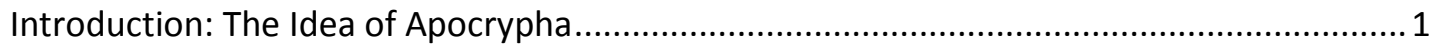

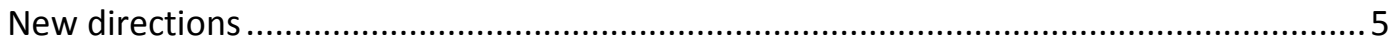

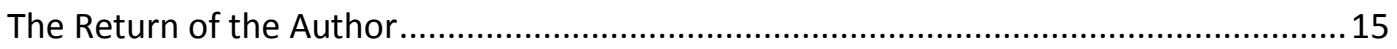

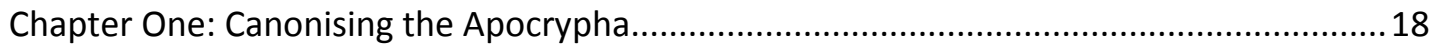

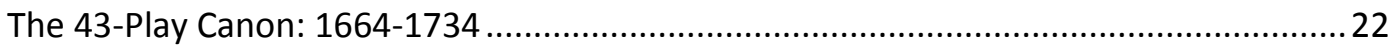

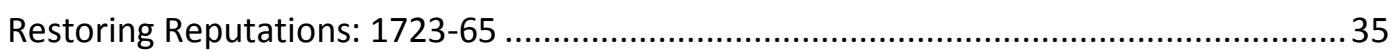

Biography, Chronology, Bardolatry: 1760-1844 …..................................................... 48

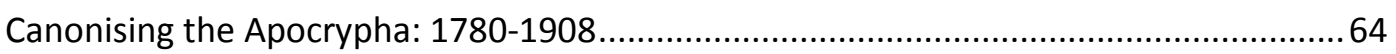

C.F. Tucker Brooke and the canonising of the Apocrypha .............................................. 88

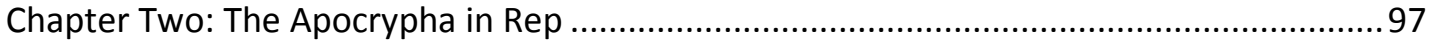

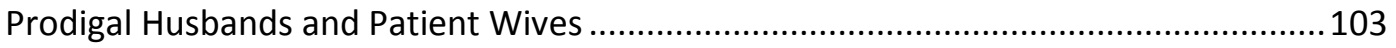

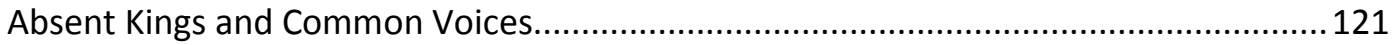

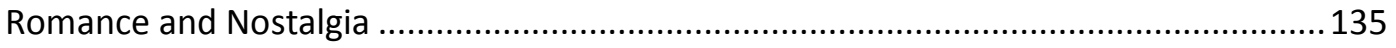

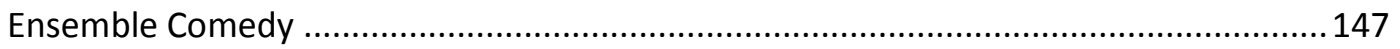

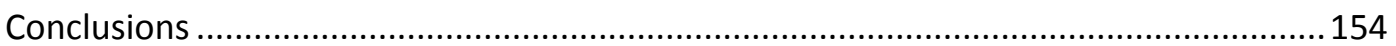

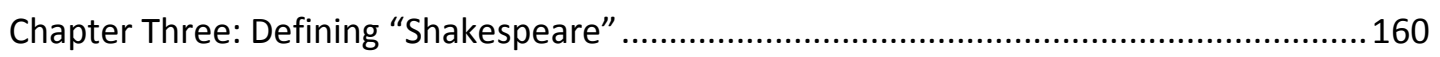

The Shakespearean corpse: physical traces of Shakespeare .............................................. 165

Sample Size, the "problem" of revision, and Locrine ......................................................177

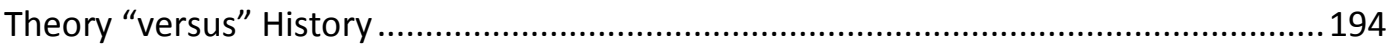

The integration of disintegration: Edward III and Arden of Faversham ..........................205

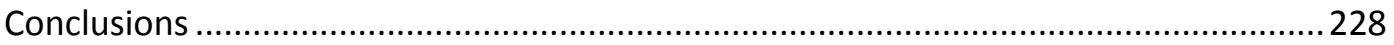

Chapter Four: Apocryphising the Canon ............................................................................. 231

The [Bibliographic] Complete Works of Shakespeare .................................................238

The [Authorial] Works of William Shakespeare [and Thomas Middleton] ......................255

The [Performative] Complete Works of Shakespeare ....................................................266

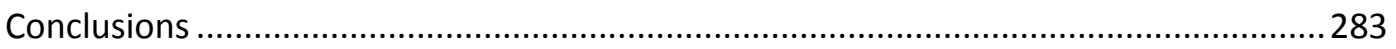

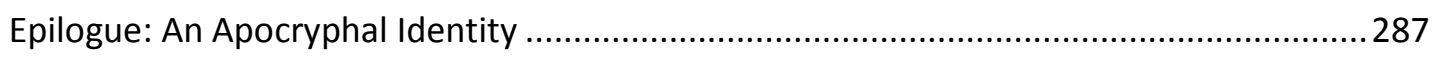

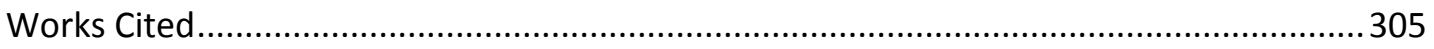




\section{List of illustrations}

Fig. 1. Frontispiece and title-page of the third Shakespeare Folio (1664).

Fig. 2. Title page of Tyrrell, Henry, ed., The Doubtful Plays of Shakspere (1853?)... 82

Fig. 3. Title pages of The London Prodigal (1605) and A Yorkshire Tragedy (1608). 105

Fig. 4. Title page of Locrine (1595) 184 


\section{Acknowledgements}

As this thesis will demonstrate, the presence of a single name on a title page rarely does justice to the number of agents who made it possible. While there isn't space here to thank everyone, I would like to acknowledge my more prominent "collaborators".

My greatest debt is to my supervisor, Jonathan Bate, who gave me the opportunity to write this thesis in conjunction with his forthcoming edition of disputed plays. Jonathan's intellectual guidance and professionalism have been invaluable throughout. My mentor, Paul Prescott, has also gone beyond the call of duty with his support and feedback. I hope that this thesis does justice to their patience and encouragement. The other members of my research team - Eric Rasmussen, Jan Sewell and Will Sharpe - have been a pleasure to work with, and I'm particularly grateful to Will for many stimulating conversations. Carol Rutter, Susan Brock and Nick Monk have been inspiring colleagues and friends. I am grateful for the support of the English faculty at Warwick, and to my past Shakespeare teachers: Mike Devitt, Tim Kershaw, Charlotte Scott and Tony Howard.

I have benefited from the generosity of several scholars who have kindly sent me advance copies of work. Thanks to David Carnegie, Ward Elliott, Brean Hammond, Christa Jansohn, John Jowett, Edmund King, Thomas Merriam, Richard Proudfoot, Bernard Richards, Emma Smith, Tiffany Stern, Gary Taylor and Brian Vickers, this thesis is significantly more up to date than it might have been.

The Arts and Humanities Research Council provided a grant that allowed me to devote myself to the project full time, and travel grants from the ISA and SAA enabled me to present at their meetings in 2011. Parts of this thesis have been trialled at conferences, and I would like to thank Adam Hooks, Lisa Hopkins, Helen Ostovich, Matt Kubus and Emily Oliver for invitations that proved especially useful. I would also like to thank the students of the Warwick Shakespeare Society who invited me to act as dramaturge for their rehearsed reading of Double Falsehood, a rich and informative experience.

The expertise of staff at the Shakespeare Institute Library, Shakespeare Birthplace Trust and the Rare Books and Reading Room of the British Library has been most helpful. The majority of this PhD was written in the Wolfson Research Exchange at Warwick Library, and I would like to thank the team for creating such a conducive environment. The administrative staff in the English office have been a source of information and good humour, and Peter Larkin and Cath Hanley have provided valuable technical advice.

Most important are the real-world contexts that have kept me healthy and sane for the duration of the project. I am lucky to have an extraordinary group of friends in Warwick, Stratford and London, who have made the PhD experience a pleasure. I owe particular debts to Charlotte Mathieson, who is still an inspiration, and to Andy Kesson, who has been a constant source of encouragement and an enthusiastic reader. I would also like to thank Kate Scarth for her generosity, and Sara Thompson, who was right. My parents, Paul and Barbara, have insisted throughout on the importance of self-belief, and their support has made the last three years possible. Mark, Ruth and Sharon have kept me grounded in family, and Fionnuala O'Neill kept me smiling in the final stages. Final thanks go to Persephone for providing much-needed perspective. She would have enjoyed sitting on the finished product. 


\section{Declaration}

This thesis is my own work; no part of it has been submitted for a degree at another university. No part of the thesis has been published elsewhere except the appendix, "The First Collected 'Shakespeare Apocrypha'”, which is a reprint of an article forthcoming in Shakespeare Quarterly and is reproduced here for reference. 


\section{Thesis abstract}

Shakespeare and the Idea of Apocrypha offers the most comprehensive study to date of an intriguing but understudied body of plays. It undertakes a major reconsideration of the processes that determine the constitution of the Shakespeare canon through study of that canon's exclusions. This thesis combines historical analysis of the emergence and development of the "Shakespeare Apocrypha" with current theorisations of dramatic collaboration.

Several new theoretical and historical approaches to early modern authorship have emerged in the last decade. This thesis breaks new ground by bringing them together to demonstrate the untenability of the dichotomy between Canon and Apocrypha. Both within and without the text, the author is only one of several factors that shape the plays, and canonical boundaries are contingent rather than absolute.

Chapter One draws on the New Textualism and studies of material print attributions, viewing the construction of the apocryphal canon alongside the growth of Shakespeare's cultural prestige over three centuries. Chapter Two applies recent repertory studies to authorship questions, treating five anonymous King's Men's plays as part of a shared company practice that transcends authorial divisions. Chapter Three seeks dialogue between post-structuralist theory and "disintegrationist" work, revealing a shared concern with the plurality of agents within disputed plays. Within all three models of authorship, the divisions between "Shakespeare" and "not Shakespeare" are shown to be ambiguous and subjective.

The associations of many disputed plays with the Shakespeare canon are factual, not fanciful. The ambiguity of canonical boundaries ultimately demonstrates the insufficiency of the "Complete Works" model for study of Shakespeare's drama. Chapter Four confronts the commercial considerations that impose practical limitations on the organisation of plays. In so doing, this thesis establishes the theoretical principles by which the neglected plays of the Apocrypha can be readmitted into discourse, dispersing the fixed authority of the authorial canon. 


\section{Introduction: The Idea of Apocrypha}

\section{Falsehoods}

On April $2^{\text {nd }} 1796$, London's Drury Lane Theatre presented what was claimed to be a recently unearthed play by William Shakespeare. Vortigern and Rowena, "discovered" by William Henry Ireland, played to a derisive crowd, whose disbelief in the play's authenticity was shared by the theatre's manager, John Philip Kemble. Kemble, in the lead role, pointedly repeated the line "and when this solemn mock'ry is ended" (5.2.62), inviting ridicule from the crowd. The production was not revived, and the whole incident contributed to the unravelling of Ireland's claims. ${ }^{1}$

The authenticity of the play - along with the other purportedly Shakespearean documents unearthed by Ireland and his father Samuel - had been hotly disputed only a fortnight earlier by the leading Shakespearean editor of the day, Edmond Malone, in An Inquiry into the Authenticity of Certain Miscellaneous Papers and Legal Instruments:

It has been said, and I believe truly, that every individual of this country, whose mind has been at all cultivated, feels a pride in being able to boast of our great dramatick poet, Shakspeare, as his countryman: and proportionate to our respect and veneration for that extraordinary man ought to be our care of his fame, and of those valuable writings that he has left us; and our solicitude to preserve them pure and unpolluted by any modern sophistication or foreign admixture whatsoever. (2-3)

\footnotetext{
${ }^{1}$ Jeffrey Kahan provides the performance text and a useful introduction to Vortigern and the circumstances of its creation (3.1-175). For a recent account of the incident's implications for an understanding of Shakespeare's presence in print culture, see Tom Lockwood, "Manuscript".
} 
Malone brings together a series of preconceptions, priorities and duties to justify his project. Shakespeare is "our" poet, with the possessive also attached to "this country" and Shakespeare's "countrym[e]n". The tone of jingoistic nationalism is exaggerated by the fear of pollution by "foreign admixture", diluting Shakespeare's indigenous purity. Yet within these communal concerns, perhaps more importantly, is an emphasis on the "individual", the "poet", "that extraordinary man". Shakespeare, both man and works, is to be protected at all costs. The values that Malone articulates continue to underpin the phenomenon that is the concern of this thesis: the division between accepted and disputed works attributed to William Shakespeare, and the implications of this division for our study.

Margreta de Grazia identifies Malone as the Enlightenment editor who, she argues, constructed the modern Shakespeare "in his own experience, consciousness and creativity", removed from "discourse, production and reception". Shakespeare, through Malone's work, became the "exemplary instance of the autonomous self" (Verbatim 10). As such, he was finally entitled to a canon "that consists not only of authentic works, like the canonical books of Holy Scripture, but also of regulating and binding tenets, like those of church dogma, inferred from the very texts over which they preside and legislate" (11). For de Grazia, this is the point at which questions of authenticity, the individual and the sanctity of canon most importantly come into play on the question of Shakespearean authorship. It is this same preoccupation with individuality as guarantor of authenticity that informs Brian Vickers's statement, in his study of collaborative authorship, that "no issue in Shakespeare Studies is more important than determining what he wrote" (Shakespeare, Co-Author 3). The canonisation of Shakespeare would continue to be dominated in the modern era by the determination of "pure and unpolluted" works. 
Every religion has its heresy, however. As Trevor Ross points out, "the agonistic structures of rhetoric require that the canon be set against a discredited apocrypha" (77). ${ }^{2}$ Shakespeare's canon is one of the few non-theological bodies of works to be split into the two categories of "Canon" and "Apocrypha." ${ }^{3}$ The works attributed to Shakespeare vary in number, but Lindley Hubbell lists seventy-five plays associated with his name (A Note). Some - such as Vortigern and Rowena - have been dismissed as forgeries or attributed to other writers. Other plays, however, persist in the category, and the term "Apocrypha" continues to operate as short-hand for the group. ${ }^{4}$ The Apocrypha exists, then, as a rare example of a canon defined negatively by the question of authorship: they are the plays attributed to, but emphatically not by, Shakespeare.

The term "Apocrypha" has inescapably biblical associations. Deriving from the

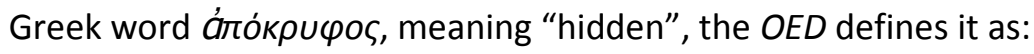

A writing or statement of doubtful authorship or authenticity; spec. those books included in the Septuagint and Vulgate versions of the Old Testament, which were not originally written in Hebrew and not counted genuine by the Jews, and which, at the Reformation, were excluded from the Sacred Canon by the Protestant party, as having no well-grounded claim to inspired authorship. (“Apocrypha, n.," def. 1a)

\footnotetext{
${ }^{2}$ See also James Shapiro on the anti-Stratfordian question as a different kind of heresy inspired by the Higher Criticism's effect on perceptions of scriptural authority (esp. 82-89).

${ }^{3}$ Many authors are associated with individual works of doubtful authorship, but I am concerned here with bodies of disputed work, a phenomenon usually associated with classical canonical authors, most obviously Homer and Virgil. Kathleen Forni, in 2005, published The Chaucerian Apocrypha: A Selection, a conscious attempt to associate another vernacular English writer with a secondary, disputed canon.

${ }^{4}$ E.g. Giorgio Melchiori, "those plays attributed to Shakespeare which go under the name of apocrypha" ("What Did Shakespeare Write" 340); Laurie E. Maguire, "the apocryphal work The London Prodigal" (Textual Formations 15); and Ward Elliott and Robert Valenza, whose use of phrases such as "middle dubitanda" ("Two Tough Nuts" [web version] 14) and "high apocrypha" (24) suggests a multi-tiered hierarchy even within the disputed canon.
} 
The biblical associations of the word point to the severity of the problem. As Robert Carroll and Stephen Prickett argue, the Bible as ratified by the early Church emerged as a holy book of a very different kind.

It encompassed the history of the world from its creation, through the fall and redemption of mankind, to the final judgement. Such completeness permitted no competition. The exclusiveness of the Bible was thus a direct concomitant of the exclusiveness of Christianity ... Unity was essential to this formula, not an extra. (xiv)

Elements of disunity were at direct odds with the project of the consolidation of canon and religion. "Excluded", "hidden", "uninspired", "historical error" - these words are similarly evoked in the use of the word "Apocrypha" to describe Shakespeare's disputed works, creating a category that casts the plays as somehow blasphemous while also implicitly pointing to those elements of disunity in the Shakespeare canon. While this thesis will challenge the appropriateness of the title, I will continue to use it throughout in recognition of the still-current negative associations attached to these plays.

The title was permanently attached to the plays by C.F. Tucker Brooke's seminal 1908 collection The Shakespeare Apocrypha, which "canonised" both the terminology for the group and the plays themselves, namely Arden of Faversham, Locrine, Edward III, Mucedorus, 1 Sir John Oldcastle, Thomas Lord Cromwell, The London Prodigal, The Puritan, A Yorkshire Tragedy, The Merry Devil of Edmonton, Fair Em, The Two Noble Kinsmen, The Birth of Merlin and Sir Thomas More. ${ }^{5}$ This group has remained surprisingly consistent over the last hundred years: The Two Noble Kinsmen has been promoted to canonical status, but even though certain others have been confidently attributed to

\footnotetext{
${ }^{5}$ It is perhaps no coincidence that the choice of fourteen plays even matches the number in most English editions of the Old Testament Apocrypha, where the Letter of Jeremiah is incorporated into the book of Baruch (Metzger $\mathrm{x}$ ). It is of note that Brooke, when conducting similar work on the constitution of the Marlowe canon in a major article of 1922, did not use the term "Apocrypha"; he reserves the term exclusively for Shakespeare's disputed plays ("Marlowe").
} 
other dramatists, the remainder retain an association with Shakespeare too strong to be dismissed, but too weak to render them canonical. This group has been supplemented by other plays since, most importantly Lewis Theobald's Double Falsehood and the anonymous Edmond Ironside and Thomas of Woodstock. Together, these plays form a deeply problematic group on the fringe of Shakespeare studies, tying Shakespeare to a range of collaborators, genres, themes and sensibilities that "pollute" the purity of the approved canon. Collectively, they highlight the indeterminacy of the canon, posing a threat to Shakespeare's ideological unity.

\section{New directions}

During the last twenty years, the notion of a pure, unpolluted canon has been challenged by several distinct theoretical movements that, combined, have destabilised the fixity and identity of "Shakespeare". Informed by post-structural approaches to notions of authorship, texts are increasingly understood as products of multiple agents and their environment rather than the sole offspring of an all-controlling Author. In textual theory, this has led to the debunking of many of the categories of authenticity postulated by the New Bibliographers in the early twentieth century. Alfred Pollard's distinction between "bad" and "good" quartos, for example, has been dismantled by Paul Werstine, who argues that the distinction between "good" and "bad" quartos is too neat, a product of desire rather than reason ("Narratives"). Werstine ("A Century") and Laurie Maguire (Suspect Texts) also argue that the "memorial reconstruction" theory of the New Bibliographers is insufficient to explain the idiosyncracies of most variant quartos. This dismantling of old orthodoxies has in turn led to widespread acceptance of the authority of variant versions of several of Shakespeare's plays, independent of linear textual genealogies. Gurr has argued that variant texts may represent different performance possibilities ("Maximal and Minimal") and Erne has revived the opinion that longer texts represent more literary versions of plays (Literary Dramatist). The 
unstable nature of the text, as articulated by Stephen Orgel ("What is a Text?") and Margreta de Grazia and Peter Stallybrass ("Materiality") underpins the recent movement in editorial practice towards the preservation of material realisations of the text. King Lear and Hamlet in particular are now frequently discussed as several plays rather than one, breaking down even in these key tragedies the idea of a "pure, unpolluted" version of a play.

All theatrical productions are, to a greater or lesser extent, collaborative ventures, made up of the contributions of multiple agencies including writers, actors, audiences, venues and censorship. Moreover, attribution studies have undergone a renaissance in the wake of increasingly sophisticated computer technology, and authorship investigators have identified widespread collaboration within the established Shakespeare canon. It is almost universally accepted that 1 Henry VI, Henry VIII, Pericles, Timon of Athens, Titus Andronicus and The Two Noble Kinsmen contain the work of other writers, while the other Henry VI plays, Macbeth and Measure for Measure all have advocates for the presence of multiple authors. ${ }^{6}$ The growing confidence in the attribution of parts of Thomas More and Edward III, and even Double Falsehood and Arden of Faversham to Shakespeare suggests that between a quarter and a third of the plays to which Shakespeare contributed contained "foreign admixture" in the form of the words of other writers. However, the dramatic Thomas More qualifies anxiety over foreignness: "Nay, anywhere that not adheres to England: / Why, you must needs be strangers (Sir Thomas More 6.145-46). ${ }^{7}$ More reminds us that foreignness, or

\footnotetext{
${ }^{6}$ Vickers (Co-Author) provides exhaustive surveys of the attribution scholarship underpinning the identification of collaborators in Timon, Titus, Henry VIII, Pericles and Kinsmen. He discusses 1 Henry VI in similar vein, but less detail, in "Incomplete Shakespeare". Disputes surrounding the other Henry VI plays have been more sporadic, but were initially prompted by Malone's 1787 dissertation on the plays and are revisited by Craig and Kinney. The question of the authorship of Macbeth and Measure for Measure is more recent and contentious, and is usefully summarised (with a bias towards a conclusion of collaboration) in Taylor and Lavagnino, Textual Culture 38398, 417-21.

${ }^{7}$ All quotations from Sir Thomas More are taken from Jowett, More.
} 
strangeness, is a relative matter, determined by context and viewpoint. That these words are most likely to have been written by Shakespeare for inclusion in a multipleauthored play reminds us of his own "strangeness" at this point. The collaborative "immigrants" are only such if we assume the sanctity of canon, rather than accept Shakespeare as a contributor to the collaborative drama of his day.

The idea of a fixed, authorially sanctioned Shakespeare canon can no longer be assured and is arguably not even desirable in the light of these movements. Studies over the last two decades have tended to subsume Shakespeare himself within the circumstances of collaborative production and his ongoing appropriability. Jeffrey Kahan notes that Vortigern and Rowena starred John Philip Kemble and Sarah Siddons, who were both established Shakespeareans, and their star power added a theatrical stamp of Shakespearean validity to the enterprise. The use of Shakespeare actors for New Shakespeare implicitly suggested a reassuring product stability; audiences almost certainly brought associations from the previous night's Shakespeare performance with them, and these perceptions influenced their acceptances of these new works. (1.xxxv-xxxvi)

The play was not "by" Shakespeare, but was produced and marketed as Shakespeare to raise a certain set of expectations and encourage a specific kind of reading. In a sense, Vortigern and Rowena became Shakespearean; it operated under the aegis of a Shakespeare "effect", where Shakespeare acted as a locus of responsibility, a governing function. ${ }^{8}$ That this function failed under the attacks of a sceptical cast and audience is indicative of the slipperiness of the author-function and the continual contestation of

\footnotetext{
${ }^{8}$ See discussion of Leah S. Marcus in the introduction to Chapter Two, below; also Jonathan Bate, Genius, which considers the "Shakespeare Effect" in a wider discourse of appropriation.
} 
what defines Shakespeare. While this postmodern treatment of authorship as

authorisation has been dismissed as unhelpfully theoretical and historically imprecise by many attribution scholars, all of these approaches seek to disrupt simple categorisations of author and text.

The notion of a "Shakespeare Apocrypha" defined by its inauthenticity cannot survive when the authenticity of the canon it is defined against is undermined. As James P. Bednarz notes, "the concept of a Shakespeare Apocrypha assumes an absolute distinction between authentic and fake versions of his plays and poems, since its very existence is predicated on the idea of a Shakespeare Canon against which it is defined" (252). If authenticity is, however, a relative rather than an absolute quality, then the plays of the Canon and Apocrypha exist at different points on a continuum, rather than in two diametrically opposed groups. It is later criticism, not a priori authorisation, which sustains the division.

The Apocrypha remains one of the least-studied aspects of Shakespeare's work. Full-length studies in English consist solely of H. Dugdale Sykes's Sidelights on Shakespeare (1919), an authorship study of several plays, and Baldwin Maxwell's Studies in the Shakespeare Apocrypha (1956) a useful textual study of Locrine, Thomas Lord Cromwell, The Puritan and A Yorkshire Tragedy, which aims to situate the plays in relation to an authentic canon and seeks to establish authorship. ${ }^{9}$ The reception received by Maxwell's volume speaks to the disregard in which the plays are held on account of their grouping together: G.K. Hunter remarks that "nothing except the accident of historical error now links these plays together" ("Review" 587), and I.B.

\footnotetext{
${ }^{9}$ Studies of individual plays are also few, and are primarily restricted to critical editions. Thomas More is the subject of Howard-Hill's collection Shakespeare and Sir Thomas More and McMillin's monograph The Elizabethan Theatre. Two indispensable reference resources are Logan and Smith, The Predecessors of Shakespeare, which discusses several of the earlier apocryphal plays in some detail (Edward III, Fair Em, Mucedorus, Arden of Faversham, Locrine, Woodstock), and Metz, Sources of Four Plays, which gives detailed introductions to More, Edward III, Cardenio and Kinsmen.
} 
Cauthen Jr argues that "Except for the specialist, no-one reads the apocryphal

Shakespeare; this able study clearly shows that there is no reason that we should" (292).

Cauthen's review rather misses the point of Maxwell's volume, which does not invite a qualitative dismissal of the plays, but instead points towards a different series of connections between the plays. "Historical error" remains, of course, part of history; whatever the reasons underpinning the plays' associations with Shakespeare, they continue to be connected by the shared and mutually reinforcing response that they are not by Shakespeare and are (therefore) of little worth.

For much of the twentieth century, as evidenced by Cauthen's remarks, the issue of the Apocrypha was easy to avoid on grounds of aesthetic judgement; but while the problematic category has become urgent in the wake of developments in textualcanonical theory, this has only been directly addressed in recent years by three scholars: Christa Jansohn ("The Shakespeare Apocrypha: A Reconsideration"), Richard Proudfoot ("Is There, and Should There Be, a Shakespeare Apocrypha?") and John Jowett ("Shakespeare Supplemented"). ${ }^{10}$ These three posit new approaches to the idea of an Apocrypha that inform respectively the first three chapters of this thesis, as follows.

Jansohn argues that the Canon is "a historically grown, not a universally available fixed construct" ("Reconsideration" 324) and quotes Frank Kermode: "[C]anons are essentially strategic constructs by which societies maintain their own interest, since the canon allows control over the texts a culture takes seriously and over the methods of interpretation that establish the meaning of 'serious'" (qtd. In "Reconsideration" 32425). Jansohn contends that the Shakespeare canon is constructed according to the editorial biases and socio-economic prerogatives of the time, rather than being subject

\footnotetext{
${ }^{10}$ Jansohn's article is a reworking in English of the first chapter of her Zweifelhafter Shakespeare. This important monograph is only available in German; but "A Reconsideration" summarises the main points. Another English language article, "Ludwig Tieck", offers a useful compression of the monograph's work on nineteenth-century German responses to the Apocrypha.
} 
to any firm or objective criteria. It cements "a repository of universally 'valuable' texts" (329) that in turn acts to cast its exclusions as qualitatively inferior, thus occasioning a lack of interest in interpretational issues. The processes of canonisation, of which Malone was a significant part, form the subject of my first chapter, which interrogates how the category of Apocrypha came to be created, and the processes and ideologies which governed its inception. Extending de Grazia's discussion of Malone and the posthumous construction of authorship and authenticity, the chapter examines how Shakespeare was sold and reproduced in early modern book culture. The divisions between authentic and inauthentic were informed by a variety of political and artistic motivations that bear little resemblance to modern scholarly standards, and I read the work of editors "locally", in Leah Marcus's use of the term (Puzzling 36), to draw attention to how decisions were informed by their historical moment. By unpacking the history of the apocryphal canon, we can move away from received notions of the quality of the plays to an understanding of their importance in constructing the modern Shakespeare. Key to this is acknowledgement of the material forms of "Shakespeare" available to early readers. Following recent work by scholars such as Sonia Massai (Rise of the Editor) and Emma Smith ("Such Readers We Wish Him"), the chapter frequently departs from the traditional linear editorial tradition, which is retrospectively biased towards those texts that most reflect modern editorial standards, to consider lesserknown appearances of the disputed plays that were less influential on later developments in textual theory, but testify to how Shakespeare was experienced historically.

Richard Proudfoot confronts the implications of "Apocrypha" within the word's biblical context as "doctrinally unacceptable" ("Is There?" 49) and traces the history of the need to categorise the plays. Importantly, he notes that until the eighteenth century, there was an "absence of sustained concern with the nature or quality" (57) of 
the disputed plays; before the Shakespeare canon was stabilised, these judgements were rarely employed in relation to authenticity. He notes that Shakespeare's role as an in-house dramatist meant that he may well have been involved in the revising and fitting-up of plays for performance, which necessarily complicates our understanding of what Shakespeare "wrote" ${ }^{11}$ He argues that it may be more productive to instead focus on companies and repertory systems, and abolish the "Apocrypha" in favour of "Shakespeare's unattributed repertoire" (65), which could take into consideration the anonymous and disputed plays from the playing companies of which Shakespeare was a member. ${ }^{12}$ Proudfoot's suggestion is consistent with an emerging critical interest in theatre companies as an alternative paradigm to authorial canons. Roslyn Knutson, Scott McMillin and Sally-Beth Maclean, Andrew Gurr and Lucy Munro all treat plays as emerging from a socialised network. ${ }^{13}$ This has much in common with post-structural theories of discursive authorship, but has a clearer historical basis that resists the easy dismissal of "theory" in opposition to "history" that Vickers posits in Shakespeare, CoAuthor. The concern in Chapter Two is thus on how this repertory focus disrupts simple dichotomies between the "Shakespearean" and the "non-Shakespearean" in the plays' historical context, focusing on those disputed plays that were performed by the Chamberlain's-King's Men and their role in contributing to a "Shakespeare effect".

Jowett, elsewhere a contributor to attribution studies, offers a textual history of the formation of the Shakespeare Apocrypha in "Shakespeare Supplemented", and covers much of the contextual ground shared by Jansohn and Proudfoot. For Jowett, it is

\footnotetext{
${ }^{11}$ See also Grace loppolo for a detailed account of Shakespeare's revising practices.

12 Jansohn refers to Proudfoot as "The Nestor of apocrypha studies" ("Reconsideration" 329). While his long-awaited edition of the Apocrypha has now been abandoned in favour of his new Arden Edward III (forthcoming), the articles that his research has produced have been deeply influential. See also "Canon", which offers another important overview of the question of constitution, "The Reign of King Edward the Third", "Shakespeare's Most Neglected Play" and "Modernising".

${ }^{13}$ Knutson, Repertory and Playing Companies; McMillin and Maclean, The Queen's Men; Gurr, Company and Opposites; Munro, Queen's Revels.
} 
specifically attribution studies and the identification of collaboration that renders the apocryphal category "redundant": "the suggestions of holy writ embodied in the terms 'canon' and 'Apocrypha' become much less compelling once we envision Shakespeare as a collaborating dramatist" (39-40). Jowett shows how, historically, the notion of impurities in the canon renders canon itself a problematic category, and he recommends in turn that the Apocrypha be seen as a supplement rather than an "other". He proposes that

the dichotomy of 'canon' and 'Apocrypha' can be replaced with a gradualist model of Shakespeare's works that recognises that even the play of purest Shakespeare authorship is susceptible to minor modifications on the part of that familiar procession of actors, playbook annotators, scribes stationers, and compositors. (66)

Jowett's language here draws attention to a prevalent treatment of single authorship as a "pure" phenomenon, and collaboration as "modifying" this perceived norm. Jeffrey Masten, in his provocative Textual Intercourse, inveighs heavily against the use of language biased in preference of single authorship, pointing out that collaboration was "the dominant mode of textual production" (Intercourse 14). Nonetheless, Jowett articulates the importance of degree rather than kind in determining the distinction between plays attributed to Shakespeare.

My third chapter goes to the heart of this negotiation between plays of disputed authorship. This thesis does not seek to advance new claims for the identity of the writers of any of these plays. Authorship studies of various apocryphal plays have been carried out recently by, among others, Brian Vickers, Jonathan Hope, Hugh Craig and Arthur Kinney, MacDonald P. Jackson, Thomas Merriam and the Shakespeare Clinic of 
Ward Elliott and Robert Valenza. ${ }^{14}$ These studies are sophisticated and utilise the latest theoretical and technological approaches to the question of authorship. However, little attempt has been made to integrate these studies effectively with literary criticism; and the larger meta-questions of the use and purpose of attribution studies for the effective reading of plays have too often been lost beneath polemic, a situation that this thesis seeks to redress. Vickers and Masten adopt opposing positions: Masten argues that attribution studies are overly determined and operate against the essential fabric of dramatic creation, while Vickers counters that theoretical approaches are ahistorical and operate against basic common sense. Gordon McMullan and John Jowett have advanced more moderate and dramatically inflected positions. ${ }^{15}$ Chapter Three intervenes in these debates to offer a productive approach for engaging with both positions, first by contrasting the positive claims of attribution scholars with the grey areas of dispute at the fringes of their research, and then by demonstrating the practical use of authorial distinctions in contributing to literary criticism. The effect of this is to liberate the disputed plays from the over-simplistic assertions of in/out that often explicitly characterise authorship work (especially that of Elliott and Valenza) and offer a means by which authorship inquiries can open up new, productive questions about a text rather than serving as a final means of categorisation and isolation.

Building on Jansohn, Proudfoot and Jowett, then, this thesis interrogates the role of the Apocrypha in understanding how we read and see the "Shakespearean". When our methodologies and frameworks for establishing "Shakespeare" are in a state of flux, then the word itself can no longer be used as a stable standard. What, in effect,

\footnotetext{
${ }^{14}$ Hope, Authorship; Craig and Kinney, Shakespeare, Computers, and the Mystery of Authorship; Jackson, "Quarrel Scene"; Merriam, "Linguistic Computing"; Elliott and Valenza, "And Then There Were None", "Two Tough Nuts".

${ }^{15}$ Masten, Textual Intercourse; Vickers, Shakespeare, Co-Author, especially the appendix "Abolishing the Author: Theory versus History" (506-40); McMullan, "Our Whole Life" and Late Writing (esp. 226-58); Jowett, "Pattern of Collaboration".
} 
does "Shakespeare" mean? By admitting the role of the disputed plays in eliding the boundaries of canon and producing multiple "Shakespeares", critics can avoid simplistic generalisations.

Yet the models proposed by Proudfoot and Jowett of extended repertoires and gradualist conceptions pose practical problems. For realisation in performance and print, Shakespeare demands firm boundaries. The fourth and final chapter, therefore, examines the practical ramifications of the issues raised by focusing on the idea of a "complete" works. The word presupposes a finality and certainty that, I argue, is a product of consumer-led market demand rather than a reflection of our theoretical or historical knowledge base. By attending to the role of the Apocrypha in contemporary (and, indeed, future) manifestations of a Complete Shakespeare, multiple possibilities emerge for adjusting the "Shakespearean" to meet the needs of particular readers, researchers, publishers and practitioners. These multiple possibilities suggest that completeness itself can never be complete, and that it is the push towards a homogeneous, embodied and individual Shakespeare that occludes the discursive relationship of the disputed plays to the canon. By removing the need for completeness, the possibility for a diverse range of Shakespeares - of which the Apocrypha can form some part - is finally made available.

This thesis brings together a range of understandings of how early modern plays are interrelated by material publication, repertory performance, authorship and canonisation. The problem of poetic miscellanies such as The Passionate Pilgrim is related to these discussions, but opens up a different set of problems concerning the circulation of poetry, the compilation of verses and the role of early modern manuscript 
culture, for which reasons this thesis is restricted to the specific category of drama. ${ }^{16} \mathrm{~A}$ more difficult exclusion is the group of disputed texts closely related to the Shakespeare canon, such as The Taming of a Shrew and The Troublesome Reign of King John. ${ }^{17}$ Discussions of the relationships between these plays and their canonical counterparts would risk relating my arguments too closely to narratives concerning sources and the role of Shakespeare's specific penmanship in the creation of these plays, issues which have been discussed widely elsewhere. My interest is in those plays which are specifically "other" to the canon, which cannot be accommodated under traditional author-centred paradigms. For the same reason, Pericles and The Two Noble Kinsmen are only discussed in passing; both plays have now been established in the canon for many years, and their histories are adequately covered elsewhere. The elevation of both plays to canonical status is, however, instructive, and will be discussed where relevant. ${ }^{18}$

\section{The Return of the Author}

In 2008, Shakespeare Studies hosted a forum convened by Patrick Cheney called "The Return of the Author": a return rather than a rebirth as, for these writers, the author never died. Responding particularly to Lukas Erne's important reassertion in Literary Dramatist of William Shakespeare's own literary ambitions and involvement in his own works, the forum aimed to reassert the primacy of the Author in studying the works of Shakespeare. The word "Coauthor" appears in preference to "collaborator" in essays by Brian Vickers and Jeffrey Knapp, and Erne himself calls for a return to the

\footnotetext{
${ }^{16}$ See Bednarz for an extremely useful discussion of the problems of poetry of disputed authorship.

${ }^{17}$ See the recent editions of The Taming of the Shrew (Barbara Hodgdon) and The Troublesome Reign of John, King of England (Charles R. Forker), both of which survey current debates over the relationships between the variant texts.

${ }^{18}$ See the Arden editions by Suzanne Gossett and Lois Potter respectively for excellent full editorial and authorship histories.
} 
editing of "full, unabridged, authorial play texts" (32). ${ }^{19}$ As Anthony B. Dawson has pointed out elsewhere, some structural principle needs to be adopted for editing, and the author offers the easiest and most appealing one (161). It is within these authordominated principles that more post-structuralist approaches to authorship have been forced to operate; McMullan, for example, justifies at length the cover attribution of his Arden Shakespeare Henry VIII which includes the series title but no reference to Fletcher: "The effect of this is to emphasise the play's status as part of an institution with its own history and its own cultural status rather than as a text written 'by' an individual" ("Our Whole Life" 455n). Nonetheless, we are reminded that Shakespeare continues to operate with a certain level of "cultural status" that creates frameworks within which disputed and collaborative plays are required to contend. Jeffrey Masten, however, notes that
setting out to produce single-author volumes and series, we see collaborative texts as aberrant productions of multiple, discrete persons; simultaneously we view the minority of plays apparently produced by one person "writing alone" as if "writing alone" were not itself crucially inflected, in ways we are only beginning to see, by writing in conversation, consortium, contention - writing together. ("More or Less" 113)

In rightly reasserting the role of real, historical individuals in the writing of plays, we do not need to return to authorial canons as the basis of our study. This thesis proposes that there is scope to forge a mutually productive path that accepts the roles of individuals within a governing collaborative context, where authors operate within,

\footnotetext{
${ }^{19}$ The collapse of the hyphenated "Co-Author" in Vickers's 2002 monograph to the single word "coauthor" here is indicative of the word's new purchase, now a category in its own right rather than a qualification of the "author".
} 
rather than determine, the conditions of production. While authors can be identified, their identification is not, as Cyrus Hoy would have it, "a necessary precondition to critical and aesthetic considerations of such drama" (4).

This thesis is therefore concerned with the practical, material circulation of plays in print and discourse; their availability, their presentation, their performance. As such, it will be attentive to paratexts, marketing materials and editorial apparatus; my focus is on how the idea of Apocrypha is mediated and controlled by external agents as well as how discourses of authorship become manifest within the plays themselves. It is in these important senses that the question of the Apocrypha becomes both more complex and more rewarding. By treating authorship as a negotiation between the socially constructed text and the individual "hand", rather than one or the other, notional divisions between Canon and Apocrypha can be dissolved in favour of a unfettered exploration of the relevance of "Shakespeare" to these neglected plays. 


\section{Chapter One: Canonising the Apocrypha}

Those wretched plays cannot be admitted as his

- Alexander Pope, Shakespeare 1.xx.

Shakespeare, as far as we understand the man and the work, is in important ways a product of his presence in material books. In the absence of significant personal or secondary documentary evidence, our sense of Shakespeare's oeuvre is primarily determined by the published materials that bear his name. Even recent approaches to authorship that rely on "internal evidence" draw their comparison samples from the plays attributed to him in print. As Masten reminds us, "dramatic authorship emerges from the publishing house and only directly from the theater ... authorship in its emergence is as much about marketing as about true attribution" ("Playwrighting" 371).

The study of the book as material artefact has become more dominant over the last twenty years, reinvestigating the authenticating strategies employed within prefatory materials and paratexts, apparatus and physical composition. This has yielded a rich understanding of the ways in which authorship, and the meanings of authorship, are constructed by a network of forces, as in the work of Leah Marcus, Sonia Massai, Stephen Orgel, Jeffrey Masten, Margreta de Grazia, Douglas A. Brooks, Lukas Erne and others. ${ }^{1}$ These methodologies, importantly, do not necessarily diminish the importance of the originating authorial mind, but rather seek to resituate the artwork within the material and practical contexts that play a major role in shaping its reception, both in the text's original period and in its subsequent afterlives.

\footnotetext{
${ }^{1}$ See de Grazia, Shakespeare Verbatim; Marcus, Unediting the Renaissance; Masten, Textual Intercourse; Brooks, Playhouse to Printing House; Orgel, The Authentic Shakespeare; Erne, Shakespeare as Literary Dramatist; Massai, Rise of the Editor. Andrew Murphy's magisterial survey volume Shakespeare in Print is indispensable in its consolidation of the bibliographic scholarship that underpins this field.
} 
Massai has recently reminded us of the importance of looking beyond the familiar, linear editorial history of Shakespeare in order to appreciate the complex mechanisms that underpin the construction of the established text. She notes, for example, how the editors of the Oxford Shakespeare "describe the cumulative effect of the changes introduced in the First Folio as a consistent progression towards ideological, as well as textual, uniformity" (Rise of the Editor 151). The danger of this kind of linear history is in obscuring more idiosyncratic textual manifestations, and of placing ahistorical importance on those moments that anticipate modern consensus. In the case of the plays of the Apocrypha, the very existence of the category retrospectively biases Shakespearean textual history according to later beliefs regarding authorship; the plays are discussed as if inauthentic from their initial moment of publication, despite the fact that standards of authenticity were established much later. This chapter is concerned to show, by contrast, that the division of Shakespeare's plays into canonical and apocryphal was a result of the work of Shakespeare's eighteenth- and nineteenth-century editors, who determined how authorship was articulated and presented. It was during this period that attempts began to be made to regularise and consolidate the meanings of the "Shakespeare" authorial attribution in accordance with the cultural ascendancy of the individual figure. This chapter therefore links the creation of the Shakespeare Apocrypha as a materially and ideologically distinct group to the wider discourses of cultural, artistic and national appropriations that have been shown to govern the creation of the modern image of both man and works. ${ }^{2}$

The continued use of the term "Apocrypha" is testament to the enduring influence of Brooke's 1908 The Shakespeare Apocrypha, referred to by Jowett as "definitive" ("Supplemented" 61), which is the most recent major collection of disputed

\footnotetext{
${ }^{2}$ Important studies of cultural and national appropriations of Shakespeare include Jonathan Bate, Shakespearean Constitutions and Genius; Gary Taylor, Reinventing Shakespeare; Michael Dobson, National Poet; and Graham Holderness, Cultural Shakespeare.
} 
plays and remains the standard scholarly text for many, thus ensuring that, even at the level of citations, they remain physically part of an Apocrypha. ${ }^{3}$ The choice of "Apocrypha" as an organising title for this group was Brooke's innovation, replacing the Doubtful Plays of Shakespeare preferred by nineteenth-century compilers. The associations of the word "Apocrypha" are themselves primarily biblical, bringing the disputed plays into line with the religious language that Dobson shows had been used since the mid-eighteenth century to articulate the cultural icon of Shakespeare in suitably reverential terms. ${ }^{4}$ In 1901, Bernard Shaw coined the term "Bardolatry" to give a name to the religion of Shakespeare (33), and Brooke's use of "Apocrypha" continues the process of formalising this religion, implicitly dividing works attributed to Shakespeare into a Bible-Apocrypha dichotomy. The reference to "inspired authorship" in the $O E D$ 's entry on "Apocrypha" is especially relevant to post-Romantic conceptions of Shakespeare's authorial genius, which derive their authority from as far back as the 1623 folio's claims that "His mind and hand went together: And what he thought, he vttered with that easinesse, that wee have scarse receiued from him a blot in his papers" $\left(A 3^{r}\right)$, which Bate notes "paved the way for the later apotheosis of Shakespeare as pure genius untrammelled by art" (Genius 29). "Inspired authorship", the flowing of divine and pure thought from God to man, associates the genuine works with the notion of Shakespeare as pure, singular creative genius, unsullied in his natural state by collaboration or earthly concerns. By implication, then, the apocryphal plays did not emerge from this mind and are unauthorised, fraudulent, even blasphemous. ${ }^{5}$

\footnotetext{
${ }^{3}$ Specifically Locrine, Thomas Lord Cromwell, The London Prodigal, Fair Em and The Birth of Merlin. Brooke is also frequently used for citations of Mucedorus and Merry Devil.

${ }^{4}$ David Garrick's Shakespeare Jubilee of 1769 is widely regarded as the apotheosis of the burgeoning Shakespeare religion, celebrating the Bard in Stratford-upon-Avon as "the god of our idolatry" (Ode 1). Dobson provides the fullest treatment of this occasion and its ramifications (esp. 214-27).

${ }^{5}$ The analogy is more complex, as one group's blasphemous texts can become another's scripture. The Catholic Church, at the Council of Trent on April $8^{\text {th }} 1546$, recognised the biblical Apocrypha as part of the canon, while Martin Luther accepted them as appendices "not to be
} 
Brooke's use of the term is the culminating moment of a two-hundred-year critical tradition that treats the apocryphal plays in inverse relation to Shakespeare's ongoing deification. The history of Shakespeare's works is inseparable from the history of the Bard; and, while ambiguities of attribution and authorship are endemic to a literary study based around authorial canons, they are even more pronounced when a canon achieves the level of cultural and national investment accorded Shakespeare. The phenomenon of a secular literary Apocrypha is almost unique to Shakespeare, and the label carries with it associations that stigmatise the plays: while other anonymous and non-canonical works sit ignored, the apocryphal grouping actively draws attention to the undesirability of the plays. The label is itself a product of critical attitudes that associate authenticity with artistic value.

As Jansohn points out, "The Shakespearean canon [is] a historically grown, not a universally available fixed construct" ("Reconsideration" 324), and understanding the processes that have led to the formation of the printed canon can help us to objectively reassess this means of organisation. The history of the Apocrypha is a fragmented and unsatisfactory one, and so this chapter exploits this fragmentation to focus on a series of chronologically-overlapping shifts in the history of these plays that occur within the more widely-documented narratives of Shakespeare's textual, performative and cultural history. In so doing, we see that modern attitudes to the Apocrypha are built on a critical foundation of inattention and cursory dismissal that throws into question the notion of an objective distinction between modern groupings of authentic and inauthentic.

regarded as highly as the Holy Scripture." See Jansohn, "Reconsideration" 325. Even against a biblical precedent, therefore, the Shakespeare Apocrypha would not be expected to disappear entirely. 


\section{The 43-Play Canon: 1664-1734}

In 1663, Philip Chetwind published the third folio of Shakespeare's plays, the first anthology of Shakespeare in just over thirty years. This edition marked an important reclamation of Shakespeare's status in the immediate post-war period dominated by the Fletcher and Jonson canons. ${ }^{6}$ It filled a commercial gap in the market and reasserted the worth of Shakespeare's works, at a time when he was often derided as an "ignorant and archaic rustic" (Dobson 18). It also promoted the theatre itself, re-offering the plays in a prestige folio format designed to lend credibility to the newly revived stage. ${ }^{7}$

Chetwind acquired the rights to Shakespeare's plays through inheritance, marrying the widow of Robert Allot who had acquired the stake previously owned by Edward Blount. ${ }^{8}$ His 1663 edition closely followed the 1632 folio; but the second impression, published in the following year, marked the first attempt to alter the constitution of the canon as established by the 1623 folio. The title page of the second imprint reads as follows:

Mr. WILLIAM SHAKESPEAR'S Comedies, Histories \& Tragedies. Published according to the true Original Copies. The third Impression. And unto this Impression is added seven Playes, never before Printed in Folio. viz. Pericles Prince of Tyre. The London Prodigall. The History of Thomas Ld.

\footnotetext{
${ }^{6}$ For the period 1659-99, The London Stage records 306 performances of 49 plays attributed to Fletcher, 228 performances of 37 plays attributed to Shakespeare, and 71 performances of 19 plays attributed to Jonson. Furthermore, the Shakespeare figures are heavily skewed by adaptations; including, for example, 44 performances of Dryden and Davenant's The Enchanted Island. While Shakespeare was nominally present in the repertory, the extent to which his plays were adapted is symptomatic of the period's attitude towards him. See Dobson 17-61, Raddadi on Davenant, and Christopher Spencer's edition of five Restoration adaptations.

${ }^{7}$ For the value of the "First Folio" and its role in constructing Shakespeare's literary authorship, see Murphy (Shakespeare in Print 41-51), Kastan (Shakespeare and the Book 53ff), Jowett (Shakespeare and Text 69-92), Brooks (From Playhouse to Printing House 14ff), Taylor ("Making Meaning Marketing Shakespeare" 55-69) and Marcus (Puzzling 2-24). Massai's discussion of the 1685 folio (Rise of the Editor 180-95) sets a standard for discussion of the distinctiveness of later folios, the independent value of which is often underestimated.

${ }^{8}$ For a full account of the early history of publishing "rights" of Shakespeare's works, see Murphy, especially 44-45.
} 
Cromwell. Sir John Oldcastle Lord Cobham. The Puritan Widow. A York-

shire Tragedy. The Tragedy of Locrine. [device] LONDON, Printed for P.C.

1664. (Title page. See Fig. 1)

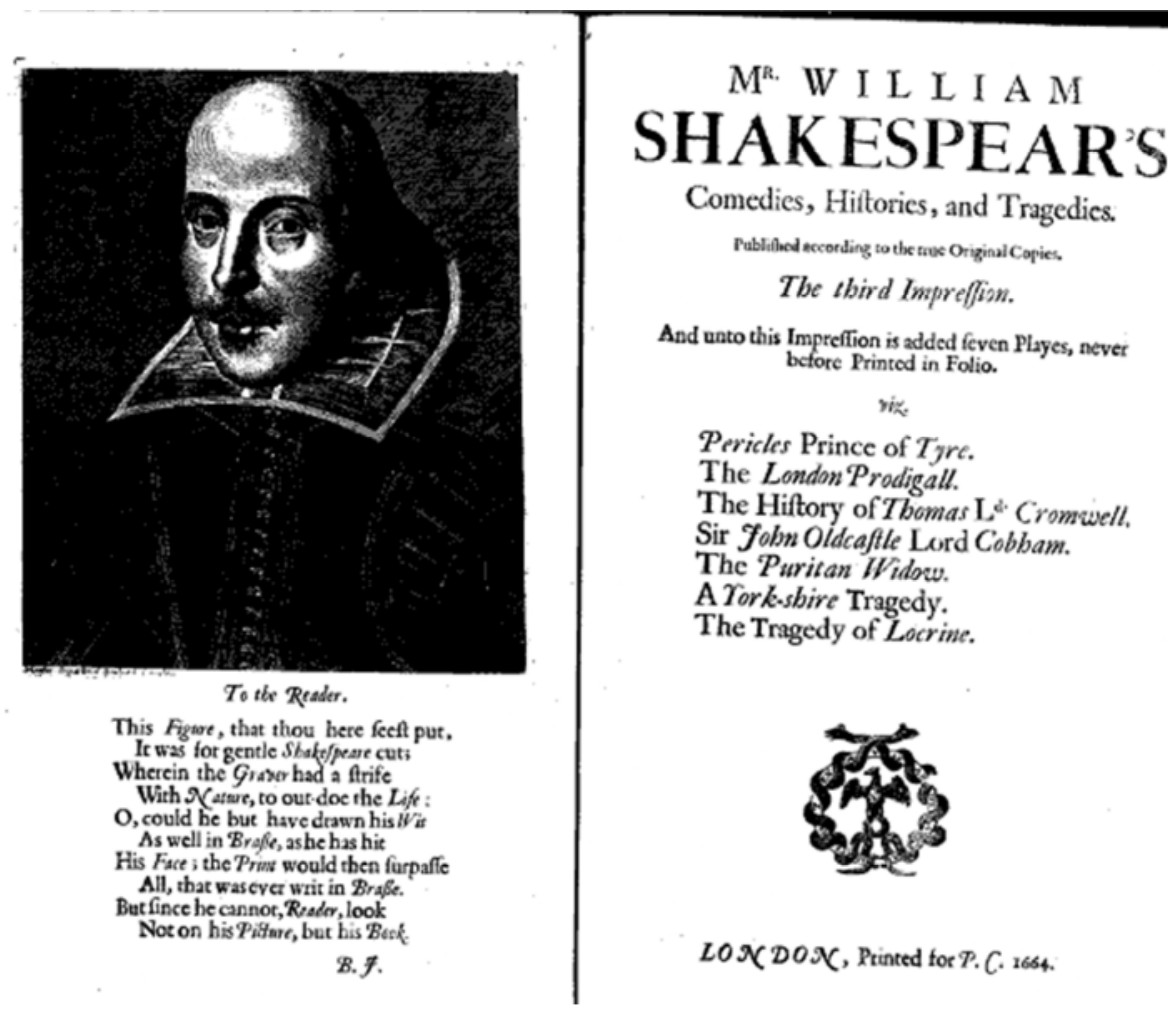

Fig. 1. Frontispiece and title-page of the third Shakespeare Folio (1664). Source: EEBO.

The retrospective authority granted to the 1623 folio has anachronistically diminished our sense of the impact of this edition on the burgeoning Shakespeare canon. Jowett notes of the additions that "all were seen as having some claim to be of Shakespeare's authorship, but in most cases the claim was weak" (Shakespeare and Text 24), a statement that projects contemporary valuations of authorial claims onto the past using the past tense. The claims of most of the additional plays are now weak, according to modern priorities of individual authorship, but in bibliographic terms, most of the additions had solid claims, better documented than those of several 1623 folio plays. 
There are no records of any attempt to collect Shakespeare's works within his own lifetime in order to consolidate a canon. ${ }^{9}$ In the absence of an authorised canon, therefore, we must turn to the book market. Erne's groundbreaking work has forced critical reassessment of Shakespeare's popularity in print, noting that Shakespeare appeared in no fewer than forty-five editions between 1584-1616, twice as many as Heywood, the second most-printed dramatist of this period ("Popularity" 25). The number of editions and the number of reprints, Erne argues, indicate respectively the scale of investment and of sales. We must therefore not underestimate the scale of Shakespeare's literary presence on London bookshelves. A committed Shakespeare bibliophile collecting all the books attributed on title pages to the author within his lifetime could have gathered a library of quartos and octavos consisting of all of the following: Love's Labour's Lost (1598), Richard II (1598), Richard III (1598), 1 Henry IV (1599), The Passionate Pilgrim (1599), 2 Henry IV (1600), The Merchant of Venice (1600), A Midsummer Night's Dream (1600), Much Ado about Nothing (1600), The Merry Wives of Windsor (1602), Hamlet (1603), The London Prodigal (1605), King Lear (1608), A Yorkshire Tragedy (1608), Pericles (1609), Shakespeare's Sonnets (1609) and Troilus and Cressida (1609). ${ }^{10}$ To these seventeen books may be added Locrine (1595), Thomas Lord Cromwell (1602), The Puritan (1607) and The Troublesome Reign of King John (1611), if readers interpreted the initials "W.S." and "W.Sh." as Shakespeare's; and Venus and Adonis and The Rape of Lucrece, which include Shakespeare's name within the books, although not on their title pages. Several other plays would not appear in print until the 1623 folio.

\footnotetext{
${ }^{9}$ Several critics have, however, postulated that such a project may have been begun, with Shakespeare's involvement, before his death. The most recent of these is Erne (Literary Dramatist 111-14).

${ }^{10}$ Dates refer to the playbook's first publication with a Shakespeare title page attribution.
} 
From the point of view of the London literary marketplace, then, the claims of several plays added to the 1664 folio were no less weak than those of their shelf-fellows, since they derived from the presses of reputable printers and shared similar strategies of title page authentication. Physically, they belonged indisputably to "Shakespeare" insofar as "Shakespeare" functioned as their principal authorising agent. Chapter Two will explore further what early audiences might have understood by "Shakespeare's The London Prodigal" or "Shakespeare's A Yorkshire Tragedy", but it is important to recognise here the dispersal of Shakespearean literary identity across poems and plays associated with a range of patrons, companies, genres and stationers. It was the buyer of books, rather than the printer, who compiled Shakespeare's literary canon during the author's lifetime. ${ }^{11}$

It was with the 1623 folio that a bookseller, in conjunction with the King's Men as the most important authorising agent for the plays, took responsibility for shaping Shakespeare's theatrical canon into a single literary entity. This involved excluding formerly "authorised" works, authorising others hitherto anonymous and introducing previously unavailable plays. In 1619, however, Thomas Pavier had begun a similar project that, while unfulfilled, demonstrates the importance of the bibliographical attribution to Shakespeare in creating a cumulative sense of the work. Pavier's collection, usually considered unauthorised, included The Whole Contention, Henry V, The Merry Wives of Windsor, King Lear, Pericles, A Yorkshire Tragedy, Sir John Oldcastle, A Midsummer Night's Dream and The Merchant of Venice. ${ }^{12}$ This apparent first attempt to create a collected edition of Shakespeare's plays (evidenced by the continuous

\footnotetext{
${ }^{11}$ The role of readers in shaping literature has been strongly reasserted in recent years, most notably by William $\mathrm{H}$. Sherman 1-24 and 151-78, who focuses on annotating readers across the Renaissance, and Massai (Rise of the Editor), who specifically focuses on notations in early Shakespeare editions.

${ }^{12}$ The Oldcastle quarto was dated 1600 despite being printed in 1619 . The mistake/forgery was not discovered until the twentieth century (Greg, "On Certain False Dates"). It is most likely that Chetwind, too, did not realise the date was false when collecting together the 1664 additions.
} 
signatures linking Contention and Pericles) represents an intriguing cross-section of texts, connected for the most part simply by Pavier's right to publish them. Just four years shy of the 1623 folio, then, Pavier's project is evidence of the inherent instability of the Shakespeare authorial corpus in print, despite his apparent desire to stabilise that corpus. Objective assessments of authorial contribution are secondary to practical concerns of ownership, prior attribution and marketability: for example, Pericles was a top-seller with three quartos already printed, Falstaff/Oldcastle was the star of the perennially popular Henry IV plays, and the story of the Calverley murders underpinning A Yorkshire Tragedy was a contemporary sensation. For Pavier, the Shakespeare attribution does not appear to have been a matter of simple forgery, as later critics assuming an inherent value in Shakespeare's name have suggested..$^{13}$ Rather, Shakespeare acts as a convenient marketing principle by which to set out a larger project: it provides the organisational framework to reproduce plays which are expected to sell on their own merits. Pavier's project is as much about using popular plays to create Shakespeare as it is about using Shakespeare to make plays popular. ${ }^{14}$

Pavier's project was undermined by the success of the 1623 folio project. The infamous "stolne, and surreptitious copies" of Heminge and Condell's preface $\left(A 3^{r}\right)$ have been taken to refer both to the so-called "bad" quartos of previous publications and/or specifically to the Pavier quartos, half of which were substantially variant versions of folio texts. ${ }^{15}$ Whether intentional or not, the exclusion of several plays already

\footnotetext{
${ }^{13}$ See especially Greg, “On Certain False Dates," which was highly influential in shaping opinions of Pavier. More recently, Marino ("Oldcastle" 95ff), Bednarz (266) and Jowett (Shakespeare and Text 71) have attempted to partially rehabilitate Pavier's reputation by stressing the accuracy of the earlier printings and the association of Jaggard with the project.

${ }^{14}$ Tara L. Lyons argues that eight of the ten plays in Pavier's collection can be considered as part of a narrative sequence, whether historical (Henry $V$ ) or character-based (Merry Wives and Oldcastle as Falstaff plays), and suggests that this became a significant aspect of the construction of Shakespeare's print identity, most obviously realised in the organisation of the histories in the 1623 folio.

${ }^{15}$ The Whole Contention, Merry Wives, Henry V, King Lear. Pericles is also usually considered a corrupt text. Maguire's study of the phenomenon of memorial reconstruction has done much to
} 
attributed to Shakespeare from the 1623 folio was compounded by their association with the Pavier project and the imputations of corrupt and/or badly printed texts that the folio made, providing a foundation for the critical degradation of the Apocrypha. Not only omitted from the canon, they are associated with unsatisfactory states of textual production. As Maguire puts it, "Heminge and Condell did not give us Shakespeare; they gave us all that we call Shakespeare" (“Composition" 142, my emphasis).

We cannot know for certain what prompted Chetwind to readmit seven plays to the Shakespearean corpus in 1664, though we can make some inferences. Proudfoot and Rasmussen have suggested that the printings of Pericles in 1633 and The Two Noble Kinsmen in 1634 were deliberately intended as supplements to the 1632 Shakespeare folio, suggesting that the canon presented by the 1623 folio was already available for challenge and extension (vii). As I have pointed out elsewhere, a contemporary collection in the library of Charles I offers another alternative informal supplement to the 1632 folio, adding Fair Em, Mucedorus and The Merry Devil of Edmonton to a grouping of other dubious plays. ${ }^{16}$ It is important to note that the 1623 folio preliminaries make no explicit claims for completeness: the title suggests only that these are "Comedies, Histories, \& Tragedies", while Heminge and Condell speak only of having "collected and published them" without specifying the parameters that define the "works" being gathered. The continued appearance of plays such as The Two Noble Kinsmen in close proximity to the publication of a Shakespeare folio suggests that the Shakespeare canon remained, at least in the publishing industry, unfixed. Orgel argues

rehabilitate many of these texts, although she accepts that Merry Wives and to a lesser extent Pericles may indeed preserve features of memorial reconstruction (Suspect Texts, esp. 285-86 and 294-95).

${ }^{16}$ The volume also included The Puritan, Thomas Lord Cromwell (the first explicit association of the W.S. initials with Shakespeare), The London Prodigal and Love's Labour's Lost. See Kirwan "The First Collected 'Shakespeare Apocrypha'" (reproduced in Appendix). The three newly attributed plays were not subsequently included in apocryphal collections until the nineteenth century. 
that the 1664 folio was the first to imply that "more Shakespeare was better

Shakespeare" ("Desire and Pursuit" 290), beginning a move towards comprehensiveness as a marker of value.

Chetwind's seven additions gathered together all of the extant plays explicitly attributed to Shakespeare within his own lifetime, thus excluding the posthumouslypublished Kinsmen and The Birth of Merlin (1662). ${ }^{17}$ Jowett notes additionally that these two plays were both the property of stationers who had no stake in the 1664 folio, which may have practically impacted on their exclusion ("Supplemented" 49). The exception is the falsely dated Oldcastle, the inclusion of which suggests that Chetwind was relying solely on the physical evidence of earlier title pages rather than possessing any independent knowledge of provenance. He also excluded Troublesome Reign, most likely owing to the presence of another King John already in the folio.

Other than on the title page, the seven new additions to the 1664 folio are not explicitly differentiated from the established plays. As with several folio plays, Cymbeline ends with a "Finis" and device, then Pericles follows directly on after a blank page. As such, the edition presents them without reservation as Shakespeare's works, subject to the same frontispiece, commendatory verses and other bibliographic material. However, David Scott Kastan notices a bibliographic anomaly in the pagination of the additions: following Cymbeline, pagination begins again at ' 1 ' on the first page of Pericles and runs through to ' 20 ', then begins again at ' 1 ' for The London Prodigal and runs continuously through the six remaining plays to ' 100 ', the last page of Locrine. Kastan refuses to speculate on the reasons for this, merely commenting that "The odd physical structure

\footnotetext{
${ }^{17}$ Proudfoot points out that Nigel Bawcutt's identification of a 1622 reference to The Childe hath founde the Father in Henry Herbert's office-book with The Birth of Merlin suggests that the play was written several years after Shakespeare's death ("Canon" 87-88). Dominik (Birth of Merlin) is the only commentator to attempt to argue seriously for Shakespeare's involvement, but his work is based on unqualified impressionistic stylistic parallels and is of little scholarly value.
} 
of the supplement is the only sign of whatever obscure distinction its publisher, Philip Chetwind, intended" (Shakespeare and the Book 64). Kastan clearly believes that there is a distinction intended, however, and his note that Pericles is the only one of the seven "plausibly thought to be [Shakespeare's]" (64) suggests an overly optimistic level of critical engagement on Chetwind's part that would see him differentiate one play over the others based on the strength of its claim. The lack of any other distinguishing marks rather suggests that the pagination reflects compositorial error, or else a simple mechanical distinction; that Pericles was obtained earlier than the other six. If Chetwind was inspired by the implied supplement to the 1632 folio offered by the 1633 quarto of Pericles, it is possible that he initially intended to incorporate only this play, before deciding to look for more.

The implications of the additions were far reaching as, during the seventeenth and eighteenth centuries, it was the usual practice for each new edition to be marked up from its predecessor, meaning that the new plays would be included by default until actively removed by an editor. Thus, the new plays remained in the fourth folio (1685), which in turn was the base text used by Shakespeare's first modern editor, Nicholas Rowe. Rowe further elided the distinction between the original thirty-six and the new seven by removing the subdivisions of Comedies, Histories and Tragedies, meaning that all the plays follow each other continuously: his sixth volume begins with Antony and Cleopatra and Cymbeline, after which Pericles follows with no bibliographic distinction made. By including frontispiece illustrations and lists of dramatis personae for all fortythree plays, Rowe further standardised their presentation, merely placing them at the end of the collection rather than marking them as in any way different. Rowe's silence on this decision is further evidence that their inclusion was passive, an acceptance of the available canon rather than an engaged re-evaluation. This passivity was finally countered by Alexander Pope in 1725 . Sidney Lee dismisses this as an insignificant 
period during which "six valueless pieces ... found for a time unimpeded admission to [the] collected works" (Life 260), but we should not underestimate its importance. On purchasing a 1664 Folio, the Bodleian Library sold its copy of the 1623 version as "superfluous" (Lee, "Notes and Additions" 21), an instance indicative of the value accorded the new arrangement. ${ }^{18}$ The 43-play canon endured for sixty years, one of the longest sustained periods of canonical stability ever achieved. ${ }^{19}$

By granting the seven additional plays the authority of the folio format, and extending to them the coverage of the commendatory verses, dedications and frontispiece that contributed to the literary construction of Shakespeare, Chetwind established their ongoing presence in Shakespeare's textual afterlife. The canon now existed in two separate states, and future compilers were required actively to choose the constitution of their edition rather than simply receiving a single authorised version. ${ }^{20}$ Taylor remarks of the additions that they "reinforced the impression that his lifework was a mess, a collection of 'indigested' plays that mixed genius and ineptitude haphazardly" (Reinventing Shakespeare 31), thus linking the extended canon to the relatively haphazard Restoration treatment of Shakespeare. The apparently passive acceptance of the additions, Taylor implies, is symptomatic of a casual attitude to the works during this period. Even in a growing climate of Bardolatry, it would take a figure as confident and intellectually independent as Pope to offer a challenge to the 43-play canon and re-evaluate the constitution of the Shakespearean corpus.

\footnotetext{
${ }^{18}$ Lee notes that it was not until 1905 that the library's original 1623 folio was recovered ("Notes and Additions" 131). See also West, "The Life of the First Folio" (77).

${ }^{19}$ See De Grazia and Stallybrass 261-62. The oscillation of Pericles, Titus and The Two Noble Kinsmen from Malone's 1790 edition onwards, as well as the debates surrounding Thomas More and various poems, have ensured an ongoing state of flux at the fringes of the canon. The importance of the 43-play canon enduring for so long, therefore, should not be underestimated. ${ }^{20}$ It could even be argued that there were three states to choose from, if one takes into consideration that the earliest issues of the 1623 folio excluded Troilus and Cressida. This appears to have gone unnoticed until Hinman's pioneering work on the folio in the 1960s, however, and therefore did not feature in eighteenth-century discussion. See Murphy (Shakespeare in Print 50) and P. Blayney (Folio 17-24).
} 
The 43-play canon gained considerable traction, and there is evidence that some of the apocryphal plays enjoyed a measure of popularity in the late seventeenth and early eighteenth centuries. Pericles was one of the first plays revived on stage when the theatres re-opened after the Interregnum, appearing at the Cockpit, Drury Lane, in the 1659-60 season (Index to the London Stage 772) and revived in the eighteenth century as Marina. The Puritan was revived in the 1660s, and Matthew Draper's The Spendthrift, a loose adaptation of The London Prodigal, was first published in $1731 .^{21}$ These later revivals occurred not long after Tonson had reissued Pope's edition in duodecimo, with a ninth volume including reprints of the 1664 additions, thus reviving the 43-play canon even under Pope's aegis. Although Theobald's 1733 edition of Shakespeare's works followed Pope's 1725 edition in returning to the canon of the 1623 folio, the 43-play canon would emerge one final time.

In 1734, the independent publisher Robert Walker began publishing inexpensive individual editions of Shakespeare's plays containing just the text. In doing so, he challenged the monopoly of the Tonson cartel (publishers of Rowe, Pope and Theobald) over the works of Shakespeare. Murphy notes that Tonson first tried to combat the publication with legal action and then retaliated with his own cheap editions, which resulted in the market being flooded with affordable volumes of Shakespeare (Shakespeare in Print 108-09). During this commercial battle, efforts to outstrip the other led to both Walker and Tonson publishing the majority of the 1664 additions in new individual editions. Jowett notes that three of these (Oldcastle, Cromwell and Prodigal) sold sufficiently well to warrant reprints ("Supplemented" 52). As Shakespeare's plays entered mass circulation through these inexpensive printings, so too did the apocryphal plays, and Tonson and Walker both appear to have anticipated a

\footnotetext{
${ }^{21}$ Edmondson (Prodigal 93-100) includes useful discussion of this adaptation. The Advertisement by Draper notes that "The Hint of this Play I had from Shakespear's London Prodigal", and that the play has been left out of Pope's "late" edition $\left(A 3^{r}\right)$.
} 
readership for them. The single editions, which King points out were "authorised" by the publishers rather than the editors ("Cardenio"), formed a major part of the ongoing public dispute between the two publishers. Appended "Advertisements" allowed the publishers to attack one another's authority, particularly over the question of King Lear. Tonson accuses Walker of stupidity in printing Tate's Lear rather than Shakespeare's (Locrine 60). Walker retaliates in the Advertisement to his own Locrine, printing " $A$ Specimen of some of Tonson's Omissions and Blunders in the Tragedy of King Lear, which render the same useless and unintelligible." Walker appeals to the authority of the stage, claiming that his version is printed "as it has been acted for near 50 Years last past (tho' Tonson's spurious Edition kills him on the stage)" (59). His inclusion of Elizabeth Barry's Epilogue and Tate's dedicatory materials is cited as further evidence of authenticity. The explicit debates over authenticity conducted in the paratexts of playbooks that are themselves of doubtful authorship draws attention to the role of the publisher in determining canonical constitution.

Walker consolidated his endeavour by issuing volume titles, allowing readers to bind their own seven-volume collection of his editions. ${ }^{22}$ Walker's collected edition is omitted from most accounts of the publishing history of Shakespeare's works on account of it being "pirated": it was produced outside the linear Tonson-run monopoly and reprinted previously available texts, rather than actively editing them. However, despite its questionable merits, it was a commercial edition of Shakespeare and therefore deserves consideration: for the contemporary reader, the edition was no less "authentic" than the myriad popular editions that can be found on modern bookshelves; and the fact that Tonson countered with an eight-volume reprint of the canon including the disputed plays (in the eighth volume) in the same year is indicative of its perceived

\footnotetext{
${ }^{22}$ For an account of this collection, see H.L. Ford 33-37. Ford also provides an overview of the quarrel between Tonson and Walker (40-45).
} 
importance. Walker's is the first edition that desegregates the disputed plays, mixing them in with the canonical plays, and its order is unique in Shakespeare publishing history. The effect is to place equal authority on all forty-three plays. The contents are as follows:

Vol. 1: Hamlet, Julius Caesar, Richard III, Cromwell, Tempest, Merry Wives;

Vol. 2: Macbeth, Othello, 1 Henry IV, Titus, Measure, London Prodigal;

Vol. 3: Antony \& Cleopatra, Pericles, Lear, 2 Henry IV, Puritan, Two Gentlemen;

Vol. 4: Oldcastle, Locrine, Henry V, Timon, Comedy of Errors, Dream;

Vol. 5: 1, 2 and 3 Henry VI, Henry VIII, As You Like It, Merchant of Venice;

Vol. 6: John, Troilus \& Cressida, Richard II, Romeo, Shrew, Love's Labour's Lost;

Vol. 7: Winter's Tale, Coriolanus, Cymbeline, Yorkshire, Much Ado, All's Well.

This ordering is inconsistent with any modern criteria for arranging the plays, and it is fair to assume that it is dictated by practical rather than critical considerations. By chance or design, however, it presents to us a very different "canon". We are used to seeing plays either in the rough generic groupings provided by the 1623 folio, or in chronological order, both of which are questionable. ${ }^{23}$ The random order here throws assumptions into question and causes us to consider the plays in a different way.

An imaginative reading of the plays in the order presented, assuming design in the organisation, offers interesting interpretative possibilities. The juxtaposition of plays

\footnotetext{
${ }^{23}$ The problems of the folio's generic groupings have been discussed in great detail. See, for example, Mowat on the "late plays" ("What's in a Name?"); Orgel, "Shakespeare and the Kinds of Drama" (The Authentic Shakespeare 143-58) and Felperin. Chronological grouping is a more common contemporary method and, in the $2^{\text {nd }}$ edition of the Oxford Shakespeare, allows for certain apocryphal plays to be integrated with the main canon. As McMullan has recently demonstrated, this is based on post-Enlightenment concerns with biography and the underlying purpose of demonstrating authorial development via the works (Late Writing 78-104).
} 
highlights themes and links that alter the reader's perception of them. Thus, Thomas Lord Cromwell comes positioned in a run of plays dealing with usurpation and the fall of great men. Gardiner's plots, hatched in his study, seem even more Machiavellian in the light of Richard III and Cassius, and set the tone for the atmosphere of political treachery in the following The Tempest. The consecutive placing of Measure for Measure and The London Prodigal brings out close dramatic links between the two: the city setting, the disguised authority figure (Duke/Father) secretly overseeing lapses in morality, the virtuous maid more interested in God's love than man's. Following Measure for Measure's concern with chastity and marriage, the central scene of The London Prodigal becomes exceptionally shocking, as Luce's forced marriage and subsequent honourable conduct causes the near-total destruction of her life, thus further dramatising the trials facing an honest woman.

Continuing with this reading, the hypothetical reader is uplifted by the happy chances of Pericles that bring reunification and peace, expecting the same as the next play, King Lear, draws to its close; and in this is satisfied, for Walker chooses to print Nahum Tate's adaptation of King Lear with its happy ending. The connection between the two is strengthened physically through Walker's placement of the "Specimen of Tonson's Omissions" prior to Pericles. ${ }^{24}$ These two plays in juxtaposition present a Shakespeare concerned with family and amenable to eighteenth-century sensibilities in the reiterated reunions of fathers and daughters. In this vein, the reader then proceeds to 2 Henry IV and finds something more approaching tragedy in the rejection of Falstaff,

\footnotetext{
${ }^{24}$ Bate, referring to Tonson's criticism of Walker's decision to print Tate's adaptation, suggests that "Tonson clearly expects the discerning gentleman to want to see Tate's version but read Shakespeare's" (Constitutions 24). Considering the commercial failure of the anti-theatrical edition of Pope, however, it is possible that Walker's more theatrically aware choice gave the public what it wanted. However, Stern observes that the prompter W.R. Chetwood "publicly rubbished" Walker's claims of theatrical accuracy in an address published in Tonson's 1734 edition (Rehearsal 223); Tonson's recruitment of a theatrical authority to critique Walker, as well as his own textual authority, ensured Walker was attacked on both fronts.
} 
here separated from the history plays that provide it with context. 2 Henry IV concludes, however, with its epilogue reminding the reader that "Oldcastle died a martyr, and this is not the man"; and sure enough, The First Part of Sir John Oldcastle follows at the start of the next volume, preceding Henry $V$, as if to support the dramatist's claim and present the real Oldcastle with due respect. Finally, the placement of Yorkshire Tragedy immediately following Cymbeline places in parallel two instances of a husband attempting to kill a wife; disaster is happily averted in ancient Britain, but no gods descend to save the children of the more contemporary marriage.

This reading is, of course, merely one conjecture of what a reader's experience could have been, but is designed to show the potential impact of Walker's integration of the disputed plays into the body of the canon. This is a different canon, a different Shakespeare, with patterns of cause, effect and resonance shaped by the inclusion and integration of the Apocrypha. Read among the authorised plays, rather than separately from them, the plays influence the reader's perception of Shakespeare, showing the dramatist building on themes explored in other plays and responding to his own work, with each play affecting the sense of the author-at-work. As the cultural figure of Shakespeare was constructed, this was the danger posed by the disputed plays: they had the potential to change the way Shakespeare was read and deciphered. Once dissociated from the canon by Pope and Theobald, then, it was imperative that the Apocrypha be hidden. Walker's treatment of the plays was the last time they were seen in print until Malone's Supplement of 1780.

\section{Restoring Reputations: 1723-65}

Alexander Pope's edition of 1723-25 is indicative of the change in Shakespeare's status and reputation that took place during the years since Rowe's edition.

Commercially unsuccessful but critically influential, Pope was both the instigator and the 
most extreme example of the Bardolatrous attitude towards Shakespeare in eighteenthcentury editorial practice. ${ }^{25}$ His approach to the plays is governed by subjective aesthetic judgments, which lead him to make decisions that have been critically derided by subsequent generations as he makes the plays "comfortably fit for $18^{\text {th }}$ century habitation" (Murphy, Shakespeare in Print 67). Of these, the most significant are his regularisation of metre, relegation of passages he considers less pleasing to footnotes (suggesting that they are spurious interpolations by actors) and his removal of the seven 1664 additions, thus disrupting the inherited lineage of the 43-play canon.

Edmund King argues that "[Pope's] criterion for canonical inclusion is clearly not the authenticity of a work, but whether that work adds to its author's reputation" ("Cardenio"); that is, that canonicity should be selective rather than objectively comprehensive. ${ }^{26}$ Pope's Preface makes apology for those aspects of the plays that are judged deficient, in a bid to create and preserve Shakespeare's reputation. Pope thus exercises unprecedented editorial control in constructing his own Shakespeare, a Shakespeare with impeccable literary taste and a thoroughly contemporary mastery of the poetic arts. In so doing, less desirable elements are removed or diminished. Some weaker passages are justified as being Shakespeare's concessions to "the meaner sort of people" (1.v) who made up seventeenth-century audiences (though "even in these, our Author's Wit ... is born above his subject"). Pope's Preface is essentially anti-theatrical: he sees a literary genius spoiled by the necessity of pandering to popular taste, and actors ("the worst of company", 1.ix) as complicit in the ruining of the works. Weimann traces this back to the self-consciously literary attitudes of early dramatists such as Jonson: "Editors [of the eighteenth century] almost unanimously agreed on the need to

\footnotetext{
${ }^{25}$ King provides an excellent introduction to Pope's newly "interventionist" approach to editing ("Fragmenting" and "Cardenio"). See also Jarvis 51-62.

${ }^{26}$ King's reading of Pope and Swift's Miscellanies (1728) provides fascinating insights into Pope's conception of canonicity and attribution, particularly the collection's insistence on the right of the authors to suppress and destroy their own works ("Cardenio").
} 
guard Shakespeare's text from the ill customs of the age and especially from those of the players" (32). Despite recognising that Shakespeare was also a player, Pope expresses the wish that the author had undertaken to publish his plays himself, in order that "we might be certain which [plays] are genuine ... [and find] the errors lessened by some thousands" (1.xx). King notes that a "belief in the inherently corrupting power of playhouse manuscript practices" ("Fragmenting" 6) licensed eighteenth-century editors to remake Shakespeare as they saw fit.

Pope sees himself as salvaging what remains of Shakespeare after lesser minds have tampered with the works, and therefore his approach is confident and absolutist. He believes that Shakespeare's hand can be identified by "the distinguishing marks of his style, and his manner of thinking and writing" (1.xx), effectively suggesting that he, Pope, has a unique insight into the workings of Shakespeare's mind. ${ }^{27}$ On this basis, he declares that "those wretched plays", the seven additions, "cannot be admitted as his" (1.xx). The emotive language stigmatises the plays in terms of their quality, but also evokes images of forsaken and worthless texts that are audacious in begging admittance, an association that would stick. Continuing with his merciless critique of the canon, he also conjectures that Shakespeare's hand is only lightly present in Love's Labour's Lost, The Winter's Tale, The Comedy of Errors and Titus Andronicus. ${ }^{28}$

\footnotetext{
${ }^{27}$ Pope's poetic subjectivity was influential on disintegrative work throughout the eighteenth and nineteenth centuries. While the work of the New Shakspere Society in the late nineteenth century attempted to regularise these methodologies, the impressions of poets continued to carry weight. Muir writes that Swinburne "has argued most persuasively against the attribution of [Edward III] to Shakespeare [although he] relied entirely on aesthetic arguments ... Swinburne's intimate knowledge of Elizabethan drama gives more weight to his opinion than Tennyson's." (Shakespeare as Collaborator 11-12). Authority here is located not in methodology but in the mind of the poet.

${ }^{28}$ Edward Ravenscroft, in the introduction to his 1687 The Rape of Lavinia, provides the first suggestion of Shakespeare's collaboration in Titus, and J.M.Robertson, a late nineteenth-century disintegrator, devoted an entire book to the subject. See Vickers, Co-Author 148-243 for discussion of Peele's involvement.
} 
It is the theatre, and Shakespeare's hypothesised role in it, that authorises Pope's intervention. He argues that the 1664 additions were anonymous contributions to Shakespeare's company, "fitted up for the theatre while it was under his administration" (1.xx), and therefore attributed to him in his role as the company's resident dramatist. Tellingly, Pope compares this to the practice of giving "strays to the Lord of the Manor" (1.xx): Shakespeare becomes part of the landed gentry, a man of wealth and power with the resources to be charitable. Authorship, in Pope's view, is ideally an individual activity, and ideas of company ownership and collective or collaborative authorship have no place in discussing individual and personal genius. This recasts Shakespeare in a mould suited to Pope's personal approach: as Jarvis notes, the implication is that "the fittest guardian of Shakespeare's text, like the ideal poet, will not be a professional of any kind, but a self-sufficient man of the world" (55). Pope's intent, then, is to separate Shakespeare's public and private lives, his work and his Works.

If we give into this opinion [that the plays are corrupted by players and editors], how many low and vicious parts and passages might no longer reflect upon this great Genius, but appear unworthily charged upon him? And even in those which are really his, how many faults may have been unjustly laid to his account from arbitrary additions, expunctions, transpositions of scenes and lines, confusion of characters and persons, wrong application of speeches, corruptions of innumerable passages by the ignorance, and wrong corrections of 'em again by the impertinence, of his first editors? From one or other of these considerations, I am verily persuaded, that the greatest and grossest part of what are thought his errors would vanish, and leave his character in a light very different from that disadvantageous one, in which it now appears to us. (1.xxi) 
It is Shakespeare's "character" that is at stake. Pope's stance is based on a fundamental textual pessimism and the optimism that Shakespeare's "Genius" could not have been responsible for what Pope considers "errors" within the texts. Pope's particular dispute continues to be with actors; it is to the "ignorance of the Players" (1.xiv) that he attributes the worst of the corruptions. This attitude is perhaps anachronistically informed by Pope's own time. The vogue for adaptation in the late seventeenth and early eighteenth centuries was keeping "original" Shakespeare off the stage, just as the emerging editorial tradition attempted to retrieve something closer to Shakespeare's original hand, as realised in Tonson and Walker's dispute over Lear. Pope, the poet, sets himself against the theatrical fashions of the time, preferring the unity of a single creative mind. ${ }^{29}$

Commendably, in terms of editorial integrity, Pope acts on his beliefs by applying his theories of corruption to the texts as edited, hence the relegation to footnotes of "spurious" passages in the canonical plays and the removal of the seven apocryphal plays, dismissed on aesthetic grounds. However, his principles were undercut in the 1728 duodecimo reprint issued by Tonson. This edition resurrects the "wretched plays" by including them as the ninth volume of ten. Orgel theorises that their reappearance was thanks to "Tonson's conviction that more Shakespeare would sell more copies, and in the hope that some purchasers of the Complete Shakespeare might be willing to replace it with a More Complete Shakespeare" ("Desire and Pursuit" 291). Jowett suggests that this edition was "probably issued without Pope's involvement" ("Supplemented" 51), though this is certainly not true of the edition as a whole: the Preface is revised, and Murphy notes that the edition incorporates many corrections occasioned by Lewis Theobald's 1726 Shakespear Restor'd (Shakespeare in

\footnotetext{
${ }^{29}$ Dobson links this to the elevation of theatre criticism begun by Addison and Steele in the Tatler and Spectator at the start of the century, which similarly tended to treat the plays as texts to be read rather than to be seen (126).
} 
Print 69$).{ }^{30}$ Whether or not Pope had a say in the addition of the ninth volume is, from the perspective of a reader, irrelevant: the seven plays are, by their silent inclusion, presented without qualification as authentic. Despite the fact that Pope was the first editor of a Complete Works in over sixty years expressly to deny the authenticity of the plays, and despite the continued appearance of this denial in the 1728 preface, the publisher continues to authenticate them via their inclusion. For editors to debate and devalue elements of the canon is one thing, but for publishers actually to remove them from view is quite another. ${ }^{31}$

Jowett argues that "over the course of half a century and more [the 1664 additions] must have become embedded in many readers' sense of what constituted Shakespeare" ("Supplemented" 52). If this is the case, then the implication is that the commercial imperative overrides the critical, prompting the devaluation of the editorial front matter by the appending of a volume that contradicts the edition's ethos. Publishers cater to the demands of a reading public that wants to see the Shakespeare with which it is familiar. This pattern is replicated throughout the history of editing Shakespeare, where published editions of complete works as often reflect popular and commercial conceptions of the canon as they do contemporary critical thought: here, as with Pope's 1728 edition, the commercial need for "completeness" in relation to competing editions overrides the immediate editorial concern. It takes time to break down a canon presented as a unified entity.

Although textual historians identify Pope as the key agent in removing the apocryphal plays from collected editions of Shakespeare, therefore, it was in fact Lewis

\footnotetext{
${ }^{30}$ This is in spite of Pope's public rejection of Theobald's volume. The problems of silent emendations based on others' notes is endemic throughout the eighteenth-century editorial tradition, where editors regarded their emendations as an early form of intellectual property. Steevens was particularly infamous in this regard: John Collins, publisher of Capell's commentaries, went so far as to accuse him of plagiarism (Murphy, Shakespeare in Print 90-91). ${ }^{31}$ The surviving correspondence of Pope does not reveal any thoughts regarding the addition of the ninth volume.
} 
Theobald's 1733 edition that enacted their lasting removal. This is particularly interesting as it contradicts Theobald's own statement regarding them: he tantalisingly informs the reader, "I can, beyond all controversy, prove some touches in every one of them to come from his pen" (1.vii). The position of the 1728 edition has been completely reversed: where Pope denied the plays' authenticity and yet included them, Theobald supports their (at least partial) authenticity, yet excludes them. Theobald's lack of elaboration on this matter is frustrating, as this marks a turning point in the history of the Apocrypha, the point in the editorial chain at which the plays are most influentially banished. The fact that Theobald is ostensibly a supporter of the plays' partial authenticity implies that the reasons for their removal are motivated by other concerns. King, following Peter Seary's assertion that Theobald may have had no say in the extent of his edition, argues that Tonson would have dictated the constitution of Theobald's edition (“Cardenio"). However, Tonson's choice to publish the seven additions in 1728, and again in 1734-35, rather suggests that Tonson took every opportunity to publish the apocryphal plays. It remains likely, therefore, that Theobald was at least partially responsible for their exclusion.

The feud over Double Falsehood offers what is perhaps the most plausible explanation. In 1726, Theobald published Shakespeare Restored, an intelligent but often pedantic criticism of the errors in Pope's edition of Shakespeare. The very title, positioning Theobald as Shakespeare's saviour, can be read as an attack on Pope's scholarship, an attack that Pope took personally. The feud was intensified shortly after by the appearance of Theobald's play Double Falsehood, first performed and published in 1728 . While there is now a greater critical willingness to accept the possibility of the play preserving something of Shakespeare and Fletcher's Cardenio, Theobald's 
contemporaries were sceptical of the attribution, giving Pope the opportunity to publicly humiliate Theobald. ${ }^{32}$

In the Preface to the first edition of Double Falsehood, Theobald addresses the most obvious objections to Shakespeare's authorship and dismisses all other complaints as "far from deserving any answer". However, he also admits that his own "partiality... makes me wish, that every thing which is good, or pleasing, in our tongue, had been owing to his pen" (Preface). This admission of Bardolatrous sentiment is indicative of Theobald's pre-emptive eagerness to associate Shakespeare and poetic quality wherever possible. The second edition, also 1728, extends the claims. "I had once designed a Dissertation to prove this play to be of Shakespeare's writing, from some of its remarkable peculiarities in the language, and nature of the thoughts: but as I could not be sure but that the Play might be attacked, I found it advisable, upon second consideration, to reserve that part to my defence" (Preface). He goes on to announce that he has begun work on a new "corrected" edition of Shakespeare's plays (again implicitly criticising Pope's edition). He anticipates that his edition "may furnish an occasion for speaking more at large concerning the present play" (Preface). Theobald is already taking a defensive position, protecting his intellectual property. His protestations are often suspicious: he apparently has proofs of the authenticity of Double Falsehood and of the 1664 additions, as well as no fewer than three manuscripts, yet chooses not to make any of them public despite the support these "proofs" would lend to his arguments. A reader could be forgiven for questioning whether these proofs ever indeed existed.

\footnotetext{
${ }^{32}$ The current positive attitude towards Double Falsehood's Shakespearean connection was initiated by Gamaliel Bradford Jr and expanded on by John Freehafer, Stephan Kukowski, Bate (Genius 76-82), Proudfoot ("Canon" 75-81), and most fully in Hammond's edition of Double Falsehood for the Arden Shakespeare. See Chapter Four for detailed discussion.
} 
The exclusion of Double Falsehood and the 1664 additions from Pope's 1733 edition of the complete works is therefore a complex issue. The conflation of two decisions - whether to include the contested plays after Pope's original decision to omit them, and whether to include a version of Double Falsehood - linked plays of doubtful authorship to one of contested and perhaps fraudulent provenance. Despite the editor's defence of them, all were equally tainted in their omission. Pope's 1728 edition gave a precedent for their inclusion that Tonson and/or Theobald decided not to use, and Tonson's reprinting in 1734-35 demonstrates that he still maintained an active claim to them. We must conclude, then, that the decision to exclude all eight plays was taken deliberately, reverting to the earlier model of the canon based on Pope's first edition, which itself derived authority from the 1623 folio. The 36-play canon may not be "complete" according to Theobald's beliefs, but it is undoubtedly safe and thus rescues Theobald's reputation. Pope had, in 1729, ridiculed Theobald as "Tibbald", the antihero of The Dunciad, "one who hath been concerned in the Journals, written bad Plays or Poems, and publish'd low Criticisms" (166). He explicitly mocked Double Falsehood in his footnotes (158n.ff.). Valerie Rumbold notes that “[Theobald's] attribution to Shakespeare prompted widespread ridicule" (293n), and that this therefore provided solid ground for Pope's attack. In the persona of "Scriblerus" he first mocks the shaky ground on which Theobald made his attribution (illegitimate family connections and hearsay), highlights Theobald's own admission of his partiality for Shakespeare and then goes on to parody the style of Shakespeare Restored by mock-correcting various passages from Double Falsehood, using Theobald's own language against him. ${ }^{33}$ In Pope's hands, the play is remade as a site of editorial and textual folly, essentially an acknowledged and recognisable joke.

\footnotetext{
${ }^{33}$ The line "None but Thy self can be thy parallel" is incorporated into The Dunciad (3.272) as a platform for Pope's critique, and Hammond devotes an appendix to discussion of the (mis)fortunes of this line (322-24). Pope's parody of Theobald's editorial style is deliberately pedantic. Jones offers a detailed account of the Pope/Theobald war of letters (100-55).
} 
Pope's criticism thus attacks Theobald not on the grounds of scholarship where Theobald was superior, but on poetic and artistic grounds. Theobald's admission of "partiality" for Shakespeare, and the general association of the Bard with poetic quality, created an opportunity for Pope, who attacked the quality of Double Falsehood, and thus by implication its authenticity. In effect, Pope (the celebrated poet) accepts Theobald's criteria but rubbishes the lawyer's ability to judge according to those criteria. Murphy (Shakespeare in Print 74) tells us that Theobald's reputation was badly damaged by Pope's attacks. It is not only the ongoing controversy over the authenticity of Double Falsehood that warranted its exclusion, but also the undermining of Theobald's "connoisseurship" (King, "Cardenio"), his critical faculty. It is only logical, then, that this is reflected in Theobald's exclusion of the rest of the disputed plays: following Pope's rejection of them, Theobald appears to have doubted his own ability to authenticate them. As King notes, despite Pope's initiation of a newly "interventionist" form of editing, Theobald chooses to restrict his opinions to his preface and footnotes: what King identifies as "ambivalence", I suggest might be even more strongly understood as editorial insecurity. ${ }^{34}$ Pope's "victory" in this dispute thus allowed him to dictate the shape of the Shakespeare canon.

The 43-play canon, then, became a casualty of a burgeoning culture of Bardolatry that, in Pope's practice, treated aesthetic quality as a form of objective proof and prioritised authorial reputation over textual origins. The plays were excluded, not for being demonstrably un-Shakespearean, but for being subjectively "wretched", and their exclusion was perpetuated in Theobald's subsequent edition owing to Theobald's lack of conviction in countering Pope's criteria. This was the most significant moment

\footnotetext{
${ }^{34} \mathrm{Cf}$. Jones: "I am rather confident that he did not himself really believe Shakespeare was the author... a man of Theobald's thoroughgoing scholarly nature, who insisted that all conclusions should be supported by proof and authority, would not have rested content with the feeble reasons [of the preface]" (105).
} 
yet in the stigmatising of the disputed plays, the point at which they were first removed from the canon for being aesthetically deficient according to a Shakespearean standard; yet this standard was determined subjectively by Pope.

Pope's specific role in removing the plays, however, was quickly forgotten. With the disappearance of the plays from collected editions of Shakespeare, the plays fell into critical neglect, and references to them became less frequent. However, volume XC of the periodical The Adventurer (1753) provides a sense of how quickly Pope's opinion of the plays had become standard..$^{35}$ The periodical, whose contributors included John Hawkesworth, Samuel Johnson and other members of the literary elite, followed the example of journals such as The Tatler and The Spectator in purporting to represent and influence contemporary tastes and manners. Volume XC, signed by "CRITO", is specifically concerned with great authors and the wish that "unworthy stains could be blotted from their works" (115). The writer (identified in the ODNB as John Duncombe by M. John Cardwell) describes a dream in which all of the authors whom he considers great line up at a heavenly altar to sacrifice those aspects of their work that warrant purgation, with Aristotle and Longinus overseeing. The dream is an opportunity for the writer to describe in detail those aspects of the authors' canons that he feels unworthy of their name, and dramatically to enact a process of selective canonisation that is explicitly concerned, not with truth or textual fidelity, but with lasting fame. Shakespeare's offering is described thus, and is worth quoting in full.

Shakespeare carried to the altar a long string of puns, marked "The Taste of the Age," a small parcel of bombast, and a pretty large bundle of incorrectness. Notwithstanding the ingenuous air with which he

\footnotetext{
${ }^{35}$ The Adventurer has received surprisingly little critical attention, and the significance of Issue XC as representative of eighteenth-century conceptions of the Shakespearean canon has not been previously noted.
} 
made this offering, some officiates at the altar accused him of concealing certain pieces, and mentioned The London Prodigal, Sir Thomas Cromwell, The Yorkshire Tragedy, \&c. The poet replied, "that as those pieces were unworthy to be preserved, he should see them consumed to ashes with great pleasure; but that he was wholly innocent of their original." The two chief priests interposed in this dispute, and dismissed the poet with many compliments; Longinus observing, that the pieces in question could not possibly be his, for that the failings of SHAKESPEARE were like those of HOMER, "whose genius, whenever it subsided, might be compared to the ebbing of the ocean, which left a mark upon its shores, to shew to what a height it was sometimes carried." ARISTOTLE concurred in this opinion, and added "that although SHAKESPEARE was quite ignorant of that exact economy of the stage, which is so remarkable in the Greek writers, yet the meer strength of his genius had in many points carried him infinitely beyond them. (118-19)

Developing Pope's concern with posthumously preserving authorial reputation through selectivity, here Shakespeare becomes the instigator of a process of self-canonisation, a poet concerned above all with establishing an impeccable canon for posterity. It is significant that Shakespeare himself is evoked to refute his hand in the disputed plays. A stage tradition throughout the early eighteenth century had seen Shakespeare frequently appearing to provide prologues to performances of his works, thereby acting as an authorising agent. ${ }^{36}$ This was especially important in a culture where plays were usually adapted: Shakespeare was invoked in order to legitimise the contemporary reworkings that replaced his originals. Here, Shakespeare's presence provides the most

\footnotetext{
${ }^{36}$ Dobson lists examples including Gildon's 1700 Measure for Measure and Granville's 1701 The Jew of Venice (120 ff). The Prologue to Double Falsehood similarly invokes Shakespearean authority, though it ventriloquises Shakespeare rather than bringing him onstage.
} 
powerful possible refutation of the authenticity of the disputed plays, drawing a line under the entire argument. The pieces are denounced as unworthy, with Longinus suggesting that even "bad" Shakespeare has an echo of his genius, while these plays are so bereft of merit that they bear no resemblance whatsoever. Aristotle, meanwhile, makes apology for Shakespeare's "nature", his lack of adherence to the classical unities and the ancient constructs of theatre. This is countered through praise of his natural genius, producing great works despite what Aristotle terms as Shakespeare's "ignorance". ${ }^{37}$

In some respects, this essay marks the end of the Apocrypha's commercial profile. The Tonson cartel had not included the plays in a collected edition since that of Pope, now twenty-five years old, and the cheap 1734 individual editions were effectively disposable. Walker's collected edition does not seem to have achieved widespread circulation, unable to compete with the Tonson machine that had already supplanted earlier editions with Warburton's new text in 1743, and is absent from accounts of Shakespeare's textual history. As the plays disappeared from the public eye, The Adventurer chose to mark the moment by resurrecting Shakespeare himself in order finally to disown them at a sacrificial altar.

If the formal disowning of the Apocrypha was the final step in cementing Shakespeare's reputation, we may perhaps understand why Samuel Johnson (who one might well expect to have had an opinion on the disputed plays) made no mention of them whatsoever in his 1765 edition..$^{38}$ Instead, in his notes on The Two Gentlemen of Verona, Johnson echoes Longinus. "If [Two Gentlemen] be taken from him, to whom shall it be given? This question may be asked of all the disputed plays, except Titus

\footnotetext{
${ }^{37}$ On Shakespeare's "genius" and relationship to "nature", see especially Bate, Genius.

38 Johnson's involvement in The Adventurer may suggest a closer relationship between the essay and his edition; with the plays formally disowned in the journal, Johnson may well have considered the issue closed. Even Pericles is not mentioned in Johnson's edition.
} 
Andronicus; and it will be found more credible, that Shakespeare might sometimes sink below his highest flights, than that any other should rise up to his lowest" (qtd. in Sherbo 173). As in The Adventurer, Shakespeare's unique genius is assumed to be discernible even in his weakest plays, setting him apart from his contemporaries. While Johnson acknowledges that Shakespeare might "sometimes sink", there is still an implied base level of quality below which Shakespeare does not descend, and to which no other writers rise. Plays that do not meet this standard are, therefore, not Shakespeare's. Duncombe's "sacrifice" of the Apocrypha is made complete in Johnson's silence on the plays: for Johnson, they no longer exist.

\section{Biography, Chronology, Bardolatry: 1760-1844}

For Gordon McMullan, writing on the idea of a "late period" in the works of a given artist, the governing principle of canonical organisation by chronology is "synecdochic of the biographical urge in general" (Late Writing 3). His pioneering study asserts that the "late" period is a subjectively created construct in which internal order is "determined by its value for the overall argument" (104); so, for example, The Tempest becomes Shakespeare's last play, both as a crowning artistic achievement and as a valedictory farewell to the stage. ${ }^{39}$

McMullan's study focuses on the "late" plays, and he argues that the idea of a Shakespearean late style cannot predate Edmond Malone "for the simple reason that nobody prior to Malone had made the effort to create a coherent and considered Shakespearean chronology" (128). McMullan is partially correct insofar as the conception of a formal grouping for the "late" plays is concerned; but the valuation and

\footnotetext{
${ }^{39} \mathrm{~A}$ position that, as McMullan points out, is inconveniently undermined by the fact of Shakespeare's later collaborations with Fletcher. Collaborative authorship creates significant problems for subjective readings of biography and chronology: "After all, if you don't know which line was written by which playwright, how can you reach useful biographical conclusions?" (Late Writing 4).
} 
explication of the canon according to biographical and chronological assumptions had been a part of discourse for several decades previously. As Alice Walker points out, Edward Capell - writing several decades before Malone - even correctly identified the late plays where Malone failed (147). ${ }^{40}$ This earlier sense of chronology also underpins attempts to explain the apocryphal plays as early or sophomore work; a line of thought which, as we shall see, has been in circulation almost as long as the plays themselves.

In his "Account of the Life" of Shakespeare, Rowe refers to John Dryden's suggestion that Pericles may have been one of Shakespeare's first plays (1.vii). The statement comes from the revised version of Dryden's prologue to Charles Davenant's Circe, in which he defends any charges of inferiority in Davenant's debut play by pointing out that even the three great dramatists of the age faltered at first: Jonson and Fletcher "hopped about" and made "short excursions", while

Shakespear's own Muse her Pericles first bore, The Prince of Tyre was elder than the Moore:

'Tis miracle to see a first good Play,

All Hawthorns do not bloom on Christmas-day. $(292)^{41}$

Shakespeare first penned the implicitly inferior Pericles ahead of the masterwork Othello, but the weaker work is excused as "Tis miracle to see a first good play." Only twenty years after the 1664 folio, Pericles is already judged to be inferior, yet this is

\footnotetext{
${ }^{40}$ Capell judged Cymbeline, Henry VIII, The Winter's Tale and The Tempest to be Shakespeare's final compositions (A. Walker 147); Malone suggested Coriolanus, Othello, The Tempest and Twelfth Night. Given McMullan's emphatic insistence on the phenomenon's emergence postMalone, his entire omission of Capell in his discussion of the development of the idea of Shakespeare's late writing is a significant oversight.

${ }^{41}$ The original 1677 Prologue to Circe was heavily revised for the Epilogue of 1684, with the references to Shakespeare, Fletcher and Jonson only being added in the revision.
} 
justified not through questioning authenticity but through asserting chronology. ${ }^{42}$ Early plays are understood to be aesthetically less pleasing, predating the artist's development into poetic maturity, and therefore both play and dramatist are excused by biography. ${ }^{43}$ Biography became an increasingly major concern for eighteenth-century critics, beginning with the very presence of a "Life" of Shakespeare in Rowe's edition. Yet we shall see that, while Dryden used biography to excuse artistic weakness, later editors would expunge artistic weakness in order to preserve biography. The "life" was to become arguably more important than the "works".

This early comment is practical and sympathetic in its treatment of Shakespeare as a working dramatist capable of producing less-than-perfect work. While Dryden's assumption of Pericles' date is incorrect, he sees no problem in attributing a fringe play to Shakespeare on the assumption that it represents early work: to include such a play in the canon does not, for Dryden, diminish Shakespeare. While Erne has demonstrated the popularity of Shakespearean playbooks in the seventeenth century, it was only during the eighteenth century that the works began to be elevated to the status of literature, made possible by the formal editing of the plays. At the time of Dryden's writing, deficiencies in the canon could not impair Shakespeare's reputation, as that reputation had not yet been established. As literary canon and reputation were consolidated, however, plays judged to be weak posed a threat to author and corpus.

Rowe addresses Dryden's suggestion of an early date for Pericles thus: "There is no judgment to be form'd on that, since there is good reason to believe that the greatest part of that play was not written by him; tho' it is owned, some part of it

\footnotetext{
${ }^{42}$ George Steevens took issue with the argument that earlier plays were necessarily of lesser quality, pointing out that both Dryden and Rowe themselves continued to write lesser plays after their greatest works $(1778,1.264)$.

${ }^{43}$ See also T.S. Eliot on the importance of maturity - both biographical and cultural - to the establishment of the classic text.
} 
certainly was, particularly the last act" (1.vii). The question of collaboration is, in Rowe's comment, conflated and confused with that of chronology. The inferiority of Pericles implied by Dryden may be caused by either the author's immaturity or his dilution by another hand. ${ }^{44}$ While both writers are silent on what aspect(s) of Pericles have occasioned this judgement, their comments acknowledge a divide between Pericles (and by association, the other apocryphal plays) and the core Shakespeare canon, yet a division which does not prevent the play from being considered Shakespearean.

The work of Edward Capell in the 1760s had important implications for the disputed plays, summarising and consolidating the views of previous editors and critics while also expanding the pool of disputed plays drawn on by succeeding generations of Romantic critics. Capell was the first editor to produce an edition of Shakespeare's plays built "from the ground up" (Murphy, Shakespeare in Print 86), rather than marking up a copy prepared by one of his predecessors. His 1768 edition of the plays places great emphasis on early quarto publications, and his "ground up" approach leads him to make new claims about the size and shape of the Shakespeare canon.

In 1760, Capell published Prolusions; or, Select Pieces of Antient Poetry, a collection of "editorial experiments" (A. Walker 143) that included the first modern edition of the anonymous Edward III, "a play, thought to be writ by Shakespeare" (title page). Capell's "evidence" for this attribution is negligible: he admits that "it cannot be said with candour that there is any external evidence at all" (ix) and "it must be confess'd that it's being his work is conjecture only, and matter of opinion; and the reader must form one of his own, guided by what is now before him, and by what he shall meet with in perusal of the piece itself" $(\mathrm{x})$. What is significant, however, is that this

\footnotetext{
${ }^{44}$ Rowe may additionally be said to sow the seeds of "disintegration" in his comments here, which not only suggest a collaboration but even identify the section most likely to be Shakespearean.
} 
is the first critical attribution of a play to Shakespeare on entirely internal grounds. ${ }^{45}$

Capell suggests that the play's source in Holinshed connects it to Shakespeare, but more importantly "something of proof arises from resemblance between the stile of his earlier performances and of the work in question," and "there was no known writer equal to such a play" (ix). ${ }^{46}$ With no more detail provided, Capell's judgement of the play appears entirely subjective, yet there is an important association between the play and the idea of chronology that assumes the importance of the latter. Implicitly, Shakespeare's early work remains beyond the scope of any other writer of his time. While accepting a development in writing style and quality over Shakespeare's career, then, Capell also contributes to the discourses of Bardolatry that separate Shakespeare from his peers.

Eight years later, Capell's ten-volume edition of Shakespeare was published. In his preface, he goes far beyond the relatively modest claims of Prolusions, suggesting that Shakespeare may have had a hand in as many as twenty-two plays not included in the 1623 folio: the seven 1664 additions; eight that are "either first drafts, or mutilated and perhaps surreptitious impressions of those plays" $(1.2) ;{ }^{47}$ and seven "upon good grounds imputed to him" (1.10): Fair Em, Mucedorus, The Merry Devil of Edmonton, ${ }^{48}$

\footnotetext{
${ }^{45}$ Although, as is regularly noted, Rogers and Ley's "Exact and perfect Catalogue of all the Playes that are Printed" (1656) gave the play to Shakespeare, along with Marlowe's Edward II and Heywood's Edward IV.

${ }^{46}$ Melchiori's discussion of sources in his 1998 Edward III is instructive. See especially 17-39.

${ }^{47}$ Capell's introduction is oddly organised, splicing his discussion of the apocryphal plays with discussion of other quarto editions. He appears to be referring to: 1 and 2 The Troublesome Raigne of King John, The First Part of the Contention, Richard Duke of York, The Taming of a Shrew, Romeo and Juliet (1597), Henry V (1600) and The Merry Wives of Windsor (1602), all considered different enough from the authentic versions of the play to count as separate plays.

${ }^{48}$ The Charles I volume that contained these plays was in Garrick's personal collection. Capell and Garrick were great friends (A. Walker 135), and Capell catalogued Garrick's extensive library after the latter's death. The attribution is strengthened by the association of Mucedorus and Merry Devil with the King's Men, by the attribution of these two plays to Shakespeare in the catalogues of Archer (1656) and Kirkman (1661) and by a 1653 entry by Moseley attributing Merry Devil to Shakespeare. Fair Em has largely entered the Apocrypha through association with these two plays, demonstrating the weight accorded the Charles I volume's evidence. See Appendix for further discussion.
} 
The Arraignment of Paris, ${ }^{49}$ The Birth of Merlin, The Two Noble Kinsmen and Edward III (1.14n), all given additional attention in his "Table of the Editions". Certain of this last group, Capell suggests, may have been written in Shakespeare's early years for venues "frequented by the lowest of people" (1.16n), linking the disputed plays not only with early chronology but also with disreputable provenances (with the implicit reminder that Shakespeare wrote for much more prestigious audiences in his later career). This is the first editorial list to associate several of the plays with Shakespeare, and this collection of titles would form the core of Brooke's Apocrypha some 150 years later.

Capell thus constructs a picture of a Shakespeare who wrote many more plays than those given to him in the 1623 folio, with the excluded plays associated with youthful endeavour and unsavoury theatrical environments. He shares Theobald's belief in the authenticity of disputed plays, and Dryden's inclination to ascribe to them an early date. However, the construction of his canon is closer to Pope in principle, preserving Shakespeare's reputation through exclusion. Rather than Capell-as-editor intervening on Shakespeare's behalf, Capell-as-critic follows The Adventurer in ceding to Shakespeare the responsibility of self-canonisation. He offers the belief that Shakespeare began to plan a volume of collected works before his death, selecting the plays that made up the 1623 folio (1.46-48). Despite Capell's own beliefs regarding the plays' authenticity, and his active championing of Edward III elsewhere, he concludes: "[Shakespeare] himself has proscribed them; and we cannot forbear hoping, that they will in no future time rise up against him, and be thrust into his works" (1.47). Capell is the first editor to articulate the threat of the Apocrypha as an attack, even a revolution, in which Shakespeare's own works might turn on him in a bid to destroy his reputation. In respecting what he

\footnotetext{
${ }^{49}$ Attributed to Shakespeare in Kirkman's 1661 catalogue. While Brooke mentioned this play in the introduction to his Apocrypha, by then the play's ascription to George Peele had been established. We have the testimony of Nashe that the play was Peele's "first encrease", and sixteen lines of the play are included in England's Helicon (1600) with the signature "Geo. Peele" added (qtd. in Child v).
} 
considers to be Shakespeare's own wishes, he omits those "weak and idle pieces, the productions of green years, wantonness or inattention" (1.47). He even criticises Jonson, the only known precedent for a self-canonising dramatist, for his lack of similar judicious self-editing. Capell claims that if he had been more selective, "his character had stood higher than it does" (1.47).

The idea of self-canonisation is thus projected back onto Shakespeare the man. In opposition to the critical commonplace that Shakespeare was careless of his published work, Capell imagines him handpicking the plays that would best consolidate his reputation in posterity. ${ }^{50}$ Jonson's assertion in the 1623 Shakespeare folio that "he was not of an age, but for all time!" $\left(\mathrm{A} 4^{v}\right)$ aligns the two dramatists in the pursuit of literary canonisation. We are asked to respect Shakespeare's wishes rather than taint his memory with plays that he intended us to forget.

In Capell's work, then, ideologies surrounding biography, chronology and Bardolatry collide to assert the apocryphal plays as simultaneously Shakespeare's and not Shakespeare's. They belong to him bibliographically, as Capell acknowledges in the Table of Contents, and in some cases in style, as he argues in Prolusions. Similarly, Capell is content to accept them as examples of his genuine "green" work; implicitly inferior to the canonical plays but still Shakespearean. Yet they are excluded en masse from the body of Capell's edition because they are not canon, not part of Shakespeare the literary and cultural icon. They are authored, but not authorised, by Shakespeare.

The process of self-canonisation was enacted in other media during the mideighteenth century. De Grazia ("Quotation Marks") writes of the importance of the growing vogue for Shakespearean quotation books that grouped together under

\footnotetext{
${ }^{50}$ See, for example, Malone's characterisation of "the careless Shakespeare ... who did not think his works worth collecting" (Inquiry 293-4).
} 
convenient headings everything that Shakespeare wrote on a given theme. ${ }^{51}$ Quotes were taken out of their dramatic context: while the source text would be identified, the character was not, thus presenting the quotes as the direct, unmediated thoughts of Shakespeare himself. William Dodd's The Beauties of Shakespear (1752) began the trend of presenting Shakespeare's fiction in a "commonplace" format hinting at a universal truth embodied in the words, often with a title designed explicitly to present the words as Shakespeare's own advice or wisdom (e.g. The Wisdom of Shakespeare in 1909). ${ }^{52}$ As a consequence of this subculture, the importance of Shakespeare as individual man became paramount: no longer seen as a product of his time and culture, he instead became established as a moral and ethical ideal, a dispenser of wisdom and of timeless values.

Inclusions in dedicated Shakespearean quotation books of the eighteenth century were drawn solely from the core thirty-six plays, as endorsed by Pope and Capell (and, by implication, Shakespeare himself). It is worth noting, however, that quotes from disputed plays appeared attributed to Shakespeare in other quotation books, such as Thomas Hayward's The British Muse in 1738, which includes passages from "William Shakespear's Cromwell" (1.1), "Shakespear's London Prodigal" (1.20) and "Shakespear's Puritan" (1.224), among others. These attributions have no authority, deriving simply from the chosen quotation's only authorial association: but, from the perspective of a putative reader, they consolidate Shakespeare's authorship of these words. The very nature of the quotation book prioritises author above work, presenting the detached thoughts of the various individuals considered worthy of inclusion. Tellingly, the selections across the three volumes of The British Muse almost entirely exclude

\footnotetext{
${ }^{51}$ Quotation books were a wider phenomenon in the period. See de Grazia, "Quotation Marks" (60-66), Taylor, Reinventing Shakespeare (107-10) and Stallybrass and Roger Chartier, esp. 44-54. ${ }^{52}$ See de Grazia ("Quotation Marks" 65). This trend continued long into the twentieth century, and the Arden Dictionary of Shakespeare Quotations was issued for a fifth time in 2005.
} 
anonymous plays. It is the thoughts of known authors that the book seeks to convey, not the anonymous wisdom contained in unclaimed plays. ${ }^{53}$

As "Shakespeare" was constructed from his works, it followed that the constitution of those works needed to be determined and fixed. If quotation books, for example, were to summarise everything that Shakespeare wrote on a particular topic, then there had to be a defined limit to "everything that Shakespeare wrote." It is at this point that religious language began to be employed in the celebration of Shakespeare, culminating in Garrick's Stratford Jubilee of 1769 at which "the god of our idolatry" (Ode 1) was deified in a festival that included not a single word of Shakespeare's plays (Dobson 214); the paradox being, of course, that the man had himself been constructed from the plays in the absence of extensive biographical record. Shakespeare was by now being culturally disseminated at an unprecedented speed: quotation books became a household feature, while the publishing war of Tonson and Walker in the 1730s had flooded the marketplace with cheap editions of Shakespeare, increasing their availability. $^{54}$

The rise of the Shakespeare "religion" thus occurred contemporaneously with the consolidation and dissemination of the Shakespeare canon, the holy book of Bardolatry. The works were used in a quasi-biblical sense, a holy text that provided a physical link to the author, directly imparting wisdom and instruction. However, as with the Bible, this kind of reading is dependent on textual and canonical authority: if Shakespeare is to be made up from his works, then we must know that those works are in fact genuine, else one's "faith" is built upon a false premise. To create a foundational

\footnotetext{
${ }^{53}$ The only anonymous apocryphal inclusion is a single quotation from The Merry Devil of Edmonton used in the third volume (3.158). See also Stallybrass and Chartier 40-42.

${ }^{54}$ Goethe famously first read Shakespeare in Beauties (de Grazia, "Quotation Marks" 65); while Crawford and Edmund in Jane Austen's Mansfield Park refer to Shakespeare in terms of his "thoughts and beauties" and "his celebrated passages ... quoted by every body" (391).
} 
Shakespeare on which this religion could be built, only those plays beyond dispute could be canonised. The disputed plays were sidelined in favour of this authorised canon, which Capell implied Shakespeare had chosen himself.

There are further associations in this narrative that must not be ignored. Dobson speaks of the nationalisation of the corpus, the crowning of Shakespeare as the British national poet (185ff). As Shakespeare and the authorised canon were brought into line with a sense of patriotic culture, so too did the marginalisation of the apocryphal plays adopt the tone of contemporary snobbery that stigmatised social groups, such as the regional figures of Garrick's 1769 The Jubilee. ${ }^{55}$ We have already noted Capell's suggestion that the plays of the Apocrypha were written early in Shakespeare's career for playhouses "frequented by the lewest of people; such audiences as . . . may be seen at this day in the country" (1.14-17n). In addition to being marginal in terms of text, repertory and chronology, several of the apocryphal plays also represent marginalised genres and locales. ${ }^{56}$ The domestic tragedies Arden of Faversham and The Yorkshire Tragedy are humble both in subject and in their provincial settings; The London Prodigal and The Puritan represent humours and city comedy, "unShakespearean" genres more readily associated with writers such as Dekker, Jonson and Middleton; Locrine represents a dated form of Senecan tragedy (and the similar Titus would also be pushed to the fringe of the canon by the end of the century); and Cromwell and Oldcastle are examples of the episodic martyr histories associated with "lesser" dramatists such as Heywood and Rowley. ${ }^{57}$ It is worth noting that Henry VIII, the only play in the established canon set in the Tudor period, is generically and chronologically closer to the

\footnotetext{
${ }^{55}$ The play, based on the Stratford Jubilee, was performed exclusively in London, allowing Garrick to employ provincial stereotypes for comic value.

${ }^{56}$ Owing to the circularity of criticism informed by Bardolatry, it is inevitably the case that these genres are less exalted because they are not associated with Shakespeare. Russ McDonald argues that these prejudices operate even within the established Shakespeare canon (77-89).

${ }^{57}$ More is another example of this genre. However, the play was largely unavailable until Dyce's edition of 1844, and not connected with Shakespeare until 1871.
} 
"late" plays and was highly regarded in the post-Restoration years for its pageantry and poetry - qualities not predominant in the earlier plays concerned with Tudor history. ${ }^{58}$

The establishment of an identity does not only involve defining oneself positively according to one's own distinctive characteristics, but also defining oneself "negatively"; that is, by what one is not. In separating Canon from Apocrypha, Shakespeare was severed from ties to works of doubtful aesthetic merit. This allowed "Shakespeare" to be more easily elevated from the unromantic practical world of Renaissance drama to the status of national poet, dealing with universal and timeless themes rather than those that represented the provincial, popular and outdated.

Capell's claiming of Edward III for Shakespeare in 1760, followed by Edward Jacob's similar claims for Arden of Faversham in 1770, illustrate the potentially unsettling effect of the apocryphal plays on the newly exemplary and British Shakespeare. ${ }^{59}$ As Shakespeare increasingly became the property of Britain, it became more important that that property be clearly defined and controlled. Shakespeare's plays now had a national responsibility, and the Apocrypha posed a threat to the unity of the national poet's thoughts, diluting the content of the works at a time when Britain was asserting its own national identity. In 1760, Britain and France were engaged in the Seven Years' War. Henry $V$, depicting the English, Welsh, Scottish and Irish united against a common French enemy, was understandably a popular play at this point: it usefully anticipates the political state of affairs following the Act of Union, presenting Britain as a united force triumphing over its enemies. William Shirley's Edward The Black Prince (1750), written in imitation of Shakespeare, avoided the Scottish question entirely, and

\footnotetext{
${ }^{58}$ See McMullan, Henry VIII 17-37. Henry VIII's theatrical success can in part be attributed to Fletcher's popularity after the Restoration, the style being recognised even though the play was not known to be a collaboration at the time.

${ }^{59}$ Brooke reminds us that Jacob himself was a resident of Faversham (Apocrypha xiv). The national appropriation of Shakespeare as a paragon of national virtue is thus enacted on a microlevel for the benefit of a particular town. I have modernised the name of the town throughout this thesis for convenience except in quotations.
} 
appealed in jingoistic terms to English pride, coupling "England's ancient fame" and "great Shakspere's flame" in one rhyming couplet (Prologue). Edward III, by contrast, allies the French with the Scottish against the English, an unsettling and potentially inflammatory state of affairs at a time when the Act of Union was still relatively fresh. Similarly, Jacob's Arden associated Shakespeare with a provincial and domestic register, only a year after the nationalisation of Shakespeare at the Jubilee and Garrick's subsequent mockery of provincial folk. Both attributions thus went against the grain of the consolidation of Shakespeare's status, and it is perhaps of little surprise that neither gained currency until the next century.

While Capell and Jacob each opened up the possibility of attributing new plays to Shakespeare, then, it would be many decades before this possibility was embraced in Britain, where both Shakespeare and canon were engaged in a process of limitation and definition. The editions of Johnson, Steevens and Malone in the late eighteenth century, followed by the Cambridge and Globe Shakespeare of the mid-nineteenth, established the constitution of the official canon until the early twentieth century, while the mass market of British Shakespeare publishing almost entirely ignored the Apocrypha during the late eighteenth and early nineteenth centuries (with the exception of Malone's 1780 Supplement, discussed below)..$^{60}$

The lapse of interest in the Apocrypha in Britain was, however, enthusiastically countered by Romantic critics in Germany. Most notoriously, in a letter of 1821 Ludwig Tieck suggested that the canon be extended to sixty-seven plays, and during his career he edited or oversaw the publication of translations of some sixteen apocryphal plays. ${ }^{61}$

\footnotetext{
${ }^{60}$ Murphy notes that over 800 new collected editions of Shakespeare were published during the nineteenth century, an average rate of one every six weeks (Shakespeare in Print 167). The canonicity of Pericles and Titus Andronicus remained contentious during this period, however. ${ }^{61}$ Altenglisches Theater (1811) included The Troublesome Reign of King John, George a Greene, Pericles (Vol. 1); Locrine, The Merry Devil of Edmonton and King Leir (Vol. 2). Shakespeare's Vorschule (1823-29) included Friar Bacon and Friar Bungay, Arden of Faversham, The Witches of
} 
Where British scholars had suppressed the apocryphal plays over a long period as part of the movement towards consolidating Shakespeare as national icon, German criticism was motivated by different concerns. Roger Paulin notes that Tieck's Shakespeare criticism had its own national agenda: Shakespeare offered the "supreme model for emulation" (249) by the burgeoning German national theatre. Tieck's extension of the canon was the result of a bid to recover Shakespeare's juvenilia, in order to create a canon that was unlearned and chaotic, demonstrating the dramatist's "popular universality" and thus countering the influence of French neoclassicism. As well as intending to uncover the works that would give a fuller sense of Shakespeare's development, his hope was that an understanding of Shakespeare's full range and mastery of popular styles would be emulated in Germany to create a "truly nationally based theatre" (249). Where British Bardolatry had attempted to reduce Shakespeare to a perfect and unified cultural ideal, German Bardolatry prompted Tieck to try to find Shakespeare in all walks of life.

The belief that the apocryphal plays represent Shakespeare's early work was a long-standing one, as evidenced by Dryden and Capell. Jacob, too, had suggested that Arden was Shakespeare's "earliest dramatic work" (title page), and expanded upon this in his Preface.

MR. Rowe, in the Preface to his Edition of Shakespear's Plays, says "it would be without Doubt a Pleasure to any man curious in Things of this Kind, to see and know what was the first Essay of a Fancy like his." It is

Lancashire (Vol. 1); Fair Em, The Birth of Merlin and The Second Maid's Tragedy (Vol. 2). A third volume would have included Mucedorus, The Fair Maid of Bristow and Nobody and Somebody. In 1836, he oversaw the publication of Edward III, Thomas Lord Cromwell, Sir John Oldcastle and The London Prodigal in Vier historische Schauspiele Shakespeare's. Other plays he attributed to Shakespeare included Wily Beguiled, Satiromastix, The Battle of Alcazar and the Ur-Hamlet. Jansohn provides full discussion, though with some disappointing errors such as her claim that the attribution to Shakespeare of The Puritan and Mucedorus is unique to Tieck "Ludwig Tieck" 50). Jansohn notes that "the reader is continually referred to the promised book on Shakespeare for more detailed discussion" (50), which was never published. 
therefore submitted to the discerning Critics to determine, whether this anonymous Tragedy of Arden is not the Thing so long wished for. (iii)

A shift has taken place. Where Dryden and Capell had used chronology to attempt to account for weaknesses in plays they believed were by Shakespeare, Jacob speaks of Shakespeare's earliest work as "the Thing so long wished for". Biography now becomes the aim, not the explanation: Jacob looks to fill in a perceived gap in Shakespeare's canon by attributing a new play to him. It is this line of inquiry that was embraced by both English and German Romantic critics in the early-nineteenth century, in accordance with a rising interest in biographical readings and Malone's pioneering attempts to establish a detailed chronology for the plays. ${ }^{62} \mathrm{~A}$ fragment in Samuel Taylor Coleridge's writings on the chronology of the Shakespearean canon, for example, suggested that The London Prodigal, Thomas Lord Cromwell, Henry VI, Edward III, The Troublesome Reign of King John and The Taming of a Shrew made up Shakespeare's "First Epoch", with Pericles as a transitional ubergangswerke linking to the Second Epoch (Foakes 1.209-10). ${ }^{63}$ Paulin notes the shared interest of Malone and Tieck in biography (241), but this rather overlooks the very different ways in which the two critics approached biography. Where Malone relied on hard evidence to construct biography, the Romantics "uncovered" new plays based on their preconceptions about biography.

The work of Schlegel and Tieck was highly regarded in the early nineteenth century, the insights of German scholars compensating for what some perceived to be a poor period for Shakespearean criticism in England. Collier wryly noted that the production by England of "the best dramatic poet that ever lived" had been

\footnotetext{
${ }^{62}$ See McMullan (Late Writing 128-36), and de Grazia (Verbatim 141- 51) on Malone's chronology; Bate (Genius and Constitutions 144ff) and Taylor (Reinventing 101-59) on Romantic treatments of Shakespeare.

${ }^{63}$ This fragment is undated, but assumed by Paulin (246) to postdate his remarks of 1811 that "if he had touched any of them, it was only very lightly and rarely" (qtd. by Collier, reprinted in Foakes 133.
} 
counterbalanced by "the most puerile and incompetent annotators and critics upon that poet" (qtd. in Paulin 243). Paulin notes that it is therefore unfortunate that Tieck is now more associated with the "most speculative and untenable aspect of his work" (243): that is, his belief in the veracity of Shakespeare's claim to the apocryphal plays. As Charles Knight remarked in 1841:

It is exceedingly difficult for us to understand how a man of great ability, like Tieck, perfectly conversant with the dramatic art and style of Shakspere - sometimes going far beyond Shakspere's own countrymen in sound as well as elevated criticism - should fancy that a play like [Fair $E m]$ could have been written by our great poet. (Doubtful Plays 305)

It is testament to the stigma attached to the Apocrypha that Tieck and Schlegel's comments on the plays have overshadowed the rest of their Shakespearean criticism. In 1810, Schlegel's influential "Lecture XII" was published, including an appendix that suggested that several of the disputed plays might be authentic. Schlegel's comments rarely extend to more than a few words, and he admits that he has never seen or read several of them, including The Accusation of Paris (sic), The Birth of Merlin, Edward III, The Fair Emma (sic), Mucedorus and Arden, the last of which he assumes is a personal tragedy concerning an ancestor of Shakespeare's mother. ${ }^{64}$ The remark which perhaps occasioned the bulk of the scorn heaped on the appendix is his opinion that Cromwell, Yorkshire Tragedy and Oldcastle "are not only unquestionably Shakespear's, but in my opinion they deserve to be classed among his best and maturest works" (qtd. in Hazlitt, Characters 259). Despite being one of the few critics of the period who distributes apocryphal plays throughout Shakespeare's chronology rather than at the start, however, Schlegel's essential concern is still to use the Apocrypha to expand biography.

\footnotetext{
${ }^{64}$ An English translation, along with counter-arguments against Schlegel's opinions, may be found in Hazlitt's Characters of Shakespear's Plays 256-60.
} 
He feels, for example, that Titus unmistakably prefigures Lear, with Shakespeare experimenting with the presentation of aged insanity in the former before realising its full potential in the latter. Tieck took a similar approach in his suggestion that Alice in Arden of Faversham prefigures Lady Macbeth (Jansohn, "Ludwig Tieck" 48).

Considering the relative brevity of Schlegel's appendix, and Thomas G. Sauer's judgement that "he was probably merely repeating Ludwig Tieck's opinions" (164), reviewers paid disproportionate attention to this section. Sauer notes that contemporaries "understandably dismiss[ed] the comments on the spurious plays, but they [did] not let them undermine their appreciation of the rest of Schlegel's critical remarks" (79). By the 1830s and 40s, however, Paulin notes that British criticism was once more in the ascendency and Schlegel and Tieck's comments on the apocryphal plays were increasingly used as ammunition in the move away from the influence of German Romanticism on English Shakespeare criticism. Delius in 1846, dismissed Tieck's work as "inspired guesswork" (qtd. in Paulin 258). ${ }^{65}$ Dyce, in 1844, was more damning. “[Tieck] can enter into the spirit of Shakespeare's works ... [but] he (as every foreigner must be ... ) is utterly incompetent to write verbal criticism on the meanest, far less on the greatest of English poets" (qtd. in Paulin 257). Dyce's stance, suggesting that only the "English" are qualified to write about their poet, is in the same vein as Charles Knight's move to reclaim "our" poet. While German criticism had claimed Shakespeare as its own, the case of the apocryphal plays demonstrated to British minds the insufficiency of German understanding of the culture and language. Shakespeare was thus reclaimed for Britain, the only nation that truly appreciated him. ${ }^{66}$ By the time

\footnotetext{
${ }^{65}$ Nicolaus Delius began preparing his own collection of "Pseudo-Shakespearian dramen" in 1854-56, choosing choice plays connected to the canon including Edward III and Arden of Faversham. It was this project that Warnke and Proescholdt continued in the 1880s with their own editions.

${ }^{66}$ In Characters of Shakespear's Plays, Hazlitt had already expressed the opinion that Schlegel "was not very well acquainted with the dramatic contemporaries of Shakespear, or aware of their
} 
Brooke came to edit the Apocrypha, Schlegel and Tieck were among the Germans ridiculed as "incapable of appreciating the delicacies of the English style" and "dazed by the newly discovered and ill-understood brilliance of the Shakespearian drama" (viii). It is perhaps fitting, considering the xenophobic prejudice that underpins these remarks, that the final shaping of the Shakespeare Apocrypha would be left to Brooke - an American.

\section{Canonising the Apocrypha: 1780-1908}

The increased degradation of the disputed plays was, as we have seen, part of the process of canonising Shakespeare as the British national poet. Notions of their spuriousness developed incidentally rather than consciously: those critics who mentioned the plays tended to believe in their partial authenticity, while those who didn't (with the notable exception of Pope) tended to ignore them rather than explicitly pursue their falsity. However, the disappearance of the plays from collected volumes of Shakespeare did not remove them from discourse entirely. A concurrent strand of scholarship and connoisseurship from the late eighteenth to the early twentieth century sought to rehouse the plays in more suitable formats, reflecting a new set of assumptions concerning authenticity.

Steevens's 1778 reworking of Johnson's edition showed some casual interest in the question of the Apocrypha, surprisingly coming out in support of the authenticity of The Yorkshire Tragedy. Steevens suggests that the survival of this playlet alone from the Four Plays in One was owing to Shakespeare's authorship. Noting that it was a King's Mens' play and boasted Shakespeare's name in full, he argues that "Shakespeare ... would naturally have taken some opportunity to shew his impatience at being rendered 
answerable, in a still more decisive manner, for entire compositions which were not his own" (1.263-64). Shakespeare, imagined to have a measure of control over publications, must have "allowed" this volume into print, thus proving its authenticity. The weaknesses of this argument are immediately transparent, as they would apply also to The London Prodigal, but Steevens pursues the matter no further. Like Capell, whose work he knew, Steevens suggests that the folio must remain the ultimate authority and that the plays included in it were specifically selected for inclusion. Steevens, though, gives the role of selection to Heminge and Condell as "discerning friends to the reputation of their associate" (1.264), suggesting that works considered to be unworthy of Shakespeare were ignored. Canonisation is thus envisaged as a joint responsibility of author and editor: Shakespeare is imagined as having direct control over what was published under his name during his lifetime, while sympathetic editors are licensed to make canonical decisions after his death. Canonicity and authenticity remain separate issues, with editors licensed to make decisions regarding the former according to what are perceived to have been Shakespeare's own wishes.

The eighteenth century's most sustained and influential treatment of the Apocrypha followed shortly thereafter. Edmond Malone's work built on Capell's, placing a particular emphasis on documentation and historical context to enhance understanding of the plays. The first fruits of his study were his 1780 Supplement to the 1778 Johnson-Steevens edition, which includes extensive Prolegomena, additional notes on the plays and fully edited texts of the poems and apocryphal plays.

Malone's strength, as highlighted by de Grazia (Verbatim), is the relative extent to which he is able to dissociate his work from matters of aesthetic or cultural value and instead treat the texts from the point of view of a scholar and historian, with a new and revolutionary emphasis on authenticity. Notably, Malone's first forays into Shakespeare 
were on works considered more or less spurious. ${ }^{67}$ In this sense, Malone's approach is in accord with Vickers's later assertion that "No issue in Shakespeare Studies is more important than determining what he wrote" (Co-Author 3): before beginning his own edition, Malone first aimed to tidy up and establish the outer limits of the canon.

The status of the 1780 volumes as a "Supplement" allows Malone to append the 1664 additions to Johnson and Steevens's edition in a spirit of academic interest. De Grazia notes that one of Malone's greatest contributions to the study of early modern drama was to use the works of Shakespeare's contemporaries to gloss the plays (Verbatim 112). In doing so, Malone not only revived interest in relatively neglected dramatists, but also anticipated modern repertory studies that insist on the importance of a broader view of the early modern drama as essential to an understanding of Shakespeare. ${ }^{68}$ As such, the apocryphal plays are inherently of interest even if not authentic. Malone freely admits he believes that "of the majority of them not a single line [was] written by our great poet", but that "other persons may entertain different sentiments concerning them" (1.v). He notes that the critical neglect of the plays has caused them to be left in a state that deters other eighteenth-century readers from discovering them and thus forming their own judgments, resulting in a situation where "the question concerning their authenticity has remained in its original obscurity" (1.vi). The textual historian, Malone understands, has no business ignoring evidence; and

\footnotetext{
${ }^{67}$ The Supplement of 1780 dealt with the poems and apocryphal plays, while a 1787 dissertation dealt with the authorship of the Henry VI plays. His belief was that Part 1 was "the entire or nearly the entire production of some ancient dramatist" (4) while 2 and 3 Henry VI were reworkings of The First Part of the Contention and The True Tragedy of Richard Duke of York, which he believed were not by Shakespeare.

${ }^{68}$ See, for example, E. Smith. "Putting Shakespeare back among these other writers rather than conscripting him to the service of literary timelessness, can highlight what is distinctive, as well as what is generic or derivative, about his work" ("Studying Shakespeare" 56). The very choice of "Supplement" is leading in this regard. In Derrida's understanding, as paraphrased by Leslie Hill, "the term implied two contrary but inseparable things. A supplement was not only an indication of abundance, a kind of additional resource adding itself to an existing plenitude; it was proof that there was already something deficient in what it was required to supplement" (20).
} 
equally, it is only through the availability of said evidence that a definitive argument against authenticity can be made.

Malone's summary of the state of the apocryphal plays is worth considering in detail.

They have perhaps been examined less attentively than any other of the dramas of that age, having been hitherto rejected out of the modern collections of old English plays, not, as it should seem, from their want of merit, but because they were considered as in some sort belonging to Shakespeare. ${ }^{69}$ They have met with the fate of other spurious productions, and have been neglected by all parties. They were originally disowned by their natural parents; and the trustees of the literary estate of their imputed father have treated them as suppositious offspring, to whom they were not bound to pay any regard.

There are echoes here of the "strays" described by Pope: again, the disputed plays are thought of as fatherless cast-offs, although still "in some sort belonging" to Shakespeare. The religious language used earlier in the period is here replaced with the language of law and estate, reflecting Malone's primary occupation as a lawyer. Their status as "disowned" is relevant to Malone's quest for authenticity, placing them outside the "family" of the canon and throwing into doubt the purity of their genealogy. The Shakespeare connection is enough to render them inadmissible to the canon of nonShakespearean drama; but equally, their Shakespearean claim is too weak for the

\footnotetext{
${ }^{69}$ In the twelve volumes of Dodsley's 1744 A Select Collection of Old Plays, the foremost of these collections, only The Merry Devil of Edmonton is included of the Apocrypha.
} 
"trustees of the literary estate" - Shakespeare's editors - to include them as part of his property.

The use of "natural" to describe the real "parents" of the plays is reminiscent of Theobald's remarks on the provenance of Double Falsehood. There, the play was described as handed down to a "natural" daughter of Shakespeare's, "for whose sake he wrote it" (Double Falshood [sic.] "Preface"). ${ }^{70}$ The imputation is surprising for suggesting a blemish in Shakespeare's exemplary moral reputation at a time when he was increasingly held up as a moral paragon, but it also serves yet again to associate an apocryphal play with discourses of illegitimacy. Unacknowledged children, particularly bastards, had few rights to recognition or inheritance according to early property laws. ${ }^{71}$ They also provided the potential for embarrassment and public shame, as when Gloucester blushes to acknowledge Edmund in King Lear (1.1.6-7). ${ }^{72}$ Malone thus interprets the hiding of the apocryphal plays in terms of the removal of children from society owing to the problems that the circumstances of their birth would cause for their biological parents. Self-canonisation becomes, therefore, a privileged activity conducted by high-status individuals whose public image is a matter of importance, and Shakespeare is considered important enough to acknowledge only selected offspring. Malone, the lawyer, recognises that regardless of whether the plays are disowned or illegitimate, they still have rights: they are unwanted, not unwritten, and however

\footnotetext{
${ }^{70}$ I.e. illegitimate ("natural”, adj., def. 15). There is, of course, no extant evidence to support Theobald's claim. Freehafer, however, speculates that the "natural daughter" may have been Mary Davenant, becoming Shakespeare's "daughter" by association with the tradition that her husband William was Shakespeare's illegitimate son. Davenant himself did nothing to suppress this story, although Mary Edmond argues that this "could mean no more than that he liked to regard himself as Shakespeare's literary heir" (14).

${ }^{71}$ This is interestingly reflected in the plea of the Bastard in King John. "But that I am as well begot, my liege - / Fair fall the bones that took the pains for me - / Compare our faces, and be judge yourself" (1.1.78-80). Legitimacy is here to be subjectively decided by the beholder. Except where stated otherwise, all quotations from plays in the 1623 folio are taken from Bate and Rasmussen, Complete Works.

72 The self-assertion of Shakespeare's bastards, particularly Edmund and Philip Falconbridge, points to anxieties over the reintegration of illegitimate children into public life.
} 
uncomfortable they may be for the critic concerned with maintaining Shakespeare's reputation, their case still needs to be heard. ${ }^{73}$

Malone thus distances himself from questions of literary reputation, articulating the negative impact that Bardolatry has had on scholarship by demonstrating how reputation has led to neglect. This has in turn led to the qualities of the plays, as well as their usefulness for glossing the canonical works, being obscured. By attending to the "suppositious offspring", Malone advocates study of the plays for the better appreciation of Shakespeare's works, elucidating phrases and explaining contextual material. De Grazia notes that, where Samuel Johnson in 1765 felt that Shakespeare's greatness came from transcending his historical period, Malone felt his greatness was best understood in relation to his contemporaries (Verbatim 115). By placing the apocryphal plays in a supplement, along with other materials such as the source poem Romeus and Juliet, Malone maintained integrity in his argument, presenting the plays as part of the editorial apparatus intended to assist the appreciation of Shakespeare. In terms of the history of the Apocrypha, this allowed Malone to become the first modern editor to edit the plays independently, thus establishing a model for an apocryphal canon.

In his individual summaries of the various plays in the second volume of the supplement, Malone begins to apply an historical approach to questions of authorship, using documentary evidence rather than aesthetic assessments. He notes that it is unlikely Shakespeare would have written for the Children of Paul's at a time when he was dramatist for the King's Men (2.533n), thus providing what remains the strongest

\footnotetext{
${ }^{73}$ Taylor's reference in the Oxford Textual Companion to the Shakespeare canon as a "family reunion" (69) invokes a far more benign variation on the metaphor. See also Jansohn, "Reconsideration" 321.
} 
external evidence against Shakespeare's involvement in The Puritan. ${ }^{74}$ He also considers early testimony from other writers that Pericles was considered to be Shakespeare's (2.5n) and suggests other candidates for 'W.S.', such as William Smith (2.190n). Malone's work on establishing a chronology of Shakespeare's works also impacts on the Apocrypha, with his suggestion that Cromwell was imagined as a rival response to Henry VIII (2.373n)..$^{75}$ Malone's work is not without value judgements, however: his comments on The London Prodigal simply state that the ascription is owing to "the impudence of the printer ... or Shakespeare's negligence" (2.449n). Where Steevens assumed that Shakespeare could not conceivably be so careless as to allow another's play to go into print bearing his name, Malone sees no other option. However, Malone's work laid the foundations for the use of external evidence in determining authorship, rather than subjective aesthetic response.

Malone, of course, has his own agenda. The Supplement acts, effectively, as a prelude to his own complete works of 1790 , announcing his entrance into the circle of Shakespearean editors. By first editing and applying his historically informed approach to the fringe works, he thus trialled the methodology that he would implement in his treatment of the established canon. His contribution to an understanding of the Apocrypha, though, cannot be disputed. He was the first editor to provide fully annotated texts of the seven plays. He also, building on Steevens's comments, critically evaluated and began making distinctions between the plays. He followed Steevens in believing that Shakespeare may have had a hand in Yorkshire Tragedy and was adamant that he wrote the vast majority of Pericles (1.vii), while denying his hand in any of the others. Malone was also the first to follow this through editorially, including Pericles in

\footnotetext{
${ }^{74}$ The play is now confidently attributed to Thomas Middleton. See especially Jackson, Studies in Attribution and Taylor and Lavagnino, Collected Works.

75 This is dependent on Malone's dating of Henry VIII to 1601, rather than the now accepted date of c.1613. However, Malone's work was more generally useful in establishing the importance of chronology. See McMullan, Late Writing, and de Grazia, Verbatim.
} 
his own edition of 1790 in place of Titus, which he believed was entirely spurious. ${ }^{76}$ In this edition, the other apocryphal plays are excluded; Pericles would continue its journey to canonicity alone. ${ }^{77}$ Malone, however, now takes a far more conservative position in keeping with the prejudices of his century, and is rather more disparaging of the plays whose value he had argued for only ten years earlier. He refers to manuscripts discovered at Dulwich College which "completely clear [Shakespeare] from that imputation [of authorship]" (1.Ix), and specifically draws attention to Henslowe's payment to Drayton, Munday, Hathway and Wilson for Sir John Oldcastle. Shakespeare, in Malone's terminology, is once more in the dock, but this time Malone feels he has the evidence to exonerate him from all culpability. Thus, the last major edition of the century once again "disowns" the plays, albeit this time based on documentary evidence. In Malone's transition from supplement to complete works, the status of the Apocrypha is re-evaluated. The plays can take pride of place in a work of fringe interest, but have no place in the prestigious mainstream lineage of Shakespeare editions.

Malone's work on the Apocrypha, therefore, is revolutionary in methodology and conservative in results. His attention to the disputed plays effectively saved them from oblivion by making them accessible for a new generation, but (with the exception of Pericles) he rescues them only to dismiss them with firmer authority. Nonetheless, his re-rejection of the plays established a set of criteria for assessing authenticity that had greater claims to objectivity, taking into account hard evidence over a desire to preserve reputation. Within the legal framework of his account, any play may be considered

\footnotetext{
${ }^{76}$ Malone notes that Pericles was to be included in the final (tenth) volume along with Titus Andronicus, but "to preserve an equality of size in my volumes" it was instead promoted to the third volume, thereby placing it more firmly within the established canon (1.lix). His belief that "it is of little consequence where it appears" is perhaps theoretically true, but the visual impression for the reader is one of unequivocal promotion of Pericles in place of Titus.

${ }^{77}$ The question of Pericles after this point, and the consolidation of its place in the Shakespeare canon, is beyond the scope of this thesis to consider in detail. See Jackson, Defining Shakespeare, and the editions by Del Vecchio and Hammond and by Gossett, the former of which continues to deny collaboration in the play.
} 
Shakespearean provided it can make a reasonable case for itself. ${ }^{78}$ It is Malone's basic model that continues to be used today by investigators into the authorship of specific plays, a combination of external and internal evidence leading to an editor's individual choice based on their unique evaluation of the strength of that evidence. Subjectivity cannot be entirely avoided, but Malone's subjectivity is in the evaluation of evidence rather than of the poetic quality of the text.

The Supplement, bringing together the disputed plays in a separately demarcated volume, initiated the strand of critical treatment that led to Brooke's Apocrypha, by re-housing the plays in a canonical space that was neither within the Shakespeare canon nor emphatically outside it. As Malone noted, the plays still "belonged" in some way to Shakespeare, even if only in the minds of certain commentators, and thus he created a new space in which they could be read without impacting on the canon. It was not until the middle of the nineteenth century, however, that this space began to be developed substantially. ${ }^{79}$

Charles Knight's Pictorial Edition of the Works of Shakspere, published serially between 1838 and 1841, followed Malone by including a volume entitled Doubtful Plays $\& c$. This volume marks the last substantive treatment of the apocryphal plays en masse within the pages of a Complete Works edition. Later Complete Works volumes would continue to print selected plays according to what the age considered to be authentically Shakespearean, but Knight provides discussion of all the plays hitherto

\footnotetext{
${ }^{78}$ The use of this kind of legal framework in providing an "unbiased" assessment of authorship has been more recently appropriated with enthusiasm by the anti-Stratfordian lobby, which has organised "trials" where high court judges have assessed the respective cases for and against Shakespeare as the true author of the plays (see Shapiro 233-37). Although Shakespeare has "won" each time, including most recently at the English Speaking Union in May 2011, law has provided a tempting framework for authorship doubters, who now use a "Statement of Reasonable Doubt" to justify the existence of a question.

${ }^{79}$ It is of particular note that Tieck and Schlegel's translation of the complete works, finished in 1833 , only included the standard canon. Their opinions on authorship did not translate into editorial practice, although the small collections of apocryphal plays overseen by Tieck may be seen as another early attempt at creating a subsidiary canon.
} 
attributed to Shakespeare. ${ }^{80} \mathrm{He}$ also includes commentary on recent critical opinion such as that of Schlegel and Tieck, and full texts for Titus, Pericles, Kinsmen and $A$ Yorkshire Tragedy. He supports the authenticity of Titus and Pericles, and acknowledges the strong claim of Kinsmen, printing it in order to allow readers to form their own judgement in the same spirit as Malone's Supplement ${ }^{81} A$ Yorkshire Tragedy is printed in full as being "of sterling merit in its limited range" (253). The remainder of the apocryphal plays are treated with typical eclecticism: none are printed in full, but long extracts are printed from some along with discussion of their qualities, while others are dismissed on grounds of their worthlessness, such as Mucedorus: "A more rude, inartificial, unpoetical, and altogether effete performance the English drama cannot, we think, exhibit" (306). ${ }^{82}$

Knight's remarks on The London Prodigal are perhaps the most striking, and worthy of extended quotation.

If Shakspere had chosen such a plot, in which the sudden repentance of the offender was to compensate for the miseries he had inflicted, he would have made the prodigal retain some sense of honour, some remorse amidst his recklessness - something that would have given the assurance that his contrition was not hypocrisy. We have little doubt that the low moral tone of the writer's own mind produced the low morality of the plot and its catastrophe. We see in this play that

\footnotetext{
${ }^{80}$ That is: Locrine, 1 Sir John Oldcastle, Thomas, Lord Cromwell, The London Prodigal, The Puritan, A Yorkshire Tragedy, Arden of Faversham, Edward III, George-A-Greene, Fair Em, Mucedorus, The Birth of Merlin and The Merry Devil of Edmonton.

${ }^{81}$ He does, however, offer Chapman as a possible alternative candidate for authorship. The narrative of The Two Noble Kinsmen's route to its current canonical position is too long to be covered in detail by this thesis. For a full history, see in particular the editions by Eugene M. Waith (1989) and Lois Potter (1997).

82 The "rudeness" of Mucedorus has blighted its critical history, despite apparently being one of the most popular plays on the early modern stage. Knight's use of the phrase "inartificial" is fascinating, however, considering that it was Shakespeare's lack of artifice that for so long was considered to be the fount of his greatness. See Bate, Genius 157-86 on "The Original Genius".
} 
confusion of principles of which the stage was too long the faithful mirror. In Shakspere the partition which separates levity and guilt is never broken down; thoughtlessness and dishonour are not treated with equal indulgence. This is quite argument enough to prove that Shakspere could not have written this comedy, nor rendered the least assistance in its composition. If it exhibited any traces of his wit or his poetry, we should still reject it upon this sole ground. (231)

Much of Knight's remark demonstrates a continuing sense of Shakespeare's responsibility as moral exemplar, and foregrounds this role by telling us in no uncertain terms what Shakespeare "would have" done with the same material. There is an implicit blurring here of "would" and "should", that insists on Shakespeare's moral propriety being equivalent to Knight's own. For Knight, the morality of The London Prodigal is faulty and compromises Shakespeare's responsibility to be "Shakespeare", to maintain a consistent authorial presence in terms of moral purpose and poetic quality.

For Knight, it is this responsibility that becomes the key factor in determining authenticity. His last sentence is the most revealing, stating that even if The London Prodigal demonstrated the literary qualities of other Shakespeare plays, "we should still reject it" on the grounds of its faulty morality - with "should" continuing to imply both "would" and "ought to". The same "Shakespeare" that was originally constructed from the works has by this point become a fixed and tangible entity, strong enough in its own identity to dictate which plays might (should, could) be part of its constitution. Knight's position is circular, and shows how embedded was the cultural conception of Shakespeare by the mid-nineteenth century. The disputed plays became the victims of the concern to preserve the accepted canon and the received conception of Shakespeare himself. In this light, it is not surprising that Knight was the first to 
introduce the term "apocryphal" as a descriptor for the doubtful plays, a notion to which Brooke would return in $1908 .^{83}$

Knight's edition reduced the role of the disputed plays in a Shakespearean collected works to that of curios, discussed rather than edited. While a substantial portion of one volume was devoted to them, the format in which they were presented served to deny the plays themselves a place and accentuated their removal from the canon. The first major academic edition, the Cambridge Shakespeare (1863-66) took this to a further extreme by mentioning the seven 1664 additions only in an account of the main canon's early publishing history. From Malone's Supplement, therefore, the disputed plays receive increasingly supplementary treatment within published editions of Shakespeare, becoming part of the ephemera surrounding the works. They are of interest, but of no real importance.

The plays similarly failed to find a home in other collections of drama. In 1808, Charles Lamb published his Specimens of English Dramatic Poets Who Lived about the Time of Shakespeare. This collection of extracts was one of the most comprehensive of the nineteenth century and served to bring to public attention several neglected early modern dramatists. ${ }^{84}$ Rather than merely providing "single passages and detached beauties" (1.1), referring to the older collections of "Beauties", Lamb contextualised the scenes presented. The aim of the collection was twofold: "to illustrate what may be called the moral sense of our ancestors" and to show "how much of Shakespeare shines

\footnotetext{
83 "We might deduce, from the foregoing imperfect observations, some general principles to apply as a test to the authenticity, not only of Titus Andronicus and Pericles, but of the more apocryphal plays ascribed to Shakspere" (Knight 54). "Apocryphal" is thus not only a category, but a comparative measure; all the disputed plays are apocryphal, but some are more apocryphal than others.

${ }^{84}$ The book passed through three editions in Lamb's lifetime, was regularly reprinted after his death in 1834, and received new scholarly editions in 1847 and 1893, helping to shape a popular sense of the wider dramatic canon. T.J.B. Spencer notes that it was only in the nineteenth century that concerted efforts were made to revive the canons of other early modern dramatists. By contrast, this was the century in which the disputed Shakespeare plays were least visible.
} 
in the great men his contemporaries, and how far in his divine mind and manners he surpassed them and all mankind" (1.2).

Lamb's remarks epitomise the continuing appropriation of Shakespeare as moral standard in the nineteenth century, and his Bardolatry is evident in his secondary aim of showing the relative weakness of Shakespeare's contemporaries compared to the man himself. The apocryphal plays, however, are almost entirely absent from Lamb's collection. Brief extracts are included from Arden of Faversham, Edward III and The Merry Devil of Edmonton, all originally anonymous and here ascribed to "Author Unknown". The 1664 folio additions, and any other play with a prior external connection to Shakespeare, are ignored. This interestingly reverses the position of the earlier quotation books: where previously an ascription was favoured over anonymity in order to authorise the maxim, now truthful anonymity is favoured over a potentially fraudulent ascription. They were also notably excluded from Elizabeth Inchbald's The British theatre (1806-09) and, with the exception of Merry Devil, from Hazlitt's Lectures on the Dramatic Literature of the Age of Elizabeth (1817), in which Hazlitt notes that "I suppose the reader to be already acquainted with them" (214). ${ }^{85}$ Hazlitt acknowledges that he has given "a general account" of the disputed plays elsewhere, by which he refers to his response to Schlegel in Characters of Shakespear's Plays. As that piece remarked almost exclusively on the question of authorship, it is clear that the unique status of the Apocrypha now served to preclude the plays from critical discussion, either as part of the Shakespearean canon or as part of the general drama of the age.

In a culture that prized the authorial canon, the Apocrypha caused difficulty, as Hazlitt's introduction to his fifth lecture indicates. Following several lectures in which he

\footnotetext{
85 Inchbald's twenty-five volume collection brings together all the plays, Shakespearean and other, performed at the London theatres in recent memory, and the omission of the apocryphal plays is testament to their disappearance from the London stage.
} 
discusses Shakespeare's contemporaries, he moves to talk about plays "the authors of which are either not known or not very eminent, and the productions themselves, in general, more remarkable for their singularity, or as specimens of the style and manners of the age, than for their intrinsic merit or poetical excellence" (188). The grouping together of anonymous plays and plays by lesser authors is suggestive of the priorities of Romantic critics. Hazlitt's study is organised around the canons of individuals whose place within the dramatic culture can be clearly defined. Unattributed plays do not fit into these canons of the writers and are therefore overwhelmingly ignored, relegated to the status of "specimens of ... the age" rather than considered as an integral part of the dramatic environment. In this period of author-centred study, the Apocrypha, disowned and homeless, failed to qualify for any canon.

However, the result of this failure to relocate the apocryphal plays was that they continued to belong to Shakespeare by default. Shakespeare's high cultural status meant that any play or artefact attached to his name immediately warranted discussion, even if that discussion was in order to deny a Shakespearean connection as in the case of Ireland's forgeries and Malone's response. While Lamb was able to publish extracts from some of the anonymous plays as anonymous, therefore, those with a bibliographic Shakespearean attribution could not be reclassified thus. The authorial attachment is inevitably more compelling than an absence of author, and "doubtfully Shakespearean" takes precedence over "anonymous". The result of this is that, despite their absence from editions, the attribution question continued to dominate critical discussion as critics attempted to locate the plays in their proper authorial home. ${ }^{86}$

Throughout the nineteenth century, the obsession with resolving issues of authorship was caused by the need to control the constitution of Shakespeare. Whether

\footnotetext{
${ }^{86}$ For the range of critics engaged in authorship questions at this time, see the introduction to Brooke, Apocrypha.
} 
the canon was being extended, limited or more finely defined, the driving desire was to have all plays neatly categorised. In the second half of the nineteenth century, the work most often associated with the New Shakspere Society was influenced by scientific standards of evidence and cataloguing. ${ }^{87}$ Anonymous and mis-attributed plays were treated as anomalies, which in the case of the Apocrypha confused and called into question the fringes of the Shakespeare canon. The first priority was therefore to ascertain the author, but the failure to reach any critical consensus regarding these plays confused the issue further as ever more alternative authors were drawn into contention. As the prolonged debate continued to draw attention to the instability of the canon, it thus became a matter of urgency permanently to re-house the disputed plays. To this end, a more formal and stable grouping of the plays began to take shape, bound together by their unresolved attachment to Shakespeare.

Several of the mid-nineteenth-century groupings of dubitanda took Malone as their model, beginning with the publication of a new edition of The Supplementary Works of William Shakespeare by William Hazlitt the Younger in $1852 .{ }^{88}$ This volume was a new edition of Malone's Supplement, designed to accompany Hazlitt's new edition of Shakespeare for Routledge. ${ }^{89}$ Hazlitt justifies his publication of the volume thus:

\footnotetext{
${ }^{87}$ At the inaugural meeting of the society on March $13^{\text {th }} 1874$, F.J. Furnivall announced that "the purpose of our Society ... is, by a very close study of the metrical and phraseological peculiarities of Shakspere, to get his plays as nearly as possible into the order in which he wrote them" (vi). However, he then goes on to describe the idealised life that he expects the results to support: "we get him at last down quietly in his country home again, with the beauty of that country, wife and girl, and friends around him" (vii). Even at the society's foundation, results are predetermined by a chronology and biography that is to be adhered to. See also Felperin 133-34 on Furnivall's pre-determination.

${ }^{88}$ The British Library integrated catalogue records this as William Hazlitt the Younger (b. 1811), although the shared name of father and son (and, indeed, grandson, William Carew Hazlitt, who issued a new edition of Dodsley's Collection of Old Plays in 1874-76) can cause some confusion. ${ }^{89}$ This edition is omitted from many textual histories of Shakespeare as of little distinctive interest. It proclaims itself as based on the text of Johnson, Steevens and Reed, and comprises the main 36 plays across four volumes.
} 
The Doubtful Plays of Shakspeare are printed with this edition of his undoubted works, because the mere fact of their having been repeatedly printed as his productions entitles them to popular perpetuation, and because there is fair presumption that, in greater or less proportion, several of them, at least, actually passed through his hands. It is now a century and a half since they were all published together as his compositions. $(v)^{90}$

For Hazlitt, the ongoing association of the plays with Shakespeare is enough to merit attention and fresh republication. His emphasis on "popular perpetuation" is an interesting indicator of the perceived cultural responsibility of editors at this point. It is not enough that the disputed plays are available for scholars, as there is also a duty to make Shakespeare - even doubtful Shakespeare - available to the wider population. This is in accordance with the increasingly democratic approach to Shakespearean criticism begun by Malone and Knight, and Hazlitt makes this explicit. "The decision of critics, however, on a point so long agitated, should not satisfy the curious and intelligent reader of Shakspeare. He will wish to see with his own eyes, and to decide by the power of his own understanding; and to him these performances, in their present form, will not be unacceptable" (v). We are reminded of Capell's belief that "the reader must form [an opinion] of his own," displacing the authority of the editor-critic in favour of the educated reader. Hazlitt does not qualify his own "fair presumption", and his notes simply echo the views of Malone, Farmer and his own father, often reprinting Malone's notes verbatim. However, his implied challenge to the "curious and intelligent reader" offers the possibility of discovery through connoisseurship, if the reader is capable enough. This is the challenge that would be taken up by the enthusiastic amateurs of the New Shakspere Society and later seekers of hidden Shakespeare.

${ }^{90}$ Hazlitt's exaggeration presumably refers to Rowe's 1709 edition. 
Hazlitt's volume was reprinted in 1887, with the new title The Doubtful Plays of William Shakespeare, omitting the poems and general preface. Where "doubtful" had previously been part of the subtitle, now it became the explicit defining feature of the plays. The renaming of the edition brought it into line with the two other major midcentury volumes of disputed plays, those of Henry Tyrrell in 1853 and Max Moltke in 1869 , which shared the same title. ${ }^{91}$

Moltke was a German translator, whose translations of the authentic plays had been published in 1865 . His volume of the plays "designated in the literary world as "Spurious" or "Doubtful Plays"” is "intended to serve as a supplement to Shakespeare's works" (vi). The prefatory material is now familiar: a claim of the plays' own merit, a cautious refusal to expand further on the editor's own beliefs ("to specify the reasons which have guided me in my selection ... would carry me too far", vi), and an appeal to the reader's own judgement, here quoting Capell. Where Hazlitt followed Malone's selection, however, Moltke's longlist of fifteen plays is influenced by the German Romantics as well as the English tradition. ${ }^{92}$ From this longlist, he selects those plays "which, according to my firm conviction, bear the most unmistakable traces of Shakespeare's authorship" (vi): Edward III, Thomas Lord Cromwell, Locrine, A Yorkshire

\footnotetext{
${ }^{91}$ There is much confusion over the date of Tyrrell's undated volume. Brooke cautiously dates it 1851, which is the date followed by Jansohn ("Reconsideration" 319), but Haney is undoubtedly correct when he notes that "this volume of Doubtful Plays formed part of an edition of Shakespeare in 4 vols., published in London by J. Tallis \& Co. in [1851-1853]. As the Doubtful Plays were probably published last, the date should be [1853] rather than [1851]" (185), thus reversing the order of Hazlitt and Tyrrell.

${ }^{92}$ He includes The Arraignment of Paris, Arden of Faversham, George-a-Greene, Locrine, Edward III, Mucedorus, Sir John Oldcastle, Thomas, Lord Cromwell, The Merry Devil of Edmonton, The London Prodigal, The Puritan, A Yorkshire Tragedy, Fair Em, The Two Noble Kinsmen and The Birth of Merlin.
} 
Tragedy, London Prodigal and The Birth of Merlin. ${ }^{93}$ A combination of eclecticism and personal preference here overrides consideration of empirical evidence.

Henry Tyrrell's far grander edition of the plays is more comprehensive. An impressive title page is headed by Thomas Banks's famous image of Shakespeare Attended by Painting and Poetry. ${ }^{94}$ On the opposite page, engravings of the contemporary Sadler's Wells and Surrey Theatres associate both Bard and plays with the contemporary theatre, reclaiming the plays for Tyrrell's own time. Around the title matter are seven engravings depicting scenes from the disputed plays, serving to add status to the collection while marketing the plays on their own sensational qualities and varied subject matter (Fig. 2) ${ }^{95}$ The image of the inspired Shakespeare on his plinth above the plays stresses the "of" of the title; these plays may be doubtful, but they remain Shakespeare's.

Tyrrell's volume is the largest edition of disputed plays to date: Titus and all seven 1664 editions are accompanied by Edward III, Merry Devil, Fair Em, Mucedorus, Arden, The Birth of Merlin and The Two Noble Kinsmen. He is, like Moltke, heavily influenced by the "great German critics" who

\footnotetext{
${ }^{93}$ As Jansohn notes, Moltke provided an introduction for Edward III's inclusion in the Leipzig Shakespeare of 1876, marking the first inclusion of the play in a collected edition of Shakespeare (“Reconsideration" 319).

94 This sculpture was commissioned for Boydell's Shakespeare Gallery, which opened in 1789. See e.g. Bate, Constitutions 45-57.

${ }^{95}$ Not all of the identifications are immediately obvious. Clockwise from top right: a man addresses a woman who appears to be in mourning clothes (likely The Puritan); a man stabs at a babe-in-arms (Yorkshire Tragedy); a woman with a dagger stands over a dead man (likely Locrine; not impossibly Arden of Faversham); a shadow appears to a man in a forest (Mucedorus or The Birth of Merlin?); a head is brought in on a platter (Titus); two classically-dressed men talk (presumably The Two Noble Kinsmen); a peasant girl walks with a basket (Fair Em).
} 


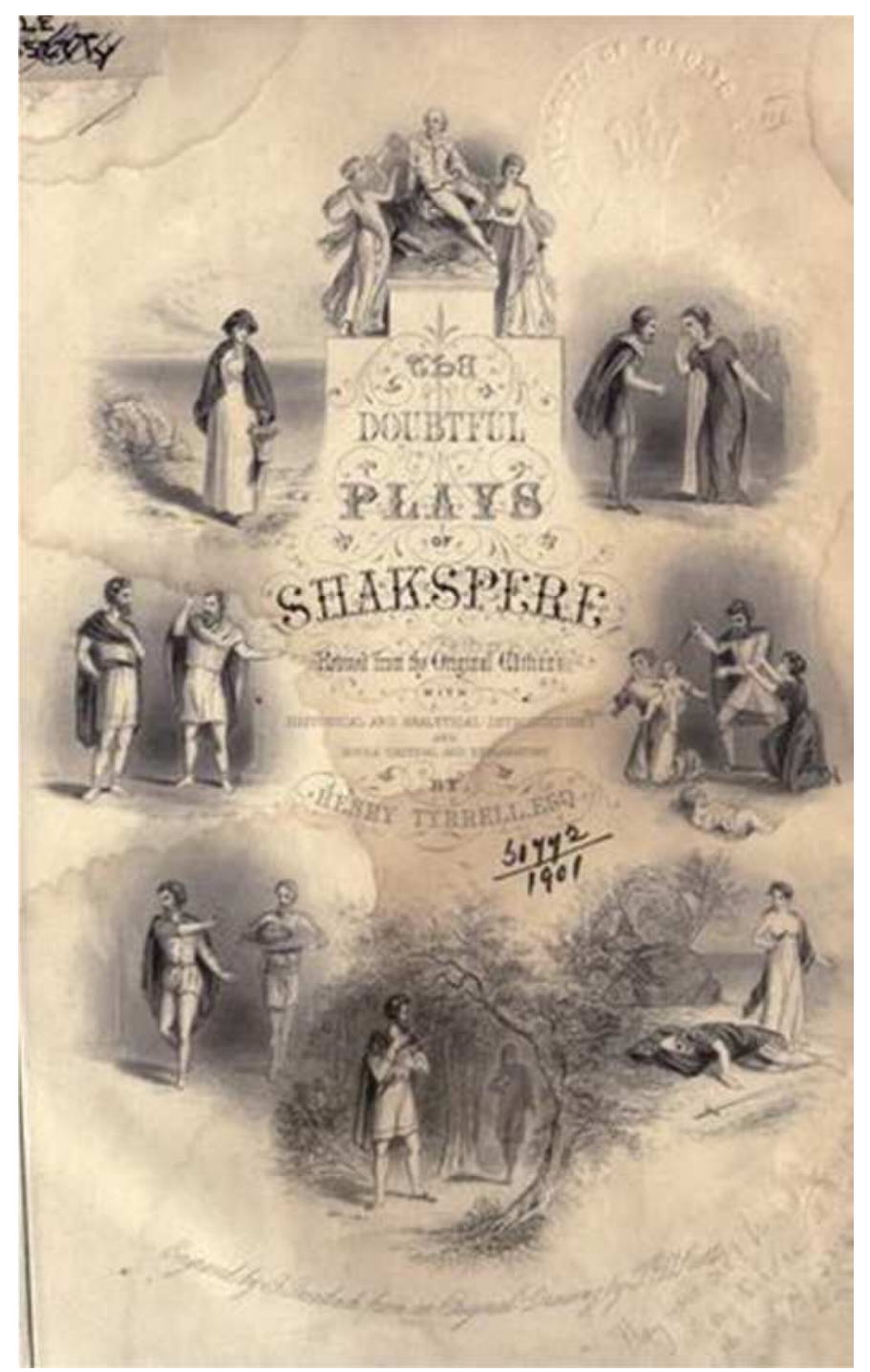

Fig. 2: Title page of Tyrrell, Henry, ed., The Doubtful Plays of Shakspere (1853?).

\section{Source: Open Library.}

have enabled the English to behold their own great poet by the aid of a new light. These distinguished writers have not adopted a philological and literal mode of criticism, but a poetical and affectionate one; and their opinions have been caught up and spread widely in this country. They bestow a far greater consideration upon the performances which have been attributed to our poet than has hitherto been given to them. This appears to be the only just and correct mode of proceeding; give these dramas of doubtful authenticity a thorough examination; point 
out the evidence for and against them; cast them upon the waters, and leave them to their fate. (1)

As Tyrrell goes on to say, "let us run no chance of losing that which is really his" (1). Assessment of the apocryphal plays continues to rely on subjective opinion, which Tyrrell here argues is the "only just and correct mode of proceeding" (1). Whether defending or attacking the plays, then, the doubtful plays remain a matter of connoisseurship and personal taste.

The importance of Tyrrell's edition in the consolidation of an apocryphal canon has been overlooked. Although preceding Moltke, he lays down the essential shape of the apocryphal canon that would form Brooke's edition half a century later, with Brooke only excluding Pericles and Titus and adding the newly attributed Thomas More. He also provides the most extensive critical commentary on the Apocrypha that they were ever to receive in a collected edition: critical introductions for all the plays deal with their attribution history, themes, plot and characters, and notes follow the texts. Tyrrell's attractive folio volume presents the plays with an unprecedented level of respect. His text is solid, and his edition calls for a greater investment in the disputed plays. ${ }^{96}$ So why is it Brooke's, and not Tyrrell's, edition that came to shape modern conceptions of the Apocrypha?

At the end of the nineteenth century, treatment of the disputed plays was more eclectic than ever before. Several of the plays believed to be more likely to contain Shakespeare's hand were receiving attention in their own right. For example, between 1883 and 1888, Karl Warnke and Ludwig Proeschoedt published a series of disputed

\footnotetext{
${ }^{96}$ The text appears to have no independent authority but is based, for the most part, on relatively good texts (e.g. Edward III 1.1.7 follows Capell's emendation of "successefully" to "successively", followed also by Melchiori in his New Cambridge edition. All quotations from Edward III are taken from Melchiori. Brooke's edition, returning to the earliest available editions, is superior, satisfying the need he articulates in his preface for "an accurate and complete text, with adequate critical and supplementary matter" (iii).
} 
plays under the series title of Pseudo-Shakespearian Plays, marking the culmination of the German apocryphal tradition with editions of the six plays most strongly supported by their predecessors. ${ }^{97}$ The proliferation of numerous editions of the plays in different formats, groupings and hierarchies, however, perpetuated the impression of the disputed plays as an undefined and inconstant grouping, in constant flux and lacking tangibility. The titles of the "Doubtful" collections underlined this uncertainty while continuing to attach the plays to an indefinite fringe space of the core Shakespeare canon. "Doubtful" they may be, but they remained "Plays of Shakespeare".

The space created by the "Doubtful" grouping occupies a similar relation to the Shakespearean canon as the more established generic categories of Comedy, Tragedy and History. This fourth grouping continued to exist as a subsection of Shakespeare's plays, but with their "type" defined by their dubious authenticity rather than by any internal qualities of the plays themselves. However, these collections were being published with an increasing measure of typographical and bibliographic independence from the main canon, thus encouraging the reading of the doubtful plays in relation to each other rather than to the Shakespearean canon. By being treated as a category unto themselves, the otherness of the doubtful plays was canonised. They were now distinctly and visibly separate to the Shakespearean and non-Shakespearean canons, rather than merely absent from both. However, the grouping was both definitive and ambiguous; its identity was Shakespearean, yet its constitution was as "doubtful" as the authenticity of the plays themselves.

This doubtfulness became untenable following another major apocryphal intervention in 1871. In 1844, Alexander Dyce had transcribed the manuscript of The

\footnotetext{
${ }^{97}$ Brooke commends their work on Merry Devil, Edward III, The Birth of Merlin and Arden, while showing more reservations over Fair Em and especially Mucedorus, which he states "cannot be accepted as a critical edition at all," having only consulted Q8 firsthand (Apocrypha Iv). Warnke and Proescholdt's work completes that begun by Nicolaus Delius some decades previously.
} 
Book of Sir Thomas More, but it was not until 1871 that Richard Simpson first advanced the theory that one of the additions to the book was in Shakespeare's own hand. Simpson was one of the enthusiasts who joined the New Shakspere Society at its inception in 1874. The society, under the direction of Furnivall and Fleay, took particular interest in questions of authorship and canon, applying scientific methodologies to identify with increasing precision those plays that contained Shakespeare's hand. Fleay was the pioneer of what S. Schoenbaum refers to as a "school" of authorship studies that quantified what had previously been the impressionistic and subjective study of resemblances between the styles of various writers (Internal Evidence 38-39).

Schoenbaum criticises Fleay for confusing science and fancy, creating elaborate theories regarding collaboration and revision, but notes that many of Fleay's results are in keeping with more recent scholarship (47). ${ }^{98}$ His work brought scientific and poetic treatments of Shakespeare into conflict, and Murphy notes that it was this dispute, fought publicly between Furnivall and the poet A.C. Swinburne, that led to the Society's collapse (Shakespeare in Print 211).

Hugh Grady links the disintegration fervour of the late nineteenth century with Bardolatry; noting that the "scientific" methods of Fleay and his colleagues were equivalent to those used on Homer and, more pertinently, the Bible, in German Higher Criticism (116). ${ }^{99}$ In the purging of non-authentic matter from a text treated as sacred, disintegrationists not only advocated the possibility of empirical certainty of attribution, but also depended upon it. It was their inability to achieve a "shared paradigm" that led

\footnotetext{
${ }^{98}$ Brooke reports Fleay's following attributions of apocryphal plays: Kyd for Arden of Faversham; Peele for Locrine; Shakespeare for the first half of Edward III; Wilkins for Mucedorus; a shared unknown author for London Prodigal and Thomas Lord Cromwell; Middleton for The Puritan; Drayton for Merry Devil; R. Wilson for Fair Em; Massinger and Fletcher for Two Noble Kinsmen; Rowley for Birth of Merlin. Despite the ridicule Fleay has received, Grady notes that a surprising number of his attributions have stood the test of time (114).

${ }^{99}$ The history of Higher Criticism provides a model for the most extreme consequences of authorship studies, as seen in e.g. in the reaction to Essays and Reviews (1860), which saw two of the volume's authors indicted for heresy. Josef L. Altholz provides a detailed account of this episode and its aftermath.
} 
to the movement being discredited. By the time Robertson claimed in the early twentieth century that through disintegration he had "presented the world with the key to ultimate values," no one was listening (Grady 119).

The appearance of Thomas More as a serious contender for Shakespearean authorship had a pivotal effect on both the history of the Apocrypha and the fate of disintegration. The manuscript became part of a major swing of critical interest away from questions of poetic style toward those of textual production. Interest in Thomas More accelerated quickly following Simpson's article, supported the following year in a note by James Spedding. Where Thomas More differed from other disputed plays was in the connection it offered to Shakespeare himself. As with Ireland's forgeries in the previous century, critics inheriting a Bard-centred study were inevitably fascinated by the possibility of viewing Shakespeare's first, original thoughts, with all forms of mechanical mediation removed. Here was the Romantic Shakespeare, the inspired genius, communicating his immediate, unfiltered thoughts onto a surviving physical document. Following an age of extreme bibliographical pessimism (Grady 112), it is perhaps unsurprising that the speed at which Hand D of More was accepted far outstripped that of the other plays of the Apocrypha. ${ }^{100}$ Hand D would go on to be one of the foundational pieces of evidence for the work of the New Bibliographers in the early-twentieth century, who would use what were perceived to be the raw spelling, punctuation and linguistic habits of Shakespeare as a guide for work on his other plays. ${ }^{101}$

Hand D and Thomas More contributed to a paradigmatic shift in the critical treatment of Shakespeare's text, with the more systematic and historically-informed

\footnotetext{
${ }^{100}$ The ascription has never been beyond question, however. See Chapter Three for discussion.

${ }^{101}$ Murphy's Shakespeare in Print provides an excellent overview of the New Bibliography, including the use of Hand D (208ff). See also Maguire and Berger 23-91, and articles by Werstine.
} 
New Bibliography replacing the quasi-scientific methods of the now-defunct New Shakspere Society and the "informed subjectivity" of Robertson, the last of the disintegrators (Grady 118). However, it also occasioned a shift in the treatment of the rest of the doubtful plays. While Hand D brought critics closer than ever before to Shakespeare himself, standing for the Holy Grail of author-centred study, it also revealed incontrovertible evidence of Shakespeare as a working collaborator. It proved that his writing was not flawless, the addition showing evidence of second thoughts and of re-writing. Most importantly, it proved that the 1623 folio, even with the addition of Pericles, was not an exhaustive canon. This was the author, pure and unmediated, existing outside of the conventionally authorised canon; and, where earlier generations had accorded Shakespeare the right to self-select his canon, a more Bardolatrous age insisted that space must be created for a fragment so tangibly close to the author. Shakespeare's section of Thomas More became one of the most important documents for furthering the study of Shakespeare, yet it came from a collaborative, anonymous and unpublished play. Its discovery and acceptance therefore re-opened the question of the importance of non-canonical works and the possibility of finding more examples of Shakespeare's writing. The image of the Romantic, independent Shakespeare, operating above and apart from his contemporaries, was no longer tenable in the face of Thomas More's evidence of jobbing work.

In 1875-76, Simpson published "On Some Plays Attributed to Shakespeare" under the auspices of the New Shakspere Society, in which he makes a case for the additions to Mucedorus being similarly Shakespearean and for Fair Em providing insight into a "Poet's War" between Shakespeare and Greene. He suggests that Shakespeare's role as the "company's poet" may have required him to provide "occasional insertions" (160) and gives a list of thirty disputed plays, his argument being that examination of them would "be a great help towards the history of opinion and belief concerning his life 
and writings" (157). In doing so, Simpson became one of the first critics to see the importance of the disputed plays not only for their glossing of Shakespeare, but for their use in holding up a mirror to critical attitudes towards Shakespeare.

The combination of the availability of the doubtful plays in Hazlitt, Moltke and Tyrrell's editions, the new critical interest in Thomas More and the disintegrative work that was still characteristic of the period meant that the canon was in greater danger of destabilisation than ever before. The shift on the verge of being enacted was from the sanctification of author to that of text; as Felperin argues, moving towards the "transcendental signified" of discourse (140). The categorisation of texts that would lead to such distinctions as "good" and "bad" quartos had to begin with a solid division between "good" and "bad" Shakespeare, a distinction too weak in the labelling of "doubtful" plays. Further, Thomas More could not be housed under the "Doubtful" label. Its Shakespearean status was by the turn of the century "probable" at worst, and a grouping among the negative associations of a "doubtful" canon would not satisfactorily reflect the positive attitude towards the play's Shakespearean interest. Equally, the play's collaborative nature meant it was effectively ineligible for the main canon, which was still maintained as a site of authorial integrity. ${ }^{102}$

\section{C.F. Tucker Brooke and the canonising of the Apocrypha}

The nineteenth-century apocryphal editions remained informed by Malone's notion of the Supplement. This is problematic as, in Derrida's formation, "as substitute, [the supplement] is not simply added to the positivity of a presence, it produces no

\footnotetext{
${ }^{102}$ During the late twentieth century, this issue was resolved in many Complete Works by the inclusion of the Hand D section alone, severed from its dramatic context: cf., for example, The Riverside Shakespeare (1974), The Oxford Shakespeare (1986) and the RSC Shakespeare (2007). Masten ("More or Less") challenges the principles behind editing a collaborative fragment in isolation. The play in its entirety was not included in a Complete Works volume until the second edition of the Oxford in 2005, and was finally published within a multi-volume series in 2011 (Jowett, More).
} 
relief, its place is assigned in the structure by the mark of an emptiness" ( $O f$

Grammatology 145); that is, it points to the necessary incompleteness of the thing being supplemented, weakening the integrity of canon. Marjorie Garber notes that the French meanings of supplemént infer "both a substitute and an addition" (19), eliding simple binary distinctions. The liminal canonical space tentatively explored by Tyrrell's edition, therefore, needed to be made more permanent and durable, with firm boundaries delineating "authentic" from "spurious", while continuing to make the plays available for scholars and interested parties. In 1908, Brooke published his seminal collection of the disputed plays, for the first time rechristened the "Shakespeare Apocrypha".

Charles Frederick Tucker Brooke (1883-1946) was an American scholar specialising in Renaissance drama, with a particular interest in Shakespeare and Marlowe. A Rhodes scholar, he was awarded a B.Litt from Oxford in 1907, and published the Shakespeare Apocrypha with the Clarendon Press the following year at the age of just twenty-five. Immediately following the publication of the edition he returned to the United States to take up a post at Yale, where he remained until his death. It is perhaps no coincidence that the work produced during his brief sojourn in England, 1904-08, was concurrent with major developments in what would become known as the New Bibliography. Oxford was at the centre of major shifts in the study of literature: 1904 saw the establishment of the inaugural Chair in English Literature at the University, and in 1906 (when Brooke was awarded his BA) the University took the decision to separate English Literature from English Language. In the same year, W.W. Greg and R.B. McKerrow founded the Malone Society, with the intention of enabling the study of early modern drama using original editions. In 1908, as Brooke's Apocrypha was published, 
Greg definitively proved the shared date of the Pavier quartos, in what Laurie Maguire describes as “New Bibliography's first major triumph" (Suspect Texts 42). ${ }^{103}$

Brooke's work thus emerges from the same context that prompted paradigmatic shifts in Shakespearean textual scholarship. It is interesting that, while British scholars focused on the core Shakespearean plays, the American Brooke attended to the fringes of the canon; in his review, F.W. Moorman notes that "the work reflects great credit upon its editor, and, indirectly, upon the English School at Oxford, where he has learnt his methods and ripened his critical judgment" (119), a backhanded compliment that qualifies Brooke's achievement by treating it as a product of a forward-thinking British institution. Nevertheless, upon leaving the country Brooke had defined the shape and constitution of the dubitanda, now "Apocrypha", leaving them in a format that would be tacitly approved and cemented by a lack of subsequent competition.

Brooke's edition of 1908 contains the core of what today are still considered the doubtful plays with the strongest Shakespearean connections: Arden of Faversham, Locrine, Edward III, Mucedorus, 1 Sir John Oldcastle, Thomas Lord Cromwell, The London Prodigal, The Puritan, The Yorkshire Tragedy, The Merry Devil of Edmonton, Fair Em, The Two Noble Kinsmen, The Birth of Merlin and Sir Thomas More. These are the only plays that Brooke considers to have a "real" claim to "doubtful status" (xi). At the same time, he talks about "establishing" an Apocrypha (vii). Brooke is actively engaging in the process of creating a second canon, a defined and limited group of plays to be bound and considered together. He treats the plays as a group according to their setting (almost all English) and themes (contemporary crime, contemporary London,

\footnotetext{
${ }^{103}$ Maguire recounts the ascension of the New Bibliography and its association with Oxford at this time (Suspect Texts 21-71).
} 
biographical history) (xii). ${ }^{104}$ Yet the only linking factor between the fourteen plays is their shared association with Shakespeare's name, an association which Brooke spends the major portion of his introduction severing, one play at a time. He seems unaware of the implicit paradox of creating a canon that is authentically doubtful, with the doubtfulness of some plays more justifiable than others. Haney approves of the inclusion of "only those plays that could reasonably be included in the 'doubtful' class", and approves the choice of title "because there is slight reason for calling anything 'doubtful' when very little doubt exists in most minds" (185). "Apocrypha" thus consolidates doubt into something more meaningful and solid, a grouping meant to be permanently and definitively indefinite.

Brooke's unstated aim in creating a secondary canon is to form a buffer between the authentic Shakespearean canon and the works of other dramatists. The language of Brooke's criticism of the Apocrypha betrays throughout his exclusive association of Shakespeare with the highest quality of poetic writing, an association which he wishes to maintain but sees under threat by the attribution to him of lesser and collaborative works. So, Arden and Kinsmen are in the "very first rank of the extraShakespearian drama" while Edward III, More and Yorkshire Tragedy "rise in parts to an equal height of poetry" (vi). Most tellingly, these are plays "where the question [of attribution] becomes less whether they are good enough for Shakespeare" (my emphasis). While ostensibly praising the quality of the plays, his criteria are clear: a play is first assessed on whether it is good enough to be Shakespeare's, and the opinion on authorship is then formed on the basis of whether it is worthy of admission. All of these

\footnotetext{
${ }^{104}$ Brooke uses the very Englishness of the plays' settings as a telling factor against the authenticity of the plays; with a few exceptions, "not a single authentic play is avowedly English either in scene or characters". (xii) Brooke's exceptions include, however, the ten history plays (and the closely linked Merry Wives) and the "three mythical British dramas"; he does not acknowledge that several of the disputed plays with English settings likewise fall into these genres.
} 
five plays are found to be wanting in the final reckoning: Arden gives its heroine vulgar (and therefore unShakespearean) vices; Edward III is good, but more "within [the] grasp" of Peele (xxiii); Yorkshire Tragedy lacks Shakespeare's "morality" (xxxv), Kinsmen always "falls just short of what it should be" (xliii) and Thomas More lacks unity and represents Shakespeare's "careless revisionary work" (liii). It is only in the insurrection scene that Brooke finds "precisely what we should expect Shakespeare, the man and dramatist, to say" (li, my emphasis), echoing Knight's language of expectation and responsibility.

The aspects that make these plays unShakespearean are also those aspects that, in Brooke's critical opinion, weaken the plays in and of themselves. The implied extension of this logic is that imperfections are themselves unShakespearean. The weakness of these plays is compounded by Brooke's grouping of them alongside plays that "bear the mark of vagabondage in every feature" (vi) such as Fair Em and Mucedorus. In less extreme vein, he comments that no playwright save Shakespeare, Marlowe or Jonson would lose reputation through association with The London Prodigal, The Merry Devil of Edmonton or The Puritan. Brooke is carefully, but emphatically, placing these plays in a sub-Shakespearean category, to which he relegates by association plays such as Kinsmen and Edward III that had been the subject of authorship debate for generations.

The importance of Brooke's contribution has been understated by subsequent scholarship. In creating a freestanding, defined canonical space for the apocryphal plays, a category between "Shakespeare" and "not-Shakespeare", Brooke gives the plays a home, a space in which the authorship question can be discussed without having a material impact on the constitution of the main canon. This in turn allowed the matter of authorship to become a subsidiary and optional question when editing Shakespeare: 
editors no longer had to make a decision between inclusion or exclusion, for the plays would now remain part of the apocryphal canon regardless. This was a decisive blow in the death of nineteenth-century disintegration, fixing the canon in a two-tier dichotomy that established firmer boundaries, diminishing the chances of canonical promotion. ${ }^{105}$ Brooke's edition would not set the constitution of the two canons in stone, but it reduced the mobility of plays in both. Any alteration would now be a product of cumulative academic study rather than an immediate aesthetic reflection of its time, and Jowett points out that "for most of the century, the plays Brooke gathered together would remain safely excluded from the canon as it was edited" ("Editing Shakespeare" 5).

Brooke simultaneously establishes and destroys the idea of an Apocrypha. He argues that the plays are not worthy to be published under Shakespeare's name, yet does exactly that; for even with the "Apocrypha" tag, they are still being associated with Shakespeare. Despite the "vagabondage" of plays like Mucedorus (vi), he still provides a scholarly, edited edition of the play, echoing the ethos of Malone's Supplement. For Brooke, it is "improbable that [Heminge and Condell's] list will ever be augmented" by more than "broken fragments" (xii), yet he allows for the existence of those fragments and provides full, readable versions of the material in which one is most likely to find them. His primary motive in this edition is to close the canonical question, and he employs a unique double strategy to do this. He hides the plays, both in his title meaning "hidden" and in his critical dismissal of each play. However, he simultaneously reveals the plays in their (perceived) weakness. By presenting the plays themselves along with his assessment of them, Brooke demonstrates his confidence that there is nothing

\footnotetext{
${ }^{105}$ However, see Elliott and Valenza's remark that "whatever scholars may say about the death of the author or the decline of bardolatry, the rewards for striking a new vein of Shakespeare gold are still far higher" ("Two Tough Nuts" [web version] 3). The effect of decreasing canonical mobility is also to make "promotion" a more prestige phenomenon.
} 
further to discover in them; that their un-Shakespearean nature is self-evident and that the plays can be safely read without the risk of further damage to the canon. This speaks to the finality that Brooke intends for his edition, a finality testified by the lack of subsequent collected editions. ${ }^{106}$ While smaller collections of doubtful plays had previously appeared, Brooke trumps them by purporting to be exhaustive in his investigations. He narrows the Apocrypha down to a core canon, presents the plays in full as his primary "evidence", argues that the claims of each of them are completely spurious or extremely tenuous, and finally concludes that Shakespeare himself would have excluded them from his canon (xii), appealing to the notion of Shakespeare's selfcanonisation first advanced by Capell.

Brooke's Shakespeare Apocrypha thus makes the disputed plays simultaneously visible and invisible, available but meritless in the context of Shakespeare Studies. There was no longer any need for scholars to rescue the plays from obscurity, as they now existed in a modern, edited form. Brooke's apocryphal canon became definitive, and discussion of the apocryphal plays in the twentieth century was subsequently dispersed. The grand edited collections and collective treatments of the nineteenth century gave way to discussion of individual plays in papers and articles. Brooke's volume therefore established the model which is still used in discussion of these plays: they are still spoken of as "apocryphal", considered as part of a group with the other plays in the apocryphal canon and associated with the negative terminology used by Brooke in

\footnotetext{
${ }^{106}$ The Malone Society, instituted two years before Brooke's edition, published editions of Locrine and 1 Sir John Oldcastle in the same year. Several once-disputed plays not included in Brooke's edition were among the Society's earliest volumes: The Battle of Alcazar (1907), King Leir (1907), The Second Maiden's Tragedy (1909), The Arraignment of Paris (1910) and George a Greene (1911), perhaps intended to make up for some of the most well-known omissions from Brooke's Apocrypha. Greg's epochal edition of Thomas More was also published in 1911. The only later collected edition of note is Kozlenko's 1974 The Disputed Plays of William Shakespeare, which includes photographic reprints of eleven plays from Tyrrell's edition. Kozlenko's introductions are riddled with errors and make no serious engagement with criticism or attribution studies, arguing instead more generally for the plays being early or revisory work, and the edition has little independent value.
} 
relation to their aesthetic quality. Proudfoot's title "Is There, and Should There Be, a Shakespeare Apocrypha?" recognises that it is Brooke's Apocrypha that needs to be dismantled before another model of understanding and reading the plays can be established.

Returning to the calls of Jowett and Proudfoot for a reassessment of the CanonApocrypha dichotomy established by Brooke, such a move is clearly both desirable and necessary. As this account of the mechanisms leading to the creation of the Apocrypha has demonstrated, both Canon and Apocrypha are artificial critical constructs rather than essentially separate entities. The Apocrypha exists as a by-product of a Bardcentred critical discourse that has shaped a canon to fit an author. Biography, chronology, reputation and quality have influenced not only the constitution of Canon and Apocrypha, but the limitations critics place on canon and the criteria according to which they may be transcended. Reception of Brooke's edition was positive, in no small part precisely because it reinforced the qualitative judgements that had hitherto governed the treatment of the plays. Haney remarks that "ever since their ascription to the pen of the master-dramatist they have been regarded with critical suspicion and in consequence of the misguided efforts of zealous champions they must suffer whatever odium attaches to presumptive illegitimacy in the anonymous drama" (184). Brooke's Apocrypha continues to fulfil the function of providing a space for plays which do not comfortably fit into an authorial canon, but whose connection to Shakespeare cannot be ignored. ${ }^{107}$ Within a current climate in which disintegration has "silently reappeared" (Grady 121), however, the impetus to categorise a play according to its originating dramatist(s) has never been stronger. In pursuing Jowett and Proudfoot's suggestions,

\footnotetext{
${ }^{107}$ Proudfoot suggests that the only remaining apocryphal plays are London Prodigal, Locrine, Cromwell, Arden, Merry Devil, Fair Em and Mucedorus ("Is There?" 61); these are the only ones in Brooke for which a strong authorial attachment remains to be made, and he thus accepts the apocryphal tag by default.
} 
therefore, it is necessary to move away from the authorial canons that have been imposed by later generations of editors and critics, and return to the context shared by certain canonical and apocryphal plays during Shakespeare's lifetime - the repertory of the Chamberlain's-King's Men. 


\section{Chapter Two: The Apocrypha in Rep}

DAMPLAY. [...] we would speak with the poet o' the day, Boy.

BOY. Sir, he is not here.

- $\quad$ The Magnetic Lady Induction 10-12.

In the previous chapter, I demonstrated the processes by which the dichotomy of a Shakespeare "Canon" and "Apocrypha" was created, culminating in Brooke's Shakespeare Apocrypha. Critical treatment of the disputed plays is still influenced by the essential framework, constitution and language of Brooke's edition. These processes are detailed in order that we might reconsider the plays historically, consciously moving beyond the later discourses that group them in a negative relationship to Shakespeare. This chapter returns to the circumstances of the plays' original production in order to pursue a different approach to the question of how "Shakespearean" the plays may be.

Marcus offers a useful starting point, noting that "we characteristically identify canonical writers with a name that stands for the sum of their work, and of their authorial identity imagined as a clearly delimited body, as in 'Shakespeare' and 'Marlowe'" (Unediting 180). That is, the authorial name signifies both the historical individual and the corpus of work, and the work takes on the authority invested in the authorial name by historical tradition. ${ }^{1}$ Marcus describes this as an authorial "effect". "Watching 'Marlowe' meant watching a theatrical event balanced on the nervous razor

\footnotetext{
${ }^{1}$ As noted in books on the anti-Stratfordian question, such as Shapiro's Contested Will: Who Wrote Shakespeare? The subtitle here is particularly fascinating; "Shakespeare" is nominally an amorphous concept, a body of work as undefined as the various anti-Stratfordian positions themselves. Yet Shapiro's choice of "Shakespeare" also underlines the insinuations of fraudulence and conspiracy that characterise the authorship dispute; for in a literal sense, one can only "write" an "author" if the author is himself a fiction.
} 
edge between transcendent heroism and dangerous blasphemy - transgression not only against God but also against cherished national goals and institutions" (42). ${ }^{2}$

Marcus's "Marlowe effect" is a phenomenon that perhaps best manifests itself retrospectively, constructed according to the critical overview of a completed canon. For early modern audiences watching Dido, Queen of Carthage, for example, Marcus's description may have been somewhat puzzling. Once the effect is established, though, Marcus argues that subsequent critical and adaptive work acts to sustain it, to keep "Marlowe" sounding like "Marlowe". "In order to keep the 'Marlowe effect' alive, to keep Marlowe sounding like himself even after his physical demise ... non-authorial revision functioned to heighten, not to destroy, an aura of authorial 'authenticity' in the theatre" (Unediting 56). "Marlowe" is thus a composite construct, rooted in an historical individual but maintained and adapted by subsequent agents, that nonetheless gives the impression of a distinctive voice, one that Robert Weimann suggests represents in Tamburlaine "the most forceful articulation of the early Elizabethan dramatist's sense of his own authority and entitlement" (56). Yet the expressers of this personal self also include Nashe, his collaborator on Dido, and the revisers involved in the 1616 text of Faustus. "Marlowe" transcends an individual, becoming a discursive site where various agents are strategically arranged in order to create a particular textual or performative "effect," and Marcus suggests it was the theatrical company who controlled this authoreffect.

\footnotetext{
${ }^{2}$ This is, of course, only one critic's view of Marlowe and, as J.T. Parnell states, "It would be a bold or foolish critic who claimed objective access to the 'real' Marlowe and the definitive meanings of his plays and poems." (1). The point is rather to consider how meaning can be construed, rather than what it universally is.

${ }^{3}$ The extent of Nashe's involvement in Dido is uncertain: Bowsher suggests that "it seems to have been finished off or edited by Thomas Nashe" (33), but his exact contribution is unclear. Bevington and Rasmussen argue that Marlowe collaborated on the A-text of Faustus, though refuse to commit to a single candidate (72); and Henslowe paid William Birde and Samuel Rowley for revisions which are assumed to be those preserved in the B-text.
} 
Recent work in repertory studies provides a framework in which to explore the relationship between author and collaborative environment in regard to the apocryphal plays. This work, as exemplified by that of Andrew Gurr, Roslyn Knutson, Scott McMillin and Lucy Munro, takes a primarily historical perspective that prioritises the material circumstances of production in the creation of drama. ${ }^{4}$ While not explicitly concerned with authorship, these studies offer a social context that uses company rather than author as the organisational framework for a body of work. As Munro argues, repertory study has become "increasingly attractive [because of] the influence of post-structuralist uncertainty regarding the place of the author;" (3) the company remains a solid, historical body in a period of uncertainty over the definition of authorship. T. Rutter, however, notes the problem of integrating Shakespeare, "who effectively represents the notion of author as individual genius" (126) into this model; and it is telling that Knutson and Gurr's titles refer to "The Shakespeare Company" or "Shakespeare's Company". This latent bias can, however, be an advantage for study of the disputed plays. While the titles are inevitably designed to sell books, they remind us that the company is itself, in a sense, "Shakespearean", and thus the works produced by the company are also implicity "Shakespearean". Neither Gurr or Knutson mean by this that Shakespeare either owned the company or wrote the whole of its repertory, but they acknowledge Shakespeare's unique role within this company as a sharer and resident dramatist, and the impact of the company and its repertory upon Shakespeare's own work. Whether writing to the talents and resources of a particular group of actors, fitting plays to the requirements of

\footnotetext{
${ }^{4} \mathrm{~T}$. Rutter provides an excellent overview of work in the field. I distinguish this movement from its predecessors, exemplified by e.g. Alfred Harbage's 1952 Shakespeare and the Rival Traditions and Bernard Beckerman's Shakespeare at the Globe (1962) by its deliberate attempt to recast the repertory as an alternative organising paradigm to authorship, rather than as contextualisation for authorship. Harbage provides useful discussion of several of the disputed plays, but is concerned throughout to underline the distinction between Shakespeare's plays and the remainder of the repertory, rather than the shared strategies. Beckerman casually stigmatises all non-Shakespearean Globe plays as "hack plays ... soap opera and grade-B westerns" (1) and "the weaker plays of the Globe" (61), treating them as contextual material for Shakespeare's "magnificent dramas" (1).
} 
the company's performance space or responding to the other drama performed by the company and its competitors, Shakespeare's plays are in turn shaped by those facets.

To dissociate the author from his environment in an author-centred canon is thus misleading, creating the impression of a career formed in artistic isolation rather than within a network of connected, and often opposing, forces. Within this paradigm, I argue, those apocryphal plays that belonged to the "Shakespeare Company" have an important role to play in discussion of the Shakespeare canon: they both influence and are influenced by Shakespeare's plays, and contribute to a company repertory that is "Shakespearean" inasmuch as Shakespeare operates as a major governing figure in the writing, performance and representation of the plays. ${ }^{5}$ In this, I follow the important work of de Grazia and Stallybrass, who argue that "the choice of [Shakespeare's] name may reflect not his authorship, in any traditional sense, but rather his centrality to the company in multiple capacities (as playwright, actor, shareholder), not to mention his distinctive loyalty to that company for which he wrote exclusively" (275-76). ${ }^{6}$

Five of Brooke's apocryphal plays were part of the Chamberlain's-King's Men's repertory during Shakespeare's lifetime, and these will be the test cases for this chapter. The anonymous Mucedorus is usually dated to the 1580s and was first published in 1598 with no company attribution, but the third quarto of 1610 - which includes new additions - was avowedly performed "By his Highnes Seruantes vsually playing at the Globe." The 1602 quarto of Thomas, Lord Cromwell (first performed c. 1599) claims it

\footnotetext{
${ }^{5}$ See also Loewenstein, who vindicates Jaggard from deliberate misattribution in The Passionate Pilgrim by arguing that "a Jacobean stationer's 'Shakespeare' might be very nearly generic", a standard descriptor for "quality love poetry" (60). Bednarz offers a counter-argument that the name was also used to distinguish variant stories (253), but this does not detract form Loewenstein's basic thesis regarding poetry.

${ }^{6}$ See also Foucault, whose note on Ann Radcliffe argues that her founding of the Gothic horror novel shows that "her author function exceeds her own work." (114) There is a danger of overgeneralisation, of course, as in the common twenty-first century use of "Shakespearean" as a shorthand for all early-modern language, which implicitly and anachronistically institutes Shakespeare as the generator of discourses that preceded and authored him.
} 
was "sundrie times publikely acted by the right honorable the Lord Chamberlaine his seruants," and the 1613 second quarto updates this to the "Kings Maiesties Seruants." Both quartos attribute the play to "W.S." The London Prodigal (performed c. 1604; printed 1605) was "plaide by the Kings Maiesties seruants," and A Yorkshire Tragedy (performed c. 1605; printed 1608) "acted by his Maiesties Players at the Globe." Both feature explicit attributions to Shakespeare. Finally, The Merry Devil of Edmonton (first performed c. 1602) boasts that it was "sundry times acted, by his Maiesties Seruants, at the Globe, on the banke-side" on the 1608 first quarto and all subsequent publications. Mucedorus and Merry Devil are also attributed to Shakespeare in the Charles I "Shakespeare, Vol. 1" volume discussed in the Appendix.

These plays range from the mid-Elizabethan to the early Jacobean, from domestic tragedy to city comedy, chronicle history to romance. Yet all avowedly shared the same stage and company in the first decade of the seventeenth century. ${ }^{7}$ The aim of this chapter is not to establish precisely what Shakespeare's involvement with the plays was: writer, reviser, adaptor, actor, selector, advisor, commissioner, mentor; the possibilities are multiple and ultimately unprovable. Rather, operating under the reasonable assumption that the company, particularly its sharers, were invested in and responsible for the company's entire output, this chapter explores how these plays interact with the concerns and themes of Shakespeare's contemporaneous plays.

Our evidence for the plays is textual, and inevitably influenced by the intervening agencies of printers and publishers. We cannot confidently state whether the Shakespearean association was first articulated before or by print. However, the

\footnotetext{
${ }^{7}$ A note of caution is necessary at this point. If we are to mistrust title-page evidence in respect of authorship, there is no logical reason to unquestioningly accept the company attribution either. Kirschbaum, arguing that Mucedorus is a "bad quarto" (1), distrusts the company assignation on this basis. However, company attribution was a more established and consistently used form of identifying ownership of plays, and academic consensus accepts the attribution of these five plays to the Chamberlain's-King's Men. Knutson demonstrates an overwhelming verification of title page company ascriptions by other evidence ("Evidence" 65-67).
} 
compiling of Mucedorus and Merry Devil in anthologies and bookseller lists as Shakespeare's despite not being printed as such is at least indicative that the Shakespeare attribution had a discursive rather than a publisher-determined basis. The very fact of each of the five plays coming to be associated with Shakespeare proves that the possibility of the Shakespeare effect existed; that the onstage distinctions between "Shakespeare" and "not-Shakespeare" were blurred enough not to preclude the Shakespeare attachment being articulated in print.

The subordination of the apocryphal plays in later textual criticism, as shown in Chapter One, was a posthumous phenomenon. There is no historical reason to believe that the plays were any less important than others in the company's repertory at the moment of their first performance. Regardless of their later fortunes, the plays represent a commercial and artistic investment that demands attention. The moment of first performance was identified by the Oxford Shakespeare as a pivotal moment in the production of plays, the moment at which an ever-shifting text was first "fixed" ${ }^{8} \mathrm{~A}$ textual Complete Works based on a series of performative moments offers a paradigmshifting attempt to socialise the canon, while at the same time limiting that canon according to the parameters set by attribution studies focusing on the individual author. Paradoxically, the Oxford project rehistoricises the plays while simultaneously continuing to separate them from their historical context. By removing canonical restrictions imposed after the plays' original production, this chapter reasserts the importance of the apocryphal plays at their moment of first performance and publication (including their relation to the repertory of the rival theatres), arguing that

\footnotetext{
${ }^{8}$ See Stern, who emphasises the importance of the moment of first performance for bringing together disparate material artefacts and actor development for the first time to create a unified product (Rehearsal 113-21).
} 
they contributed to and were shaped by a "Shakespeare effect", the authorial presence of Shakespeare. ${ }^{9}$

\section{Prodigal Husbands and Patient Wives}

“This isn't what we think of as Shakespeare's kind of play" ("Shakespeare's Most Neglected Play" 152). Proudfoot's statement could have applied to the majority of the apocryphal plays, though here he is specifically discussing The London Prodigal. It is a regular feature of apocryphal plays that they are of genres which modern criticism does not associate with Shakespeare. A cursory browse of Brooke's Apocrypha reveals chronicle histories of martyrs, city or humours comedies, domestic tragedies, and plays on ancient British history. A substantial number of the plays do not share their genre, subject or sensibility with the established canon, and critical assessment of their "Shakespearean" quality is thus already biased towards the negative.

The subjectivity implicit in the remark "what we think of as Shakespeare's" (my emphasis) reminds us, however, of the slippery associations of the word "Shakespearean" itself. As I demonstrated in the previous chapter, the primary concerns dictating what constituted Shakespeare in the eighteenth and nineteenth centuries were historically contingent and influenced by the politics and morals of successive ages. Underlying this is a commercial imperative; the suggestion that Shakespeare is defined by what can be sold as Shakespearean. As such, we must be alert to broad generalisations that seek to reduce and organise the Shakespearean into categories that are unrepresentative of their contents.

\footnotetext{
${ }^{9}$ For the importance of the interrelation of opposing repertories, see especially Gurr, Opposites and Knutson, Playing Companies. As Gurr notes, the plays of both companies "give ample notice that writers and players alike expected a majority of their listeners to be familiar with the plays appearing on the other side of the city" (33).
} 
The choice to divide the plays of the 1623 folio into genres of Tragedy, Comedy and History represents, in Jowett's words, "an arbitrary [division] that remains familiar today and yet creates difficulties in seeing some of the plays for what they are" (Shakespeare and Text 86). He goes on to point out that

The overall picture of Shakespeare as a writer of three kinds of play and three only is a serious distortion. Modern criticism slowly found alternative labels: romantic comedy, Roman plays, problem plays, late plays. It has been repeatedly stressed that Shakespeare is a writer whose works constantly overflow the narrow bounds of genre. (88)

It is now commonly accepted that the folio's genres are part of that volume's particular publishing strategy, presenting Shakespeare (following Jonson's model) as a playwright in the classical mould in order to justify the extravagant packaging of this literary form in folio format. However, while later criticism has sought to undo the generic ordering imposed on Shakespeare by the compilers of the folio, the implications for Shakespeare's generic associations before the folio have been largely overlooked. Proudfoot's assertion that we do not now think of The London Prodigal as "Shakespeare's kind of play" assumes that readers start from a position of thinking of Shakespeare in terms of his "Comedies, Histories, and Tragedies", but prior to the folio a reader would have no reason to think of the play being outside a usual generic range for "Shakespeare". Munro, however, draws on Derrida's "The Law of Genre" to argue that early modern audiences may have had a sophisticated and flexible understanding of generic boundaries (9-10); ${ }^{10}$ a view supported by Gurr's historical observation that "the

\footnotetext{
${ }^{10}$ Of particular relevance is Derrida's "idea of generic participation without belonging" (Munro 10), which becomes important in understanding the appropriation of generic elements to achieve specific effects. As Derrida writes, "in marking itself generically, a text demarcates itself" (qtd. in Munro 10); that is, the self-conscious appropriation of genre itself acts to push the play beyond the constraints of genre.
} 
typology of Elizabethan and Jacobean drama has always struggled when it attempts to identify distinctive play species of dramas" (Opposites 189). Shakespeare's "kind of" play may, in fact, be better thought of in terms of its generic indeterminacy than of its strict categorisation. As Paul Edmondson and Stanley Wells argue, "Shakespeare's work is essentially eclectic, often drawing on a wide range of literary and dramatic traditions and conventions within a single play" (28).

The two plays under consideration that are most firmly associated with Shakespeare are The London Prodigal and A Yorkshire Tragedy, both unambiguously attributed to him in print in his lifetime (see Fig. 3). These plays both belong, on the surface, to genres with which Shakespeare was largely unconcerned, the city humours comedy and the domestic tragedy. Yet the links between the two and several of Shakespeare's contemporaneous plays for the King's Men suggest a unifying set of conventions and motifs that allow both plays to exceed the normal constraints of their genre and become part of a broader company interest.
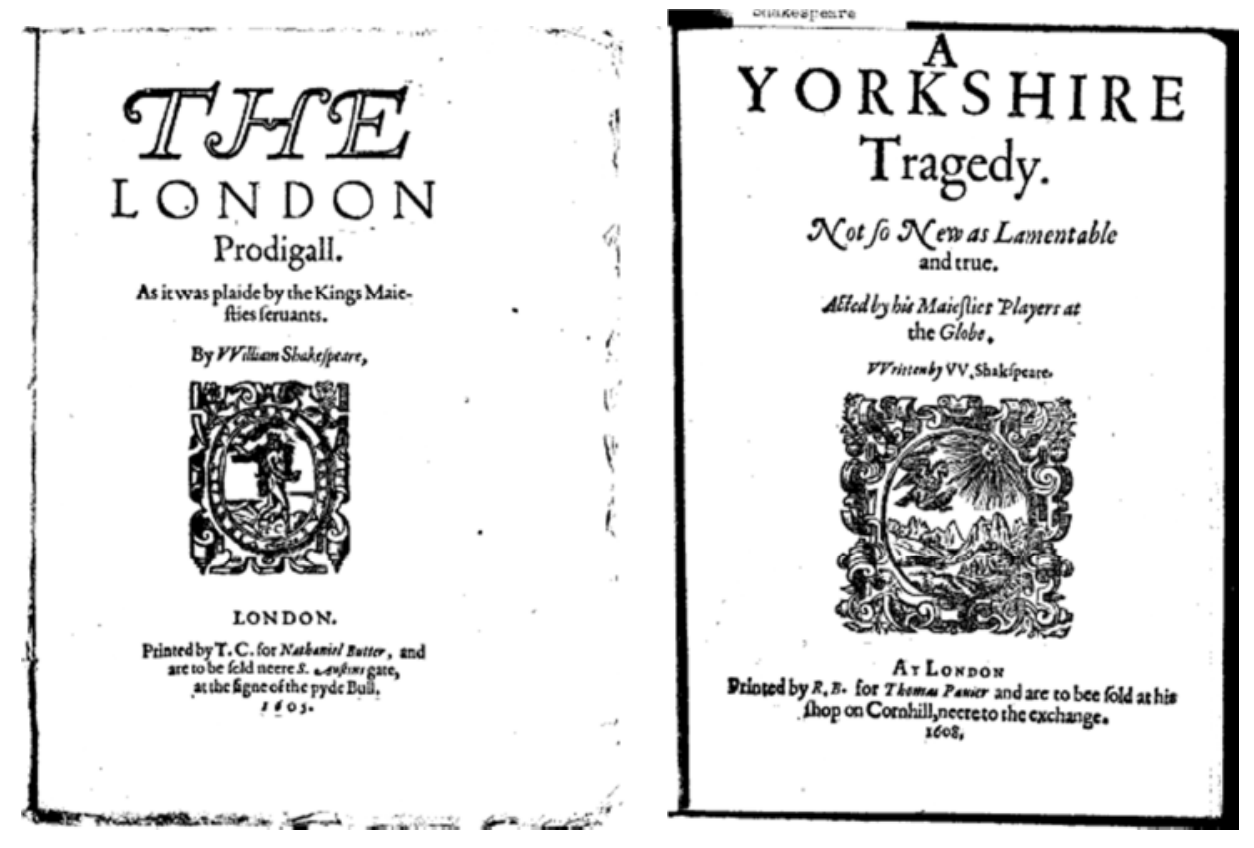

Fig. 3: Title pages of The London Prodigal (1605) and A Yorkshire Tragedy (1608).

Source: EEBO. 
Shakespeare's own comedies, as has long been noted, are often unusually complex in their presentation of more serious elements within the comedy. All's Well that Ends Well, Troilus and Cressida and Measure for Measure are foremost, long christened "problem plays."11 The Merchant of Venice and The Taming of the Shrew both also incorporate extremes of suffering into their essentially comic plots, and even The Comedy of Errors frames its main action with the uncertain fate of Egeon. The difficulties that the folio editors clearly faced in attempting to distribute the plays across their three genres are most notable in the case of Troilus: a history on the title page of the quartos, prefaced as "passing full of the palm comical" (title page) and rechristened a tragedy on its appearance in the 1623 folio (see Bevington, Troilus 1-6). We witness here an attempt to impose a classical generic framework on a play that defies classification. Similar problems will have faced the compilers of the folio as they made the decision to place Cymbeline among the tragedies or The Winter's Tale among the comedies, deliberately ignoring the new label of 'tragicomedy' which dominated the stage by the 1620s.

The London Prodigal, as an essentially comic play structured around a serious and disquieting series of plot twists, perhaps bears more in common with the difficult comedies of Shakespeare's middle period than the city comedies or humours plays that provide its most obvious precedents. Proudfoot himself points out that The London Prodigal bears certain resemblances to the problem plays. Flowerdale, like Bertram, goes out of his way to avoid his wife once they are married, and is later suspected of murdering her. Like Angelo, he is shadowed by a disguised authority figure who acts to prevent his behaviour, resulting in tragic consequences. The connections to All's Well

\footnotetext{
${ }^{11}$ See Yachnin, who locates the origin of the term in F.S. Boas's 1896 study Shakspere and his Predecessors (46). Yachnin argues for the continued utility of the grouping, although the terminology has caused much comment. It refers to the working out of problems within the plot (as in Ibsen, Shaw and other drama of Boas's period), but modern alternatives include "dark comedies" or "problem comedies".
} 
and Measure for Measure, however, are more than superficial. The London Prodigal shares with these plays a treatment of marital issues and patriarchal authority in a domestic context that explicitly points to the utilisation of the stock figures of the Prodigal and the Patient Wife. This in turn links the plays to the later Yorkshire Tragedy and its close cousin The Miseries of Enforced Marriage, which dramatise even more narrowly the relationship between a prodigal husband and a patient wife. By bringing these plays into conversation with one another, we see the newly christened King's Men displaying a sustained interest in the possibilities of the prodigal narrative at this time, developing it into a more complicatedly moralistic form of comedy - and, in the case of Yorkshire Tragedy, tragedy.

The London Prodigal provides the most explicit point of intersection between the prodigal narrative and the motif of the disguised ruler that became popular following the succession of James, which makes it a fascinating locus of genre collision within the repertory of the King's Men. As Hunter points out, the Jacobean moment is usually used to explain the proliferation of disguised ruler plays such as Measure for Measure, The Phoenix, The Malcontent and more, but these plays are also a response to the advent of Italianate tragicomedy,

a series of plays that reflect, in the period 1602-1604, a movement away from the grand confrontation with corruption that Hamlet had implied and toward the compromises by which justice and forgiveness could be embodied in the action ... the sovereign mind, though eclipsed and dispossessed of its effortless superiority, is able, in the midst of corruption, to retain an adequate control through disguises and cunning and verbal superiority. ("Italian Tragicomedy" 137) 
Understanding the family as a microcosm of state, though, the "disguised ruler" motif also recurs in domestic contexts, particularly in Middleton's The Phoenix for the Children of Paul's and the King's Men's The London Prodigal, in both of which the "ruler" is the head of the family, a father. The drama of this period exploits the intersection of state theory and family management through the shared motifs of disguised authority figures, prodigal dependents and personal versus state responsibility, and it is in The London Prodigal that these themes most explicitly coincide.

Paul Edmondson offers both an "alternative canon" for The London Prodigal (Prodigal 76) and a separate grouping of contemporary prodigal plays. Both groups range widely in chronology, company and authorship. ${ }^{12}$ My grouping of plays, by contrast, all belong to a five-year period in the repertory of a single company, the King's Men, and are uniquely characterised by their balancing of a prodigal protagonist with a strong female counterpart. ${ }^{13}$ Where the Patient Grissil narrative traditionally renders the suffering female passive and pious, in these plays the lead females are proactive and far more balanced. The playwrights do not set up two opposing extremes, but rather a realistic heroine and an outrageous husband. The effect of this is twofold. Firstly, it locates the prodigality of the male in a non-mythological environment: he is juxtaposed with relatively realistic characters, rather than types. Secondly, it gives the Grissel figure the power, if not the responsibility, to influence the reformation of the man. While there remains an element of the man having to come to his senses, it becomes possible for

\footnotetext{
${ }^{12}$ His canon of eight includes Prodigal, The Miseries of Enforced Marriage, How a Man May Choose a Good Wife from a Bad, The Fair Maid of Bristow, The Wise Woman of Hodgson, Patient Grissil, 1 and 2 The Honest Whore and The Knight of the Burning Pestle. The "prodigal" plays he notes include All's Well that Ends Well, The Winter's Tale, 1 Henry IV, Eastward Ho, Coriolanus, Histriomastix and Cynthia's Revels.

${ }^{13}$ In the absence of a consensus on dates, I accept that of Knutson, who dates the plays as follows: Prodigal 1603-04, Measure 1604-05, Yorkshire 1605-06, Miseries 1606-07 (Repertory). Knutson suggests a date of 1602-03 for All's Well, though it is more usually considered to be an early Jacobean play of 1603 or 1604 . For this discussion I suggest it precedes Prodigal; however, the clear proximity of the two allows for influence to work in either direction.
} 
the woman to employ her own methods of persuasion - Helena's tricks, Luce's disguise, Isabella's debate - to effect that realisation.

The reactions of Helena and Luce to their respective rejections by their new husbands show that the two characters are cast from a similar mould, with both prioritising the comfort and wishes of their rejecter over their own happiness and vowing to take active steps to remedy the situation. Helena "will be gone, / That pitiful rumour may report my flight / To consolate thine ear" (3.2.120-22), leaving the country in order that Bertram may return home. Luce, meanwhile, vows to Flowerdale that "All that I can or beg, get, or receiue, / Shall be for you" (3.3.221-22), offering to demean herself even further after being disowned by her family by turning beggar to save her husband. ${ }^{14}$ Both women are pious and selfless, yet both are proactive in their grief, seeing it within themselves to rectify their husbands' situations through self-sacrifice.

The London Prodigal stands midway between All's Well and Yorkshire Tragedy, stressing the immediacy and impact of the husband's rejection of the wife. Bertram, for all his flaws, at least spares Helena public humiliation, deferring the breaking-off of their attachment and arranging for her to be sent home to receive the news in a safe environment where, one supposes, she will be looked after. Flowerdale, by contrast, rejects Luce in the street before her family and friends, climaxing with the shocking instruction to: "turne whore, that's a good trade, / And so perhaps ile see thee now and then" (3.3.295-96). Bertram's disregard for Helena's future is exaggerated in Flowerdale's callous instruction. Shakespeare's play sets up the potential for miracles with Bertram's conditions for his return, and Helena's task becomes to engineer the fulfilment of those conditions through ingenuity and trial. The dramatist of The London Prodigal, by contrast, constructs a rejection scenario so damning that it seems to be

${ }^{14}$ All quotations from The London Prodigal are taken from Brooke, Apocrypha. 
irreversible. Even the disguised father cannot see a way for them to be reconciled, and his comfort is limited to being able to offer her a position in a house where she can live disguised (and therefore not in shame) and an encouragement to "Come, greeue no more, where no helpe can be had, / Weepe not for him that is more worse than bad" (3.3.312-13). This pivotal scene pushes the play far beyond the usual boundaries of comedy. Where the prodigal's public humiliation, his bankruptcy and his wife's display of loyalty would usually be expected to provoke his conversion and end the play, they instead cause him to descend to cruel discourtesy in addition to his other behaviour. In doing so, the prodigal character is rendered no longer a harmless rogue but a dangerous and potentially irredeemable villain, as his own father opines. The traditional prodigal narrative is endangered by his attempts to destroy the possibility of homecoming, and the outcome is thus uncertain.

Luce shares with Isabella in Measure for Measure the strength to stand up for moral right against authority figures: Luce's public refusal to forsake her husband at her father's instruction is echoed in Isabella's refusal of Angelo's requests and promise to "tell the world aloud / What man thou art" (2.4.161-62). ${ }^{15}$ The two are further linked by their immediate condemnation by the people for whom they have taken a stand.

Flowerdale's "bring me your dowrie, or neuer look on me" (3.3.256-57) is of a piece with Claudio's “What sin you do to save a brother's life, / Nature dispenses with the deed so far" (3.1.146-47). The tone of Claudio's rebuke is very different to that of Flowerdale's, but both men fail to appreciate the sacrifice made by the woman in her moral stand, and exhort her to commit vice. Both women are then comforted by the play's disguised authority figure. In Measure for Measure, however, the Duke is able to intercede

\footnotetext{
${ }^{15}$ See also Desdemona's "divided duty" in Othello 1.3.196-205, another play which Proudfoot comments he is reminded of when working on London Prodigal (156). Harbage remarks that "Flowerdale, although bad enough, exists chiefly as the occasion of good in others" (87).
} 
between Isabella and Claudio, and offer the beginnings of a plan to rescue the situation.

Old Flowerdale can do neither.

Measure for Measure is not a prodigal narrative in the traditional sense, but in its structural parallels with The London Prodigal it appropriates important themes from that narrative, imagining Angelo as a sexual prodigal who is temporarily given the power to pursue his sinful persuasions until his engineered reformation. ${ }^{16}$ Shakespeare is thus experimenting with a prodigal structure as an indictment of other forms of aberrant behaviour; here, the abuse of power occasioned by lust. Flowerdale's prodigality sees him, rather than softened by marriage, moved instead to abuse and forsake his domestic responsibilities, as does Bertram. There appears to be a wider intent within this group of plays - and therefore within this company - to reorient the prodigal story to focus on the effects of the prodigal's behaviour, not on his own happiness and financial situation, but on the welfare of those around him. The young irresponsible rakes of plays such as A Mad World, My Masters or 2 If You Know Not Me, You Know Nobody (the character type common, in fact, to much city comedy) are replaced by men with political or domestic responsibilities that are jeopardised.

These aspects of The London Prodigal, whether or not it was successful, were clearly in mind when the company first became aware of the pamphlet Two moft unnaturall and bloodie Murthers... (1605). ${ }^{17}$ At a time when the King's Men had been expanding the role of the stage prodigal to treat discourses of moral and social responsibility, the story of a young spendthrift murdering his family offered a fitting conclusion to this short period of the company's work. Wilkins's The Miseries of

\footnotetext{
${ }^{16}$ See Ervin Beck for a tightly argued discussion of the motifs which strictly define the prodigal narrative: the young man, newly come of age and accountable; the rejection of a father figure or social inheritance; the humiliating defeat; the conversion and attempted homecoming.

${ }^{17}$ The publication of London Prodigal ahead of All's Well or Measure for Measure may imply some measure of stage popularity.
} 
Enforced Marriage is ostensibly a comedy, though Knutson points out that the play reads more as though "Wilkins reimposes a happy ending on the prodigal's story" (Repertory 119), and Sykes sums up several critic's impressions in his note that it looks like a "hurried alteration" (94). Several critics around the turn of the nineteenth and twentieth centuries argued that this patched-up ending was a result of the play's original ending, extant as $A$ Yorkshire Tragedy, being excised. ${ }^{18}$ My contention is that this is an aspect of the play's direct response to The London Prodigal, taking the prodigal's behaviour even nearer to disaster and subverting it at the end with a yet more miraculous recovery on the protagonist's part. Wilkins's primary agenda is a critique of the practices of wardship and arranged marriage, as Glenn H. Blayney suggests ("Wilkins's Revision" 30-31), relating it to the wider contemporary trend for plays on domestic relations, such as $A$ Woman Killed with Kindness and The Wise Woman of Hogsdon. As such, although Wilkins pushes the prodigal behaviour of his protagonist to an extreme, it continues to be restricted by the conservative, self-righting conventions of the comedy. Prodigality in the early modern drama is usually comic, inevitably resulting in humiliation and repentance. ${ }^{19}$ The prodigal (following the word's biblical origin) is usually a young man deliberately rebelling against a father figure or, as Beck notes in a context peculiarly applicable to Yorkshire Tragedy, "his inheritance from a preceding generation" (109). The behaviour of the prodigal is thus made safe for the audience by the social structures within which he moves; thus, even in The London Prodigal, which threatens severe consequences for those affected by his behaviour, the presence of a disguised father figure and other senior characters promises that the

\footnotetext{
${ }^{18}$ See Sykes (94), Hopkinson (vi), and Fleay (207) for examples.

${ }^{19} \mathrm{Cf}$. Munro's comment that "the prodigal story seems to suit comedy" (59), detailing examples from the boy companies. The reliance of many prodigal narratives on a deus ex machina figure (92) opens up a space for audiences to acknowledge the potential for tragedy, but the flirtation with prodigal tragedy seems to be particularly prevalent in the repertory of the King's Men. For more detailed discussion of the prevalence of prodigal narratives in Elizabethan prose fiction, see Helgerson.
} 
prodigal will ultimately repent and be assimilated into polite society. An essential part of the prodigal parable is the return "home" of the protagonist.

By contrast, the dramatist of Yorkshire Tragedy is concerned with the destructive nature of prodigality, which Knutson notes was being similarly explored in other King's Men's works of the time, notably The London Prodigal but also The Fair Maid of Bristow (Repertory 115-16). Prodigality is central to several of Middleton's comedies of this period, including The Puritan, A Mad World My Masters and A Trick to Catch the Old One; however, it is more instructive to note here the play's connections to its predecessors in the prodigal comedies of the King's Men. The initial situation is similar, but takes a far more severe stance against prodigality. Here, the "young master" (1.10) is removed from a wider social structure and becomes the senior figure himself: his Wife's uncle is his "late guardian" and too far away to exercise influence over his former ward. ${ }^{20}$ Uncurbed by polite or restraining influences, and with the domestic authority to fully indulge his prodigality, the Husband cannot be saved by the conventional devices of prodigal comedies, as in Bristow or Prodigal. Knutson argues that this is because his crime is too heinous (Repertory 118). In fact, the reverse is the case: his crimes become thus heinous because he cannot be saved. Without the restraining influences of family and authority, prodigality is unfettered and results in tragedy. There can be no return home when the home itself is the locus of prodigal behaviour.

This fits with the theory that the Husband is influenced by demonic possession. As Keith Sturgess notes, the clue for this comes from a woodcut on the title-page of the source pamphlet, which shows a clawed, demonic figure reaching out to Calverley as he raises a club over his prostrate family (33). In the readings of various critics, the

${ }^{20}$ Quotations from A Yorkshire Tragedy are taken from Taylor and Lavagnino, Collected Works. 
Husband's prodigality leads to "spiritual consumption" (Cawley and Gaines 17), which in turn allows him to become possessed by the devil as a "scorner" (Adams 129). The relative subtlety of this device has led it to be missed by some critics, including Viviana Comensoli who writes off the Husband's behaviour as a madness caused by the loss of his reputation and property (100). Cawley ("A Yorkshire Tragedy" 113), however, notes that it is the source pamphlet that refers to madness, while the play deliberately sets out to establish his state of mind as something worse: "beggary of the soul" (2.37). The language of devilry and damnation is iterated throughout the play and leads to the inevitable conclusion of this Christian tragedy, leaving him "spiritually defeated" (Cawley, "A Yorkshire Tragedy" 117) even after the devil's departure.

The amalgamation of prodigal play, domestic drama and Christian tragedy creates a truly unique piece of theatre whose most intriguing parallels may arguably be found with Doctor Faustus. ${ }^{21}$ Jackson notes of Yorkshire Tragedy that "[the] Husband is shown to be damned because he is convinced he is" (Studies in Attribution 49); that is, he is in a state so far from grace that he believes he cannot be saved, and thus is incapable of asking for the requisite forgiveness. This debate similarly occupies Faustus, another play in which prodigality is unmonitored by authority figures, where a demonic influence is wielded over the protagonist and where damnation is the only possible consequence of the behaviours chronicled in the play. The two Edmonton plays similarly feature devils conjured up at the bidding of human characters: comically in the King's Men's The Merry Devil of Edmonton, and ultimately disastrously in The Witch of Edmonton (c.1621). All of these plays are concerned with damnation as the ultimate end

\footnotetext{
${ }^{21}$ First printed in 1604, the year before the Calverley murders occurred and A Yorkshire Tragedy was written. While an old play, the reappearance of the play in print at this time suggests that the author of $A$ Yorkshire Tragedy may well have had it in mind.
} 
of dabbling in the demonic. ${ }^{22}$ While Yorkshire Tragedy shares these concerns, its strategy is far more sober. Both Faustus and The Witch of Edmonton visit an uncompromising end upon their devil-influenced characters, but the bulk of their plots is essentially comic. Most pertinently, the devils themselves are represented; expressly comically in Witch, and at least familiarly in Faustus, where Mephistopholes has the leisure to engage in conversation with his victim. The spirits of Yorkshire Tragedy are, by contrast, invisible. They may or may not exist, despite being blamed for the Husband's behaviour by several characters. They are not the fantasy demons of a morality tale, but the real, uninvited monsters of daily life. While Faustus may be considered a Christian tragedy, therefore, Yorkshire Tragedy presents the lessons uncompromisingly, locally and terrifyingly. ${ }^{23}$

It is in this play, too, that the patience of the Patient Grissel figure finds its outer limits in the act of murder. As the Wife awakes to find her children slain, there are no more apologies for his behaviour:

What is it has beguiled him of all grace

And stole away humanity from his breast,

To slay his children, purposed to kill his wife,

And spoil his servants? (5.81-84)

Further, she is immediately willing to forsake the family home, as murder "wil ne'er out as long as the house stands" (5.89). In its final and most daring inversion of the prodigal story, the company finally deny the prodigal his homecoming, with his actions

22 Albeit, in Merry Devil, damnation is postponed in the Induction to a time seven year's hence, after which it is not referred to for the rest of the comedy. Merry Devil is in this respect an unfulfilled version of Faustus: the spectre of damnation is raised but not realised.

${ }^{23}$ For a contrasting opinion that "Even in a story as black and violent as that of $A$ Yorkshire Tragedy, the world remains a healthy world", see Harbage 174 . To merely contrast the "healthy world" with the violence of the Husband is to underestimate the dramatic power of the play's destructive tendencies. For further discussion prompted by a recent production, see Kirwan, "If The Law Could Forgive as Soon as I". 
condemning both his body to death and his household to ruin. The ending of The London Prodigal is usually judged to represent, in Dieter Mehl's words, "a conventional pious solution" (172), while Edmondson notes that this is generally taken critically, positioning Prodigal as "a carefully conservative play, which presents an unquestioned notion of social conformity. It is not surprising, then, that charges of sentimentality are not too far away" ("Beyond the Fringe" 213). Criticism of the ending of Miseries is perhaps best expressed in Adams' opinion that it "mutilates [the Calverley story] beyond all recognition" (160). Yorkshire Tragedy shows the dramatist's mature, if bleak, recognition of the ultimate end of the prodigal narrative by allowing the action to uncompromisingly follow its factual source, in which the prodigal pursues his course to complete destruction. It is perhaps no coincidence that the company's Lear, first performed around this time, took a similar direction in offering a bleak conclusion to a story where audiences may have anticipated Cordelia's survival.

While Yorkshire Tragedy has attracted attention for its speed and efficiency, it is perhaps even more interesting that this short, tightly focused drama also succeeds in experimenting with a range of genres, pulling together elements familiar from contemporary dramatic traditions and distinguishing itself in each. The play is most commonly referred to as a domestic tragedy or murder play: Sturgess groups it with Arden of Faversham and A Woman Killed with Kindness, while Knutson also links it to other contemporary crime plays such as the Chamberlain's Men's own A Warning for Fair Women and The Fair Maid of Bristow, and the lost plays Page of Plymouth, Cox of Collumpton and Thomas Merry (Repertory 45). It is inarguable that Yorkshire Tragedy fits this category, yet the category itself is rather general, running the risk of overlooking the subtle differences in the play's approach. With the domestic tragedy, Yorkshire Tragedy shares the characteristics of murders based on a contemporary true story, relatively 
lowly (i.e. non-aristocratic) characters and a setting primarily located in the home of the protagonists.

Yorkshire Tragedy is, however, of a relatively late date compared to other domestic murder plays, as has also been pointed out in reference to Shakespeare's authorship. ${ }^{24}$ Cawley has argued that the primary difference is in the method by which religious and moral instruction is delivered. The Elizabethan murder plays pointed towards a spiritual redemption at the end of the play; the "scaffold speeches" of Arden or Kindness turning the plays into what he describes as "Christian penitential plays" (English Domestic Drama 11). Yorkshire Tragedy, on the other hand, does not allow the Husband a final repentance. In the final scene he acknowledges that he is "void of grace" (8.42), and tells his wife "O, would you could pray heaven me to forgive" (8.47, my emphasis). His earthly repentance is tempered by an understanding that there is no divine forgiveness for his actions; this must be compared to Arden, in which Alice is accepted to be "now going to God" (18.2) and requests of Bradshaw "let me meditate upon my savour Christ, / Whose blood must save me for the blood I shed" (18.10-11). ${ }^{25}$ Cawley thus makes a distinction between the penitential play and the "Christian Tragedy", which completes the fall by damning as well as killing the wrongdoer, warning by negative example rather than through successful repentance.

The domestic tragedy is so called primarily in order to distinguish it from "high" tragedy, the genre for which Shakespeare is particularly celebrated. Yet Cawley's identification of Yorkshire Tragedy's distinction from other domestic tragedies actually serves to bind it more closely to the agendas of high tragedy within the repertory of the

\footnotetext{
${ }^{24}$ See Brooke: "the late date (1605-08) is in itself an almost conclusive argument against the possibility of Shakespeare's authorship" (Apocrypha xxxiv). As Shakespeare was working at this point on the plays history has judged to be his greatest tragedies, opinion of the domestic Yorkshire Tragedy has suffered by comparison.

${ }^{25}$ Quotations from Arden of Faversham are taken from Wine.
} 
King's Men. Othello, performed a year or so before Yorkshire Tragedy, is an essentially domestic tragedy that similarly denies spiritual redemption: Othello is concerned only with his earthly memory, lago will not speak word, "not to pray" (5.2.343) and even Desdemona is denounced by Othello as "a liar gone to burning hell" (5.2.150). In the company's other early Jacobean tragedies, Macbeth is unable to pray, and Vindice and Hippolito will "die after a nest of snakes" (5.3.125), although their mother at least has converted. ${ }^{26}$ The Lady's Tragedy - itself associated at one time with Shakespeare - sets up a sustained dichotomy between the Tyrant's damnable acts and Govianus's divinely sanctioned revenge.

While A Yorkshire Tragedy's setting and characters define it as a domestic drama, therefore, its more complex treatment of spiritual issues links it to higher forms of tragedy. ${ }^{27}$ We see the King's Men experimenting at this time with notions of tragedy and the extents to which the qualities of domestic and high can be integrated: Shakespeare's Othello takes the stock figures of comedy and an essentially domesticbourgeois story, elevated through the rank of the characters and Othello's mythologising to the status of tragedy; while Middleton's Yorkshire Tragedy uses a popular domestic drama to explore higher concerns. This is a deliberate strategy, made apparent in the anonymising of the characters of the latter play. Throughout the entire of The Yorkshire Tragedy there is no reference to Yorkshire, the Calverleys or any of the characters' real names. The only location mentioned, in fact, is London. In the opening scene, which Jackson has convincingly argued is by the author of the remainder of the

\footnotetext{
${ }^{26}$ Quotations from The Revenger's Tragedy are taken from Taylor and Lavagnino, Collected Works.

${ }^{27}$ Lena Cowen Orlin makes a similar claim on grounds of economic history for Arden of Faversham. "It is in his house that the gentleman is king, and that house is seen by the Elizabethan playwright as a little kingdom, a microcosm in which tragic action can ensue" (82). This forms part of a larger argument about the dramatic response to anxieties over the Elizabethan homestead, however, rather than the spiritual questions with which I am concerned here.
} 
play, Oliver and Ralph are based at the house of their mistress, she who is in a "passionate humour for the long absence of her love" (1.2). It is iterated to a conscious degree throughout Scene 1 that Sam, who brings the news of the Husband's marriage to the Wife, arrives "from London": $(11,15.1,23,34,73,76)$. The phrasing suggests that the news is London news, and the setting is implicitly backed up by the failure of the remainder of the play to specify location at any point. Maxwell noticed this but dismissed it as an error symptomatic of the "dreadful inaptness" of the scene (146).

Marc Friedlaender's argument is that Scene 1 is a later addition that deliberately sets the play in London in order to officially disguise the play's factual basis. It has been noted by many commentators that the anonymity of the characters in scenes 2-8 may be part of an effort to avoid the censure of the authorities, and Friedlaender believes the new setting is part of an effort to make the play acceptable for performance. He adds, however, that "the disguise was transparent, and was meant to be" (251): the currency of the Calverley story would ensure that audiences would recognise the play's true subject regardless. Maxwell's arguments against Friedlaender's theory are entirely unsatisfactory; he contends that lines such as "I am right against my house, seat of my ancestors" (8.1) are clearly, by reference to the pamphlet, glossed as being in Yorkshire. In this he misses the crucial point of Friedlaender's argument; that, despite the play's dependence for language on its source material, it exists independently of it in the theatre. As Orgel points out, articulating the problems of trying to amend Shakespeare's history plays by reference to "real" history, "The problem [with this approach] is what it implies about drama: the logical corollary is that the reality of drama is not what it presents but what is represented in it, the world of fact behind the text, which the play purports to bring to life" ("Desire and Pursuit" 294). On its own terms, A Yorkshire Tragedy does not tell the story of the Calverleys, but the story of an anonymous family who appear to be located in London. By deliberately stripping away the pamphlet's 
references to locale, and using Scene 1 to localise the play in London, the setting is comprehensively changed, yet remains recognisable to anyone familiar with the pamphlet. I agree with Friedlaender, except to follow Jackson in suggesting that the scene was part of the play as written, with its anonymity and vague location part of the fundamental structure of the play. While this may well have been a means of avoiding censure, the anonymity of the story serves to universalise its themes, raising the stakes by avoiding specific contemporary reference.

If the title $A$ Yorkshire Tragedy was only introduced to the print publication by Thomas Pavier in order to capitalise on the sales potential of the popular scandal's currency, then the play may even have originally been performed under its far more enigmatic, broader-reaching and leading secondary title, All's One. Stanley Wells notes in his introduction to the play for Thomas Middleton: Collected Works that "the headtitle unequivocally presents it as an alternative title for this particular play" (452), as opposed to being an overall title for the "Four plays in one". Wells is, however, at a loss to explain what he considers to be an "entirely inappropriate" title for the play. He glosses the phrase as meaning "of no account", which he finds inappropriate for a murder play (452). The route to the play's meaning, however, is suggested by Annabel Patterson's work on Henry VIII. Patterson's argument is that the play's original title, the enigmatic All is True, is deliberately ironic, directing the audience to question the very conception of historical truth (147-49). With this in mind, and in the context of the putative censorship issues surrounding this play, the title of All's One yields a possible further meaning: "All is the same."28 This London-based murder play was meant to be

\footnotetext{
${ }^{28} \mathrm{Cf}$. The London Prodigal: "if there be any thing betweene vs, then there is; if there be not, then there is not: be or be not, all is one" (3.2.66-68). The dual senses of "All is the same" and "It does not matter" need not be mutually exclusive. Stern notes that "All is one" was Robert Armin's "own personal verbal tick" (Rehearsal 104), recurring throughout that character's roles for the King's Men, and in his own Nest of Ninnies the line "fooles thinking to be wise, become flat foolish, but all is one" (sig. $\mathrm{B}^{\mathrm{r}}$ ) similarly lends itself to the sense that the fool is the same
} 
interpreted as a dramatisation of the popular Calverley murders, yet it could not openly advertise it as such. Thus, the enigmatic title of the piece is designed to alert the audience to the fact that the events are the same as those reported in the pamphlets and ballads currently circulated. Yorkshire murders, London murders, all's one; and the audience would have understood it as such. In doing so, the concerns and themes of the play are rendered less specific, and the play can act to conclude the company's exploration of the limits of the prodigal motif.

The London Prodigal and A Yorkshire Tragedy are therefore, in these senses, very much Shakespeare's kind of play, in that they share the motifs and generic complexity of his plays of the same period and act alongside them to tease out the ramifications of a popular set of stage figures. ${ }^{29}$ It therefore seems no accident that both were published bearing Shakespeare's name, forming the natural climax to the company's investment in a genre which Shakespeare had pioneered. Where we don't see his hand in the actual writing of these plays, we see it in the shaping of the concerns which the plays' dramatists appropriated to further their exploration of the figures of the prodigal and the patient wife, explorations which in turn fed back to Shakespeare's work.

\section{Absent Kings and Common Voices}

0 , what a dangerous time is this we liue in!

Theres Thomas Wolsay, hees already gone,

And Thomas Moore, he followed after him:

Another Thomas yet there doth remaine,

\footnotetext{
regardless. Hodgdon glosses The Taming of the Shrew's "that's all one" (Hodgdon 3.2.78) as "[that's] the same thing" (229) and "and all one" (4.2.102-03) as "no matter" (259).

${ }^{29}$ Joseph H. Stodder remarks on performances of the two plays in which "the portrayal of Wife, reproaching her husband but finally choosing to indulge him rather than leave him, recalled Luce's submissiveness to the prodigal Matthew Flowerdale" ("Review: Continued" 238).
} 
That is farre worsse then either of those twaine,

And if with speed, my Lords, we not pursue it,

I feare the King and all the land will rue it. (Thomas Lord Cromwell

$$
4.5 .53-59)^{30}
$$

Within the play-world of the anonymous Thomas Lord Cromwell, the words of Gardiner refer, with no small amount of relish, to the dangerous political climate of King Henry VIII's court, a world in which the rise and fall of great men is repeatedly enacted. Taken out of their dramatic context, however, the words resonate with both the theatrical world at the start of the seventeenth century and the editorial and bibliographic study of the early twenty-first century. McMillin notes that "The end of Elizabeth's reign and the beginning of James I's saw a wave of plays on the reign of Henry VIII" (Elizabethan Theatre 82). The audience for Cromwell at the Globe in c.15991600 would soon be able to enjoy Henry Chettle's now-lost two part play on the rise and fall of Thomas Wolsey at the rival Rose playhouse, and may perhaps have also been aware of an aborted attempt to produce a play dealing with the life of the second Thomas, Thomas More. ${ }^{31}$

The dates and company allegiance of this last play are in more doubt, but Jowett has recently put the case for the original play being written c.1600 by Anthony Munday and revised c.1603-4 (More 415-60). ${ }^{32}$ It has recently been suggested that the play may

\footnotetext{
${ }^{30}$ Quotations from Thomas Lord Cromwell are taken from Brooke, Apocrypha. I retain the traditional title in preference to Brooke's abbreviation The Lord Cromwell.

${ }^{31}$ Payments are recorded in Henslowe's diary for "The Boocke of carnawlle wollsey" and "the 2 perte of carnowlle wollsey" in 1601-02 (qtd. In Gurr, Opposites 258-60). Payments for Part Two were also made to Munday, Drayton and Smith; the first of these is, of course, important in light of the possibly contemporaneous Thomas More.

${ }^{32}$ A consensus on the dates of Thomas More is yet to be reached; the Revels editors, summarising the debate, uphold a generally accepted date for the original of 1592-93 (11). They suggest the additions were written shortly after, no later than 1594 based on contemporary allusions (27), but this is out of keeping with the longer-held consensus articulated, among other, by McMillin and Taylor that some or all of the additions belong to 1603-04 (see Howard-Hill 70, 126).
} 
even have been revised for the King's Men. David Kathman destabilises some of the "facts" surrounding a crucial piece of historical evidence. Following suggestions made by McMillin ("Building Stories"), he argues that the plot of 2 Seven Deadly Sins in fact belonged to the Chamberlain's Men rather than Strange's. Establishing first that the manuscript may have come into the possession of Dulwich College by way not of Edward Alleyn but of William Cartwright - who had connections with both Alleyn and the King's Men (18) - he opens up the possibility that the names of the actors can be more easily associated with the Chamberlain's Men of c.1597-98. As 2 Seven Deadly Sins provides the strongest evidence for the association of the scribe known as "Hand C" with Henslowe, then the reassignation of this plot also suggests that Hand $\mathrm{C}$ may have been connected with Shakespeare's company. This strengthens Taylor's assertion that "a plausible case could be made for revival by the King's Men" ("Date and Auspices" 124), and allows Shakespeare to have made the revisions in the middle of his career, as supported by internal evidence. It also supports McMillin's argument that the revisions are designed for a downscaled revival by a smaller company with a lead actor accustomed to substantial roles - in this case, Burbage rather than Alleyn. Gurr has challenged Kathman's arguments, and Jowett remains ambivalent, suggesting that the revisions could equally have been made for Worcester's Men in 1603-04. ${ }^{33}$ For the purposes of this chapter, it is the probable contemporaneity of the revised play and possible shared company ownership with Cromwell that are important.

\footnotetext{
${ }^{33}$ The argument for the re-assignation of 7 Deadly Sins to the Chamberlain's Men was initially refuted by Gurr in The Shakespeare Company (18n) and "Elizabethan Plotters", but G. Egan points out that Gurr bases his arguments regarding the assignation of company personnel on a misprint in the Cambridge edition of Henslowe's Diary that Kathman "is to be congratulated for putting us right on" (156). In Shakespeare's Opposites, Gurr maintains that the biggest problem remains the identification of Hand C with the plot of Fortune's Tennis (c.1602) for the Admiral's Men, which would suggest that the scribe moved from the Rose to the Globe and back again. However, as Jowett argues, "the possibility still remains that Hand C was a freelance scribe/play-doctor with no fixed tie to a single company" (More 102).
} 
The fates of the plays seem to mirror those of their protagonists as described by Gardiner. Cardinal Wolsey is, indeed, "already gone", a lost play whose contents we may only guess at. The Book of Sir Thomas More, too, threatened to have "followed after him" and may never have been performed: however, since its reintroduction to critical attention, a patchwork manuscript of the play has become one of the most important theatrical documents to scholars of the period. By contrast, Thomas Lord Cromwell indeed "doth remaine". Two extant quartos (1602 and 1613) are suggestive of theatrical revival, and the play was later included in the third and fourth Shakespeare folios of 1664 and 1685, leading to the play's continued presence in the earliest eighteenthcentury collections of Shakespeare and the play's publication as apocryphal Shakespeare in subsequent generations.

The three plays are undeniably connected by subject matter, and the two extant plays share a focus on the rise and fall of a public figure that is also likely to have been shared by the lost plays on Wolsey. ${ }^{34}$ Whether or not those playgoers would have thought of the Thomas that "doth remaine" as any worse than the others cannot, of course, be known, but the cameo appearances of the two other Thomases in 3.3 of Cromwell points to the currency of Henry VIII's most famous courtiers on the stage. It is striking, moreover, that all three stories have come to share a connection with William Shakespeare, despite no contemporary evidence suggesting his involvement in any of the three plays. The initials "W.S." on the title page of Cromwell were first interpreted as indicating Shakespeare by the compiler of the Charles I volume in the 1630s, and consolidated by Chetwind in the 1664 Shakespeare folio. The three pages of additions in what has since become known as "Hand D" in the manuscript of Thomas More have

\footnotetext{
${ }^{34}$ Henslowe's records refer to the first part of Wolsey as "the Rissynge of carnowlle wollsey" (qtd. in Gurr, Opposites 260), which gives our most solid indicator that the two part play followed a similar structure to More and Cromwell. This would appear to follow the popular model of Tamburlaine.
} 
been associated with Shakespeare since the end of the nineteenth century, and a

current scholarly consensus maintains that they are not only Shakespearean in origin, but are in his own hand. ${ }^{35}$ Finally, while the play of Wolsey has no known connection to Shakespeare, it is interesting that the fall of Wolsey is one of the key structural strands of Fletcher and Shakespeare's later Henry VIII, a play which also touches on Gardiner plotting against Cromwell, linking it with the earlier Chamberlain's play.

Excessive attention to Shakespeare's history "cycle", as a result of the desire to show Shakespeare's unity of thought and grand design, means that Henry VIII is often excluded from book-length studies or collections of criticism on Shakespearean history, contributing to the division between Shakespeare and the popular trend for plays on Tudor history. ${ }^{36}$ It is significant, then, that two of the apocryphal plays most likely to be associated with Shakespeare - More through the apparent Shakespearean revisions, Cromwell by virtue of being a property of Shakespeare's company, and thus strictly speaking Shakespeare's partially-owned play - both deal with the court politics of the reign of Henry VIII, which was also the matter of one of his final collaborative plays. My concern here is with how we might define this "Shakespearean" connection.

Cromwell and More, together with Samuel Rowley's roughly contemporary When You See Me, You Know Me, share as their protagonists major figures in the court of Henry VIII, but also share a series of concerns surrounding kingship: the conflict

\footnotetext{
${ }^{35}$ Simpson was the first to make the argument, and Metz provides a useful summary of the manuscript's rise to prominence. Howard-Hill, in positioning his edited collection, asserts that it "tips the balance further in favour of Shakespeare as the author and hand of Addition IIC" "Voice and credyt" 8). For a more recent, albeit isolated, argument that Hand $D$ is scribal rather than authorial, see Downs.

${ }^{36}$ Holderness, for example, notes that Henry VIII belongs "more to the particular cultural moment of its production ... than to other plays in the 'Shakespearean' history cycles" (Histories 6) and suggests that its position in the 1623 folio positions it as a "sequel to the great dramatic miniseries of English history" (7) before ignoring it for the remainder of his study. Tillyard's vastly influential work on history plays "omitted Henry VIII, not being convinced that Shakespeare wrote it all" (viii), while Campbell ignores the play on the grounds that "Shakespeare had only a minor part in the writing" (120).
} 
between obedience to king and to God; the negotiation between force and mercy in treating subjects; the morality of rebellion and protest; the obtaining of power versus the dangers of ambition; and the authority of religion and religious leaders. ${ }^{37}$ By bringing these three plays into close conversation with one another, we see the shared environment of Henry VIII's court becoming a crucible for these debates, played out within the episodic structure of the chronicle history. The debates are not exclusive to these plays, but the court setting creates a conducive language and framework for their discussion, a framework that was available to Fletcher and Shakespeare for appropriation and adaptation to the concerns of 1613 when the Henrician court was reinvigorated for Henry VIII.

The revival in 1986 of the alternative title All is True by the editors of the Oxford Shakespeare as the "title by which [Henry VIII] was known to its first audiences" (1193) underscores a key difference between that play and the other histories included in the 1623 folio. ${ }^{38}$ While it is assumed that the folio's compilers re-titled the play "for purposes of continuity with the titles of the other history plays" (McMullan, Henry VIII 150), the enigmatic and aphoristic title also connects the play with the small canon of early Jacobean plays on Tudor history, most relevantly When You See Me, You Know Me but also 1 and 2 If You Know Not Me, You Know Nobody (c.1605). The three titles all alert audience members to the layers of truth and allegory inherent in the plays themselves; that the audience, as it "sees", is expected also to "know" the "truth" of

\footnotetext{
${ }^{37}$ When You See Me was a Henslowe play, printed 1605 and dated to 1604 by the Annals of English Drama, quoted by McMillin (Elizabethan Theatre 84) who argues for more similarities between More and When You See Me. An early Jacobean first performance tallies with assumptions that representations of Henry VIII would be unlikely on stage during Elizabeth's reign. Gurr suggests that it may have been the play that launched the company's "new role as Prince Henry's Men" (Opposites 37).

${ }^{38}$ Wells and Taylor's decision to retitle the play is based on contemporary testimony and the assumption that this was the title the play was first performed under, even if in print the play has only ever been known as Henry VIII. "An exceptional number of spectators recorded the event, and all agreed that the play being performed was called 'All Is True' and was about 'The Life of King Henry the Eight'" (Textual Companion 28).
} 
what it is seeing. As Patterson argues, the title of All is True is deliberately ironic, articulating a conception of historical truth that sees the creation of history as a collaborative and politically interested process that is freely inventive in its appropriations of "fact" to advance the chronicler's agenda (149). ${ }^{39} \mathrm{It}$ is revealing that these titles, which make explicit their strategies of truth and interpretation, coincide with plays that take as their subject the early Tudor court. No plays are extant dealing with the reign of Henry VII, a situation which gives the impression of a clear divide between the concerns of the chronicle plays on pre-Tudor history (most obviously Shakespeare's tetralogies) and the later histories that take as their subject the courts of Henry VIII and his children. ${ }^{40}$ It is to this later group that Cromwell and More also belong, both in terms of their subject matter and in the form in which their themes are explored.

Cromwell and More are rare examples of English history plays that deliberately avoid portraying the monarch on stage while depicting his closest courtiers. King Henry VIII is a continual presence throughout More and the second half of Cromwell, yet never appears in person or has his words spoken verbatim. He is also, crucially, criticised only through implication, never directly. In this, the two plays show an Elizabethan discretion towards potentially slanderous treatment of the current Queen's father, a discretion relaxed by Rowley in When You See Me, first performed during James's reign. The absence of the king in Cromwell and More is emphasised through the extraordinary amount of testifying to the title characters' worth by low-status characters. Cromwell is praised by Banister's Wife (2.1.33-35), Seely and his wife (4.2.55-61), nameless merchants (4.3) and citizens (5.4), while More's reputation is established by the rebels (6.51-53, 67-69, 7.100ff), the players (9.301-06, 355-60), his warders and the Poor

\footnotetext{
${ }^{39}$ See McMullan on the play's complex negotiations with concepts of "truth" (Henry VIII 57-146).

${ }^{40}$ The future Henry VII, of course, does appear onstage in both 3 Henry VI and Richard III.
} 
Woman (14.9-14, 43-44) and his servants (15). The dangers of showing the King on stage are turned into an opportunity by the dramatists to re-make history from the ground up, allowing audiences to see statesmen through the eyes of their peers, in opposition to the earlier chronicle plays that allowed kings to create their own reputation. This is in keeping with the successful strategy of Shakespeare's Henry $I V$ and Henry $V$ plays, which shift towards an emphasis on the commons' view of their leaders. As Edna Zwick Boris notes:

In the first tetralogy the people, particularly the commons, have little formal apparatus through which to make their views known yet have great power in helping determine through their support who will be king; in the second tetralogy, the people and the support they offer a leader progress from being a recurring theme to being accorded formal recognition. (158)

The important point to draw from this is that it is the formal apparatus that is lacking in the earlier plays. Where rebels such as Jack Cade and Jack Straw appropriate power in the form of rebellion, the influential shift in Henry IV and Henry $V$ is towards monarchs actively seeking and listening to the views of common people, allowing the common voice to be mediated through dialogue and argument as well as violence. This is commensurate with the "Jacobean moment", most often discussed in relation to plays such as Measure for Measure and The London Prodigal, which courted royal favour upon the Jacobean succession by engaging with the new king's theories of government. ${ }^{41}$ The removal of the king and the prioritisation of lower-class voices in establishing the

\footnotetext{
${ }^{41}$ This is particularly relevant to the years 1603-04 (the estimated date of the Thomas More additions and of The London Prodigal and related plays discussed above) during which James's own True Lawe of Free Monarchies and Basilicon Doron were reprinted two and seven times respectively. See E.M. Pope for a survey of the materials dealing with the responsibility of the ruler during these years ("The Renaissance Background", esp. 70).
} 
characters of upper-class individuals is a concurrent step in this movement, and thus we see Cromwell and More evolving out of Shakespeare's work on history plays, just as the related When You See Me borrows directly from Henry $V$ in its depiction of the disguised king moving among his subjects. ${ }^{42}$

The absence of the king, however, becomes both criticism and warning in Cromwell, a play that has received surprisingly little critical attention. Here, the king's absence may be read as a form of political impotence, as he is reduced to little more than a powerless name. Crucially, as Gardiner's plot closes in around Cromwell, Cromwell trusts to the King to save him: "The king! Let me goe to him face to face; No better triall I desire then that" (5.4.35-36). The king, however, is absent, and Cromwell's bitter words later articulate the lesson of the king's absence. "And is his Princely eares so much bewitched / With scandolous ignomie, and slanderous speeches, / That now he dooth denie to looke on me?" (5.5. 47-49). The final irony, the arrival of a reprieve and summons from the King moments after Cromwell's execution, shows Henry suffering the penalty for his distance from the affairs of his court. He is dissociated, so out of touch even with matters concerning the man who he called "euen halfe himselfe" (5.5.46) that he is unable to prevent that same man's execution. While the play never says anything explicitly negative about Henry VIII, therefore, his weakness is implicit and constructed as a direct extension of the lessons learned by Hal/Henry V in Shakespeare's second tetralogy; that only through a connection with one's subjects can a king become strong. This discussion also underpins When You See Me, dramatising Henry's strength in his interest in all subjects and his weakness in being manipulated by courtiers with their own agendas.

\footnotetext{
${ }^{42}$ The episode of Henry VIII's disguise in When You See Me is evoked by Henry's elaborate masque in Henry VIII, in which he is disguised as a shepherd and "revealed" by Wolsey (1.4.10810). In both, Henry VIII is concerned with strategies of self-presentation that control the revelation of the royal person and manipulate the dynamics of power, strategies familiar from James's writings.
} 
It is no coincidence that the Roman Catholic Gardiner is a key manipulator in both plays, and his reappearance in a similar capacity in Henry VIII is telling of the use of Henry VIII's court by dramatists. While retaining individual characteristics, several of the persons of court such as Wolsey and Gardiner become figures of Vice and Temptation, stock villains with a functional role as the testers of kingly integrity. The strength of Henry VIII is repeatedly tested across these plays by his ability (or not) to overcome the voices of evil and assert his kingly authority to restore justice.

Thomas More's absent king figure is used differently. Here, there is no visible antagonist or enemy. ${ }^{43}$ At worst, characters are misguided (the rebels) or foolish (Suresby, Falkner), but even those nobles who maintain opposing stances to More in regard to the King's articles remain sympathetic to his case; Surrey's closing epitaph "A very learned worthy gentleman / Seals error with his blood" (17.125-26) betokens frustration rather than malice. Unavoidably, it is Henry VIII himself who is recast in the Gardiner role here, deliberately orchestrating More's downfall. For obvious reasons, however, this would be unpresentable on the Tudor or early Stuart stage. The removal of Henry and foregrounding of More allows instead for criticism of the king through comparison. More is everything in this play that Henry VIII should be. He is connected to the concerns of the people, charitable, just and, most importantly, possessed of an absolute integrity. It is this integrity that is openly tested through his refusal to accede to the King's articles, in much the same manner as Henry's is tested in When You See Me, but here the battle is, as More himself articulates, "'twixt conscience and my frailer life" (13.185), whereas in both When You See Me and Cromwell the stakes are worldly and political, dealing with accusations of treachery.

\footnotetext{
${ }^{43}$ With the exception of the arrogant Lombards in Scene 1, whose appearance is designed to justify (at least partially) the origins of the rebellion. Their subsequent removal from on-stage presentation, and the changing nature of the rebellion, prevents them from being seen as developed antagonists.
} 
The key fear of both Cromwell and More is of hypocrisy, the taint of which both are keen to avoid. In More's case, this is figured through an absolute - and merry refusal to subscribe to the unnamed articles, allowing him to go to heaven "void of fear" (17.124). In Cromwell's case, the fear is more general and long-lasting. Bagot is able to play on this fear in Antwerp, telling him "But if your conscience were as white as Snow, / It will be thought that you are other wise" (2.2.62-63), directly prompting Cromwell's departure in order to avoid even the suspicion of hypocrisy. While he is far less stoic in accepting his fate than More ("O God! had I but read this letter, / Then had I beene free from the Lions paw", 5.5.20-21), in his final moments his primary concern is still his reputation: he expresses bitterness at Henry's ears being "bewitched" with false report (5.5.47) and ensures that the King is informed of the truth. Together, the two plays define the virtue of their central characters as a combination of private and public integrity, loyalty and conscience, which is impervious to human influences. The two take the place of the King in their respective plays, and are rendered sympathetic through their charity and generosity; the King's absence therefore implies his separation from these values, and thus from necessary qualities of kingship. That these are the values expected of a monarch is clearly shown in the portrayal of Queen Elizabeth in Heywood's slightly later 1 If You Know Not Me, You Know Nobody (c.1604). The action of the play itself is slight and repetitive, dealing with the persecution of Elizabeth as she moves between different forms of prison, but the play is designed to demonstrate the future Queen's patience, resilience and loyalty to her monarch, which is in turn rewarded as she ascends the throne. Mary, meanwhile, is strongly influenced by Cardinal Winchester and ignorant of these qualities in Elizabeth, placing her in the same position as the absent Henry of Cromwell and More. ${ }^{44}$

\footnotetext{
${ }^{44}$ Recent history, of course, made it far easier to vilify Mary onstage than her father, hence her presentation in this play. In this regard, 1 If You Know Not Me is less daring than When You See
} 
The presence of these qualities in the king-substitute protagonists positions them as necessary for kings; but the fact that More and Cromwell are also subjects argues that the same qualities are also to be expected of the lower orders. Cromwell makes this clear with its moralistic subplot, portraying a cycle of goodness, justice and reward among a group of merchant-class characters that Ribner sees as part of the play's ongoing "mutability theme" (208). While the subplot can seem tedious to a modern readership, with its fortuitous meetings and tidy resolutions, it provides a context for Cromwell's story that draws attention to the play's concern with the individual's moral compass and the consequences of not adhering to it. The simplicity of the subplot is countered and complicated by Cromwell's fate. More, meanwhile, focuses on civic disobedience in its first two acts, in which More demands the same qualities of the rebels that he later exhibits himself: patience, sufferance and an adherence to God and authority. It is these scenes, believed to be in Shakespeare's hand, which are most often related back to the Shakespeare canon, particularly the Jack Cade scenes of 2 Henry VI and the crowd calmed by Menenius in the later Coriolanus, but the connections are too structurally integrated into the body of the play to isolate these scenes exclusively as having a Shakespearean connection. The web of influence is wide, and extends into other histories: Jack Straw, despite being set during Richard II's reign, shares the foregrounding and individualising of its rebels in 2.2 and 2.3 , inviting sympathy for them if not their cause. Just as, in that play, Richard is implicitly criticised for his inability to engage directly with the rebels by the success of the ensuing rebellion, this time. 
so too is the king of Cromwell and More criticised for his absence from the practice of necessary values. ${ }^{45}$

It is in the presentation of the lower orders that More and Cromwell differ significantly from the other plays on Tudor history and approach their subjects in a manner perhaps more associated with Shakespeare's earlier history plays. Both When You See Me and 1 If You Know Not Me focus entirely on monarchs, their courts and their immediate servants, with the only exception being Henry's disguised excursion in scenes 4-7 of When You See Me. ${ }^{46} 2$ If You Know Me, by contrast, focuses primarily on merchant-class characters, but when it does so its concerns are with a merchant history, the founding of the Royal Exchange. Only in the final four scenes does the play return to a political history, and in doing so it rather clumsily cuts short the story that has dominated the previous four acts and introduces a new, entirely courtly class of characters to conclude the play with the story of the Armada. By contrast, Cromwell and More integrate into their plots a host of lower-class characters through whose eyes political events and figures are sketched, privileging a street-level sense of politics that complements the courtly plot. The opening presentation of Cromwell himself, studying above his father's shop, grounds the action in city life. Further, the concept of Cromwell and More as king-substitutes is echoed in the presentation in both of serving characters dressed up as nobles: Hodge in Cromwell 3.2 and Randall in More 8, both of whom reflect on the effects of their costumes on their own sense of self. McMillin argues that Randall's “Before God, I have practised your lordship's shift so well that I think I shall grow proud" (More 8.24-26) represents "a moment of pointed irony" (Elizabethan Theatre 26) following More's discourse on the dangers of the trappings of office. More's

\footnotetext{
${ }^{45}$ Act and scene divisions for Jack Straw are taken from Muir and Wilson. The rebellion itself is later halted by an unexpected trick (the killing of Straw by the Mayor during a conversation) that brings to mind Prince John's treatment of the Archbishop of York in 2 Henry IV 4.1.

${ }^{46}$ Scene divisions for When You See Me are taken from Wilson, When You See Me.
} 
annoyed dismissal of Randall ("Fool, painted barbarism, retire thyself / Into thy first creation" 8.180-81) anticipates More's own fall from grace, and emphasises that even his own point of view is that of a servant.

Cromwell and More, therefore, straddle a line between the "Shakespearean" history and the contemporary plays on Tudor history, welding the class-conscious commentary of the Hal plays onto the content of Henry VIII's court. The lack of aphoristic titles for these two plays neatly underlines a conceptual difference to the other Tudor history plays: where those impose all-encompassing titles on their focused perspectives to imply universality, these plays embed universal perspectives on their title characters into the text of the plays themselves. The dual title of Henry VIII/All is True, meanwhile, draws attention to its difference from other "Shakespearean" histories and from the similar content of Cromwell and More. It distinguishes itself through its exclusively courtly focus and the centrality of the king that more closely associate it with the aphoristically-titled plays of Rowley and Heywood. Yet the mediation of debates surrounding kingship through the recognisable figures of Henry's court connects Shakespeare's late collaboration with the earlier plays with which he was also, at least nominally, involved.

The close connection of More and Cromwell to the Shakespearean repertory is one of content and strategy rather than authorship; yet the sympathy in Shakespeare's plays for the viewpoint of the common man, and his carefully managed depiction of civil disorder (previously in 2 Henry VI and Julius Caesar, later in Coriolanus), binds these plays more closely to the influence of the company's resident writer. It has long been thought that it was this aspect of Shakespeare's reputation that led to him being recruited to meet Tilney's instruction to "leave out the insurrection wholly with the 
cause thereof" by creating a version that would be acceptable to the authorities. ${ }^{47}$ If this was so, then there is a case for the Shakespearean connection underpinning the prioritisation of lower-class viewpoints in both Cromwell and More, rendering them, in the repertory sense, importantly Shakespearean.

\section{Romance and Nostalgia}

If Thomas More did belong to the Chamberlain's-King's Men, and Hand D is Shakespeare's, then the extant manuscript may preserve an example of the kind of (re)writing expected of a resident dramatist in fitting up plays for performance. While it is a commonplace that Shakespeare's role in the company is likely to have involved this kind of work, however, there has as yet been no critical acceptance of Shakespeare's partial revision of any other extant company play; his collaborative work either includes works he initiated or in which he had a substantial involvement (Two Noble Kinsmen, Timon of Athens etc.) or is limited to works that predate the formation of the Chamberlain's Men (Edward III, Arden of Faversham, Titus Andronicus), thus sustaining a narrative that emphasises Shakespeare's independence over his company role. Two possibilities other than More have been proposed. George Chalmers was one of the earliest to suggest that Shakespeare "did read, and amend Ben Jonson's Sejanus, in 1603" (273), extrapolating from the reference in Greene's Groatsworth of Wit to the "absolute Iohanues fac totum" (F1') that this was a standard part of Shakespeare's role. The revisions are, of course, not extant, and our knowledge of them is limited to Jonson's reference to "a second pen" whose work he has excised ("To the Readers" 40). ${ }^{48}$ More recently, Hugh Craig and Warren Stevenson have revived the argument that

\footnotetext{
${ }^{47}$ McMillin argues against this; see "Dates and Acting Companies" for a persuasive argument that the Hand D section was written contemporaneously with the original, and therefore before Tilney's intervention. This has failed to find widespread acceptance, however, as the identification of Hand D as Shakespeare hinges on parallels with Shakespeare's middle period. See Taylor ("Date and Auspices").

${ }^{48}$ Quotations from Sejanus and its paratexts are taken from Ayers.
} 
Shakespeare was the author of the additions to the 1602 quarto of Thomas Kyd's The Spanish Tragedy and, while the research is flawed, the case for Shakespeare's authorship has gained some traction. ${ }^{49}$ It is worthy of note, of course, that these three potential Shakespearean piecemeal contributions are roughly contemporaneous with one another, which may be suggestive of a particularly intensive period of collaborative work and fitting up during this period.

One of the few company plays which we know to have been revised during Shakespeare's tenure is Mucedorus. Although the play is thought to date from the late 1580s, and thus to pre-date the Chamberlain's Men, the 1610 third quarto advertises it as "Amplified with new additions, as it was acted before the Kings Maiestie at White-hall on Shroue-Sunday night. By his highness Seruantes usually playing at the Globe." (title page), indicating it belonged to the company by this point. Richard T. Thornberry, further, has drawn attention to the fact that the second quarto (1606) subtly revises the epilogue of the play to take account of James's ascension to the throne. ${ }^{50}$ This evidence of the continual updating of the play in response suggests that the play was performed more than once at court between the late 1590 s and 1610 , supporting the suggestion that it was the Chamberlain's Men - favourites at court - who owned the play during this period. Gurr notes that during Elizabeth's reign, the official position was that "shows to the public were merely rehearsals for the real aim, to entertain the queen" (Company 167); if the implication is that any plays performed at court were also being "rehearsed" in the public theatres, then Mucedorus was almost certainly also performed regularly in

\footnotetext{
${ }^{49}$ See Kirwan, "Review" and Vickers, "Shakespeare and Authorship Studies" for discussion of these specific claims.

${ }^{50}$ The changes are minor, but consistent, and begin in Comedy's penultimate speech. "Yeeld to King lames" replaces "Yeelde to a woman"; "womans fwaie" is replaced by "Worthies Sway"; simple pronoun changes render the monarch masculine rather than feminine, although "Prince" is used for both Elizabeth and James $\left(\mathrm{F} 4^{\mathrm{v}}\right)$. Alterations this straightforward are important, but need not have been made by the play's original author(s). They might even have originated in the printing house under a careful compositor's eye.
} 
the city during the same period. References to the play in Beaumont's The Knight of the Burning Pestle (c.1607) and Massinger's The Guardian (1633), as well as a publication record that stretches to some eighteen extant editions, attest to the play's ongoing popularity.

The perceived popularity of Mucedorus has damaged its reputation in modern scholarship. Richard Preiss counts that, in the last fifty years, there have been just seventeen scholarly articles on Mucedorus; "or one for every (extant) early modern printing" (118). ${ }^{51}$ Preiss's point reveals an apparent and fundamental inconsistency in the reception of Mucedorus. By the only meaningful measure available to us, Mucedorus appears to have been one of the most popular of all early modern plays, yet it stands in a critical neglect that speaks to the relative embarrassment that the play causes for a critical tradition founded on Bardolatrous standards. Mucedorus is a relatively unsophisticated entertainment rooted in earlier traditions of chivalric romance and pastoral comedy. It is short and straightforward, described by Preiss as "stylistically obsolescent from the first" (118) and boasting additional passages that Brooke finds of "workmanlike mediocrity" (Apocrypha xxvi). Preiss attempts to account for the unusual print record by suggesting the play was deliberately set apart for use by provincial companies, "surrendering a single product to disseminate an entire platform" (127). While Preiss's theory perhaps relies too heavily on modern notions of intellectual property rights and marketplace protection, his assertion that, according to the extant evidence, "after 1610, the play's entire pre-Restoration stage record is provincial" (117) cannot be ignored.

\footnotetext{
${ }^{51}$ The preciseness of his figure is open to question, it being dependent merely on an MLA basic keyword search. Preiss is unaware of Proudfoot's work on the play which has identified an eighteenth edition. See Proudfoot, "Modernising".
} 
Yet the critical interest in explaining away Mucedorus's popularity rather occludes the play's importance to the company's repertory. It exerted a major influence on the development of the tragicomic genre, and examination of the context of the 1610 additions is particularly instructive. The passages added to Q3 of Mucedorus are, with the exception of a short piece of comic business featuring Mouse and the bear, entirely concerned with Mucedorus's back-story and Valentia. ${ }^{52}$ This is immediately clear from comparing the two lists of Dramatis Personae, which increase the number of players needed from eight to ten. The additional scenes introduce Mucedorus's friend Anselmo and his father, the King of Valentia, but most important is a new opening scene set in Valentia which shows Mucedorus telling Anselmo of his plans to go disguised to Aragon. Reynolds notes that this introduction means that "the $B$ audience [his term for spectators of the Q3 version] was never in doubt as to who the hero really was" (254), but does not explore this further. The few modern editions follow the 1610 text. $^{53}$

The notable feature of the 1598 text has gone largely unremarked; that an audience watching the play would not know, until the final act, who Mucedorus really was; or, indeed, that he was anything other than a shepherd. The purpose of the additions is to make clear, and regularly remind the audience, that Mucedorus is in fact a disguised prince. Leo Kirschbaum notices this, but sees it as little more than a defect in the original that the additions "make clear" (4); while Pavel Drábek argues that the aim

\footnotetext{
${ }^{52}$ There are notable errors in some critics' description of the nature of the additions. Preiss, for example, describes "several new characters", and states that Mouse's additions, as well as the encounter with the bear, include "more jokes, and an altogether irrelevant skirmish with an alewife whose beer he has stolen" (120). This last, the opening portion of 3.5, is in the original version, and there are no other additions for Mouse. Reynolds, however, also works under the impression that $Q 3$ is generally more comic, reflecting a move away from Elizabeth's liking for "serious mixed with comic" (266). There is no good reason for suggesting that Q3 is substantively funnier than Q1-2, and the bulk of the additions rather render the play more serious and melancholy, particularly 4.1 which, as Valentia orders away the music that "ads to torment", recalls Orsino in 1.1 of Twelfth Night. Quotations and act/scene references to Mucedorus are taken from Brooke, Apocrypha.

${ }^{53}$ The exception is Arvin Jupin's 1987 modern-spelling edition, which offers some useful insights but is poorly printed and riddled with errors.
} 
is to draw attention to the illusory and self-consciously theatrical nature of the play. I dispute Drábek's reading: his suggestion that the additions mean "the audience know the truth and willingly take in the illusion of the stage action" (50) misses the point that in neither version are the audience aware of knowing anything other than the truth. While he is right to note that the explicit adoption of a disguise in the opening scene opens up a layer of theatricality, this theatricality has already been asserted by the framing dialogue of Comedy and Envy. In terms of self-consciously articulating the illusory nature of the stage, the revisions merely shift the articulation of stage illusion from the climax to the main action.

Jackson, the only critic to realise the significance of the additions, uses it to argue for Shakespeare's authorship of them, suggesting that the change is "precisely that which one would expect from the author of Cymbeline" ("Edward Archer" 246). The implications for authorship, however, are less significant than those for the way in which an audience interprets and experiences the social aspects of the play. In the 1598 version, the hero is understood to be a pastoral figure, a common man, which may well have appealed to the audience in the public theatres. ${ }^{54}$ However, for an aristocratic audience there is an implied social threat: a princess falls in love with a courageous commoner and plans to flee her royal life. This can be related to the "threat of disorder" that Abigail Scherer notes in the play in the person of Bremo, the wild man, who she argues personifies the failure of society (65). The play is full of figures of exclusion: the renegade soldier employed to murder Mucedorus; the outlawed Bremo; the wandering shepherd. It is perhaps no coincidence that in 1610, the year of the revisions, James

\footnotetext{
${ }^{54}$ This offers a very different interpretation to Hattaway, who fails to distinguish between the two versions of the play. He discusses the effect of Mucedorus donning his disguise as if it was contemporary with Tamburlaine putting aside his shepherd's weeds in the late 1580s, thus misrepresenting the play's contextual interactions with popular traditions (Elizabethan Popular Theatre 135).
} 
introduced a special statute to counter the impingement on the royal forests of wild wood-dwellers (Scherer 57).

The 1598 text represents an attempt to experiment with audience conceptions and cater to both popular and elite tastes, while not fully accommodating either. By introducing as its chivalric hero a man who appears to be a rustic commoner, the play subverts dramatic convention and makes a unique appeal to the public audience by inviting sympathy and admiration for a character of low social status, in contrast to the cowardly courtier Segasto. Wiggins, speaking of Tamburlaine, argues that

$$
\begin{aligned}
& \text { An Elizabethan shepherd could not normally expect to become a } \\
& \text { gentleman, let alone a lord: the rigidly stratified society of } \\
& \text { contemporary orthodoxy was organized as an ascending hierarchy of } \\
& \text { allegiance and responsibility, culminating in the immense and } \\
& \text { centralized might of the crown; peasants and aristocrats each had their } \\
& \text { place and were expected to remain in it, their lofty or lowly status } \\
& \text { defining the nature of their actions. (Drama of his Time 37) }
\end{aligned}
$$

Tamburlaine and Mucedorus thus both appeal to a fantastical interest in over-reaching commoners. The introduction of a second antagonist, the "animalistic" Bremo (Scherer 58), acts further to raise the status of the shepherd by comparison. The implicitly transgressive and upwardly-mobile social agenda of the play is, however, subverted and made safe by the revelation that Mucedorus is, in fact, a disguised prince, retrospectively conventionalising the politics and sympathies of the play. While this revelation is effective in bringing about the play's only inevitable ending, however, the deception practised on its audiences is less satisfactory. The public audience is denied its folk hero; the "worthy shepheard" (1.3.17) is, in fact, not that at all. More problematically, the revelation of the prince's true identity may have come 
unacceptably late for the aristocratic audience. Scherer (63) identifies this audience as already feeling vulnerable in the presence of a depiction of social anarchy, personified by the "untameable wild man" (Rabkin and Fraser 463) who is later echoed unmistakably in Caliban. The social destabilisation is compounded by the lack of regard for class boundaries perpetrated by a shepherd, however worthy, who kills a noble and elopes with a princess. While the final act revelation justifies Mucedorus's presumption, any play that kept a courtly audience in a state of social anxiety for three quarters of its length may have been taking a serious liberty. Presuming the play was performed around the time of its first publication, we might productively contrast it with the company's slightly later As You Like It, which makes explicit the playfulness of the nobles living "like the old Robin Hood of England" (1.1.78), and Munday and Chettle's Huntington plays at the Rose, the first to turn the folk hero into an outlawed nobleman. These plays adhere to a clear social order that Mucedorus deliberately subverts.

The 1610 additions establish Mucedorus's character and pedigree from the start, making the audience complicit in his disguise and allowing the plot to proceed in a conventional way. The action becomes more ordered and planned: whereas in the 1598 quarto it is implied that Amadine and Mucedorus have met by chance, the 1610 quarto makes it clear that he was actively seeking her. ${ }^{55}$ By removing the surprise of the prince's disguise, Mucedorus is made safe; he is a self-excluding figure, exercising the patriarchal right to adopt disguise previously practised by Henry V, Old Flowerdale and the Duke of Measure for Measure. The protagonist's actions are understood in advance to be those of a prince and are evaluated thus, according to James's own political

\footnotetext{
${ }^{55}$ Mucedorus's revelation that he is "borne of Royall blood - my fathers of / Valentia King, my mother queene - who for / Thy secret sake tooke this hard task in hand" (5.1. 162-64) is present in all texts and gives the reasons for his disguise towards the play's end, but the Q3 additions emphasise the object of his quest much earlier and more prominently.
} 
theories that legitimise the use of disguise in maintaining order. ${ }^{56} \mathrm{His}$ presumption in defying Segasto and declaring his love to Amadine are justified, and the ultimate outcome of the comedy assured.

The changes made to Mucedorus for the 1609-10 performance become more significant in the light of the new innovations in the King's Men's dramatic output. ${ }^{57}$ This revival coincides with what many critics identify as the beginnings of tragicomedy: Gurr suggests that Pericles, in 1607, was the company's first major foray into the genre (Company 46), but Knutson, taking the view that the genre is more properly indebted to Beaumont and Fletcher's early experiments, suggests that Philaster (1609) is a more fitting point to locate the beginnings of the generic shift (Repertory 41). Given that Pericles was printed twice in 1609, and that plays such as Cymbeline and The Winter's Tale followed hard upon, it seems that the 1609-10 revival of Mucedorus with its new additions is intrinsically linked to the development of the new form.

Gurr, in discussing the early days of tragicomedy, makes an important observation:

Fletcher's plays, starting with Philaster at the Globe in 1609, depended on their ability to hold the audience in suspense until the surprise revelation of the ending. The Winter's Tale is the only play in all Shakespeare to surprise its audience with Hermione's living statue, as

\footnotetext{
${ }^{56}$ See E.M. Pope, who cites William Willymat in A Loyal Subiects Looking-Glasse (1604): "Kings, Princes, and governors do use oftentimes to use diverse causes to disguise their purposes with pretences and colours of other matters, so that the end of their drifts and secret purposes are not right seen into nor understood at the first" (72). Compare Kastan, however, who notes that "anxiety was directed not merely at dressing 'up,' at the potential derogation of authority that its miming might effect; it was equally directed at dressing 'down' . . what was worrisome was that class positions could be mimed at all." (Shakespeare after Theory 154)

${ }^{57}$ I follow Knutson in reading the evidence of the Q3 title page as implying a court performance during this winter season (Repertory 197).
} 
Philaster surprises its audience with the boy page who turns out to be a woman. (Company 46)

At this time, too, Jonson was experimenting with the surprise revelation in a more traditional comedy, Epicoene, at the Whitefriars. The "twist ending" came into vogue as part of the new experiments in dramatic form, providing miraculous revelations by the means of which disaster, or at the very least an uncomfortable ending, was averted. If the "surprise revelation" is, as Gurr suggests, assumed to be an essential part of the fashionable new form, it seems particularly surprising that it was at this time that revisers were called in to remove the surprise element from Mucedorus. It is in this removal of the surprise element that Jackson believes the revised version reflects Shakespeare's practice as opposed to that of his contemporaries. It is important, then, to consider Mucedorus's relationship to the tragicomic genre.

Mucedorus has long been recognised as a precursor to tragicomedy, a link between the old Elizabethan pastorals and the more sophisticated versions of the Jacobean and Caroline theatre. Mowat notes that Mucedorus is one of a very few plays to explicitly set up a tragicomic debate in its very framework, a dialogue between Envy and Comedy ("What's in a Name" 141). Fletcher's remarks in The Faithful Shepherdess on the nature of pastoral tragicomedy are also applicable:

Understand therefore a pastorall to be a representation of shepheards and shephearddesses, with their actions and passions, which must be such as may agree with their natures ... A tragie-comedie is not so called in respect of mirth and killing, but in respect it wants deaths, 
which is inough to make it no tragedie, yet brings some neere it, which is inough to make it no comedie. ("To The Reader" $11-26)^{58}$

Mucedorus, until the final revelation, appears to take a shepherd as its lead character. Despite being unambiguously sold in print as " $A$ Moft pleasfant Co-medie" (title page), the lead characters are under constant threat of their lives: the bear attack, Tremelio's attempted assassination and Bremo's capture of the fleeing lovers are genuine threats, and there are two onstage murders.

This commixture of comic and tragic elements, characteristic of earlier romances, was unusual in a play that had survived so long. It is perhaps possible that the 1610 additions to Mucedorus were designed explicitly to distinguish the old play from the burgeoning tragicomic form. As Beaumont, Fletcher and Shakespeare in 1609-10 drew on the pastoral traditions of the past in the development of their new form, the company perhaps became aware of a need to separate the "badly worn antique" (Reynolds 257) from the new plays.

Munro, discussing the development of tragicomedy by the Children of the Queen's Revels, identifies a courtly influence on the interest in the genre, emanating from Anna of Denmark's fascination with Italian culture (102). She notes that the "Pastoral Trage-comedie", as applied to Daniel's Arcadia Reformed, is an "Italianate generic tag" (103). Mucedorus, on the other hand, is a "Sidneian pastoral" (104), rooted in English traditions rather than the new Italianate influences. The distinction between Sidney and Daniel speaks more to a distance in time than in matter, but it is perhaps this sense of the old versus the new that is emphasised by the title page descriptions of

\footnotetext{
${ }^{58}$ For useful discussion of the exact nature of the experiment being undertaken in The Faithful Shepherdess, see Munro (124ff) and Marco Mincoff. Both agree that despite the general applicability of the defence of tragicomedy, the problems encountered in the presentation of this play were specifically local to a play that, as Munro puts it, "is a more thorough attempt to recreate Italian pastoral tragicomedy than any other commercial play of the period" (124). Quotations from The Faithful Shepherdess are taken from Kirk.
} 
Mucedorus as a comedy, and by the additions that remove the tragicomic element of surprise from the play. As the King's Men, along with the Children of the Queen's Revels, were one of the two companies most influential in developing the genre, it seems entirely possible that the company neither wanted Mucedorus to be masquerading as a tragicomedy in the new form, nor wished what Mowat defines as the "new Italianate Jacobean tragicomedy" (142) to be viewed as one of the outdated folk-based entertainments that the old play represented. Gossett identifies this very strategy in the writing of Beaumont and Fletcher's Philaster, "demonstrating that the mixed form could be separated from the pastoral elements that had accompanied it in Fletcher's Faithful Shepherdess" (Philaster 2). Mucedorus belonged to the same pastoral tradition that had caused Faithful Shepherdess, in George Chapman's eyes at least, to fail (Philaster 11).

The additions to the 1610 quarto are widely accepted by modern editions because they are "superior to the rest of the comedy" (Brooke, Apocrypha xxv) and "make it a better play" (Fraser and Rabkin 463). In context, though, I would contend that they actually serve to make the play more formulaic, softening those elements that preempt the newer tragicomedy. By removing the surprise of the final revelation, much of the dramatic excitement and tension of the play is lost, the outcome now being clear from Mucedorus's first explanation of his intentions to Anselmo. In its new form, the outdated Mucedorus could serve a fresh purpose. Considering the new vogue for pastoral themes, the revised play acted as a simple, palatable entertainment that catered to a newly popular trend while not being confused with the newer tragicomedies, which are in turn cast as innovative. Cymbeline at this time performed the same function, a deliberately archaic romance that functions as a form of parodic entertainment for a sophisticated court. ${ }^{59}$ Perhaps adding to the element of parody,

${ }^{59}$ See Frost, who also connects Pericles to Cymbeline and the revised Mucedorus, and argues that they share a sense of self-parody. 
Reynolds argues that the 1610 revival made use of a real bear rather than a man in costume (259-60), linking the play to The Winter's Tale and The Masque of Oberon in court performances. ${ }^{60}$

In some senses then, Mucedorus appears to have been a victim of its own success. Munro notes that "with the revival of Mucedorus ... the King's Men began to develop a tragicomic form" (105), and Mowat also notes the importance of the play in establishing many of the motifs developed by the Jacobean tragicomedy ("What's in a Name" 139-40). As it inspired the new work, however, so too did it need to be severed from it, in order that it not impact on the reception of tragicomedy. Fletcher's defence of the genre in The Faithful Shepherdess perhaps indirectly refers to Mucedorus when he explains:

It is a pastoral Tragie-comedie, which the people seeing when it was plaid, having ever had a singuler guift in defining, concluded to be a play of country hired Shepheards, in gray cloakes, with curtaild dogs in strings, sometimes laughing together, and sometimes killing one another: And missing whisun ales, creame, wassel and morris-dances, [the people] began to be angry. ("To the Reader" 3-9)

This new play is to be distinguished from the old play (in which a "shepherd" kills a woodland dweller) that is primarily known for its folk entertainments, "the merie conceits of Moufe" (title page). Mucedorus was remade, both internally and externally, as a straightforward, unsophisticated folk play, popular but unfashionable; the state in which history continues to judge it. This fits with Drábek's suggestion that "In effect, Mucedorus gets much closer to the 'mouldy' tale of Pericles - the 'song that old was

\footnotetext{
${ }^{60}$ See especially Teresa Grant, "White Bears in Mucedorus". The arguments for and against the use of bears in performance are pursued by Helen Cooper and Grant ("Pursued by Bearists").
} 
sung'" (50) and Frost's suggestion that Cymbeline and Mucedorus were part of a short trend for self-conscious, backward-looking parody. In these senses, the revised Mucedorus does indeed share a quality associated with the "Shakespearean" at this moment, regardless of whether or not he wrote the additions. Meanwhile, with the unnecessary weight of the Elizabethan pastoral jettisoned, the tragicomedy of the younger dramatists would go on to become the dominant form in "a generic transition that would affect plays until the closing of the theatres" (Gossett, Philaster 2); a transition that would continue to develop long after Shakespeare's death.

\section{Ensemble Comedy}

This chapter has so far explored the innovations in genre, dominant motifs and dramatic strategies that bind canonical and apocryphal plays closely together within the King's Men's repertory. Implicit in this is an understanding of the ensemble as a unifying principle, the familiarity of actors and other personnel creating a shared identity for the plays that generated "a community experience, a game of the mind free from the subjection to cinematic realism that blinkers modern eyes" (Gurr, Company 16). This emphasis on communal identity rather than on the contributions of individual writers/actors has been particularly lacking from discussion of disputed plays, whose lack of dominating individuals translates into a lack of critical identity. Yet the anonymous popular comedy The Merry Devil of Edmonton, first performed c.1602-03 at the Globe, offers one of the clearest examples of authorship being subsumed into ensemble identity rather than governing it.

What little criticism there is of The Merry Devil of Edmonton aside from the question of authorship falls largely into two categories. The first links the play with the "superstition" plays of the 1580s and 1590s: John a Kent and John a Cumber, John of Bordeaux, Friar Bacon and Friar Bungay and Doctor Faustus. Both William Amos Abrams 
(13) and Nicola Bennett (xii) argue that the main plot is adapted from the prose pamphlet The Famous History of Friar Bacon, which also provided the source for the play of Friar Bacon. ${ }^{61}$ All, of course, feature magicians in prominent roles.

This line of inquiry has perhaps consumed more attention than it merits, with critics misled by the play's title and Induction, both of which position Peter Fabell, the "Merry Devil" as the play's central figure. Bennett notes, however, that "Fabell's role in the actions seems rather marginal, as the play exploits his magical powers less than one might expect" (xii); and Knutson points out that the magic of the play is "recreational", with the promised disruptions of nature and the nunnery failing to take place, in contrast to the John a Kent and Bacon plays, where the magicians "have more interest in their own magical experiments and in duels with rival magicians" (Repertory 89). The core tricks of the play revolve around disguises, substitutions and night-time evasions, all performable without supernatural aid; as Fabell himself notes, "some pretty sleights .. / Such as but sat upon the skirts of art: / No conjurations"(5.1.257-59). ${ }^{62}$ In noting these differences, it must also be remembered that Merry Devil is generally dated to about 1602 (Knutson, Repertory 81), while the remainder of the magician plays belong to the late 1580 s or early 1590 s.

To group the play with the earlier conjuror plays is to obscure fundamental differences between Merry Devil and the sub-genre. Fabell's role as magician is actually dealt with summarily, completed within an Induction after which his magic is only referred to and never seen. This performs two key functions. The first is to act as a response to the recent revival of Marlowe's Faustus at the Fortune in 1602 (Knutson, Repertory 90-91) and the advent of a newly irreverent form of "devil comedy" in London

\footnotetext{
${ }^{61}$ This assumes that the pamphlet was in circulation long before its first extant printing of 1627, as Bennett notes (xii).

${ }^{62}$ Quotations from Merry Devil are taken from Bennett.
} 
from 1600 (Gurr, Opposites 43), which may have provided a brief resurgence of interest in the old genre. The Prologue and Induction to Merry Devil serve as a response to and parody of Faustus's final scene, remade with a happy ending: here, the magician tricks the devil and wins from him another seven years of life. ${ }^{63}$ This leads Joseph Horrell to conclude that the author "capitalized on the predilection of contemporary audiences for Marlovian protagonists . . . by means of a clever parody in which his superman, the necromancer Fabell, clearly outshines Dr. Faustus" (36). ${ }^{64}$ Magic, devilry and Fabell's deferred fate form no part of the subsequent action. Secondly, it acts to dispense with necessary elements of the source text. While the main action of the play is lifted from the Bacon pamphlet, the other key source is Thomas Brewer's pamphlet The Life and Death of the Merry Devill of Edmonton. With the pleasant prancks of Smug the Smith, Sir John, and Mine Host of the George, about the stealing of Venison. ${ }^{65}$ From the subsequent action, it seems apparent that it is the "pleasant prancks" that captured the imagination of the playwright, rather than the story of the Merry Devil. Smug's antics were sufficiently popular for the 1657 edition of the pamphlet to be rechristened The Merry Jests of Smug the Smith, and the pamphlet's woodcut of Smug atop the Garter Inn adorns the title page of the 1655 quarto of the play. It is this comic story, integrated with the Raymond-Millicent plot, that forms the action of The Merry Devil of Edmonton: the Merry Devil himself is not the focus of interest, and his story effectively ends before

\footnotetext{
${ }^{63}$ In the source pamphlet, Fabell strikes a deal with the Devil that he shall have life until a candle is burned out, which he then immediately extinguishes and preserves. The altering of this in the play to a set period of time ("Seven years from this hour", Induction 74) echoes the deal for "four-and-twenty years" struck with Faustus (A-text 1.3.93), with damnation imagined as an inevitable consequence of time rather than a condition to be avoided through wordplay. See Faustus A-text 5.2.65-117. All quotations from Faustus are taken from Bevington and Rasmussen. ${ }^{64}$ Horrell's point, which assumes a collective audience memory of Faustus stretching back fifteen years, is strengthened by later discoveries of evidence for a revival of Faustus immediately prior to the original performances of Merry Devil.

${ }^{65}$ The first extant printing is 1631; however, the same wording appears in Brewer's 1608 stationer's register entry for what we must assume was the first edition (Bennett xiii).
} 
the play proper even begins, though with enough of a spectacular scene to capture the imaginations of audiences newly reminded of Faustus at the rival theatre.

Ignoring the framing device, then, we are left with a more conventional comedy of cross-generational trickery, romantic love and comic buffoonery. In this, we find the second body of criticism on the play, which is concerned with the play's relationship to Shakespeare's plays, particularly The Merry Wives of Windsor. Beyond the obvious connection of the titles, the two plays share an out-of-town setting; ${ }^{66}$ a drunken and criminal Sir John; parents thwarted in a forced marriage attempt; an inn as primary setting; and a night-time woodland scene featuring the hunting of deer (literal or figurative). Brooke argues that the "apparently purposeless" Induction is intended to imply an "infernal" element in the "nocturnal" scene of Merry Devil, and compares Merry Wives and also A Midsummer Night's Dream (“'Nocturnal' and 'Infernal'” 121). While these elements are to a greater or lesser extent conventional, the combination of them all in the later play is suggestive of influence by the elder, strengthened by more specific resonances. Rudolph Fiehler (364) persuasively argues that the catchphrase of Host Blague, "I serve the good Duke of Norfolk" (1.1.7-8 and throughout) is deliberately intended to bring to mind Falstaff, he that was "page to Thomas Mowbray, Duke of Norfolk" (2 Henry IV 3.2.18-19). Fiehler further points out that both of Falstaff's antecedents, John Fastolf and John Oldcastle, were also associated with the Duke in their stage representations, though probably inaccurately in historical terms (365). The figure of the Host himself may have carried further Falstaffian connotations. In his edition, David Crane refers to the Host of Merry Wives as "larger than life, a smaller version of Falstaff, given to a ranting style of speech ... merrily dedicated to drink and

\footnotetext{
${ }^{66}$ Windsor and Edmonton were both a reasonable distance from the City of London, while still "local" enough to share concerns of city comedy rather than provincial domestic drama.
} 
money" (31n). The prominent presence of a Host in both plays is, of course, in itself a further suggestive link.

It is in the reminiscences of Falstaff that the connection of Merry Devil to notions of a Shakespearean influence may be most pertinently noted. One of the most notorious reactions to Shakespeare's work was what Peter Corbin and Douglas Sedge refer to as "The Oldcastle Controversy" (9-12), the presentation of the protestant martyr Sir John Oldcastle as a drunken, deceitful and gluttonous comedian in 1 Henry IV, and the subsequent change of the character's name (possibly following complaints by the current Lord Cobham) to Falstaff. ${ }^{67}$ This controversy acknowledged in the pronouncement of the Epilogue to 2 Henry IV that "Oldcastle died a martyr, and this is not the man" (5.5.114-15), but the incident had further-reaching ramifications, serving to occasion - to author - two more plays, both of which came to be associated with Shakespeare's name.

1 Sir John Oldcastle, for which Munday, Drayton, Wilson and Hathway received payments from Philip Henslowe in 1599, was the first of these. ${ }^{68} \mathrm{~A}$ critical consensus trusts the evidence of Henslowe's records over the evidently erroneous assertion on the title page of the second (1619) quarto that the play was "Written by William Shakespeare. ${ }^{\prime 69}$ While in this sense, therefore, it is clear that Shakespeare did not write Oldcastle, in another sense it is true that this play was "authored" by William Shakespeare, in the sense allowed by the OED meaning "to originate, cause, occasion" ("Author, v", def.1). Oldcastle exists only and entirely because of Shakespeare, as the

\footnotetext{
${ }^{67}$ On the change of name, see Wells and Taylor, Companion 330-31, Bevington, "Determining" 502-03 and Kastan, After Theory 93-108.

${ }^{68}$ On this play's links to Cromwell and More, see Jowett, More. He groups them as "a small group of plays dealing with the lives of the friends and advisers of kings," though his primary interest is in the connotations of the name "Doll" shared by characters in Henry IV, Oldcastle and More (2930).

${ }^{69}$ For an isolated argument for the accuracy of the attribution, see Dominik, A Shakespearean Anomaly. He believes that Shakespeare co-authored the play in order to make up for his indiscretion in Henry IV, and bases his argument on insubstantial and unchecked parallels.
} 
play's prologue makes quite clear: "It is no pamperd glutton we present, / Nor aged Councellor to youthfull sinne" (Prologue 6-7)..$^{70}$ In existing solely to counter Shakespeare's Oldcastle, the play admits its dependence on the source it aims to replace. The addition of Shakespeare's name by Thomas Pavier to his 1619 edition of the play is perhaps disingenuous, but it is also arguably justified in attaching the play to the originator of the discourse that occasioned it. James Marino argues that the stage and print presence of Falstaff/Oldcastle acted with extra-textual authority to "author" and connect the various plays in which he featured ("Oldcastle" 105). To this end, Pavier and Jaggard may have understood the character as the intellectual property of the King's Men, and attributed it to Shakespeare accordingly in order to consolidate the connection. Pavier's simultaneous reprinting of Yorkshire Tragedy may remind us of another link: as Stodder reminds us, the Wife of the latter play's real-life counterpart was "of the Cobham family who had objected to Shakespeare's Oldcastle" ("Review: Continued" 237).

Extending this argument to Merry Devil, we see a subtler continuation of the Oldcastle Controversy that evokes the ghost of Falstaff to supply its humour. Falstaff is evoked in spirit by Host Blague's references to the Duke of Norfolk and in name by Sir John the priest. ${ }^{71}$ This is in addition to the substantive plot parallels with a play that, in its first quarto appearance, was entitled A Most pleasaunt and excellent conceited Comedie, of Syr lohn Falstaffe, and the merrie Wiues of Windsor (Marcus, Unediting 6869). The company may have had a further motivation for this deliberate referencing of the character. As David Wiles, among others, has argued, the role of Falstaff may originally have been conceived as a star vehicle for Will Kemp, whose departure from the Chamberlain's Men in 1599 not only deprived the company of its leading comedian,

\footnotetext{
${ }^{70}$ Quotations from Oldcastle are taken from Brooke, Apocrypha.

${ }^{71}$ James R. Siemon notes, with reference to the OED (“John," def. 3), “'Sir John' was itself a generic name for a priest" (268n).
} 
but also caused the promised return of Falstaff in Henry $V$ to be reduced to a report of his off-stage death. ${ }^{72}$ The tribute to Falstaff in Merry Devil thus not only referenced some of the company's greatest comic successes, but redistributed them in an ensemble comedy with a wide range of equally weighted comic characters. The company's contemporaneous Twelfth Night offers a corollary. While there is a dedicated Fool role, doubtless written for Robert Armin, Falstaffian elements are distributed between several characters including Sir Toby (the play's largest role both in terms of lines and, in stage tradition, corpulence), Sir Andrew and Fabian, as well as Feste. Merry Devil includes no obvious Armin role, and the comic characters are evenly split in an ensemble dynamic of drunkenness, braggartism, petty crime and playfulness that evokes that of Shakespeare's group ensemble. Together, the two plays demonstrate the company negotiating the challenges of establishing a new comic identity in the wake of Kemp's departure. While Twelfth Night is symptomatic of the company's movement towards the more sophisticated musical clowns in which Armin specialised, however, Merry Devil looks back to the company's Elizabethan work, offering a retelling of Merry Wives without its Falstaff.

This evocation of old Shakespeare, even as the company dramatist moved on to the more complex comedies of the early Jacobean period, was evidently popular judging by the number of editions it went through, and potentially had lasting influence. ${ }^{73}$ Victoria Hayne notes that Fabell's disguising of himself and Raymond as friars was "a popular novelty at the time" and provides "interpretative context" for the Duke's assumption of the same disguise in Measure for Measure (24)..$^{74}$ The flight of lovers through the wood, in addition, echoes Mucedorus and A Midsummer Night's Dream and

\footnotetext{
${ }^{72}$ See 2 Henry IV 5.5.111-14 and Henry V 2.1 and 2.3.

${ }^{73}$ Brooke lists six seventeenth-century editions (Apocrypha xxxvi).

${ }^{74}$ See also Smout, who believes these "visual echoes . . . are perhaps no coincidence" (180). A comparable situation is the liberation of Leonora from the nunnery in Double Falsehood.
} 
anticipates pastorally influenced tragicomedies such as The Faithful Shepherdess and Philaster. Bednarz argues that "Shakespeare's audience and readers would have strongly identified him with the pastoral genre at the beginning of the seventeenth century, when he became, on the model of Spenser and Sidney, a shepherd-poet" (263); the inclusion of Dumaine's love-poem in England's Helicon (1600) under the new title of "The Passionate Sheepheard's Song", he argues, is part of Nicholas Ling's deliberate appropriation of poets both dead and alive into a multivocal evocation of pastoral ideals at the turn of the century. Within this network of associations, we thus see Merry Devil occupying a similar position to the revived Mucedorus. Both plays are deliberately oldfashioned at the time of performance, embodying outdated but popular forms of entertainment; it is perhaps no coincidence that, in their first appearance under Shakespeare's name, they were bound together.

\section{Conclusions}

Roslyn Knutson prioritises the importance of commerce and economics in the generation of material within a theatrical company. "Companies repeated the subjects and formulas that had been successful in their own offerings and in the repertories of their competitors" (Repertory 40). The plays generated by any one author, particularly one such as Shakespeare who worked within a single company, are thus dictated by a wider theatrical context than his own oeuvre. To separate the authorial canon from its fellow plays, its material and economic conditions and its moment of production is to prioritise, anachronistically, one paradigm of authorship at the expense of others.

Scholarship has been slow to appreciate the compatibility of the individual author with the commercial and social environment of the playhouse. An early need to protect Shakespeare from any imputations of hackwork extended, in the late nineteenth and early twentieth centuries, to a denigration of the usefulness of Henslowe's diary as 
a model for the Chamberlain's-King's Men, on the assumption that the Shakespeare company would operate on prestige lines: Collier's assertion that the company "sought to produce plays of lasting interest", for example (qtd. in Knutson, Repertory 17). On the other hand, more recent work - particularly that building on post-structuralist theory has prioritised the social nature of the playhouse to a point where the individual author is lost as all words become socially produced. Jowett resists this, suggesting that "the initial premise that language is 'socially produced' places the writing of a text within the widest cultural environment. It suggests that a text has a fundamentally nonauthorial determination. To the extent that this is true, it must be true of any text, irrespective of the structure of its authorship" ("Pattern of Collaboration" 182). However, attention to the social environment does not necessarily dissolve the author, but redefines the authorial presence. Bednarz argues that "a current heightened awareness of the historical conditions under which Shakespeare's work was written and disseminated through manuscript, print and performance has prompted a re-examination of how these modes of production have shaped and continue to shape what 'Shakespeare' means" (252). Despite this re-evaluation, the "apocryphal" plays belonging to the repertory of the King's Men - perhaps the most important governing set of historical conditions on Shakespeare's work - have remained in a steadfastly "unShakespearean" space.

We have some slight evidence that the Chamberlain's-King's Men understood its authors as part of a group ensemble. Thomas Dekker's Satiromastix (c.1601) stages, as its finale, the arraignment of Horace, who stands in for Ben Jonson. ${ }^{75}$ Sir Rees ap

\footnotetext{
${ }^{75}$ Dekker lifts the analogous characters from Jonson's own Poetaster. Harbage suggests that "Kemp's" line in 2 Return from Parnassus "our fellow Shakespeare hath giuen him a purge that made him beray his credit" (1771-73) may be referring to Satiromastix (108). If this is the case, this may be another instance of Shakespeare ideologically "owning" the wider repertory of the Chamberlain's Men. W. Bernhardi took this a step further in 1856 by ascribing Satiromastix to Shakespeare (see Brooke, Apocrypha x). Quotations from Parnassus are taken from Leishman.
} 
Vaughan makes Horace/Jonson swear to several oaths including that "you shall not sit in a Gallery, when your Comedies and Enterludes have entred their Actions, and there make vile and bad faces at euerie lyne, to make Sentlemen haue an eye to you" and "you must forsweare to venter on the stage, when your Play is ended, and to exchange curtezies, and complements with Gallants in the Lordes rooms" $(5.2 .298-301,303-05) .{ }^{76}$ Jonson is usually presented as one of the pre-eminent voices of individual authorial authority on the early modern stage, but here a Chamberlain's Men's play resists the prominence that Jonson is accused of according himself. Rather, the Chamberlain's Men's staging of "authorship" takes a more subtle form even in one of the plays that most explicitly represents contemporary authors on the stage. Where Poetaster concludes with an apologetical dialogue where the author (perhaps Jonson playing "Jonson") is brought on stage to explain his own play, the Epilogue to Satiromastix is delivered by Tucca, who explicitly breaks away from "authorship": "I recant the opinions which I helde of Courtiers, Ladies, and Cittizens, when once (in an assembly of Friers) I railed vpon them: that Hereticall Libertine Horace [Jonson], taught me so to mouth it" (Epilogus 6-9). While an audience would understand the metatheatrical joke that, of course, Tucca is a fictional character whose lines are written by Dekker (himself personated in Poetaster and Satiromastix as Demetrius Fannius), it also understands that authorship here is represented through authorial proxy. Tucca becomes his own "author" and that of the play, accepting responsibility for it and petitioning the audience for their approval.

Peter Fabell's isolation from the main plot of Merry Devil has a related function. His role as the young man helping his friends to achieve their romantic ends is a standard one but, unlike analogous figures (such as Rynaldo in Chapman's All Fools), Fabell is not related to any other character in the play. His separation from the rest of

\footnotetext{
${ }^{76}$ Quotations from Satiromastix are taken from Bowers, Dekker.
} 
the characters, emphasised further in the Induction, renders him detachable, the more so because we see so little of the magic that would integrate him with the main plot. Fabell, in fact, is himself a representation of authorship: the play is not about him, but scripted by him.

In the Induction Fabell is challenged, forced literally to overcome the demons of his own story in order that he might proceed to the matter of comedy, a plot concerning others that Fabell shapes and manipulates. Crucially, the only explicit piece of magic Fabell subsequently performs is also the most explicitly authorial. In 1.2, Fabell arrives at the George and is introduced to Sir Arthur Clare, who makes a single disparaging remark about Raymond, and within twenty lines Fabell is left alone onstage. In soliloquy, he reveals that he is aware of the compact between Clare and Jerningham to thwart Raymond and Millicent's courtship and their motives. When his three friends re-enter, it is then Fabell who reports to Frank that the match has now (i.e. while he has been alone onstage) been made; that Frank is to marry Millicent; and that Millicent is to be sent to the nunnery. With the young generation armed with the knowledge, Fabell announces that "Age and craft with wit and art have met" (1.2.189), and he is in a position to stage his rewriting of the fathers' plot. ${ }^{77}$ Fabell's true magic is an authorial privilege; he has an entire overview of the narrative, knowing what is and what will happen. The absence of the manifestly supernatural throughout the play allows this power to remain benevolent: the "merry devil" is not a trickster but a plotter, describing the action and casting players to perform it. Fabell himself is absent for all the key action: the liberation of Millicent, the escape through the forest, the switching of inn signs to confuse the fathers. Instead, as Joseph Horrell points out, his "infrequent appearances do not

\footnotetext{
${ }^{77}$ Beckerman claims that "the father" of Merry Devil is the play's "judge-figure", the figure "sometimes central to the story, sometimes not, [who] usually referees the conflict and, at the conclusion, either passes judgment or grants mercy" (37). This is extrapolated from the fact that Arthur Clare speaks the play's final line; however, while Clare does accept the outcome of the love plot, it is Fabell who retains most of the characteristics of the authoriser of action.
} 
project him with any of the appurtenances or characteristics of the necromancer" (36). ${ }^{78}$ Instead, he arrives at the conclusion of episodes, approving the interlude and instructing his players on their next scene. That is, he performs the role of the embedded author, separate from but intrinsically connected to his fellows.

It is perhaps not surprising that the plays of the Chamberlain's-King's Men, the first company to employ an embedded playwright, follow a general pattern of embedding ideas of authorship into the content of their plays rather than into paratextual material. Weimann sees Shakespeare's manifestation of authority as different to Marlowe's, with which I opened this chapter, because it "is prepared to share an ensemble commitment," (58) inscribing modes of performance into his plays (88). In these plays, representations of authorship are invested - whether through free choice (Fabell), fate (the unseen devil of Yorkshire Tragedy) or politic intervention (Old Flowerdale). These instigators of action ingratiate themselves within the plot structure, becoming inseparable from the "plays" they create. We are accustomed to speaking of authorial self-conception in the terms articulated by more self-consciously classical dramatists such as Jonson or Webster. In these, authoring is an individual activity and the author is separated from the text they create, particularly in print where the authorial voice manifests as prefatory material and addresses to readers. Yet the plays of the Chamberlain's-King's Men, especially the "apocryphal" plays whose critical treatment has been defined by these notions of detached and disinterested authorship, also demonstrate a fascination with authorship. In these, however, attention is drawn to the collaborative and integrated processes of authorship that this company, generating plays from within its capitally invested circle of shareholders, was pioneering.

\footnotetext{
${ }^{78}$ Compare Bacon and Bungay's interventions in the love triangle of Edward, Lacy and Margaret, where their actions are overtly necromantic throughout.
} 
By resituating the "apocryphal" plays in their original context, this chapter has argued that the plays individually demonstrate a range of authorial influences that can only be understood in a pluralistic sense: the author(s) of the text work within a network of requirements and influences that include sources, genre, political context, company strategy and acting personnel. The plays are generated by a collaborative company in which the author plays an integral role, neither completely socialised nor clearly individual. They are then subject to a further range of interventions as they pass into print. "Shakespeare" on title pages and records recognises the influence of the individual William Shakespeare on the plays discussed in these chapter, and his "ownership" of them insofar as they are commensurate with the narratives of company ownership, genre experimentation, response and style explored above; but "Shakespeare" also begins to recognise the beginnings of "Shakespeare" as authenticating agent independent of the historical individual. Shakespeare is both individual and plural, a physical creative agent and a locus for converging collaborative forces. Hitherto the apocryphal plays have only been discussed as Shakespearean or non-Shakespearean with regard to the former; with regard to the latter, however, their "Shakespearean" interest has been obscured by questions of attribution. Only by allowing for the more general participation of "Shakespeare" will the critical rehabilitation of the apocryphal plays be able to take place unencumbered by a rigid canonical framework based on post-Romantic conceptions of individual authorship. 


\section{Chapter Three: Defining "Shakespeare"}

To know the author were some ease of grief

- The Spanish Tragedy 2.5.40.

In order to explain what makes Shakespeare Shakespeare, then, it would be necessary to know who or what Shakespeare is, which is an impossible task, not least because what may properly be deemed to be Shakespeare's does not in fact belong to Shakespeare.

- $\quad$ Leslie Hill, Derrida 98.

Hill employs Shakespeare as a case study in his analysis of the slipperiness of Derrida's definitions of literary property; but, as we have already seen, Shakespeare offers a particularly compelling case because of the levels of national and cultural investment in the Bard. "Shakespeare" stands as shorthand for an individual, a body of texts, a standard of literary quality (the commonplace criticism "It's hardly Shakespeare"), an historical period (e.g. Gurr's The Shakespearean Stage), a field of academic research ("Shakespeare studies" as synecdoche for research into the early modern drama) and a marker of mood, dignity and cultural value. ${ }^{1}$ To explain what makes Shakespeare Shakespeare is impossible in any objective sense, because the signifiers stand for a range of indefinable and contradictory effects.

In the previous chapters, I discussed authorship as a bibliographic phenomenon and a performative "effect". I argued that "Shakespeare" in early modern performance and print culture was associated with collaborative developments in genre and dramatic form; and that the attribution "William Shakespeare" does not signify a carefully

\footnotetext{
${ }^{1}$ See, for a compelling example, B. Holland's concert review: "From simple sadness Mr. Kremer's violin-playing created major tragedy. The enlargements were not inflations. There was unadorned dignity in every stroke. As a result, melancholy folk melody took on a tone that was very nearly Shakespearean" ("Review/Music").
} 
demarcated and unified body of work that can be simply divided into "authentic" and "spurious", but instead acknowledges the links between a collaborative and unstable group of plays. This is not an attempt to expand the Shakespeare corpus; rather, it questions whether or not a corpus - the word itself suggesting an embodied "Shakespeare" with physical, definable dimensions - can adequately reflect the relationships that bind these texts together. As an organising principle, the soleauthored canon has limitations.

In this chapter, however, I shall turn to the question that has dominated study of the Shakespeare Apocrypha: attribution, the assignation of plays, acts, scenes, lines and words to the production of (an) individual writer(s). Attribution research is one of the most contentious fields in the study of early modern literature. Results of "tests" are contested on grounds technical (is a particular computer programme reliable?), statistical (is data accurately displayed and standardised?) and interpretative (are these results anomalous or indicative?). ${ }^{2}$ Methodologies, inevitably unique to the inquirer, are contested: parallel passages, preferred vocabulary, collocations, verse-metrical tests, imagery and linguistic habits have all been championed and attacked by leading scholars. ${ }^{3}$ The fact that these disputes are often couched in deeply personal invective, as in the Foster/Elliott-Valenza feud over A Funeral Elegy, only serves to stigmatise the field

\footnotetext{
${ }^{2}$ Schoenbaum lays out the basic principles for effectively critiquing authorship analysis in Internal Evidence, which provides literary critics with the tools to assess the effectiveness of a statistical argument. A more technical but thorough examination of methodologies is available in Chapter Two of Vickers, Co-Author. Both concur on the basic standards required of attribution scholarship, including the all-important "negative check" that contextualises results within the literature as a whole. More general manifestos designed to rehabilitate the reputations of computational study in humanities research include the 1994 special issue of Computer and the Humanities (27.5/6) and Joseph Rudman's excellent “The State of Authorship Attribution Studies", the latter of which addresses the practical methodological issues that continue to blight poor attribution work.

${ }^{3}$ For recent surveys of attribution scholarship on Shakespeare, see Vickers, "Shakespeare and Authorship Studies", which advocates the use of carefully qualified parallels; and Elliott's forthcoming "Language: Key to Authorship", which stresses the importance of utilising multiple methodologies to tend towards consensus. Elliott and Valenza's "Shakespeare Clinic" uses some 51 tests to distinguish between Shakespeare and non-Shakespeare ("And Then There Were None").
} 
further. ${ }^{4}$ Beyond the disputes among authorship scholars, however, are wider questions of approach. How far are individual studies equipped to deal with the intricacies of texts that contain multiple collaborative hands and may incorporate revision, adaptation, abridgement, censorship, actor interpolation, scribal-compositorial idiosyncrasies or other anomalies of transmission? How is the balance between internal and external evidence to be governed? What degree of certainty is possible and necessary in order to make confident claims of authorship?

As such, there is cause for concern over the confidence placed in internal evidence. Schoenbaum, supporting the title page ascription of The Spanish Gypsy to Middleton and Rowley, asserts his "First Principle", which states "External evidence cannot be ignored, no matter how inconvenient" (Internal Evidence 163) in countering attempts to reassign the play to Ford and Dekker. Taylor, arguing for a four-way collaboration, replies that "we cannot generalise about external evidence" ("Spanish Gypsy" 267), suggesting that both internal and external evidence need to be individually assessed. While caution regarding ascriptions is justified, this approach runs the danger of approving an inconsistent approach to external evidence that allows it to be effectively disposable when "inconvenient". This is the case in Taylor and Lavagnino's Middleton: Collected Works, where the strong external evidence for Shakespeare's authorship of $A$ Yorkshire Tragedy is summarily dismissed by Stanley Wells as "probably a deliberate fraud, and [the ascription] has met with little belief" (Taylor and Lavagnino, Textual Culture 356). While the ascription to Middleton is almost certainly correct, it is indicative of the modern tendency among attribution scholars to prioritise internal evidence over external when the two are in conflict.

\footnotetext{
${ }^{4}$ See in particular Foster's "Response" (1996), which undoes its methodological impact through a concluding "discussion" articulating a bitter sense of personal betrayal. The debate continued in Foster, "Claremont", and Elliott and Valenza, "The Professor" and "So Many Hardballs". See also Rosenbaum, Shakespeare Wars 157-95 for an entertaining overview of the controversy from a journalistic perspective.
} 
Moving further afield, larger questions circulate around the relationship of attribution studies to other areas of literary studies. Can such abstract concepts as "style" and "authorship" be quantified? Can computers replace connoisseurship and literary appreciation? $?^{5}$ Scepticism about the efficacy of attribution studies is widespread, partly as a result of local disputes over methodologies and results leaving non-specialists distrustful of the field as a whole. The investigation of authorship has been tainted further by association with the much-maligned but increasingly vocal anti-Stratfordian project. ${ }^{6}$ Finally, a general reluctance to engage with the apparatus of statistical research has resulted in the field being increasingly dominated by professional statisticians and a relative handful of literature scholars. Yet it is the results of statistical and computer-assisted attribution scholarship that are primarily responsible for determining the constitution of authorial canons in major publishing projects. ${ }^{7}$ If the work of attribution studies is to hold so central a role, literary critics cannot afford to be dismissively sceptical.

The final and larger project of contestation has come from work heavily influenced by post-structuralist theory, specifically that of Foucault in which "the author's name manifests the appearance of a certain discursive set and indicates the status of this discourse within a society and culture" (107). Foucault's "author-function" sees the author as a locus of responsibility and culpability that announces and legitimises a socially produced text. Within a Foucauldian paradigm, critics such as

\footnotetext{
${ }^{5}$ Elliott and Valenza have recently launched an online conoisseurship test ("Golden Ear"). Volunteers are presented with sections of decontextualised verse which they are required to indicate as Shakespearean or non-Shakespearean. However, the test fails to account sufficiently for the influence of recognition or non-recognition on the tester.

${ }^{6}$ See Love, who offers a thought-provoking and balanced critique of the methodologies of antiStratfordians on logical grounds (198-208). Leahy (2009) and Shapiro (2010) offer more recent overviews, with particular attention to history and psychology. Older, but still influential, treatments are offered by Marjorie Garber (esp. 1-36) and Bate (Genius 65-100).

${ }^{7}$ Most notably in the Cambridge Beaumont-Fletcher (1966-94), the Oxford Shakespeare (1986) and the Oxford Middleton (2007), but also underpinning ongoing work on the canons of other authors.
} 
Masten and McMullan have argued for attribution studies to be contextualised or supplanted by greater attention to environment and culture rather than to an individual or individuals.

These are the battle-lines of the "Shakespeare Wars" in Rosenbaum's phrase, of which Elliott sums up the tone:

The few American professionals who dared experiment with quantitative analysis were either damned as wrong-headed, or overpraised as Sherlock Holmeses of Literary Detection, or both, but rarely exposed to serious criticism. The professionals' estrangement from authorship studies helps explain why the Shakespeare Wars were so unusual, so much more rhetorical than evidentiary, so hard to resolve, so open to outsider involvement, and, in the end, so ephemeral. (“Language")

This particular war has no foreseeable conclusion, as the various levels of contestation dispute not only specific attribution questions, but also the nature of the battle itself. Within this melee, the plays of the Shakespeare Apocrypha are some of the highestprofile casualties. While bibliographical and theatrical provenance associate many of these plays with Shakespeare, it is the work of attribution studies, which seek to find "Shakespeare" within the texts rather than without them, that has resisted the plays' integration into the canon while admitting Pericles and The Two Noble Kinsmen. Assertions that the attribution of plays no longer matters have been proven untrue by the volatility and durability of the dispute. The cultural bias towards the importance of the Shakespeare canon has meant that the ultimate goal of the "wars" has been to confirm the apocryphal plays as "no longer in the running" (Elliott, "Language"). That is to say, despite the theoretical advances of the last few decades that have supposedly 
moved towards the democratisation of authorial canons, the death of Bardolatry and the reorientation of early modern drama around texts rather than authors, the attitude towards the Shakespeare Apocrypha in twenty-first-century attribution studies remains the same as that of the eighteenth-century editorial tradition. They are to be categorised and defined, as firmly as possible, as "not Shakespeare".

The purpose of this chapter is not to add to the growing body of attribution scholarship that seeks to ascertain the authorship of the disputed plays, but to consider the implications of the attempts to define Shakespeare finely in the plays at the fringes of the canon: Thomas More, Locrine, Edward III and Arden of Faversham. What does it mean to (not) find Shakespeare in these plays, and how precisely can we identify it? The claims of statistical studies need to be brought into positive conversation with literary, theatrical and theoretical approaches to authorship. As Foster points out, "the attitude of many is that [quantitative and statistical] analysis cannot be trusted, is not interesting, and that it can discover nothing of value to advance the more traditional work of the humanistic disciplines" ("Response" 254). This chapter confronts this attitude by arguing that it is through the combination of attribution study, critical theory and traditional literary study that the "Shakespearean" must be defined. Yet it is definition itself that poses the key difficulty, the attempt to use these methodologies in order to achieve a binary answer, the "in" or "out" that characterises the work of Elliott and Valenza. Through the case studies in this chapter, I will seek to use these methodologies to define more precisely the areas of ambiguity in attribution.

\section{The Shakespearean corpse: physical traces of Shakespeare}

The process of attribution study, at its most fundamental level, seeks to attribute text to an author. In order to do this, it must first theorise how this authorial presence will manifest itself within the text. A recurring sequence of images evokes the 
impression of Shakespeare in a disputed text: Stanley Wells, discussing Double Falsehood, speaks dismissively of "a bit of Shakespearean DNA" (qtd. in Britten and Alleyne); while many researchers, such as David Holmes, prefer the term "fingerprint" (99). Elliott and Valenza explicitly move away from the implied certainty of fingerprints, preferring a Cinderella metaphor that speaks more broadly of "glass slippers" and "seven-league boots" ("Glass Slippers"). The most common shorthand for the Shakespearean presence, however, is the "hand", as in Hope's assertion that "Sociohistorical linguistic evidence attempts to use the predictable patterning of incoming and recessive variants during language change in order to detect the hand of a chosen author" (6)..$^{8}$

Regardless of the methodology employed, the object of attribution study is rhetorically physical, an embodied authorial presence encoded within text, couched in the language used by early modern authors themselves, most famously in Thomas Heywood's claim in The English Traveller to have had "an entire hand or at the least a main finger" in 220 plays ("To The Reader" 4). ${ }^{9}$ "Penmanship" and "penning" form a related sub-set of euphemisms for authorial presence, notably in Jonson's preface to Sejanus which states that "a second pen had good share" ("To the Readers" 40). Despite the warning of Weimann to remember that terms such as "author's pen" and "actor's voice" are "embedded in culturally saturated types of space and production; as such they constitute agencies for writing and playing" (12), however, the search for an author is indistinguishable from that for biographical traces. Implicit in the idea of a hand is the rest of the authorial body, the moment of physical individual creation at which an idea passed from brain, through hand and quill, to the ink and paper that formed the basis

\footnotetext{
${ }^{8}$ See also the Pollard collection on Thomas More; Merriam, "Marlowe's Hand in Edward III"; Kukowski, "The Hand of John Fletcher in Double Falsehood" and the Oxford Middleton, which uses "hand" as its preferred term for authorship throughout .

${ }^{9}$ Quotations from The English Traveller are taken from Wiggins, Domestic Plays.
} 
for the texts under investigation. What is even more striking is the implied hierarchy of evidence: "hand" is used in the most confident of claims, and Shakespeare's "hand" is manifest in both authentic and the least dubious of disputed works. It is the most physical of traces, the surest connection to the authorial body. And yet, even as Marcus can "here have writ my name / Without the help of any hand at all" (Titus Andronicus 4.1.72-73), so too is the hand scientifically the least reliable identifier. ${ }^{10}$ Wells uses "Shakespearean DNA" in a derogatory context, arguing that the Shakespearean contribution is negligible; yet in modern forensics, DNA profiling remains the most compelling indicator of identity or family resemblance. This interesting inversion in the value accorded to evidence is perhaps indicative of the divide between scientific and literary authorship investigators: for the former, cold data and number-crunching provides measures of statistical likeness, but for the latter, like Othello and Leontes, the likeness needs to be visible at a less forensic level. ${ }^{11}$ The preferred terminology of "hand" further allows for the implication of divinity, as in Lee's remark that Oldcastle, The London Prodigal and A Yorkshire Tragedy are "equally destitute of any touch of his hand" (261); the power carried in the lightness of a "touch" to confer value calls to mind the healing properties of a very different Messiah.

The rhetoric underpinning the search for Shakespeare finds its ultimate realisation in the three pages of Thomas More written in the handwriting that Greg, in his Malone Society edition, called " $D$ ", identified as William Shakespeare (More xiii). As McMillin has pointed out, however, the word "hand" is taken as a synecdoche for the writer, but is actually a metonym for writing, the process rather than the creator (Elizabethan Theatre 158). Masten similarly warns against the dangers of conflating

\footnotetext{
${ }^{10}$ Garber points out the unconscious recurrence of the word "hand" in critical discussion of Titus, where the disembodied hands of Peele or others haunt critics in the same way as those of Titus and Lavinia haunt the play itself (32-33).

11 "Give me the ocular proof" (Othello 3.3.398); "whole matter / And copy of the father" (Winter's Tale 2.3.120-21).
} 
"writing habits" with "identities"("More or Less" 115). Nonetheless, the slippage between "Shakespeare's writing" and "Shakespeare" in discussion of Hand D is indicative of the biographical interest in these pages. Here, the search for the embodied, historical and biographical author achieves its most physical and complete manifestation as a material artefact: these pieces of paper can be handled as Shakespeare himself once handled them, bypassing the intermediary agencies of theatre and print.

The speed at which this identification became a critical orthodoxy is, in hindsight, disquieting, and Werstine has drawn attention to the biased motivations that underpinned the championing of Hand $D$, which he suggests were a partial reaction to anti-Stratfordian claims ("More or Less"). Simpson's assertion of Shakespeare's authorship in 1871 on impressionistic grounds was supported by Greg in 1911 and confirmed by the eminent palaeographer E. Maunde Thompson in 1916, and Pollard's 1923 edited collection brought together an intimidating array of reputed scholars to settle the question beyond reasonable doubt. Even in 1923, Pollard felt able to build on an assumption of Shakespearean authorship in his statement that the book's object was to "strengthen the case", rather than establish it (Preface). This collection, still seminal and hugely influential, is surprisingly weak according to modern criteria for attribution scholarship. It relies heavily on impressionistic readings of imagery and ungraded parallels that are unchecked with reference to negative examples. ${ }^{12}$ Chambers's article is instructive in this regard; he demonstrates a shared "expression of ideas" between Hand D and Shakespeare's plays, but is not concerned with showing that these shared expressions are unique to Shakespeare. As such, what Chambers does extremely

\footnotetext{
${ }^{12}$ The importance of the negative check has been asserted repeatedly by critics on both sides of the attribution studies argument. The clearest statement is that of Muriel St. Clare Byrne: "In order to express ourselves as certain of attributions we must prove exhaustively that we cannot parallel words, images, and phrases as a body from other acknowledged plays of the period; in other words, the negative check must always be applied" (qtd. in Schoenbaum, Internal Evidence 192).
} 
effectively is to demonstrate the utility of comparison between play and author subsequent to the establishment of authorship, and Werstine demonstrates how far his readings are informed by his prior assumption of authorship ("More or Less" 135). A similar attitude of connoisseurship applies to Wilson's analysis of likenesses in spelling and letter forms between Shakespearean quartos and the manuscript, which again rely on Wilson eclectically noting likenesses rather than systematically demonstrating unique coincidences. These critiques are not to say that their conclusions are incorrect or invalid; the continued citation of this volume suggests the enduring appeal of Chambers and Wilson's arguments, particularly for literary critics. Jowett has recently responded to Werstine by systematically checking many of the parallels using LION, but he misses Werstine's primary purpose, which is to cast doubt on the intentions rather than the results of the collection. ${ }^{13}$ What should be recognised is that the methodologies applied in their papers to the question of authorship are akin to those of maligned modern parallel-hunters such as Eric Sams and Michael Egan (Werstine, "More or Less" 137). ${ }^{14}$ It is the authority and persuasiveness of Chambers and Wilson, rather than the objectivity of their methods, which have influenced future generations.

What remains is Thompson's palaeographic argument, the most enduring and important of the authorship tests conducted on Thomas More for its apparently scientific basis. Thompson discussed the issue in his 1916 monograph and again as part of the Pollard collection. The leading palaeographer of his day, Thompson makes a case that is both technically intricate and near-irreproachable except by a palaeographer of

\footnotetext{
${ }^{13}$ Jowett's own evidence is convincing, but his extensive citation of Timothy Irish Watt's work on the play (448-49) fails to account for the inconsistencies and errors in that work. See Kirwan, "Review".

${ }^{14}$ The practice has been referred to as "deck-stacking" (Elliott and Valenza, "So Many Hardballs" 456); that is, by measuring a disputed play against Shakespeare and only Shakespeare, the investigator biases him/herself in favour of finding Shakespearean likeness. Jackson has highlighted the ease with which this practice can be fallen into in his recent critique of Vickers's work on the Kyd canon ("New Research").
} 
similar prowess, prompting Pollard's pre-emptive defence that "thoroughly to test the conclusion reached requires ... a gift of palaeographic wisdom of a very unusual kind" (11). It is the 1923 volume's most authoritative pronouncement, and compelling for its association with Shakespeare's biographical life. The comparison sample of Shakespeare's handwriting against which Thompson builds his case consists of Shakespeare's six extant signatures, the state of which Thompson explains according to Shakespeare's conjectured state of mind and health at each signing. ${ }^{15}$ That these six signatures do not amount to anything like a reasonable base set is, however, conveniently ignored in the throes of what McMillin refers to as a "Eureka!" moment (Elizabethan Theatre 152), and the palaeographic argument has come under increasing attack in recent decades, most powerfully by Michael L. Hays who argues that any claims based on such a weak control must be advanced with extreme caution. ${ }^{16}$ McMillin rather mischievously reminds us of the unresolved assertion that Hand C and Hand D are surprisingly alike (Elizabethan Theatre 153-54); Gerald Downs has recently argued that the handwriting betrays the marks of a copying scribe rather than a composing author; and inconsistencies in the handwriting of Shakespeare's six signatures are a primary piece of evidence cited by the anti-Stratfordian lobby. ${ }^{17}$ None of these arguments have, however, come close to toppling the orthodox position any further than R.C. Bald's note that "The palaeographical argument, which might have been conclusive, depends more than any other on a delicate balance of probabilities" (57).

Despite these weaknesses in the argument, the identification of Hand D as Shakespeare has stood, betraying the context of this activity within a late Victorian and

\footnotetext{
${ }^{15}$ This is expanded in the 1916 monograph version.

${ }^{16}$ Among Hays's concerns are the uncertainty over whether Shakespeare himself wrote his signatures; the variety in the samples; and the impressionistic and uncontrolled noting of "likeness" as a methodology.

${ }^{17}$ See Shapiro (258-59) and William D. Rubinstein (48-49) for sample positions. Thompson imaginatively accounts for the inconsistencies in Shakespeare's Handwriting, with important attention to the material restrictions of the samples.
} 
early twentieth-century Bard-centred academic discourse that invested disproportionately in the idea of the unmediated Shakespeare. Although Pollard conceded that the play yielded "some interest in its own right" (1), the manuscript's perceived importance hinged on the identification of Hand D. The fact that the object of attention was a series of handwritten pages obscured all other interest, fetishising the physical manuscript and providing a platform upon which, as Murphy notes, the New Bibliographers were able to construct a notion of "Shakespearean peculiarities" (Shakespeare in Print 219), as in the idiosyncratic spellings noted by Dover Wilson which helped him later to distinguish between "good" and "bad" quartos. The pattern of investigation prioritises the author: Hand D tells us about the man's habits, which in turn inform upon his extant texts. As Spedding remarked, "it is a 'new fact' of much more value than all the new facts put together ... to know what kind of hand Shakespeare wrote would often help to discover what words he wrote" (227).

The attribution of Hand D to Shakespeare thus stood, and became a foundational piece of evidence in Shakespearean bibliographic study due to the centrality it accorded Shakespeare the individual author. The authority of the connection was biographical as well as literary, utilising documents from Shakespeare's "real" life. Theatrical questions of collaboration, date and company were suborned to the "fact" of Shakespeare's authorship, as in Pollard's pronouncement that "if More can be proved to be as late as 1599 I should regard the date as an obstacle to Shakespeare's authorship of the three pages so great as to be almost fatal" (31). The sense of the author, "the tone and the temper" (31) of Shakespeare is apparent; other matters are subsidiary. It is an irony that an identification which acted as the most powerful proof for Shakespeare's involvement in plays as a collaborator was used instead to refocus interest on the figure of the author as a solitary penman. 
In many ways, Pollard's language (he describes Oliphant as "a fellow-believer" who "has done good work for the cause", 31) recasts the debate as a matter of faith. The speed with which the Shakespeare-Hand D connection became a critical orthodoxy can be understood in terms of the wider national crisis of faith that Willy Maley argues also informed the origins of the anti-Stratfordian question.

The Victorians earthed some of their ecclesiastical energies in Shakespeare at a time when faith was in doubt and fiction had to fill the breach. The 'Shakespeare redemption' was the answer to the prayers of those experiencing a crisis of faith, and his canonisation is directly linked to questions of faith and doubt of a theological nature. (38)

The controversy over the identity of "Shakespeare" took a popular hold on imaginations from the 1850s, with one argument being the lack of documentary evidence connecting the man from Stratford with the writing of drama. ${ }^{18}$ The discovery of Shakespeare's hand in Thomas More, however, provided the necessary "missing link" between man and work, linking the documentary life to the theatrical. As Werstine points out ("More or Less" 126), the opening of Pollard's preface explicitly states that the object of the book is to "strengthen the evidence" and that success will cause "the discrepant theories [of anti-Stratfordians to] come crashing to the ground" (v). For Pollard and his fellow "believers", Hand D acted as a reaffirmation of faith, both in the power of their writer and in the wider project of the New Bibliography that sought to find the "true" text concealed behind the veil of print.

The identification of Hand D as Shakespeare, therefore, was established within an ideological and rhetorical framework that presented a formidable show of authority

\footnotetext{
${ }^{18}$ See Shapiro for the fullest contextual history of the development of the authorship question. For a less balanced account, see Schoenbaum, Shakespeare's Lives, under the forthright heading "Deviations" (385-454).
} 
and certainty; and, as Werstine argues, was structured as an accumulation of different methodologies in a deliberate mirror of anti-Stratfordian tactics $(125,131)$. It acted to consolidate and legitimate both the orthodox Shakespearean establishment and the centrality of a Shakespeare-centred methodology: "Shakespeare" was more tangible, more achievable, than ever before, and the language of embodiment acted to solidify this new proximity to Shakespeare the individual.

The literature supporting the orthodox identification of Hand D as Shakespeare is extensive and does not need to be rehearsed here. ${ }^{19}$ The case is compelling, and it is my intention here not to dispute the attribution but rather to draw attention to how its perceived importance has affected scholarship. The excerption of Hand D alone into collected volumes of Shakespeare reduces the visibly Shakespearean interest in the play to an abstracted textual scene that sits alongside other literary works; but, as Masten notes, the inclusion of Hand D in isolation means that the play is "editorially incompleted" in order to create a "Complete Works" ("More or Less" 110). This also serves to occlude theatrical provenance and complexities. Attribution scholarship based on parallels argues for a date of c.1603 for Hand D; as Carol Chillington notes, even Chambers's parallels "are consistently to be found in mature plays" (444). ${ }^{20}$ Yet Pollard announced that a date as late as 1599 would be "almost fatal" to Shakespeare's authorship owing both to style and to problems with company provenance (31). Much of the critical concern with the play over the last twenty years has been to reconcile the evidence for the late date with the retention of Shakespeare's involvement, resulting in several conflicting narratives that have resisted resolution despite their significant bearing on the authorship question.

\footnotetext{
${ }^{19}$ See Jowett, More; Gabrieli and Melchiori, and Howard-Hill for the fullest summaries. ${ }^{20}$ Metz offers a thorough survey of scholarship on More, including dating ("Voice and credyt"). See also Vickers, Co-Author 39-43 and 67-70. Jowett (More) supports this date for the additions, but goes further in arguing for a date for the original text of c.1600, much later than the 1592-93 usually advanced.
} 
A date of the mid 1600 s causes significant problems for theatre historians working within accepted narratives of early modern working practices, notably Chillington. While Chillington's case for John Webster has been convincingly rebutted, she raises the important issue of why the resident dramatist of the Chamberlain's-King's Men would be collaborating with Munday, Chettle, Heywood and Dekker at a time when they were associated with the Admiral's Men at the Rose. ${ }^{21}$ Taylor attempts to account for this by shattering the preconceived notion that Shakespeare would have written exclusively for his own company. "The fluidity of professional relationships between most playwrights and most companies in this period gives us no right to rule out the sort of personal and professional link which could have led one of the More collaborators to approach Shakespeare" ("Date and Auspices" 110). He points out that Fletcher, Massinger and Shirley all wrote for other companies while also acting as resident dramatist for the King's Men. ${ }^{22}$ Taylor earlier articulates the dangers of attempting to draw inferences about authorship from theatrical provenance or vice versa, and concludes his article with the statement that "the place where does not predetermine the time when, or the man who" (126). While offering a useful reminder that assumptions should not be taken as unbreakable facts, however, his purpose remains to preserve the Hand D-Shakespeare connection within a newly-created potential narrative of theatre history; attribution remains the constant. Even this narrative, however, still fails to address the issues raised by Pollard of the manuscript's close connection to that

\footnotetext{
${ }^{21}$ For rebuttals, see Taylor, "Date and Auspices" and Forker, "Webster or Shakespeare?”. The importance of Chillington's argument should not be underestimated, however: as Taylor notes, she was "originally and provocatively wrong" (101) in reminding scholars reliant on internal evidence of the importance of reconciling their narratives with theatre history.

22 If accepted, this argument would have important ramifications for the exclusion of plays such as 1 Sir John Oldcastle and The Puritan, whose Shakespearean attribution is denied in part on the basis of their respective attributions to the Admiral's Men and the Children of Paul's.
} 
of 2 The Seven Deadly Sins, traditionally thought to reside within Strange's Men in the late 1580 s/early $1590 s^{23}$

McMillin demonstrates the opposite approach to Taylor by ignoring internal evidence entirely, constructing a persuasive account of company assignation that is not dependent on the Shakespeare attribution; indeed, his Elizabethan Theatre makes a point of referring to the disputed pages as "Hand D" rather than "Shakespeare." An ingenious reading of the dramaturgy of the play concludes that the staging requirements of the original version (a larger-than-usual leading role, an exceptionally large cast, a substantial raised acting area and repeated calls for an enclosed space on stage) place it within the repertory of Strange's Men in the early 1590s. More controversially, he goes on to argue that Hand D contributed its addition at the same time, explaining its apparent unawareness of either Tilney's instructions to cancel the insurrection scene or the work of the other revisers. ${ }^{24}$ In removing the assumption of a single origin point for the additions, he is able to then argue that the purpose of the later additions is to revise the play for a smaller company, suggesting that the large leading role recommended it for revival following Edward Alleyn's return to the stage in 1603. This argument supports the traditional attributions of the "hands": Shakespeare's putative connection to Strange's Men in the 1590s and the association of the other revisers with the Admiral's Men in the early 1600s fits McMillin's model. This argument remains incomplete, though, as it cannot be reconciled in this form with the work on internal evidence that dates "Hand D" much later that McMillin suggests. The reader is still, implicitly, asked to

\footnotetext{
${ }^{23}$ The shared occurrence of the name "Goodal" as an actor in both, and the identification of the handwriting of 7 Deadly Sins as that of Hand C of More are the closest points of connection. For detailed discussion of Seven Deadly Sins, see McMillin, "Building Stories"; Kathman, "Reconsidering" and Gurr, "Elizabethan Plotters".

${ }^{24}$ P. Blayney ("Booke") makes a similar argument, suggesting that the manuscript was submitted to Tilney twice and that Shakespeare's contribution occurred at an earlier stage of revision than the remainder of the additions.
} 
choose between a narrative predicated on ascription studies, and a narrative rooted in theatre history.

Kathman's work, as discussed in Chapter Two, offers the possibility for reconciliation of these two strands, by severing the connection of Hand C to Strange's Men and thus allowing Thomas More to be the property of the Chamberlain's Men in the late 1590 s. However, even as the external evidence finally presents a narrative coherent with the conclusions of investigators of internal evidence, the internal evidence has become shakier. Elliott and Valenza have recently made a strong statistical case against the likelihood of Shakespeare's authorship of Hand D. While the size of the disputed section is usually considered too small for confident quantitative analysis, they identify ten linguistic tests that distinguish effectively between Shakespeare and nonShakespeare at this level, of which Hand D fails as many as four, depending on when it is to be dated. ${ }^{25}$ Their conclusion is that Shakespearean authorship is "less probable than not, but not impossible" ("Two Tough Nuts" [rev. version] 73). While confirming that the extract tends much more closely towards Shakespeare's style c.1603 than to his earlier work, they conclude with a response to Jackson's "99\% certainty" of Shakespeare's authorship. "We have found too much discrepancy to support a likely Shakespeare ascription and, though Jackson has plausibly explained away some of the discrepancy, we don't think that he has gotten it all ... for now, the best resolution of the conflicting evidence would be greater willingness on both sides to confess uncertainty" (78-79). High-end disputes over statistical data may have limited interest for the wider academic community, but Elliott and Valenza's closing remark perhaps offers the most constructive and progressive approach for the play's future. Authorship, particularly in

${ }^{25}$ Only 3 of 90 "baseline" 750-word Shakespeare segments (roughly matching the sample size of Hand D) achieve even two rejections as Shakespeare's across the ten tests. This "amounts to an acceptably-low 3\% Discrete false-negative rate for our Shakespeare baseline" (73). By contrast, $75 \%$ of non-Shakespeare text blocks are rejected (73n). 
the case of so small a passage, must remain a matter of greater or lesser probability, not certainty. To treat an authorship ascription based on internal evidence as a foundational fact for further study is to misunderstand the nature of internal evidence. Data offers possibility; only rhetoric promises certainty.

I have already argued in Chapter Two for the utility of Thomas More in discussion of one network of interrelated early modern plays, those dealing with the court of Henry VIII, regardless of authorship. While the notion that Shakespeare may have contributed a portion of the play in the mid-1600s would go further in supporting a Shakespearean resonance with the roughly contemporary Cromwell and When You See Me, You Know Me, this line of argument does not depend upon attribution. The degree of certainty over authorship does not affect discussion of the play in and of itself; its implications are for the play as part of an authorial canon, the practical question of whether or not the scenes are to be included in a Shakespearean "Complete Works". Elliott and Valenza's call for acknowledgement of uncertainty relocates the attribution debate within the realistic and achievable goals of probability, rather than the imaginative and fundamentally rhetorical search for a tangible presence. If study of More is to progress, then the preservation of the "totemic status" of Hand D (Masten, "More or Less" 112) must be replaced by a more balanced and embedded acknowledgement of the ambiguity of historical data pertaining to this document. To this end, we must be as willing to lose Shakespeare as we are to find him.

\section{Sample Size, the "problem" of revision, and Locrine}

As discussed in Chapter Two, if Thomas More did eventually come into the possession of the King's Men, and Shakespeare contributed additions to it around 1603, then Hand D could be evidence of a piece of revisory work conducted as part of his responsibilities as the company's resident dramatist. The manuscript is a complex 
collaborative document, incorporating no fewer than seven distinguishable contributions. ${ }^{26}$ The physical nature of the manuscript, conveniently, allows scholars to make an a priori separation of the contributions according to the divisions created by the mechanical and material differences of handwriting and pasted insertions. However, the document also reminds us of how complex and unpredictable the process of dramatic composition may have been. It is sobering to realise that no other early modern play has been distributed so finely between so many different collaborators. Either the case of Thomas More is particularly unique, or similar piecemeal contributions throughout the extant literature of the period have been overlooked.

The area of collaboration has provided attribution studies with some of its greatest successes over the last century. The pioneering work of Cyrus Hoy demonstrated the possibility of distinguishing the shares of the various authors in the Beaumont and Fletcher canon; the division of several Shakespeare plays into collaborative sections is now widely accepted, and ongoing work on the Middleton canon has demonstrated the pervasiveness of an authorial style within a particularly fluid set of multiple-authored texts. ${ }^{27}$

However, these enterprises have also led to a conflation of modes of dramatic collaboration, despite the fact that different forms of collaboration may be more or less discernable or integrated. Masten, to whose arguments I shall return below, describes Hoy's formulation of dramatic collaboration "merely as a more multiple version of authorship" (Intercourse 19); that is, the same practices that might give a whole play to a single author are used to give smaller sections of plays to a plurality of single authors. The assumption governing the assignation is that collaboration will manifest itself -

\footnotetext{
${ }^{26}$ Usually identified as Munday, Chettle, Heywood, Dekker, Shakespeare, an anonymous scribe and Tilney.

${ }^{27}$ Vickers's chapter "Identifying Co-Authors" (Co-Author 44-134) provides a magisterial survey of the application of attribution studies to the wider early modern drama.
} 
generally, if not universally - in a series of definable, isolatable blocks of text that make themselves available for analysis as single-authored.

Taylor notes the problems of such assumptions in discussion of The Spanish Gypsy, pointing out that the strong arguments for two different pairs of collaborators can be resolved by admission of a four-way collaborative process. ${ }^{28}$ By reducing the number of collaborators, attribution scholars can utilise larger sample sizes yielding more positive results and a cleaner narrative, at the expense of local inconsistencies. A greater number of collaborators, by contrast, has the advantage of being able to explain any number of variants from a pre-established style, but reduces the available comparison samples and thus the efficacy of statistical data. As Elliott and Valenza have shown, only ten of their tests were able to distinguish effectively between Shakespeare and non-Shakespeare when presented with extracts of fewer than two hundred lines. At what point does a contribution become too small to be recognised by attribution studies?

Jowett acknowledges that attribution research is "poorly equipped" to deal with local transcription and revision ("Pattern of Collaboration" 183). We have little evidence for how local such transcription/revision might be, though there are clues. As Thornberry has demonstrated, someone made revisions to the second quarto of Mucedorus (1606) that carefully adjust individual words to reflect the change in the gender of the reigning monarch. The identity of this reviser does not survive in external evidence and cannot be determined by internal analysis. Conjecture is unnecessary; we are required to accept the uncertainty and theatrical contingency of this "authorial" intervention.

${ }^{28}$ See Taylor, "The Spanish Gypsy" and Taylor and Lavagnino, Textual Culture 427. 
A more complex case is presented by Locrine, another play which poses difficult questions concerning historical provenance, authorship and external evidence. As with Thomas More, the question of authorship has been prioritised, although here in order to dissociate Shakespeare from a play so manifestly "composed in the most exaggerated manner of the "university wits'"' (Brooke, Apocrypha xvii). However, I wish to re-open the issue of the play's title page attribution in order to argue once more for an acceptance of uncertainty regarding authorship.

The most common argument levelled against the apocryphal plays with early external attributions to Shakespeare is that the ascriptions are fraudulent. In speaking of fraud, deliberate or accidental, we should not render the paratext of a title page entirely independent of the text it markets. The notion of "external" evidence implies an independent, separate or impartial witness, an outside corroboration of authorial origin. However, in the case of most of our early editions, these attributions are brought into being at the same moment as the printed text; they are part of a simultaneous reconstitution of "author" and "work". We must be careful not to imagine an unmediated play with an authorial attachment added separately by an external agent, thus disregarding the authority of external evidence that is in fact part of the original publishing moment. ${ }^{29} \mathrm{I}$ have already discussed the ways in which The London Prodigal and $A$ Yorkshire Tragedy might be thought of as Shakespeare's in the sense that the ascription reflects on the plays' provenance and genre. It is perhaps more appropriate to consider external evidence in terms of how it shapes and contributes to the play's presentation, rather than as "right" or "wrong".

\footnotetext{
${ }^{29}$ The simultaneous construction of author and text has been of particular interest in discussions of the 1623 folio. See Jowett (Shakespeare and Text 69-92), de Grazia (Verbatim 14-48), Taylor ("Making Meaning" 55-69) and Kastan (Shakespeare and the Book 53-77).
} 
In Shakespeare as Literary Dramatist, Erne argues for an increase in

Shakespeare's prestige after the publication in 1598 of Francis Meres's Palladis Tamia that led to what he considers to be unambiguous "attempts to profit from Shakespeare's name" (69n). Among his "whole series of attempts to capitalise on the name of Shakespeare" (69) he includes Thomas Lord Cromwell (1602), The London Prodigal (1605), The Puritan (1607) and A Yorkshire Tragedy (1608). While Erne's chronology and argument are sound, he overlooks the important differences in the quality of these attributions. While Prodigal and Yorkshire are attributed to "William Shakespeare" and "W. Shakespeare" respectively, Cromwell and Puritan are rather more questionably ascribed to "W.S." Even more damningly to the strength of Erne's examples, he omits to mention that the title page of Locrine (1595) similarly claimed to be "newly set foorth, ouerseene and corrected By W.S." (title page). Addressing this play in his appendix, he instead dismisses it from his discussion. “Considering Shakespeare's name did not appear on a title page for another three years, it seems unlikely that the initials were used to induce the reader to think that Shakespeare wrote the play" (247). Erne borders on an untypical inconsistency here: the later W.S. attributions form part of his evidence for the importance of 1598 as a turning point in the establishment of Shakespeare's literary authorship; but then, accepting that turning point as a given, he then dismisses the possibility that the "W.S." of Locrine might refer to Shakespeare as it occurs before that turning point. ${ }^{30}$ In fact, if Erne is correct in assuming that "W.S." refers to somebody else, this provides evidence of another W.S. involved in the creation of dramatic texts in the mid-1590s, allowing for the unacknowledged possibility that Cromwell and Puritan refer honestly to this writer rather than fraudulently to Shakespeare.

\footnotetext{
${ }^{30}$ Erne is correct to point out that the initials on Locrine predate any printed title-page appearances of Shakespeare's name, although he does overlook the fact that Shakespeare's name had recently appeared in full at the end of the dedications to the first three quartos of Venus and Adonis (1593, 1594, 1595) and that of The Rape of Lucrece (1594).
} 
Maxwell's Studies in the Shakespeare Apocrypha provides a model of caution over assumptions regarding these initials, arguing strongly that they are neither forged nor refer consciously to Shakespeare. While several of his "W.S." candidates are most unlikely, his point is that, regardless of any names that may have been lost to posterity, we know that "W.S." may have referred to several men of the theatre other than Shakespeare. ${ }^{31}$ Maxwell further points out that there is no consistency between the three extant appearances of "W.S." on playbooks: Locrine was printed by Thomas Creede in 1595, Cromwell by Richard Reade in 1602 and Puritan by George Elde in 1607. None of these publishers show any evidence of deliberate misattribution in other circumstances; there are very few other instances of initials on a dramatic title page being demonstrably wrong; and "W.S." never appeared on an undisputed Shakespearean work.

Taking the cases for the plays' association with Shakespeare individually, Maxwell notes that, in the case of The Puritan,

No London playlover would in 1607 have taken for Shakespeare's a play which, though said to have been written by "W.S." was further declared to have been acted by the Children of Paul's. Elde, it would seem, unless he were remarkably stupid, could hardly have been seeking to mislead the purchaser into thinking he was being offered a play by William Shakespeare. $(19)^{32}$

\footnotetext{
${ }^{31}$ He includes William Stanley, Will Sly, William Smyght, William Sheppard, Will Smithe, Wentworth Smith and another W. Smith who may or may not have been Wentworth. There is no evidence that Smyght, Sly or Sheppard ever wrote plays and, while Stanley was for a time a favourite candidate of the anti-Stratfordians, it is most unlikely he would have written for the public stage. See Maxwell 10-13.

${ }^{32}$ See Taylor and Lavagnino, Textual Culture for a useful summary of the play's critical and attribution history.
} 
While this argument allows The Puritan to be dismissed from having any reasonable deliberate connection to Shakespeare, however, it rather strengthens by negative example the case for Cromwell deliberately inferring Shakespearean authorship. As the play is simultaneously attributed to the Lord Chamberlain's Men, at the moment which Erne identifies as the tipping-point of Shakespeare's literary fame, this "W.S." attribution may well deliberately intend to refer to Shakespeare, a reading which I explored in the previous chapter.

Locrine is the last of the three "W.S." plays (see Fig. 4). Maxwell "suspects" that Shakespeare's name may have had currency by 1595 , while noting that only the narrative poems had been attributed to him in print thus far (7-8), while Erne, as stated above, mentions the unlikelihood of the initials being intended to capitalise on Shakespeare's name. Both of these, it should be noted, are arguments against the deliberate forgery of Shakespeare's name; not against the possibility of the name honestly referring to Shakespeare. Interestingly, Maxwell overlooks his own observation that "For printed plays of few of the authors whose initials appeared on the playbooks had a demand been previously demonstrated" (7). He lists no fewer than seven playwrights whose first acknowledgements in print were in the form of initials: Jonson, Marston, Wilson, Wilmot, Warner, Middleton and Peele, although the latter two had had works published anonymously beforehand. All of the above then progressed from initials to having their full name on title pages. ${ }^{33}$ To provide a counter-argument against Maxwell's assertion, four dramatists (Chapman, Norton, Studley and Greene) all appeared first in a fuller title page attribution and then later in initials, although in the

\footnotetext{
${ }^{33}$ My own study of Greg's Bibliography disputes one of Maxwell's examples: the attribution to "G. Peele" on the pageant Descensus Astrae (1591) preceded the intials "G.P." on Old Wive's Tale (1595), suggesting that Maxwell was limiting his search only to plays for the public stage. Peele's exception, however, is even more suggestive of a Shakespearean model, with a prestige work (Descensus Astrae and Venus and Adonis) being fully attributed ahead of a popular work (Old Wive's Tale, Love's Labour's Lost) being merely initialled.
} 
case of the first two, as with Peele, the initials mark only their second appearance in

print. The evidence is nonetheless suggestive of a trend of initials appearing early in the print career of dramatists, though does not proof of a definitive convention. This fits neatly with what we know of Shakespeare's career in print: if "W.S." was indeed Shakespeare, then the appearance in initials on the Locrine title page, followed by subsequent fuller attributions, would closely match the pattern of these other major contemporaries.

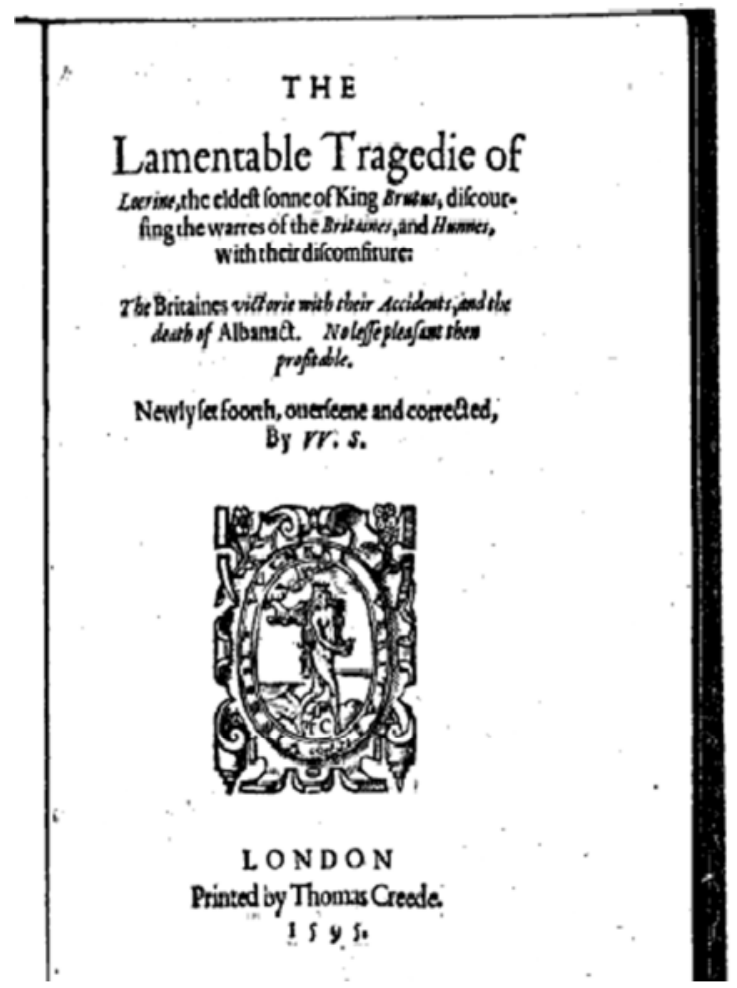

Fig. 4: Title page of Locrine (1595). Source: EEBO.

Attribution research has convincingly dismissed the possibility of Shakespeare being substantively involved in the original authorship of Locrine. ${ }^{34}$ However, the tests are dependent on the model of substantive single-authored chunks discussed above,

\footnotetext{
${ }^{34}$ Hope's socio-linguistic study finds a certain amount of closeness to Shakespeare, but Marlowe emerges as the most likely (though still extremely tentative) candidate (126-28). Merriam ("Linguistic Computing" 188) makes a firmer case for Marlowe, while Elliott and Valenza ("Two Tough Nuts" 69-70) achieved a convincing 22 rejections from their Shakespeare baseline, tying with Fair Em and The Second Maiden's Tragedy as the least likely apocryphal candidate for Shakespearean authorship.
} 
and are less confident in ascertaining local revision. The wording of the Locrine title page must be taken into account at this point. The play is "newly set foorth, ouerseene and corrected By W.S." (title page). To correct and oversee a text implies local intervention, the kind of work which nowadays might be described as editing, but which in the environment of playhouse and printing house could be carried out by one of a number of agents. It is the claim that the play is "newly set foorth" that suggests the reason why this intervention is worthy of notice. "Set forth" appears attached directly to an attribution on only one other dramatic title page of the period, that of The Interlude of Minds (1574). ${ }^{35}$ The full title page reads $A$ worke in Ryme containing an Enter-lude of Myndes, witnessing the Mans fall from God and Christ. Set forth by HN, and by him newly perused and amended. Translated out of Base-almayne into English.

"H.N." is the author Hendrick Niclaes. Here, the wording clearly suggests that H.N. wrote the original and then emended it himself: "set forth" appears on a text that has been revised and translated. Looking beyond dramatic literature, "set forth" continues to have a much broader range of meanings than "wrote" or "made", the more usual occurrences on dramatic title pages. When coupled with an attribution, it usually appears on anthologies and translations, for example:

A rich store-house or treasury for the diseased Wherein, are many approued medicines for diuers and sundry diseases, which have been long hidden, and not come to light before this time. Now set foorth for the great benefit and comfort of the poorer sort of people that are not of abilitie to go to the physitions. By A.T. 1596. (title page)

\footnotetext{
35 I am here discounting unattached uses of "set forth" where it appears to suggest a presentation for publication. The 1610 quarto of Mucedorus, for example, is more generally "newly set foorth."
} 
The Psalmes of Dauid truly opened and explaned by paraphrasis, according to the right sense of euerie Psalme. With large and ample arguments before euerie Psalme, declaring the true vse thereof. To the which is added a briefe table, shewing wherevnto euery Psalme is particularly to be applied, according to the direction of M. Beza and Tremellius. Set foorth in Latine by that excellent learned man Theodore Beza. And faithfully translated into English, by Anthonie Gilbie, and by him newlie purged from sundrie faultes escaped in the first print, and supplied with the principal pointes of euerie Psalme, summarily set downe in a table at the end of the booke 1590. (title page)

The wording invariably implies an element of presentation in the attributed agent's role: they have a creative and authorial voice that is governed by additional considerations such as the selection of materials or the translation of another's words. Taken without an attribution, the phrase more literally suggests "presented". In the case of Locrine, the "newly" lends weight to the idea that an older play is now being re-presented for performance or publication. W.S. is in some way responsible for the text's new form in a capacity substantive enough to elevate him to the level of a translator or compiler, the individual mediating the text for its new audience. The pattern of initials, and the careful qualification of the role of W.S., certainly fits with the possibility that this could be the first, modest announcement of Shakespeare's participation in the creation of a dramatic text, what Crinkley refers to as his "producer's prerogative" (519).

The authorship of Locrine is an open question, and the play is usually conjecturally attributed to Greene or Peele. Peter Berek's argument that the play is in fact by Charles Tilney, based on George Buc's handwritten note in a copy of the 1595 quarto, has not received much attention ("Locrine Revised" and "Tamburlaine's Weak 
Sons"). ${ }^{36}$ There are two problems with his reading of this note. Firstly, he claims more confidence than Buc himself in the identification of Tilney's Estrild with the extant Locrine; Buc states "I think [Estrild] is this" (my emphasis). Secondly, he argues that Buc provided dumbshows for Tilney's play. The implication is rather that Buc has more recently contributed dumb shows to the published play, which may or may not be Tilney's. Ignoring Greg's emendations, the note at this point reads "s[gap] fellow hate published [gap] i made dube shewes for it"; it is possible that Buc commissioned dumbshows rather than writing them himself. ${ }^{37}$ However, the uncertainty over the play's original author does not prevent the possibility of Shakespeare fitting it up later for his company.

The question of Shakespeare's involvement in Locrine has recently been reopened. Loewenstein allows for the possibility, pointing out that, "the title page is doubly ambiguous and may be construed as having claimed only that W.S. had revised the play, and not necessarily that he had written it; moreover, the phrase "overseene and corrected" seems to imply that W.S. had set forth the play specifically for print" (99). Sonia Massai makes a more active case. While she rather overstates the case by claiming that Brooke also "believed ... William Shakespeare is the most likely candidate" ("Text and Paratext" 7), she argues that Shakespeare may have contributed the epilogue "in keeping with the William Shakespeare who as a company man would continue to regard the stage and the page as extensions of his service to his patron,

\footnotetext{
${ }^{36}$ A transcription of the note is available in Greg, "Three Manuscript Notes" 314.

${ }^{37}$ We are unaware of Tilney or Buc ever having written drama, and Dutton, in his accounts of Buc in Mastering the Revels and Licensing, Censorship and Authorship, makes no mention of Locrine. See also Logan and Smith 259-61 for earlier critical debates over Tilney's authorship.
} 
possibly as a member of the Queen's Men first and then more prominently as a member of the Chamberlain's Men" (7-8). ${ }^{38}$

Massai may well be overstating matters here as well: Shakespeare is not alone in the period in demonstrating loyalty to a patron, and epilogues to the Queen are not uncommon. However, she makes a strong case for not ignoring the attribution that also calls into question our latent assumptions:

This blind spot may be due to our expectation of what Shakespeare's debut in print should have looked like: 'W.S.' is not a literary dramatist self-consciously using the medium of print for the sole purpose of shaping his literary reputation; 'W.S.' is a popular dramatist whose name is for the first time deemed attractive enough to entice readers to buy the edition of an older play. (7)

Massai here effectively counters Erne's dismissal of the "W.S." attribution's applicability to Shakespeare. In conjunction with Maxwell, we see the possibility of the title page implying an early Shakespeare connection that may well extend beyond Brooke's "crossing of an occasional ' $\mathrm{t}$ '" to an engaged and important repackaging of the text, representing a company's first investment in the potential of his name as an attributed author.

Massai's remark on our "expectation" of what Shakespeare "should" look like reminds us of Proudfoot's observation about The London Prodigal not being what we would consider "Shakespeare's kind of play" ("Shakespeare's Most Neglected Play" 152). Reading retrospectively in the light of the canon authorised by the 1623 folio, Locrine does not look like the beginnings of the literary career we know Shakespeare to have

\footnotetext{
${ }^{38}$ Brooke's comment that the initials "may well stand for 'William Shakespeare" (Apocrypha xvi) may be more accurately described as indifferent: "the activities of W.S. can hardly have extended beyond the crossing of an occasional ' $\mathrm{t}$ ' or the dotting of an ' $\mathrm{i}$ '” ( $\mathrm{xx})$.
} 
subsequently embarked upon. In the light of the Shakespeare canon as it stood in 1595, however, Locrine is less anomalous. The only Shakespeare plays published at this point (all anonymously) were Titus Andronicus (1594), The First Part of the Contention (1594) and Richard Duke of York (1595); whose militaristic focus and Marlovian influences are shared by Locrine.

It is Titus that provides the most compelling links, however. Both plays are heavily influenced by Senecan tragedy, the highly rhetorical vein favoured by Greene, Peele and other of the University "wits". The core of the action, despite a marked difference in perspective, follows a near-identical pattern when viewed through the persons of Locrine and Saturnine: both begin with the assumption of power by a firstborn son following the death of his father; both new emperors are victors against foreign enemies, despite not personally participating in the conflict; both are brought the captured queen of their defeated enemy, with whom the new emperor falls imprudently in love; both are challenged by honourable old soldiers dissatisfied with their new emperor's behaviour; and both track the consequences of the emperor's lust to the ultimate destruction of him, his queen and their children. The specificity of these plot connections has been entirely overlooked by editors of Titus. ${ }^{39}$

Perhaps even more telling is the character of Ate. In Locrine Ate, the personification of revenge, is the presenter of the tragedy, introducing each act with a dumbshow which she interprets for the audience. ${ }^{40}$ It is worth noting that, of the four other references to Ate in the Elizabethan drama, two are by Shakespeare, in Julius Caesar and Much Ado About Nothing, while the others are by Peele and Greene

\footnotetext{
${ }^{39}$ Waith is the only recent editor of Titus to mention Locrine, but only notes a slight resonance of style before arguing that "the most successful of Shakespeare's experiments are more adventurous and result in moments of greater dramatic power" (63). It is, perhaps, the felt need to demonstrate the superiority of Titus to its Senecan forebears that has caused editors to ignore the remarkably close parallels of plot between the two plays.

${ }^{40}$ Dieter Mehl provides an impressive and compelling overview of the history of the convention, with specific reference to Locrine (72-76).
} 
respectively - the two candidates most usually advanced for the authorship of Locrine. ${ }^{41}$ In addition to these might be added Tamora's disguise as Revenge in Titus, the most significant and integrated embodiment of Revenge as a woman in the period. The recurrence of the figure is suggestive of a strong link between the two plays, though this need not be one of authorship. Practically, if the plays belonged to the same company, Tamora's disguise may capitalise on the availability of a fabulous Revenge costume made for a boy. ${ }^{42}$ Thematically, moreover, Tamora's disguise conflates into a single body the figures of Ate and Estrild from Locrine, turning the dual authoresses of that play's action into Titus's single significant persecutor. That Titus sees directly through the allegorical figures to the "pair of cursèd hellhounds and their dam" beneath (5.2.144) speaks to the performativity of the Senecan Revenge figure: by subsuming the older play's presenting figure into the body of action itself, Titus himself is able to overcome that figure and become the ultimate author of his own tragedy.

The relationship between Shakespeare and the so-called "University wits" has been an object of some interest in recent years. One of the most significant cumulative triumphs of attribution studies has been to ascertain the collaboration of Shakespeare with George Peele on Titus; the influence of, and perhaps even collaboration with, Marlowe on Edward III and the Henry VI plays remains an ongoing source of contention; and Vickers has made a powerful case for Nashe's involvement in 1 Henry VI. $^{43}$ Further,

\footnotetext{
${ }^{41}$ According to a search of LION for Ate and variants. The mentions are in Orlando Furioso (first printed 1594) and The Arraignment of Paris (1584), in which Ate fulfils a similar role as the Prologue - and which, presumably by coincidence, was listed as Shakespeare's in Kirkman's unreliable catalogue of 1656. Even in the early seventeenth century, other mentions are limited to Jonson's Catiline and The Masque of Queens, Goffe's Orestes, Elizabeth Cary's Mariam and (Chapman's?) Alphonsus, Emperor of Germany.

${ }^{42}$ There is no early evidence for the assignment of Locrine to any of the known companies. As the title page of the 1594 quarto of Titus claims it belonged (at various times) to three separate companies, however, there is every possibility that the two plays may at one time have belonged in the same repertory, of which Shakespeare could have been a member.

${ }^{43}$ On Titus, see Vickers, Co-Author 148-243. For Marlowe in Edward III, see Merriam “Marlowe's Hand" and "Revisited". For Marlowe in Henry VI, see most notably Craig and Kinney 40-77. For Nashe in 1 Henry VI, see Vickers, "Incomplete Shakespeare".
} 
Bate has suggested that the infamous diatribe of "Robert Greene" in Greene's

Groatsworth of Wit may have been inspired by collaboration:

Yes trust them not: for there is an up-start Crow, beautified with our feathers, that with his Tygers hart wrapt in a Players hyde, supposes he is as well able to bombast out a blauke verse as the best of you: and beeing an absolute lohanues fac totum, is in his owne conceit the onely Shake-scene in a countrey. (F1 $\left.{ }^{v}\right)$

Caution must be taken in interpreting a passage that has been hotly contested by critics. ${ }^{44}$ However, "as the best of you" is implicitly addressed to "Greene's" fellow wits. It is "our feathers" that the Crow wears; it is against their blank verse that Shakespeare's attempts are measured. The implication is of mimicry: the Crow's threat stems from his arrogance in tackling the kinds of drama that the wits are engaged in creating. Bate's suggestion is that 1 Henry VI may, however, have been

a work of collaboration between Shakespeare and one or more of the university wits, perhaps even Greene himself. A partnership which ended in tears, with Shakespeare ending up gaining all the credit for the hit play, is as good an explanation as any for Greene's bitterness.

(Genius 17)

The specific suggestion is muted by more recent attribution work suggesting that the Groatsworth was actually written by Henry Chettle, though of course, insofar as "Robert Greene" thus becomes a literary character rather than an historical voice, it remains

\footnotetext{
${ }^{44}$ Loewenstein, for example, argues that it is specifically directed at plagiarism; charges to which he suggests Shakespeare then spent much of his professional life responding (85-89). Weimann, by contrast, suggests it is an expression of the social distance between "pen" and "voice" which Greene and other wits felt Shakespeare transgressed (50-51).
} 
appropriate to consider the character's motivations for his critique of the Crow. ${ }^{45}$

However, it is worth noting, following Bate's reading, that the title-page of Locrine sees

"W.S." taking sole credit for a play he has only "corrected". This is a play for which, as

Massai and others note, Greene remains one of the best candidates. While it is most

unlikely that the Groatsworth, published three years earlier, refers specifically to

Locrine, W.S.'s credit for the latter play resonates with the complaints levelled against

him by Chettle/Greene. Perhaps more interestingly, the candidacy of Peele for the play's

original authorship is also long-standing. ${ }^{46}$ It is not impossible that, alongside

collaborating with or rewriting Peele in Titus Andronicus, Shakespeare turned his

attention to fitting up another of Peele's Senecan revenge tragedies.

I do not wish to make firm claims here for Shakespeare, Peele or Greene's

partial authorship of Locrine. What I wish to accentuate is the possibility of

Shakespeare's contribution, based on the information provided by the 1595 quarto. In

terms of subject matter and style, the play fits with Shakespeare's interests at that time, and has very specific connections to Titus Andronicus. In terms of the slim evidence from Shakespeare's contemporaries, there is room to suggest that this is the kind of play and work Shakespeare was thought to be doing. In terms of the title page attribution, the initials are suited to Shakespeare at this point in his career according to the attribution patterns of several other contemporary dramatists. Finally, in terms of theories about Shakespeare's specific collaborations at this time, a Locrine revised by Shakespeare from the work of one of the University wits is certainly feasible.

\footnotetext{
${ }^{45}$ W.B. Austin and Jowett (“Johannes Factotum”) offer the major arguments for Chettle's authorship. More recently, Richard Westley has contributed a reappraisal of Austin's study that uses a much wider comparison base and argues for Greene as the author.

${ }^{46}$ Interest in Greene and Peele was at a peak in the first two decades of the twentieth century. See, for example, W.S. Gaud, "The Authorship of Locrine" F.G. Hubbard cautioned that the amount of rhetorical repetitions and parallelisms is beyond Peele's usual limits ("Repetition and Parallelism"). Other authorship studies have focused on the play's relationship to The Faerie Queene and, more importantly, Selimus, which shares extensive identical passages with Locrine. See Hubbard, "Locrine and Selimus" and W. Bang's Malone Society edition.
} 
In accepting the possibility, we also accept the necessary indeterminacy

provided by the historical evidence. The wording of the title page alerts us to the presence of multiple agents contributing unspecified proportions of input to the extant text. What the above-mentioned attribution studies have clarified for us with some degree of certainty is that Locrine was not substantially written by Shakespeare. We cannot say, with any confidence, that Shakespeare definitely contributed nothing to the play. At the least, as Brooke and Massai have argued, we might consider the epilogue, which is apparently new in 1595 as it refers (slightly inaccurately) to the thirty-eighth year of Elizabeth's reign. ${ }^{47}$

This call for acknowledgement of the limitations of attribution scholarship is important given the organisation of the study of early modern drama around authorial canons. While scholars have long accepted the probability that Shakespeare began his career as a contributory author, no early appearance of his hand in anything other than a substantive capacity has yet been accepted, except where those contributions are distinguished a priori as bibliographically distinct (as in the additions to More and The Spanish Tragedy). The canon thus preserves a body of substantively authored work that is materially and ideologically partitioned off from other possible minor work, obscuring other relevant links. The relationship between Locrine and Titus may reflect influence, competition, collaboration, repertory ownership or a combination of the above without

\footnotetext{
${ }^{47}$ The full epilogue reads:

Lo here the end of lawless trecherie,

Of vsurpation and ambitious pride;

And they that for their priuate amours dare

Turmoile our land, and set their broiles abroach, Let them be warned by these premisses.

And as a woman was the onely cause That ciuill discord was then stirred vp, So let vs pray for that renowned mayd, That eight and thirtie yeares the scepter swayd, In quiet peace and sweet felicitie; And euery wight that seekes her graces smart, Wold that this sword wer pierced in his hart! (5.4.261-72) Quotations are taken from Brooke, Apocrypha.
} 
the need for shared Shakespeare involvement; yet the unjustified certainty over the falsity of the "W.S." attribution has excluded Locrine from the narratives surrounding Titus. By adopting a model of caution and gradation in attribution scholarship, and a canonical framework that does not enforce a binary division of "in" or "out", relationships such as these may be returned to the forefront of study, providing the necessary contextualisation that renders a play such as Titus less anomalous.

\section{Theory "versus" History}

Having discussed the problems of the ambiguity of the attributions of Hand D and the Locrine revisions, it is now necessary to consider the wider debates surrounding the applicability and relevance of attribution studies, a field which has experienced something of a renaissance over the last decade but which is still largely misunderstood. The most cited critique of authorship studies remains E.K. Chambers's 1924 lecture "The Disintegration of Shakespeare", in which he attacks the work of notable disintegrationists such as Fleay and, especially, Robertson. While the essay is usually discussed as a wholesale dismissal of the project of attribution studies, with particular reference to his celebrated quote "I come to accept Shakespeare, not to praise him" (32), his essay is actually far more moderate. He draws just attention to Fleay's "grossly inaccurate" data tables (33); the problems of sample size ("obviously [percentages] have no value, unless they are worked upon a sufficient number of lines to allow a fair average to establish itself" (35)) and the uncertainties of dramatic collaboration and personal development that must be taken into account. These are legitimate concerns that do not invalidate the attribution project, but rather demand more rigorous application of tests and scrutiny of results than was common practice. That the tone of the paper is sceptical is undeniable; but Chambers is more concerned to dispute the 
notion of Shakespeare as a revising writer, a position that has since been overturned. ${ }^{48}$ Schoenbaum takes a similar stance in Internal Evidence, in which his similarly sceptical tone calls for greater rigour and the adoption of more stringent principles in the establishment of authorial attributions. He then goes on to approve the work of the Pollard volume in applying varied and independent methodologies to the case of Hand D (104-07). ${ }^{49}$ Such studies offer a productive and cautious set of criteria necessary for literary critics to begin trusting statistical studies, and need to be distinguished from more general critiques such as that of Rabkin, who dismissively argues that the "question of who did exactly what ... is really only a matter of curiosity" (10) and predicts that authorship studies will inevitably self-destruct.

That authorship studies have not self-destructed is evidence that the "search for individuality" Rabkin criticises has a far more powerful hold on the critical imagination than he believes (12). However, a more sustained and considered series of challenges to attribution studies has emerged in the last twenty years from post-structuralist theory. The "Death of the Author" has coincided with the critical, if not cultural, death of Bardolatry, and a newly focused attention to the contingencies of collaborative writing in the early modern theatre. The question is now whether it is reasonable, or even desirable, to continue to extract individual authorial contributions from an historically and theoretically socialised text.

McMullan seeks to address what he refers to as a "considerable gulf ... between theorists of collaboration and practitioners of 'disintegration'” (“Our Whole Life" 438). It is this same gulf, relegated to an appendix, which Vickers also discusses

\footnotetext{
${ }^{48}$ On the groundbreaking work of the 1980 s on King Lear, and the controversy, see: Taylor and Warren, Division of the Kingdoms; Taylor, Reinventing Shakespeare 358; and Rosenbaum, Shakespeare Wars $46 \mathrm{ff}$.

${ }^{49}$ His coda, "Such triumphs have been few, however, and unfortunately overshadowed by the bedlamite antics of the wildmen" (107), however, makes clear that this is an exception. The exception is made owing to the authority of Pollard's contributors, rather than to any difference in methodology.
} 
under the chapter-heading "Abolishing the Author? Theory versus History" (Co-Author 506-41). The difference in emphasis is of great significance. McMullan's "gulf" suggests a separation between two fields that struggle to find connection or common ground; while Vickers's "versus" implies an unavoidable irreconcilability that results inevitably in direct conflict. Whether gulf or conflict, it is this division between two different approaches to collaboration that needs to be resolved.

Even the terms of collaboration are contestable. Since Chambers's address, "disintegration" has taken on negative associations. Cary DiPietro notes that Shakespeare as author/corpus is treated as a unitary author whose 'disintegration' suggests an assisted decomposition or decaying of his corporeal body, a deliberate and irreverent disturbing of the grave which, as any early twentieth-century Shakespeare enthusiast would have known, the inscription on Shakespeare's gravestone explicitly cautions against. (147)

Vickers explicitly attempts to dissociate the identification of co-authors from "disintegration", in terms that demand close scrutiny:

If scholars analyse plays in which readers have long noticed major discrepancies with Shakespeare's language and dramaturgy ... they are not 'disintegrating' Shakespeare's solely authored text but reclaiming the appropriate parts for their original authors. This is a work of elementary justice, to begin with ... Such a study should properly be called not 'disintegration' but 'restitution.' (137-38)

In Vickers's formulation, then, the practice is to be called "disintegration" when it is incorrectly applied to sole-authored text and "restitution" when it correctly identifies a collaborative author. Yet this is an impossible distinction to make in regards to 
methodology and purpose, as it presupposes the correctness of the putative results. Both "disintegration" as practised by Fleay and "restitution" as practised by Vickers are characterised by attentiveness to difference, and the attempts to quantify and explain that difference by reference to other authors. The difference between the two approaches is one of gradation. Modern scholars, with the aid of computers and databases, are able to apply far more rigorous and stringent procedures, thus producing statistically coherent and therefore more defensible results. The availability of these resources, in turn, allows for a stricter adherence to quantitative difference over value judgement. In short, the school of "disintegration" remains exactly the same in theory, but with a more sophisticated approach in practice that takes on board the criticisms of Chambers and Schoenbaum and presents the evidence for collaborators in a more objective manner. The shift is important in justifying the school, but is not enough to move away from the label of "disintegration". It is not the author that is the object of disintegration but the text, and as such "disintegration" remains an appropriate word.

The language of "reclamation" and "restitution", in fact, offers a more troubling set of associations which would relate Vickers's work more closely to that of the nineteenth-century disintegrationists from whom he is attempting to distinguish current work. He relates his terminology to that of "Justinian's well-known definition of justice, suum cuique tribuere, to give to each man what belongs to him" (137-38). By moving to a language of justice, responsibility and personal ownership, Vickers identifies words as authorial property rather than textual property, tied more closely to their originating mind than to the circumstances of their circulation and production. While seeking to avoid value judgements, he approves the framework of intellectual property that allows those judgements to be made. As his own invocation of justice reminds us, the establishment of responsibility and ownership inevitably acts as a precursor to 
vindication or condemnation, to the kinds of evaluative judgement that Chambers and Schoenbaum warned against.

It is at this point that post-structural theory enters the equation, most prominently in the work of Masten and McMullan. Masten rightly points out that "the collaborative project in the theatre was predicated on erasing the perception of any differences that might have existed, for whatever reason, between collaborated parts" (Intercourse 17), a position endorsed by McMullan who argues that collaborative works are designed "to give an impression of dramatic coherence, not to allow the audience to perceive the fissures between one authorial contribution and another" (Late Writing 237). This acts in direct contrast to Bowers's assertion that "scholarly investigation of the authorial problems posed by collaborative drama is ... a necessary precondition to critical and aesthetic considerations of such drama" (1.vii), a position followed by Vickers's assertion that “We cannot form any reliable impression of [Shakespeare's] work as a dramatist unless we can distinguish his authentic plays from those spuriously ascribed to him ... [and] those parts of collaborative plays that were written by him together with one or more fellow dramatists" (Co-Author 3).

Masten is particularly concerned to stress Bowers's reference to "authorial problems", arguing that to treat early modern collaboration as a "problem" is anachronistic, imposing post-Enlightenment paradigms of authorial creation onto an environment in which collaborative writing was a normative and necessary defining condition of the writing process. ${ }^{50}$ While Masten pushes this too far in arguing for a later emergence of the concept of individual authorship, for which he is rightly criticised by Vickers (528-30), his basic point is sound: that to assume the division of authorship is a

\footnotetext{
${ }^{50}$ See also McMullan, "Our Whole Life", which argues that the "problem" is, in fact, an advantage for editors. If all dramatic texts are collaboratively produced, then the fact of collaborative authorship prioritises this model of thinking from the start, rather than establishing a collaborative text and individual author in uneasy opposition.
} 
"necessary precondition" for the appreciation of the drama is to impose valuations of authorship onto the drama that are inappropriate to both period and form. Vickers comes closer to the mark in his assertion that "No issue in Shakespeare studies is more important than determining what he wrote" (Co-Author 3). This is literally correct; but only if what we are engaged with is, indeed, "Shakespeare Studies", the postEnlightenment study of the individual's works. If we wish to pursue "a reliable impression of his work as a dramatist", then the project of disintegration is necessary and valuable. If the project is the study of early modern plays, then Masten's scepticism is justified; the project of disintegration is not essential to the enjoyment, study and critical evaluation of drama, whether singly or collaboratively written.

I wish to stress here that these are not necessarily mutually exclusive positions, but represent different priorities in the valuation of a dramatic text that both serve legitimate scholarly purposes. The extreme positions adopted by Vickers and Masten, insisting on the foundational importance or fundamental invalidity of determining authorship, are both unhelpfully reductive.

Vickers is fighting a somewhat lonely war on two fronts. His critique of "theory" defends the historical ideal of the author, with particular reference to classical notions of the author inherited by the Renaissance.${ }^{51}$ However, the volume is also concerned with promoting the cause of collaboration against those clinging to sole Shakespearean

\footnotetext{
${ }^{51}$ The use of the umbrella term "theory" is problematic. Vickers is, of course, referring specifically to post-structuralism as applied to authorship, most importantly post-Foucauldian paradigms, but there is an implicit lumping-together of theoretical positions (see Kastan, Shakespeare After Theory 23-26 on the conflation of theoretical paradigms into an easily combatable, homogeneous grouping). There is an implicit hostility towards other oppositional theories, manifesting itself in troubling language. For example, Vickers approves Masten's critique of Leah Marcus in the sentence: "Masten indicts one woman critic for 'her assumption that authorship ...'" (538n), with an odd emphasis on Marcus's gender; Later, he argues that Masten's "wish to appropriate co-authorship to a modern gay agenda added another level of anachronism to his interpretation" (541), a loaded and reductive treatment of Masten's carefully historicised reading of homosocial behaviours. It is difficult to avoid a sense of discomfort at Vickers's unnecessary stress on his "opponents'" gender and sexuality, particularly at the end of an historical narrative largely approving the work of a succession of white male academics.
} 
authorship, arguing historically for the dispersal of authority among numerous collaborative agents. This is a fight he continues in "Incomplete Shakespeare", long after the battle has nominally been won in regard to Shakespeare, at least in editorial practice if not universally.

Vickers is thus concerned with defending a position whereby authorial agency remains distinct and identifiable, but where multiple agencies can exist alongside one another in the same text. This position is a tenable one, but needs to be severely qualified. Kastan offers a much more productive approach:

It is only by attending to the actual conditions of playwriting in early modern England that the historical Shakespeare can be saved either from the mystifications of idealist criticism or from the no less mystifying moves of poststructural theory, where instead of disappearing into the putative unity and self-sufficiency of form he would disappear into the assumed priority of the linguistic order itself. Historical scholarship at once disperses and reconstitutes Shakespeare, revealing him to be something more than a product of the text and something less than its exclusive producer. (Shakespeare after Theory 38)

Like Vickers, Kastan accepts the discernible agency of the author of early modern drama. However, his catalogue of agents draws on a much wider and discursive field than does Vickers's. The formulation "Theory versus History" is not only reductive insofar as it reduces "theory" to a homogeneous set of impractical ideals, but also in its conflation of "history" into a single, unified set of facts. Vickers's history of early modern dramatic authorship (Co-Author 3-43) focuses on writers, and the networks of contribution defined in Henslowe's diary. As Kastan points out, however, the processes of 
transmission involved more agents than just authors. Taking a materialist approach to the text, he argues for the intervention of scribes, book-keepers, compositors etc., resulting in the vaguer, but more sophisticated, conclusion that Shakespeare is "something more than a product of the text and something less than its exclusive producer" (38). That is, Shakespeare and his co-authors are major contributors to the production of the text, but they cannot necessarily account for the total product. Lene Petersen notes the peculiarity of Vickers's partial approach to history, arguing that

The general lack of consideration of the impact of dramatic transmission upon the sample texts reviewed is indeed peculiar ... at worst it may undermine the credibility of some of the achieved attribution results. In other words, testing for early modern authorial style against a theoretically limited background, when a more fully representative view of the Elizabethan and Jacobean dramatic industry might possibly alter stylistic test results, can only ever be partially convincing. (202)

The areas of uncertainty I have alluded to in the first two sections of this chapter are a case in point. Attribution studies have told us, convincingly, that Shakespeare almost certainly wrote an addition to the play of Thomas More, and that he almost certainly did not write Locrine. The did-didn't binary is, however, reductive from any perspective. It oversimplifies attribution, as divisions cannot be made with absolute certainty. It disregards history by proposing an authorial integrity for dramatic texts that cannot be sustained, as for example in the revision of Hand D by another agent. Finally, it is theoretically unsatisfactory, as it denies the social mobility of the text that is best expressed theoretically, but is related intrinsically to the material practicalities of the theatrical environment. Disintegration, as Vickers rightly notes, allows us to understand the historical practices of playwriting, in revealing how the composition of plays was 
organised. What Vickers fails to give sufficient attention to is that this process of composition relates only to the creation of one stage of text. Plays are far more than texts, as Weimann reminds us in quoting Ruth Finnegan's assertion that "it is now accepted among serious students of verbal oral performance that the text alone is an insufficient guide to the art form" (6). ${ }^{52}$ The writer's contribution to the total work, a socialised and historically contextualised performance(s), reveals the writer as "one among other agencies" (16) and thus the writer cannot be considered as the autonomous or "complete" creator of the "work". The books in which the art form has survived preserve a manifestation of part of the text, which in turn circulated in the early modern theatre as a locus of authority between writing and playing (Weimann 30), and have passed through additional layers of rehabilitation, agency and revision. Some of these, such as large-scale revision, disintegration is well equipped to help us acknowledge and interpret; but many of these occur at too local and material a level to be neatly reduced into authorial sections.

It is this understanding that informs Jowett's far more practical approach to the dispute. He critiques Masten's complete subordination of the author to a socially produced model of textual circulation, which he contends "collapses the collaborator as well as the author" ("The Pattern of Collaboration" 182). That is, Masten's theoretical deconstruction of the author only works on a purely theoretical level, insofar as it denies any level of individual agency; a position belied by Masten's own insistence on collaboration as an embodied process between individuals elsewhere in his study. Instead, Jowett states that he "will assume instead that writers play an overwhelmingly important role in the social production of the written word" (182). This chimes with an earlier study of collaboration by McMullan; in The Politics of Unease (1994) he argues

\footnotetext{
${ }^{52}$ McMullan's critique of Vickers's dismissal of Foucault picks up on this distinction. Vickers "seems not to understand the detachment of 'author' (rhetorical category) from 'writer' (producer of text) that Foucault's intervention requires" (Late Writing 235).
} 
that authorial division is "a necessary prerequisite of analysis" (154) and argues for "the distinctiveness of the individual as an orchestrator of voices" (155). While McMullan's later work on collaboration has tended to more emphatically deprioritise the individual author, his wording here remains useful. "This organization or orchestration can be distinctive without requiring belief in romantic notions of originality" (155). He argues for a more practical acknowledgement of the broad areas of distinctive authorial identity, which locates the individual manipulating the environment without necessarily attributing words at the most local level. This fits with Jowett's acknowledgement that attribution study is "poorly equipped" to deal with local transcription and revision (183), which establishes the limitations of the field before going on to pursue its strengths.

Jowett's middle ground offers a basis for compromise in a debate in danger of becoming circuitous. What we know of the historical circumstances of writing in the early modern theatre allows that collaboration was a normative mode of production. To an extent, collaborative parts can be individually identified, and provide invaluable insights into some of the processes involved in constructing a dramatic text. We see here an echo of Jerome's third criterion of authenticity, as reported by Foucault: "one must also exclude works that are written in a different style, containing words and expressions not ordinarily found in the writer's production (the author is here conceived as a stylistic unity)" (111). That an author is a stylistic unity is a necessary precondition of stylometrics, which depend upon an authorial style that remains within a limited set of parameters. For Kinney, the success of his attribution methodology depends on "the demonstrable fact that authors tend to draw on the same set of words in their various works" (197). Whether or not the limitation of the author to a stylistic unity is unsatisfactory as a theoretical principle does not necessarily prevent it from having practical relevance. As Merriam points out, neither fingerprinting nor DNA analysis were 
fully understood or theorised before finding acceptance in practical use ("Linguistic Computing" 187).

To another extent, however, the contingencies of writing in an inherently collaborative environment, particularly one in which the primary intended mode of transition is oral/aural and multivocal, insist that the division of a text into authorial contributions is neither necessary nor always appropriate. This is clear in the case of the apocryphal plays, for many of which attribution studies have failed to establish an authorial origin, yet which have proven to be of great utility in studies such as that conducted in Chapter Two. To surrender the idea of being able to identify authorship is unduly sceptical; to prioritise it is limiting. At the heart of this dispute resides a fundamental anxiety over the role of authorship and attribution that resists the dissolution of the author, yet is largely sceptical of the efficacy of attribution studies to determine authorship. The "gulf" - for I agree with McMullan that this must be a bridgeable division, rather than a battle for supremacy - is fuelled by a lack of common language. Merriam points out that attribution studies are caught in a "Catch-22" ("Linguistic Computing" 190) of being unable to be simultaneously accessible and comprehensively accurate. "Quarantine has been observed between the factual emphasis of computational ascription, and postmodernist considerations of authorship attribution" (185). Merriam sensibly reminds the readers of Literary and Linguistic Computing that attempts to "prove" authorship are naïve, and that it is the certainty with which results are announced that makes sceptics of non-specialists. Conversely, however, he makes a powerful case for the necessity of exploring the possibilities opened up by new technologies with an open mind, arguing that interdisciplinary misconceptions and suspicions are no reason to discontinue exploring an avenue of research. He offers, ultimately, a constructive summary: 
Postmodernist critiques play a valuable role in counteracting the overconfidence of positivist attempts at 'proving authorship' ... none the less, the underlying subjectivism of modern philosophy is ultimately corrosive of the engagement of reason ... Real authors exist and have real intentions, no matter how often their traces have been mediated, diluted, and obscured in the process of transmission, no matter how contradictory their original expression, and no matter how great the creative freedom on the part of the reader to interpret them. (191)

While acknowledging Merriam's "real intention" in this formulation is to assert the case of linguistic computing over the concerns of "theory", my own "creative freedom to interpret" finds this most important as an articulation of the provisos and caveats that need to be applied to authorship studies if they are to be accepted by literary critics. If authorship studies can take into account the historical and theoretical networks of agency that literary criticism now understands as a matter of course, then the "gulf" may be bridged.

\section{The integration of disintegration: Edward III and Arden of Faversham}

Having argued for the need - both practical and theoretical - for compromise, I would like to now turn to two of the most prominent apocryphal plays, Edward III and Arden of Faversham. Both represent triumphs of disintegrationist practice that have tended to identify Shakespeare's hand within them, but also the limits of the same approach in having failed to reach a consensus over the extent and identity of Shakespeare's collaborators. Both are also often linked within non-authorial paradigms to the work of Shakespeare and his contemporaries as examples of Elizabethan chronicle history and domestic tragedy, and have generated wide bodies of criticism away from the question of authorship. The plays thus provide important case studies for 
the combined use of authorial and non-authorial based methods in approaching anonymous drama.

Arden of Faversham is the most frequently produced and edited of the Apocrypha, and is considered important enough to appear anonymously, on its own terms, in anthologies such as Wiggins's A Woman Killed with Kindness and Other Domestic Plays and McLuskie and Bevington's Plays On Women. Yet it has also been one of the most recent targets of disintegrative work, with Jackson and Kinney both arguing for Shakespeare's partial authorship of the play. For one group of scholars, the play's worth exists in its anonymity and relation to its generic cousins. For the other, the interest of the play resides in the identification of the author in the central scenes of the play. The play itself occupies Arden's own position, progressing on its own terms while opposing forces struggle over possession of it.

Wiggins, the most recent editor of Arden, takes an extreme stance. He casually dismisses the entire body of attribution work on the play thus: "a great deal of thought about Arden of Faversham has been unhelpfully preoccupied with the question of its authorship, which is neither answerable nor particularly illuminating about the play" (xli). For Wiggins, "with Arden of Faversham, the play itself really is the thing" (287). Wiggins is concerned that an excessive focus on authorship reduces the perceived value of the work itself. His scepticism towards attribution studies implies both ineffectiveness (the question is unanswerable) and questionable purpose (the answers tell us little). Wiggins's edition occurs instead within the context of a volume of domestic dramas in the Oxford English Drama series, which "offers plays from the sixteenth to earlytwentieth centuries in selection that make available both rarely printed and canonical works" (back cover). The purpose of the series is to transcend canon and seek other points of intersection between texts, rendering the question of authorship a subsidiary 
issue. Again, this is not necessarily an irreconcilable gulf, but does point towards a notional distinction between "Shakespeare Studies" and "English drama", represented by Oxford UP in its two distinct publishing series.

Wiggins, however, is not content with the "gulf" that allows him to ignore attribution work, but goes on to take a stance on the question of attribution that offers a reading of theatre history and dramaturgy in opposition to (uncited) quantitative and stylometric forms of establishing authorship. He contends that the anonymous dramatist "was not a theatre professional" (285), and his remarks, based on what he perceives to be the dramatist's lack of practical theatrical knowledge, bear serious consideration. To summarise briefly:

1) The letter that Alice receives from Greene in Scene 8 describes action that has taken place since the letter was sent, thus creating a plot inconsistency;

2) Alice's role is two-to-three times bigger than any other written for a boy actor during this period;

3) The stage directions describe the action as if from an audience perspective;

4) There was no suitable "ditch" on an early modern stage for the action described in Scene 12;

5) There is not enough time in Scene 12 for Shakebag to be "berayed" in mud, and facilities for cleaning the costume would render this impractical;

6) There are two occasions on which there is no dialogue to cover stage action.

Most of Wiggins's points are easily dealt with, as they involve an overly literal reading of the text that denes the imaginative capabilities of an early modern audience. The use of a ditch, he argues, shows that the writer "does not see the theatre at all" (285), but use of the represented location rather than the physical in Elizabethan stage directions is not unusual: Faustus is revealed "in his study" rather than in a discovery space (1.1.0.1), for example, and Gloucester receives Winchester "at the Tower Gates" at 1 Henry VI 1.3.28.1. "Berayed" occurs in dialogue rather than in a stage direction (12.55), implying 
that the mud may well have been imagined rather than literally rendered. The inconsistency of the letter may offend literary logic, but accords perfectly with linear theatrical logic in reporting on action that the audience has already experienced, and is typical of the kinds of inconsistency in the period. That the stage directions reflect the action as experienced from the audience rather than as managed backstage may reflect nothing more significant than that the source manuscript was authorial rather than theatrical; Wiggins's own note that "there is no sign that the text as printed has been transmitted through the theatre" (xxxvii) explains this neatly. ${ }^{53}$ Wiggins also answers his own concern about the moments of silent action by noting recent stage productions that have used the silences to great effect (286), and as Mehl demonstrates, the use of dumb-show was not uncommon at this time.

Wiggins may be wrong but, to appropriate Taylor's critique of Chillington's attribution of Hand D to Webster, he is "originally and provocatively wrong." In applying the practicalities of theatrical realisation to the question of attribution, he reminds us that the quantitative analysis of words must work in conjunction with attention to problems of theatre history; thus, Craig's attribution of the 1602 additions to The Spanish Tragedy to Shakespeare remains unconvincing, not only in quantitative terms but in the author's unwillingness to put forward a narrative that explains Shakespeare contributing to a Henslowe play in $1602 .^{54}$ A case can be made, but Craig's failure to do

\footnotetext{
${ }^{53}$ Wine plausibly suggests that "the care with which stage directions evidently were prepared points to a scribe who was concerned that the reader should have a sense of what the play was like in performance" (xxxi). Wiggins does not consider that the stage directions may be for a readership, rather than for a performance text; although, of course, the same effect may well be expected in a closet play.

${ }^{54}$ See Kirwan, "Review." The claims are hugely overstated based on the presented results, which show only that the additions tend more closely to Shakespeare than to Jonson, Webster or Dekker in three one-on-one lexical tests (Craig and Kinney 175-78); and in an all-comers test (the bedrock of other experiments), the additions tended more closely to non-Shakespeare (179). The comparative nature of the tests is meaningless unless carried out exhaustively between all possible pairs of writers. Vickers agrees with Craig's conclusion, but based primarily on Stevenson's work rather than Craig's ("Shakespeare and Authorship Studies").
} 
so is discouraging for theatre critics wanting to interrogate the results. ${ }^{55}$ Wiggins's important observation on the unusual size of Alice's role in Arden is an example of the kind of important and potentially destabilising anomaly that needs to be taken into account in arguments that Shakespeare, or any professional dramatist, wrote the play.

To treat the play as written by an amateur dramatist is arguably the play's intention. Franklin's final words turn him into a choric narrator figure, substituting for the concealed author:

Gentlemen, we hope you'll pardon this naked tragedy

Wherein no filèd points are foisted in

To make it gracious to the ear or eye;

For simple truth is gracious enough

And needs no other points of glozing stuff. (Epilogue 14-18)

The author of this tragedy is "simple truth" itself, the author disappearing behind an assertion of unmediated history that explicitly denies authorial or artistic agency. Lockwood argues that this is a deliberate effect, that "Arden of Faversham is constructed with the special kind of artfulness that can look like apparent artlessness" ("Introduction" $\mathrm{x}$ ). The theatrical success of the play in subsequent generations, as well as its powerful and intricate dramatisation of economic, domestic and artistic concerns, belies Franklin's claims and argues for the presence of a professional writer. ${ }^{56}$ Attention

\footnotetext{
${ }^{55}$ Bate suggests that Henslowe's "geronymo" is a different play to the extant Spanish Tragedy. As the rival playhouses are known to have sometimes staged competing dramatisations of the same story, as in Henry IV/Oldcastle, Bate argues that the extant Spanish Tragedy may have been a Chamberlain's Men's play in which Burbage acted, and to which Shakespeare contributed additions as part of his role as resident dramatist (private communication). This narrative is compelling and plausible, particularly in its accounting for Burbage's fame in the role of Hieronimo, but in the absence of further documentary evidence must remain an appealing conjecture.

${ }^{56}$ The self-consciousness of the play's art is explored interestingly by Ousby and Ousby, who argue that the play enacts a distrust of "art" throughout in the deliberate hyperbole and narcissistic mythologising of its character. See also Leggatt, "Arden".
} 
to the skill and complexity of the play has therefore, as Wiggins notes, exerted a

"powerful temptation" on critics to give the play to a known writer, ever since Edward Jacob's 1770 attribution of the play to Shakespeare. The most commonly claimed authors remain Shakespeare, Kyd and Marlowe, tying the play to the most prestigious names of the period.

The tendency in debates over authorship is to allow competing claims to run their course before disinterested parties evaluate the claims, no doubt owing to anxiety on the part of non-specialists over their ability to critique the methodologies employed. While inevitable, this has the unfortunate side-effect of allowing history to be written by the "winners", with only the arguments supporting the eventual consensus subsequently being read. To intervene in a live debate is to risk being obsolete by the time of publication; however, if literary critics are to do more than passively accept the consensus results of attribution studies, they must also engage with the process.

The most recent intervention in the dispute over Arden has been Vickers's highprofile assertion of Thomas Kyd's authorship, made in the Times Literary Supplement. ${ }^{57}$ Using a programme entitled “Pl@giarism," Vickers claims the whole play for Kyd based on parallels with the three plays attributed to him by consensus (Spanish Tragedy, Soliman and Perseda, Cornelia). ${ }^{58}$ However, Vickers's results have been convincingly rebutted by Kinney and Jackson, both of whom point out that his parallels constitute only positive connections between Arden and Kyd, which are not contextualised with

\footnotetext{
${ }^{57}$ The TLS provides the ideal platform for scholars wishing to consolidate an authorial claim as quickly as possible. The speed of publication ensures that any rebuttals - the tests for which require substantial planning and implementation - risk being either over-hasty or too slow to destabilise the attribution. Vickers's case against Middleton's involvement in Macbeth was published in TLS on 28 May 2010 ("Disintegrated"), with copies distributed to the London Forum of Authorship Studies the previous evening. Jowett's letter of the following week ("Shakespeare") attacked not only Vickers but the platform, arguing that "Vitriol is a poor vehicle for truth ... and it is clear that all the claims made by Vickers will need to be checked before any response to them is possible", drawing attention to the rigour demanded in refutation.

${ }^{58}$ Full details of the methodologies and programs employed, as well as detailed lists of the unique links found between Kyd's canon and the plays, are available online (Vickers, "Canon").
} 
appropriate negative checks against other authors. Kinney's purpose is to destabilise Vickers's claim in order to create space for his own contradictory results, while Jackson offers a more sustained interrogation of Vickers's methodology. Running the same tests between sections of Arden and Shakespeare's corpus, Jackson demonstrates that Scene 8 of Arden shares more parallels with 2 Henry VI alone than with the entirety of the core Kyd corpus (“New Research” 114). ${ }^{59}$ While Vickers disputes Jackson's findings, he is yet to publish a rebuttal (private communication). Further, despite carrying out different tests, Jackson and Kinney both come to the same conclusion that Shakespeare contributed to the middle section of Arden, although the extent and precise range of Shakespeare's contribution has yet to be agreed.

Kinney's arguments suffer from the lack of theatrical-historical contextualisation mentioned earlier. For example, he suggests that the names Black Will and Shakebag "seem to point to Shakespeare" (86), an older argument that betrays ignorance of either the play's sources, which identify Black Will as the historical villain, or of the stage tradition that saw a character called Black Will appear as a rogue in Rowley's When You See Me, You Know Me and the anonymous True Tragedy of Richard III, both of which suggest that the character was a popular and transferable stage figure with no necessarily unique connection to Shakespeare. ${ }^{60}$ Kinney's further parallels of style, such as the use of soliloquy and the vividness of the imagery, are similarly impressionistic and uncontextualised.

The lexical-word tests employed by Kinney are similarly questionable. The Preface admits, for example, that only 112 of 174 single-author plays from the period

\footnotetext{
${ }^{59}$ It should be noted that Jackson reduces the core Kyd canon to The Spanish Tragedy, Soliman \& Perseda and Cornelia, refusing Vickers's parallels with other attributions such as Fair Em and 1 Henry VI on grounds of circularity.

${ }^{60}$ Terry Hands's 2010 production for Theatr Clwyd played on this by having Michael recognise Will at 3.130 in the excited tone of a layman recognising a celebrity, suggesting that the character's reputation preceded him. This had the additional effect of resolving the notorious logical crux that asks how Michael can, at this point, recognise a character that he has never met.
} 
are tested, as opposed to the entire corpus (xvii), despite the availability of the corpus on LION. A lexical-word test measuring Arden's relative likeness to Shakespeare, Marlowe and Kyd is reported to have placed the play in its entirety closer to Shakespeare's range than to either of the other authors, but these results are not shown. Finally, rather than use the 2000-word chunks that Kinney's team claim are necessary for tests to be unaffected by local anomalies (e.g. content), Kinney begins with individual scenes, which he admits are too short for confident results (94), and then groups the scenes roughly together according to these results. All that Kinney's tests can claim within these very broad limitations is a vague indication of a different style roughly in the middle of Arden of Faversham and that, of the very few dramatists tested, this style tends most nearly towards Shakespeare. The confidence of their final analysis, "Arden of Faversham is a collaboration; Shakespeare was one of the authors; and his part is concentrated in the middle section of the play" (99), is not justified on the basis of the evidence presented here.

Jackson's evidence, however, is far more persuasive, precisely because of its fusion of historical, literary and statistical readings, and its modest remit. Jackson's seminal 2006 article focuses on the authorship of a single scene (Scene 8, the "quarrel scene") and analyses it from a range of perspectives. He begins with acknowledgement of other critics' subjective reader responses and offers his own literary critique of the scene's dramaturgy, its structural role within the play as a whole and its relation to Shakespearean norms. He only then moves on to his primary research methodology, the gathering of parallels and collocation across the entire corpus of plays in the period 1580-1600. Despite his prior thesis (the possibility of Shakespeare's involvement), the search parameters are set broadly and objectively from the start, and search samples are rigorously checked throughout. He then moves on to literary analysis of the parallels he considers to be of most interest, qualifying computational data with a human eye 
rather than fully deferring to cold data, which allows him to draw out the significance of particular rhetorical tricks and specific parallels. The "reflexive conceit" ("Quarrel Scene" 266), for example, is something particularly curious to Shakespeare (e.g. "It is not love that loves to murder love"), of which he finds forty examples in Shakespeare's works and only one elsewhere. Finally, and most importantly, he contextualises his findings within the attribution research of other investigators. For example, he scrutinises Elliott and Valenza's work on the play and demonstrates that, although they are conclusive against sole Shakespearean authorship, their tests do allow for the possibility of collaboration.

Jackson's study is confined to a single scene and only makes a modest claim. However, it draws its authority from its accessibility and from its foregrounding of the subjective approach as qualified by objective data. All "unbiased" attribution scholarship is compromised by the investigator's own beliefs: even Jackson's generous critique of Vickers's work on Kyd takes as its primary bone of contention Vickers's disagreement with Jackson over Arden. If objectivity can only be gestured towards rather than achieved, then the foregrounding of the subjective investigator serves to enhance transparency. Jackson's authority stems from the ease with which it can be crossexamined: the same tests can be run on LION by any scholar; his statistics can be crosschecked without specialist training; his literary readings can be challenged or sophisticated by other readers. In many ways, Jackson's claim for Shakespearean authorship of this scene is subsidiary to the real value of his paper, which demonstrates the practical use of linguistic computing for the literary scholar, and offers deeper insights into the language of Arden which can be used for criticism of the play as well as for the authorship question. 
Wiggins is correct to point out that "the play really is the thing"; but to extrapolate from that that attribution scholarship serves no useful purpose is misleading. Arden of Faversham participates in a number of networks: domestic tragedy plays; plays drawn from chronicle history; plays on marriage and commerce; plays of heightened rhetoric; serio-comic Elizabethan plays; plays featuring Black Will. To deny that the play participates in a lexical network with Shakespeare's early work is, as Jackson points out, is to deny the play an important aspect of its circumstances of production and circulation. As we have seen, critical positions that accord either no value or all value to the authorial attribution both suffer from incomplete attention to the complexities of dramatic creation. Through not attempting to pre-define the importance of the role of writers, and allowing their identification a visible but nongoverning participation in criticism, the text is allowed to reveal its own important networks.

The new case for Shakespeare's involvement in Arden is still too young to have had an impact on publishing and criticism. While Jackson's claims have been taken into account by both the revised New Mermaid edition and the RSC Shakespeare, which publishes the scene in question on its website, the counter-arguments of Vickers and Wiggins suggest that the issue will continue to be contested. Yet even once a claim has been established, once Shakespeare's involvement in a play is determined to the satisfaction of a substantial majority, what then? The isolation of the "possible Shakespearean scene" on the RSC Shakespeare website removes the play from the dramatic context that makes sense of it, in line with the older treatments of Hand D critiqued by Masten and Werstine. Unlike the majority of other anonymous dramas, further, Arden is unusually well served by excellent scholarly editions, arguing that 
attribution is (at least in this case) not a prerequisite to appreciation. ${ }^{61}$ I have argued thus far that attribution scholarship must accept the limitations of its ability to precisely define authorship, but even taking a positivist stance on findings, what is to be gained from identifying a "Shakespearean" section of a play?

Several scholars have begun to use collaboration as an active tool for literary critique, rather than as a way to excerpt individually authored extracts. McMullan analyses the politics of Fletcher and Massinger's Love's Cure with attention to authorial divisions, demonstrating persuasively that the play does not mute its politics but rather that there are two different political viewpoints in operation (Politics of Unease, 149-

53). Brian Boyd argues that Shakespeare was unaware of the killing of Mutius in Titus, a scene written by Peele, and that this scene obscures Shakespeare's intention to contrast Aaron and Titus throughout ("Kind and Unkindness"). Jowett, in the same collection, examines Timon of Athens with attention to the layers of revision, providing a literary reading of Middleton's strategies of adaptation ("The Pattern of Collaboration"). While this kind of disintegrative work does serve to operate against the idea of the play as having its own dramatic unity, all three scholars demonstrate the utility of close attention to authorial distinctions as a literary tool. If the attribution project is to have literary merit, this is the direction it must pursue.

The debates surrounding Edward III offer productive ground for exploring this approach. Now included in several major Shakespeare editions, the play is materially accepted as canon, even though the authorship questions concerning the play remain interestingly unsettled. ${ }^{62}$ For the late Eric Sams, who infamously proclaimed

\footnotetext{
${ }^{61}$ As well as the editions by Wiggins and McLuskie-Bevington, see also Wine's Revels edition, White's text for the New Mermaids, Sturgess's Three Elizabethan Domestic Tragedies and Fraser and Rabkin's Drama of the English Renaissance.

${ }^{62}$ Melchiori's Cambridge text is the only current single edition, but the new Arden text is currently near completion. The play is also included in the second edition of the Oxford Complete Works, and selected scenes are included on the website of the RSC Shakespeare.
} 
Shakespeare's authorship of Edmond Ironside, the value of Edward III consists in its univocality. Sams offers an extraordinary case against collaboration, worth quoting in full:

In Academia, furthermore, what is not known is not knowledge. Under cover of this darkness, the notion of 'collaboration' has crept in and gained ground. It purports to explain the presence in Edward III of a style unfamiliar to many an expert eye ... He cannot possibly have written thus, at any stage of his career; so the explanation must be some unknown person or persons 'collaborating' with him or 'imitating' or 'plagiarising' him, or 'memorially reconstructing' him (in almost every modern edition of every two-text play); and so forth. This preserves him as a 'late-developing' dramatist, free from the least taint of inferiority. But the unanswerable point has been made that all these conjectures are just literary inventions emanating from the elitist attitudes of 1920s Oxbridge that still dominate scholarship world-wide. Before then, no such notions had ever existed. (Edward III 1-2)

While memorial reconstruction may be a recent theory, collaboration is (as Sams knows) an historically documented phenomenon, and one apparently predominant in the early modern theatre. The possibility of Shakespeare having collaborated is evidenced as early as the 1634 quarto of The Two Noble Kinsmen, and was critically mooted as early as Edward Ravenscroft's adaptation of Titus in $1687 .{ }^{63}$ To claim that early modern dramatic collaboration is a twentieth-century invention is Sams's most audacious reshaping of evidence to advance the case for Shakespeare. From the first page of his edition, he

\footnotetext{
${ }^{63}$ Sams does mention Two Noble Kinsmen later in the volume, qualifying his argument so that there is no evidence for Shakespeare having collaborated during the early stages of his career (161). Sams's other significant work, The Real Shakespeare, offers a revisionist account of Shakespeare's "lost years" that establishes him as a writer in London from the mid-1580s.
} 
positions himself as battling against a wilfully obtuse academic establishment that relies on conjecture and refuses to engage with simple truths. His anger is borne from the negative reception accorded Ironside; though, as the Oxbridge reference insinuates, there are more personal grievances being vented (see Rosenbaum, Shakespeare Wars 71).

Much of Sams's argument is taken up with demonstrating the overall quality of Edward III, and thus its sole authorship. His case yokes the greatness of Shakespeare and the greatness of England together in an individual microcosm of a unified state and culture. Sams's mission is to allow Shakespeare, as the "national poet", and thus a property of the people, to once more tell the English people their national story without mediation and without collaboration: his issue is that the presence of more than one author would distort what he perceives to be the essential unity of the piece. Speaking of the two subplots, he claims that their "contrasts provide large-scale structure, their interlinkages create phrases and imagery. Further, each is adroitly aligned as a separate aspect of one single unifying topic, namely the rights and wrongs of vows and promises" (3), and "there is an overriding moral: those who make passionate vows are taught salutary lessons" (12).${ }^{64}$ For Sams, the project of Edward III is a moral and instructive one, whose lessons derive their authority from the author in much the manner of the quotation books discussed in Chapter One. Morality and unity derives, in Sams's formulation, from a single moral and unimpeachable mind, that renders the lessons of Shakespeare's Edward III authoritative.

\footnotetext{
${ }^{64}$ Compare Melchiori: "The most undoubtedly Shakespearean part of the play - the so-called 'Countess of Salisbury scenes' - is in the nature of a second thought, an insertion and substitution of presumably shorter scenes, not greatly different in substance and quality from the famous 'Addition in Hand D' in the play of Sir Thomas More" ("What Did Shakespeare Write?" 347). For Melchiori, the strength of the Shakespearean claim comes from its piecemeal state, and he critiques Sams's case as "further weakened by his coupling Edward III with Edmund Ironside as being both exclusively Shakespearean works." (347n).
} 
Easy criticism of Sams's methodology and conclusions has led to derision rather than serious consideration of the implications of his rhetoric. Sams is appealing to the cultural authority of Shakespeare, the governing principle of the English Bard that continues to operate as a byword for English history, literary culture and human morality. For Sams, as Ian Robinson implies, value is inherent not in Edward III and Ironside but in Shakespeare, who acts to authorise the plays, accord them status and bring them into line with a wider cycle of English history (268). Edward III, according to the folio's ordering of history, would not only stand neatly prior to Richard II, but also feeds interestingly into the pattern of the second tetralogy, concluding with the victories of Henry V in France that evoke those of the Black Prince. ${ }^{65}$ Further, the inclusion of Edward III in the Shakespearean history cycle allows Shakespeare to dramatise the beginnings and conclusion of the Hundred Years' War, culminating in 1 Henry VI.

The reliance on univocality is not shared by the majority of scholars, but the same interest in unification of subject matter and authorial origin underpins much of the play's history. Eliot Slater and M.W.A. Smith have both also argued for the play's sole authorship, the former suggesting that there were two stages of composition which account for differences in style. ${ }^{66} \mathrm{~A}$ belief in Shakespeare's involvement has long accorded this anonymous history substantial attention, but the general consensus over Shakespeare's authorship of the "Countess scenes" must be contrasted with a widespread lack of agreement over the identity of Shakespeare's collaborator on the play. The positive identification of Shakespeare takes priority over other concerns: certainly, the willingness to include the play in Shakespearean series despite the

\footnotetext{
${ }^{65}$ See Ribner for a different connection between the play and the second tetralogy. He argues that "the Henry IV plays are 'education' plays in the manner of Edward III. They show us the process by which the ideal king is made" (168). His overwhelming focus on the Countess scenes in relation to Shakespeare's plays, however, betrays his bias towards the discussion of authorial links.

${ }^{66}$ Smith ("Authorship") takes issue with Slater's methodology, but is content to follow him in attributing the whole play to Shakespeare.
} 
majority share of an unknown collaborator suggests that what Bowers calls the "problems" of authorship have not forestalled criticism of Edward III as a Shakespearean history play.

Scholarly consensus generally attributes $1.1,2.1,2.2$ and 4.4 of Edward III to Shakespeare, the division advanced by E.K. Chambers, Facts and Problems (1930) and supported most firmly by Muir in "A Reconsideration" and Shakespeare as Collaborator ${ }^{67}$ As Sams rightly points out, there is an element of circularity to Muir's arguments: he begins with the assumption of this division between the "Shakespeare" and "non-Shakespeare" sections, and then goes on to demonstrate it using image clusters, but advances no evidence for the initial split (Edward III 154-56). Muir's approach is that of a literary critic, unqualified by statistical evidence or negative checks, but was influential in bringing an authoritative literary opinion to bear on an older argument advanced by several earlier disintegrators. ${ }^{68}$ While this remains the division of general consensus, including in the second edition of the Oxford Shakespeare, more recent attribution studies than Muir's have been less willing to treat the division with such confidence. ${ }^{69}$ M.W.A. Smith approaches the play as a whole within a very limited sample group (Edward II, 2 Henry VI, Richard III, Edmund Ironside) and uses Primary Component Analysis to demonstrate that the play's usage of function words corresponds roughly to Shakespeare's usage ("Edmund Ironside" 203-05). He does not comment on the fact that his figures for Marlowe also correspond closely to those of Shakespeare, therefore not allowing for more than a general statement of likeness. The resemblance of the play to Marlowe's style shall be returned to below.

\footnotetext{
${ }^{67}$ Act and scene divisions are taken from Melchiori's Cambridge edition.

${ }^{68}$ Tennyson, Ward, Fleay and Moorman were among the early critics content to attribute the play only partially to Shakespeare. See Muir, "Reconsideration" 39.

${ }^{69}$ The Oxford editors state "We believe, however, that Shakespeare was responsible only for Scene 2 [1.2 and 2.1 in Melchiori] (from the entrance of Edward III) and Scene 3 [2.2], and for Scene 12 [4.4] (which includes a Hamlet-like meditation on the inevitability of death), and possibly Scene 13 [4.5]" (Complete Works, $2^{\text {nd }}$ edition 257).
} 
Hope's excellent socio-linguistic study, which brings statistical research to bear on historical questions of language development, begins by treating the play as a whole, and then makes a seemingly arbitrary division between Acts 1 and 2 (his Part A) and 3-5 (Part B). His strongest indicator of Shakespeare's presence is a relatively low rate of standardised auxiliary "do" forms, and the count for Edward III of $84 \%$ across the whole play fits Shakespeare's profile, though again this is not sufficiently distinct from Shakespeare to generate full confidence. ${ }^{70}$ This test shows little differentiation between Parts A and B. However, a less reliable "relative marker" test allows Part B to show "observance of the 'who'/'which' personal/non-personal distinction, whereas acts 1 and 2 do not, albeit on a small sample" (136). The figures for Part A are a close match to Hope's Shakespeare sample. It must be stressed, however, that Hope's comparison groups are far from exhaustive, and that he is only attempting to establish likeness or not to the Shakespearean sample in this instance, so the tests cannot claim to be thoroughly cross-checked. ${ }^{71}$ They are, however, broadly indicative of a general likeness to Shakespeare's style, which is more marked in the earlier acts of the play, especially in 2.1. ${ }^{72}$ Elliott and Valenza's most recent work, however, is most confident in its ascription of 2.2 to Shakespeare, the only scene identified as such by both discrete and continuous analysis ("Two Tough Nuts"). They further argue that 4.5-9 are also very close to a Shakespearean profile and should be strongly considered. Finally, Watt's survey of the

\footnotetext{
${ }^{70}$ For full description of the "auxiliary 'do' test, see 11-26. For the "relative marker" test, see 2753.

${ }^{71}$ Hope's study was one of the last to involve manual, rather than computer-assisted, counting. As such, his comparison samples include only ten Shakespeare plays and five each for Fletcher, Marlowe, Dekker, Middleton and Massinger.

${ }^{72}$ Adjusting the figures in Hope's statistical appendix for use against the standard divisions of the play, it is notable that the scene which provides the most auxiliary dos (2.1, whose 139 uses almost double those of the scene with the next largest frequency, and therefore provide statistically the most reliable sample) has a percentage of regulated uses of only $77 \%$, one of the lowest in the play. The other scenes traditionally attributed to Shakespeare, however $(1.2,2.2$, 4.4) score respectively $91 \%, 90 \%$ and $85 \%$, which are among the higher frequencies. In combination, these scenes have an overall frequency of $83.5 \%$, which supports Hope's observation that auxiliary "do" evidence is not effective in discriminating sections of the play, even when different divisions are considered.
} 
attribution history of the play inexplicably ignores the question of the fourth act altogether, focusing entirely on the Countess scenes (Craig and Kinney 116-33). The Craig-Kinney team instead investigate two "distinct, self-contained episodes" (123): the Countess scenes (1.2-2.2) and the campaign against the French (3.1-4.4), the former of which is given to Shakespeare, the latter to an unidentified collaborator. It is disappointing that they do not provide a perspective on the standard divisions.

A consensus, then, suggests that Shakespeare had some involvement in the play, at least in the "Countess" scenes, a consensus significant enough to deem the play "Shakespearean," at least for the purposes of contemporary publishers. In a broader sense, the play sits neatly alongside the Shakespearean history cycles: it dramatises the beginnings of the Hundred Years' War that Shakespeare concluded in Henry VI, and it provides an obvious reference point for the frequent mentions of the Black Prince and earlier French wars in Shakespeare's second tetralogy. These are the broad areas of coherence which encourage an integrationist position on canonical acceptance; but here I am interested in the specifics of disintegration, particularly the still-disputed 4.4 where the authorship question remains unclear.

For Alexander Teetgen in 1875, neglect of Edward III and its Shakespearean connection was more than a mere oversight:

The suppression into the Kingdoms of Darkness of this masterpiece, King Edward III., for more than two centuries, is simply in its way a national scandal, blot, and reproach. I repeat, another of the Incredible Facts! one of the most ridiculous, futile, humiliating things in literary history. But, O Shakespeare! even in thy death thou teachest us lessons. What is Fame? - and merit? (17) 
For Teetgen, neglect of the play is not only a literary problem but a national one (the emphases are his), reflecting badly on Britain's treatment of its national poet. This is interestingly qualified by the widely held conjecture that it is Edward III referred to in a 1598 letter sent by George Nicolson, an agent of Elizabeth in Edinburgh, to Lord Burghley. "It is regrated to me in quiet sort that the comedians of London should in their play scorn the King and people of this land and wished that it may be speedily amended and stayed lest the worst sort getting understanding thereof should stir the King and country to anger thereat" (qtd. in Melchiori, Edward III 12). ${ }^{73}$ Nicolson's concerns about the play's disruptive impact on English-Scottish relations contrast with Teetgen's belief that the "masterpiece" has an important national role to play. It is of especial note, moreover, that the scene which "scorn[s] the King and people of this land" is 1.2, one of the Shakespearean scenes (although the Oxford editors, perhaps reluctant for Shakespeare to have caused offence, would have Shakespeare's contribution begin at Edward's entrance in 1.2, after the Scots have exited). Teetgen's assertion of Shakespeare's treatment of "fame" and "merit" is vague, but appears to refer rather to the patriotism and derring-do of the French wars, the majority of which is considered un-Shakespearean. However, the attribution of 4.4 to Shakespeare grants the Bard the most impressive and invigorating moment of national heroism, as the embattled Black Prince refuses quarter against overwhelming odds and steals himself for immortal fame at the cost of his own life. The sceptic might observe that the careful selection of scenes (1.2 from after the point at which mockery of the Scottish might have caused offence; the single most patriotic scene from the fourth act) is representative of the kind of piecemeal disintegration that Vickers rightly warns against in “Disintegrated" (2010),

\footnotetext{
${ }^{73}$ Melchiori remarks that, if the play was stayed in 1598 and never revived, then "by the time Heminges and Condell prepared the 1623 Folio they would hardly have remembered or thought of including, alongside the early histories and comedies which were still alive on the stage, a play which had totally disappeared from it a quarter of a century before (13)". This plausibly justifies the absence of this particular play on grounds more persuasive than simple collaboration.
} 
carefully choosing the bits of the play that most suit our prior conception of what Shakespeare "would" have written. Certainly Chambers's division appears subjective. "[The Shakespearean style] begins in i.2, not I think before I.94 [1.2.72 in Melchiori], and goes on to the end of Act ii ... Its literary quality is higher than that of the bulk of the play, and it makes a comparatively free use, about 12 per cent, of feminine endings" (Facts and Problems 516). He enigmatically notes a "constant habit of ringing the changes on individual words" and argues that "This feature is not apparent in the rest of the play, except in iv.4, and as this scene is also of better quality than the rest and again has a fairly large number of feminine endings, it may possibly be due to the hand of Act ii" (516). The relatively idiosyncratic addition of 4.4 here is accepted a priori by Muir, who includes it as Shakespearean in his comparison of frequencies of new words in sections $A$ and $B$; however, very few of his image clusters relate to this scene, and those that do are unconvincing: "the comparison of a face to a book" (Collaborator 44), which is commonplace; the collocation "double guild" (45) which is more closely matched in Heywood's The Brazen Age (1613); and two general resemblances of materials beating the sky (45) and an imploration not to fear death if we are running towards it anyway (47), both too vague to be convincing. Coupled with Elliott and Valenza's recent results that demonstrate an even stronger statistical unlikeness to Shakespeare's profile, I am inclined to agree that the case for 4.4 being written by Shakespeare is looking increasingly weak.

What do Shakespeare and the canon lose with the un-attribution of 4.4? This mid-length scene (162 lines) dramatises the plight of the besieged Prince Edward and Lord Audley, surrounded by overwhelming French forces. The two men describe the French manoeuvres that have left them outflanked, at which Edward takes courage, declaring that the mere ability to name them makes them beatable: "As many sands as these my hands can hold / Are but my handful of so many sands" (4.4.42-43). The Prince 
then defies three Heralds from the King of France (offering surrender), the Duke of Normandy (warning him to fly) and Prince Philip (who counsels him to absolve himself), who the Prince answers in like vein. As they prepare for battle, Audley delivers his great stoic defiance of death:

\author{
If then we hunt for death, why do we fear it? \\ If we fear it, why do we follow it? \\ If we do fear, how can we shun it? \\ If we do fear, with fear we do but aid \\ The thing we fear, to seize on us the sooner. (4.4.141-45)
}

which sentiments are then echoed and appropriated by Edward in the scene's closing lines:
Since for to live is but to seek to die, And dying but beginning of new life. Let come the hour when he that rules it will: To live or die I hold indifferent. (159-62)

The scene is dramatically dependent on its context, acting to set up the Black Prince's forthcoming triumph (which, of course, an early modern audience would have expected). It has its corollaries in the period, not least in the Shakespeare canon. The heroic, patriotic spirit of the St. Crispin's Day speech is here present, but the more private focus (two men, rather than a speech to troops) tips the balance towards the preparation for death rather than the exhortation to fame and victory. In this, a closer analogous scene is 4.6 of 1 Henry VI, a scene that more closely replicates the besieged situation but with no hope of victory. Stoicism is here compromised by Talbot's concern for his son's safety, setting up a (realised) expectation of pathos not present in the 
Edward III scene. These two scenes work closely in tandem here, offering piquant counters to one another. Edward's comfort drawn from Audley ("a thousand thousand armours / These words of thine have buckled on my back", 4.4.150-51) are inverted by John Talbot ("The sword of Orléans hath not made me smart: / These words of yours draw life-blood from my heart", 4.6.42-43). For one young hero, the older generation offers the necessary fortitude to pursue glory; for the other, his bravery is undercut by his father's faltering words and subsequent desperate charge. ${ }^{74}$

Edward's bravery lacks irony. The scene offers a sincere account of courage under duress, the newly knighted Prince discovering mature fortitude in the face of death. His triple defiance of French condescension (reminiscent of Henry $V$, which demonstrates its debt to this scene in 1.2 and Henry's encounters with Montjoy) perhaps best epitomises the "merit" Teetgen found exemplified in the play, countering the taunts with unfaltering wit and nerve. The rejoinders, though, follow an obviously neat rhetorical patterning, seizing on the physical offers and rearticulating them within his own equally-weighted assertion. The first Herald's ten lines playing on a conceit of bloody colours being withdrawn to spare English blood are answered with ten lines urging the redness of Edward's own army and courage; the Second Herald's six lines delivering a horse are answered with six in which the horse is re-gifted to Normandy; and the Third Herald's nine lines offering a prayer-book are countered with thirteen in which the book is re-offered, and Edward begins a new digression in his ninth line harping on the reciprocity of the two Princes' prayers. With the rejoinders delivered in a rhetorical game, Edward becomes more type than character, playing out the idealisation of chivalric and patriotic virtue that Talbot's lament for John's death renders hollow following the equivalent scene in 1 Henry VI.

${ }^{74}$ Compare also Henry V, where Westmorland takes comfort from Henry (4.3.74-79). 
These two "Shakespearean" scenes inform on one another, and have both been isolated by attribution scholars on account of the differences that distinguish them from the surrounding text. Yet these same attribution studies also underline differences between the two passages. This scene of 1 Henry VI is attributed by Vickers to Nashe ("Incomplete Shakespeare" 341-43), and the features he picks out as distinctively unShakespearean are not shared by the Edward III scene. ${ }^{75}$ The links between the passages do not suggest correspondence of authorship, but the application of the tools of attribution studies here alerts readers to the linguistic distinctiveness of these two passages within the plays they are drawn from.

The question of Shakespeare's collaborator on Edward III must enter at this point. The strongest claims remain for Marlowe (as advanced especially by Merriam) and Kyd (Vickers). Interestingly, both Merriam and Vickers are willing to accept an overwhelming number of shared collocations between the play and Tamburlaine, but differ in their interpretation. Vickers's claim is that Tamburlaine needs to be discounted from results as it has too wide and pervasive an influence on the drama of the subsequent decade; Merriam believes that this discounting is overly presumptive and may be indicative of authorship, arguing that Spanish Tragedy (with the next largest number of shared collocations) might justifiably be discounted on similar grounds ("Marlowe versus Kyd" 549). The idea that Marlowe collaborated with Shakespeare (a theory also advanced by Craig and Kinney for 1 and 2 Henry VI) appeals additionally to advocates of a neat ordering of history according to dramatic canons. Edward III links Marlowe and Shakespeare's canons chronologically and, more specifically, bridges their respective treatments of Edward II and Richard II. The tying together of English history and English "historians" in this way serves to preserve not the unity of the author

\footnotetext{
75 These include rhyming couplets, the use of "thou" to a superior, the heavy use of alliteration and polysyllables.
} 
(whose authority has survived the integration of collaborators), but the unity of English history as dramatised by our leading cultural figures. It treats history as an ordered, preconceived narrative that reinforces conservative values and voices them from a standpoint of recognised moral authority. ${ }^{76}$ Regardless of authorship, however, the influence of Marlowe and Kyd indisputably hangs heavily over Edward III in the use of declamation, rhetoric and, particularly in 4.4 , attention to the empowering force of the courageous underdog.

The scene may certainly be considered Shakespearean, particularly as it serves the nationalistic appropriation voiced by Teetgen. This does not equate to it necessarily being by Shakespeare. The rhetorical patterning, the situation of heroic defiance against overwhelming odds, the preparation for death and the description of the battle to this point are typical of the history plays of the early 1590 s, which operated in a register of grandstanding declamation under the influence of Tamburlaine. The scene's resonance with Shakespeare is, first and foremost, a resonance of genre and period. To mistake this for authorial idiosyncrasy is to deny the value of the scene in pointing up the erosion of the boundaries between authorial styles. In this context, Edward's own final ambivalence about the author ("he that rules" of his fate, which "I hold indifferent", 4.4.161-62), calls to mind the closing remark of Foucault's treatment of authorship: "behind all these questions, we would hear hardly anything but the stirring of an indifference: What difference does it make who is speaking?" (120). Where Foucault's indifference is realised as a textual shrug, however, Edward's galvanises him to successful action against his enemies. To suspend the attribution question of 4.4 is not to avoid the issue, but rather to loosen the critical frameworks that impose limitations

\footnotetext{
${ }^{76}$ See Tillyard, who offers the most influential statement of the chronicle histories as representative of an Elizabethan world order. He argues that Edward III, Woodstock, Oldcastle and Thomas More share these interests, but assumes that this is indicative of Shakespeare's influence on the wider drama (106-24).
} 
on interpretation, freeing the scene to actively engage with these multiple surrounding contexts.

\section{Conclusions}

The author, with the resilience of the Black Prince, has survived the assaults of post-structuralist thought. As I shall discuss in the next chapter, the author remains the governing principle by which the early modern drama is organised, and the ever more sophisticated work of attribution scholars has demonstrated convincingly the distinct traces of historical individuals within the text. More important, however, is the light shed by these studies on the nature of the collaborative partnerships that were engaged in by living, embodied writers. To use Weimann's formulation, "the institution of [authorial] agency is vital, even though it must not be conceived as a source of anything autonomous" (15). The crisis facing authorship studies is not whether the pursuit of authorial identities is a valid course of research - for, despite the theoretical arguments of Masten et al., a practical and historical study of the period demands that we do acknowledge the presence of dramatists - but how we then use that knowledge. Authorship research assumes authorship study, the concern with how an identified author or authors wrote, even if that author is "Anonymous". For many areas of literary criticism, particularly those concerned with the use of language, this remains a key element of study, and the partition of authorial segments has purpose.

As I hope I have demonstrated with 4.4 of Edward III, however, the attribution of specific sections need not be a necessary precursor to all forms of study. Whether or not this scene was written by Shakespeare, Marlowe, Kyd or another does not impact significantly on discussion of the scene in relation to the rest of the play, or to its corollaries in the drama of the day. Further, the insistence on authorial attribution becomes a limiting factor, tying the scene down to one paradigm of authorship and 
implicitly partitioning it away from its more significant frames of reference. As Kastan puts it:

If we must, of course, grant that the author is a historical agent and no mere instrument or effect of a linguistic order, we must also recognise that the author is not autonomous and sovereign, neither the solitary source nor the sole proprietor of the meanings that circulate through the text. This is not to dismiss or denigrate the claims of authorship, only to observe that the act of writing is inevitably fettered and circumscribed. (Shakespeare after Theory 32-33)

Coupled with the levels of uncertainty that attribution scholars must accept, as in the cases of More and Locrine, it becomes clear that the integration of attribution studies with literary scholarship is dependent on recognition of the utility of its results within a broader discursive study of the drama. That is to say, if we insist on isolating and analysing small sections of text such as Hand D, W.S.'s contribution to Locrine, Scene 8 of Arden and 4.4 of Edward III, we must recognise that their "restitution" is only useful insofar as it allows them to be productively reintegrated into their historical contexts, rather than segregated into authorial canons. The identification of authors assists in the reconstruction of the conditions of authorship, the physical and literal manifestations of the networks of discursivity this thesis has been discussing. As Weimann suggests, "once the agency of playwriting is reconstructed as an important component of a larger nexus of socio-cultural and economic relations, this agency is neither totally determined nor altogether autonomous in collaborating with, or dissenting from a given set of institutional circumstances" (39). This allows critics to visualise the active methods of writerly collaboration between named individuals, as in Vickers's work, and to extend our understanding of the multiple and complex ways in which a writer may influence a 
work, as in Kastan's formulation. It also permits arguments for a deeper and more embedded form of collaboration, as the identification of Beaumont and Fletcher as cowriters/collaborators allows Masten to envisage. An understanding of the physical and mental processes that went into the creation of a social text, including its author(s), necessarily contributes to the appreciation of both text and context.

If the value of attribution studies is in opening up further possibilities and questions, rather than in attempting to solve "problems", then literary critics need to develop the necessary skill sets to be able to properly critique it. However, it remains necessary to sever the productive use of authorship studies from the single focus on the author for authorship's sake. Elliott confidently remarks that "The area [of Shakespearean authorship] still in dispute is smaller, and the disputes more tightly defined than before" ("Language"). If the study tends towards narrowness and finality, towards an "end", then it can only by definition be of limited value. Work such as that of Jowett on Timon, McMullan on Love's Cure and Boyd on Titus, however, has demonstrated the potential of authorship studies to open up further grounds of inquiry, and this chapter has argued that this can serve, rather than stigmatise, the apocryphal plays. Now, however, it is the implicit "end" of authorship studies as a limiting discipline to which I shall turn: the constitution and presentation of the Canon. 


\section{Chapter Four: Apocryphising the Canon}

Tonight we are going to attempt a feat which we believe to be unprecedented in the history of theatre. That is, to capture, in a single theatrical experience, the magic, the genius, the towering grandeur of 'The Complete Works of William Shakespeare.' Now we have a lot to get through tonight...

- Reduced Shakespeare Company, The Compleat Works of WIIm Shakspr (abridged) 2.

In 2010, the scholarly question of the constitution of the "Complete Works" of Shakespeare became international news. The decision of the Arden Shakespeare to add Brean Hammond's edition of Double Falsehood to its ongoing third series caused outrage on both sides of the Atlantic. Ron Rosenbaum, posing as the "Shakespeare Cop", is typical in his denouncement of this "Shakespeare fraud". With journalistic invective, he accused Arden of diminishing Shakespeare: “This move is 'brand extension' that demonstrates yet another triumph of marketing over art. And one that will have lasting - and unfortunate - consequences for the reputations of both Arden and, alas, Shakespeare as well" ("The Double Falsehood"). Once more, as for Pope, the very notion of what Shakespeare is has come under threat.

The inclusion of the play, which has no prior editorial history as part of a Shakespeare series, will mean that Arden's version of the Shakespeare dramatic canon will eventually include forty-one plays (not counting Thompson and Taylor's supplementary volume of variant Hamlet texts). Rosenbaum's article raises important questions about canonical constitution, reacting against the notion that the last word on defining "Shakespeare" rests in the hands of publishers who decide what can be 
legitimately sold as Shakespeare. In the last two years Double Falsehood has, in this sense at least, become canonical.

Rosenbaum has an explicit agenda of quality control that prompts him to try to defend the sanctity of the canon against this "profoundly worthless, virtually incoherent play" ("The Double Falsehood"). I suggest, however, that the entry of Double Falsehood into the Arden Shakespeare instead gives us the opportunity to "apocryphise" the idea of the fixed canon. For if the OED definition of Apocrypha, as explored in Chapter One, describes texts "having no well-grounded claim to inspired authorship" ("Apocrypha, n.," def. 1a), then this chapter will argue that the modern Shakespeare canon itself has no well-grounded claim to "inspired" authorship. The canon is a posthumous construction that is contingent, not on absolute principles of authoritative inclusion, but on criteria specific to the time and context of its various manifestations. Munro argues that it is paradoxical that "the study of Elizabethan and Jacobean drama has been so often organised around dramatists, whose control over their texts was limited and local" (12). One of the effects of this limited control is that, while Shakespeare may have written plays, he did not author(ise) a "complete works." ${ }^{1}$ Posterity does not allow even a selfcanonising dramatist such as Jonson to dictate his own legacy: despite his exclusion of The Case is Altered and Eastward Ho from his seventeenth-century folios, both plays are included in all recent editions of his works.

As discussed in my Introduction, Jansohn, Proudfoot and Jowett have all called for the breakdown of the Canon-Apocrypha dichotomy, and previous chapters have demonstated the ways in which book history, repertory history and attribution theory all

\footnotetext{
${ }^{1}$ See Erne, Literary Dramatist for an alternative view, however. He explains the drop in publication of Shakespearean quartos after 1600 by suggesting that he and his company were already thinking about a collection (114). Cheney (Literary Authorship) and Knapp (Shakespeare Only) similarly argue for Shakespeare's vested interest in his own printed appearances. The arguments of these scholars offer useful correctives to purely theatrical views of Shakespeare's work. However, for the purposes of my argument here, the point is that there is no evidence of Shakespeare approving his literary legacy.
} 
resist the imposition of firm divisions between the established and the disputed plays.

However, it is insufficient to merely theorise away the distinction. The division has been historically and commercially reinforced by material formations of the Shakespeare canon, which resist dissolution. It is here that the "in" or "out" absolutism of attribution scholarship is most significantly realised. The material form of the canonical object, most obviously the "Complete Works" volume, acts as a physical embodiment of the compiler's assertion of canonical authenticity. This object then takes on a commercial function in the marketplace that disseminates and claims value for that manifestation of the canon. It is in commercial circulation, not literary criticism, that Shakespeare and his canon acquire their cultural capital.

The importance of material considerations is apparent in the history of The Two Noble Kinsmen, the only play from Brooke's Apocrypha which has since progressed to canonical status. Despite near-universal scholarly acknowledgement of the accuracy of the 1634 quarto title page, however, it remains marginalised owing to its more dubious position at key moments of commercial canonisation. ${ }^{2}$ It was omitted from the only "complete" collection of Shakespeare films, the BBC-Time Life Shakespeare, which is a significant pedagogic resource, particularly in areas with less access to live theatre. It is currently unavailable as a single edition in the New Cambridge Shakespeare, the RSC Shakespeare and several non-scholarly series, and the modern RSC has granted it only one full production in its fifty-year history. In many important senses, despite the presence of the play in most major editions of the Complete Works, for many communities The Two Noble Kinsmen is not a conscious component of "Shakespeare."

\footnotetext{
2 "Written by the memorable worthies of their time; Mr. lohn Fletcher, and Mr. William Shakspeare. Gent." (Title page). See Vickers, Co-Author (402-32) and Potter 16-34 for the play's attribution history.

${ }^{3}$ The latent bias against even The Two Noble Kinsmen is implicit in the plethora of casual/accidental references to a thirty-seven play canon in academic and public articles. For two recent examples see Bristol, who begins "If I were to say 'Shakespeare is the author of all thirty-
} 
Much work has been carried out on the mechanisms of canon-formation. For Frank Kermode, speaking of the classics (which he at one point defines as "old books which people still read", 43), the value of the texts which enter the canon is in their ability to be reinterpreted by successive generations: "The books we call classics possess intrinsic qualities that endure, but possess also an openness to accommodation which keeps them alive under endlessly varying dispositions" (44). It is the mechanisms that "keep texts alive" that are vital to this chapter, for which wider theoretical arguments about the nature of canon offer a useful language. Kermode's formulation, which follows T.S. Eliot's 1944 lecture "What is a Classic?", considers the process of canonisation as a literary and interpretative activity. He argues that "the survival of the classic must therefore depend upon its possession of a surplus of signifier" (140), locating value in posthumously (re)generated readerly interpretations as well as in the text itself. However, Kermode's perspective still relies on aspects of ambiguity and openness embedded within the text itself. Jan Gorak takes a different stance, arguing that the canon survives "only by virtue of institutional control and sponsorship" (3). This control is supported by what Jane Tompkins describes as "the machinery of publishing and reviewing" (qtd. in Gorak 3) and by a conservative educational system, as explored by John Guillory in Cultural Capital. A complex relationship therefore governs the dissemination and reproduction of works deemed to embody significant "cultural capital". In the language of attribution study, there are the "internal" factors, the perceived aesthetic, political, religious, historical and critical merit of the text itself, and the "external" factors, the physical availability, accessibility and marketability of books.

seven [sic] plays in the collected edition known as the First Folio,' what question would I be asking?" (122), and West, who notes "The Folio contains 36 plays, that is, all of the traditionally accepted dramatic works of Shakespeare, except Pericles" (71). The "Globe to Globe 2012" festival at Shakespeare's Globe in 2012 which "will present every one of Shakespeare's plays in a different language over six weeks" will likewise only include thirty-seven plays ("Globe to Globe"). 
The reassertion of the value of the Apocrypha on internal grounds, as discussed in previous chapters, therefore needs to be accompanied by the material rehabilitation of the plays. As Kermode remarks:

There are, to speak very broadly, two ways of maintaining a classic, of establishing its access to a modern mind. The first of these depends on philology and historiography - it asks what the classic meant to its author and his best readers, and may still mean to those who have the necessary knowledge and skill. The second is the method of accommodation, by which I mean any method by which the old document may be induced to signify what it cannot be said to have expressly stated. (40)

Accommodation requires availability and accessibility. A play needs to be readable in order to be read and reinterpreted, or performed in order to be seen and heard. This chapter is therefore interested in the mechanisms by which the Apocrypha can be accommodated to the early twenty-first century. With the concept of canon itself being interrogated and attacked, new value is being found in non-classic texts, repositioning the established canon as a marker of historical value that serves as both a standard of historical value and a target for deconstruction. Grouping apocryphal plays alongside familiar plays within different material formations of the Shakespeare canon fundamentally affects the possibilities for interpretation, and offers potential for the cultural and commercial reappraisal of the plays. This is not to pursue a political agenda of representation for representation's sake, a formula that Guillory argues is reductive when not socially contextualised (8). Contemporary canon theory is inevitably political in its interrogation of the institutional processes of "exclusion" and "selection" that act according to institutional values and exclude the writing of minority groups (Guillory 6). 
However, the principles within which the canons of early modern dramatists are made "complete" in the early twenty-first century have ostensibly abandoned subjective aesthetic selection in favour of theoretically objective criteria for selection/exclusion. The very different constitutions of available canons demonstrate that there are several different sets of criteria in use. Shakespeare and the mechanisms through which we determine what qualifies as Shakespeare are in a state of flux.

This chapter is interested in specific manifestations of canon and how the disputed plays fit into them. A disinterested push towards theoretical consistency in canon construction within multiple paradigms of authorship serves to make transparent the social and material contexts within which Shakespeare's works need to be read and understood. As Gorak argues, there is a "need for some version of a canon in order to transmit to the next generation works of cultural value and to show the interrelationships between valued works" (8). I suggest that multiple versions of canon act both to destabilise Shakespeare's exceptional cultural authority and to offer choice to readers and audiences, expanding the kinds of interrelationship made available.

The key obstacle to multiplicity is the word "complete". As in this chapter's epigraph, which comically punctures the grandeur of the promise of completeness, the concept is fundamentally quixotic. Within the governing frameworks of cultural capital, "completeness" instead functions as a consumer-targeted marketing device that makes claims of finality and imposes limits on the commodity it markets. This is a position particularly challenged by Masten in reference to the decision of several editions to include only Hand D of Thomas More:

More, already excluded in the Longman edition because "Shakespeare's contribution to it is fragmentary," is in the other editions made incomplete (is editorially incompleted) in order to produce a Works that 
is Complete. Though it does not exist incompletely (McMillin and Gabrieli/Melchiori argue that the play is complete and performable), More is nevertheless presented as a less-than-complete work - no work, in the conventional sense of the term, because not completed by Shakespeare, or not completely by Shakespeare. ("More or Less" 110)

Masten forces us to question our definition of completeness, as completeness here requires excerption and exclusion. Even without cherry-picking disintegrated sections of text, the idea of a Complete Works acts to excerpt certain plays from the repertory within which they were bibliographically and historically integrated. As More becomes incomplete in the push towards completeness, so too does Shakespeare's Complete Works become simultaneously incomplete through its decontextualisation.

The case of Double Falsehood is a live and ongoing example of the processes of canonisation, and I shall return to it throughout this chapter. Alongside this, I will address in turn the three most important current paradigms of authorial canon and a recent specific manifestation of each. The notion of bibliographic authorship (The Complete Books Attributed to William Shakespeare) is exemplified by Bate and Rasmussen's William Shakespeare: Complete Works for the Royal Shakespeare Company/Modern Library. The canon of individual authorship (The Complete Works to Which William Shakespeare Contributed Some Part) has recently been provocatively disturbed by Taylor and Lavagnino's Thomas Middleton: Collected Works for Oxford UP. Finally, the performative canon (what I shall define as the "Shakespeare Repertoire") was made available to scrutiny by the Royal Shakespeare Company's Complete Works Festival of 2006-07. It is in the disjunct between the theoretical potential of each paradigm and its practical compromise in the search for completeness that the 
apocryphal plays become displaced. By reappraising the "Complete Shakespeare", however, it becomes clear that there is ample space for the plays to be accommodated.

\section{The [Bibliographic] Complete Works of Shakespeare}

Over the last twenty years, a reevaluation of the importance of material books has given us a vastly improved sense of how Shakespeare was read and interpreted by his contemporaries. ${ }^{4}$ Yet in imagining how Shakespeare's contemporaries read Shakespeare, we must also understand what the available "complete" Shakespeare consisted of. As discussed in Chapter One, Shakespeare's book presence consisted of some thirty volumes of plays and poems by 1622 , split between works now considered authentic and dubious. This mix of authentic and spurious plays is reflected in Pavier's aborted collection of 1619 , which Massai argues was deliberately designed to look like a "nonce" collection (116), and in the c.1631 anthology in the library of Charles I, as well as in the influential decision by Philip Chetwind to add seven plays to the 1664 folio.

The rise of post-structuralist theory and the New Textualism has deeply affected editorial practice relating to Shakespeare over the last twenty years. The orthodoxies of the New Bibliography (narratives of original copy, textual corruption, a genealogy of copy) have been systematically re-evaluated and largely countered by a new materialist focus that prizes physical manifestations of the text over essentialist notions of the work. ${ }^{5}$ This has been supported by a growing belief in Shakespeare as a revising dramatist, which has resulted, particularly in the cases of King Lear and Hamlet, in variant texts being treated as different authoritative versions of the same play, rather

\footnotetext{
${ }^{4}$ In addition to the work of Erne, Cheney et al. on Shakespeare as a literary author, Massai's work on reader-collated collections and the annotating reader in Rise of the Editor is of particular importance. See also Sherman, Used Books and Stallybrass and Chartier.

${ }^{5}$ On the New Textualism, see Orgel, Authentic Shakespeare 1-20, Marcus, Unediting, Erne and Kinnie 1-17, and especially de Grazia and Stallybrass, which makes a seminal case against the notion of an "original" text. Kastan argues that a materialist focus offers the most productive intersection between literary theory and history (Shakespeare After Theory 17-36).
} 
than as corruptions of a lost original. ${ }^{6}$ These shifts in theoretical priorities have been realised in editorial practice in series such as the "Shakespearean Originals" and the New Cambridge Shakespeare Early Quartos, which have been instrumental in bringing these textual manifestations back into mainstream discussion. ${ }^{7}$ Multiple-text versions of Lear and Hamlet have been published respectively by Oxford and Arden.

A plurality of texts, however, inevitably causes problems in achieving the goal of completeness. Knight argues that the fundamental principle of editing is "that not a line which appears to have been by Shakespeare ought to be lost" (qtd. in Kastan, "The Mechanics of Culture" 32). However, Orgel points out "even when we have the Really Complete Works, how complete are the plays and poems themselves? Surely the impulse to conflate quarto and folio texts ... springs from a conviction that none of the individual texts is complete" ("Desire and Pursuit" 292-93). Orgel follows this by addressing lacunae of plot and history, and draws attention to textual variant lists as a means of tending towards completion. I wish, however, to address the more fundamental question he implies: how, within a materialist paradigm that accepts variant versions of plays, can one edit a bibliographically "complete" works?

The only single volume Complete Works that is theoretically constructed on principles of material bibliography is Bate and Rasmussen's 2007 edition for the RSC, entitled William Shakespeare: Complete Works. This edition, following the ethos of edition-based editing, prioritises the 1623 folio as a material book: it begins with a physical moment of textual incarnation rather than a hypothesised moment of textual

\footnotetext{
${ }^{6}$ Taylor and Warren's Division of the Kingdoms (1983) was a significant early statement in the "revisionist" movement, and remains influential. More recently, it has been pointed out that the theory of revision is in many ways still more orthodox than its proponents have suggested, maintaining the spectre of individual authorial control over the text in ways which materialist editorial theory has questioned. See Werstine, "End of Editing" 50-51 and Massai, Rise of the Editor 150-51.

${ }^{7}$ See Holderness and Loughrey for an illuminating and provocative defence of the maligned "Shakespearean Originals" project, that particularly focuses on the marketing of the series (393418).
} 
origin. While the core objective of edition-based editing, the retention of the distinctive features of an early authoritative manifestation of the text, is not new in itself, the edition's innovation is in applying it to an early anthology. In a very real sense, this is the first Complete Works of Shakespeare to explicitly model itself upon an early modern manifestation of a "Complete Works of Shakespeare." ${ }^{8}$

The authority accorded to the text by edition-based editing is heightened in this instance by the unparalleled cultural authority accorded Shakespeare's 1623 folio. One of the most studied volumes in the English language, the "First Folio" has become a symbol of cultural and artistic value. ${ }^{9}$ Its relative rarity and the prestige of its presentation contributed to the rise of Shakespeare in the popular mind as a paragon of culture. The market value for copies is a seven-figure sum, and the organisation of holdings into prestigious libraries (the Folger, the Bodleian, the Shakespeare Birthplace Trust, the British Library) has allowed those locations to become devotional shrines for textual pilgrims. ${ }^{10}$ Textual authority and cultural authority are bound together in a material artefact, an authority drawn on by the RSC Shakespeare. The edition's website features a series of introductory videos to the book, hosted by the RSC's Chief Associate Director Gregory Doran at the Shakespeare Centre Library in Stratford-upon-Avon. He sits before windows through which the Shakespeare Birthplace is clearly visible, with the library's copy of the folio before him (Doran, "First Folio"). The barrage of visual associations casts the folio as an object of veneration while simultaneously rendering it accessible to the viewer. In turn, the RSC edition is implicitly authorised as a proxy for

\footnotetext{
${ }^{8}$ See Bate, "The Case for the Folio" for discussion of precedents for editions based primarily on the folio, which are invariably less rigorous in their principles and choose folio for reasons of preference rather than ideology.

${ }^{9}$ West gives a concise introduction to the folio's reception. Taylor argues that this value was encoded in the play's original authenticating strategies ("Making Meaning"). See also Mowat, "Constructing", and Kastan, Shakespeare and the Book, especially 69-78 on the volume's prefatory materials).

${ }^{10}$ These shrines are the main stages in J.L. Carrell's popular novel The Shakespeare Secret, which features a killer who is bent on destroying Shakespeare folios, while also attempting to recover the manuscript of the lost Cardenio which will reveal the "truth" of Shakespeare's real identity.
} 
the original artefact handled by Doran. The authorisation operates in both directions, as Doran's physical association with the volume presents the authority of the RSC itself deriving from the "First Folio." Michael Boyd, Artistic Director of the company, asks us in the edition's Foreword (positioned, along with a collection of performance photographs, in the space occupied in the 1623 folio by the list of principal actors) to "Trust the Foliobased text as being as close as we can get to the favoured draft of Shakespeare's original acting company. And trust the author" $(64) .{ }^{11}$ Thus, the material book is reconfigured as a manifestation of both collaborative theatrical and individual authorial authority, acknowledging the compromise involved in terms of "authenticity" (it is "as close as we can get") and diverting attention back to the textual evidence.

The excellent work of the RSC Shakespeare as an experiment in edition-based editing applied to a compendium is undermined, however, by its choice of title: William Shakespeare: Complete Works. This is the same title shared by most editions of the complete works, including Oxford's. The shorthand of "The Oxford Shakespeare" and "The RSC Shakespeare" not only usefully distinguishes between the two editions, but draws attention to the fact that the authenticating institutions of both contrast markedly with the editions' guiding principles. Oxford is authorised by an established University Press, yet aims to recreate a moment of original performance; while RSC is authorised by a theatre company, but roots its authority in a specific and material printed book. In the case of the latter, it is at odds with the edition's source. As Jowett points out, "the words 'William Shakespeare' and 'Complete Works' appear in an early modern typeface; the words are not reproduced from the Folio itself, where the expression 'Complete Works' is nowhere used" ("Editions" 396). While the volume may

\footnotetext{
${ }^{11}$ Jowett notes that the "trust" of directors in the folio is part of a tradition in the theatre world that suggests folio punctuation is deliberately designed with actors in mind. He dismisses this as "the surface manifestation of a reverence for the Folio that reflects the emotional need for real authorial presence that textual scholars insist is simply not available to us" ("Editions" 402).
} 
imply completeness in the prestige of its presentation, it is nominally only a collection of Comedies, Histories and Tragedies. "Completeness" is thus a newly-added aspect of the RSC Shakespeare, bringing the edition into line with commercial competitors and conflating two different paradigms of completeness, the bibliographic and the authorial. As a result, the non-folio works occupy a liminal position in the book, "appended at the end" (Bate, "The Case for the Folio" 49), much as the 1664 folio added seven plays as an apparent afterthought. Following the core thirty-six plays, the editors add Pericles, The Two Noble Kinsmen and the poems in a double-column layout, cramped and more difficult to read in comparison with the luxurious single column of the earlier plays. ${ }^{12} \mathrm{~A}$ transcription and edited version of Hand D's contribution to Thomas More is also included, though not the remainder of the play, contrasting with the decision of the Oxford Shakespeare to include the entire play in its second edition. Finally, although not included in the physical volume, the edition's website also presents edited versions of possibly Shakespearean scenes from Arden of Faversham (Mosby and Alice's quarrel) and Edward III (the Countess scenes).

Within a "Complete First Folio Plays" volume, there is no place for established "Shakespearean" plays such as Pericles or The Two Noble Kinsmen, let alone the Apocrypha. Where their omission would make a clear distinction on objective principles, their inclusion in a subordinate format preserves an outdated hierarchy of texts that implicitly presents non-folio texts as secondary to the core thirty-six plays. ${ }^{13}$ This is the necessary compromise occasioned by the commercial imperative of completeness.

\footnotetext{
${ }^{12}$ Although the Introduction justifies this as "a deliberate inversion of the original distinction whereby Quartos were single column and Folio double" (57).

${ }^{13}$ A different, and interesting, implicit hierarchy is preserved in the single editions of the series, from which The Two Noble Kinsmen is excluded. Several folio plays are grouped together in formats that suggest a hierarchy even within the main thirty-six. The Henry VI plays share a volume on account of their continuous storyline; the two collaborative classical plays, Timon and Titus, share a volume; and, more problematically, the collaborative Henry VIII is grouped with King John, a decision that more tenuously pairs the two stand-alone history plays. While some justification can be made, the groupings are obviously designed to increase the selling potential of the less commercially successful plays.
} 
Exhaustiveness competes against theoretical principles that would result in an "incomplete" book. The apocryphal plays are the casualties of this compromise, marginalised here in direct relation to the "authentic" canon in a visibly fragmented, disintegrated and uncontextualised state.

Yet while this compromise is far from ideal, Bate and Rasmussen's choices still offer an alternative set of principles for presenting the canon. The problem of "completeness" is the ideological uniformity that it imposes on a non-uniform collection of texts, eliding important historical and material distinctions between the objects being edited. As editorial theory pushes towards a plurality of canonical models for the early modern drama, arguments over constitution risk becoming subjective and idiosyncratic. The prioritisation of one recent attribution argument over another, or the choice of plays to be included in an open-ended series such as the Revels Plays or Arden Early Modern Drama, comes down to editorial preference. Bate and Rasmussen's clear distinction within their volume between folio and non-folio plays, however, offers an absolute and empirical division based on bibliographic principles, distinguishing the plays included in one particularly authoritative manifestation of canon. Within a consistent materialist paradigm, the RSC Shakespeare offers the potential for a fresh understanding of the Shakespearean corpus based not on attribution studies but on the historical principle of what "Shakespeare" was available to early modern readers.

A Complete Works of Shakespeare based on historical bibliographic principles would include the thirty-six plays of the 1623 folio, Pericles, The Two Noble Kinsmen, the sonnets and poems. It might also include The London Prodigal, A Yorkshire Tragedy, 1 Sir John Oldcastle, The Troublesome Reign of King John and perhaps The Birth of Merlin, depending on the editor's choice of cut-off date. This model obviously causes problems according to a modern commercial sense of what the Shakespeare canon should be. 
Bate and Rasmussen's model provides a practical means of dealing with this through the adoption of different presentational layouts. What we are left with, then, is a canon and sub-canon, the constitution of which are decided upon objective and clearly defined criteria, fixing a model for study that is not dependent on attribution studies or aesthetic preferences. The implicit hierarchical distinction remains a problem, but the distinction can be better justified.

This formation of canon further allows for multiple possibilities according to editorial guidelines. A different permutation of the canon might organise the plays into those available in Shakespeare's lifetime and those attributed posthumously, creating a canon in two stages along the lines of the early Jonson or Beaumont-Fletcher folios. Other groupings might feature adaptations, "implied" Shakespeare texts (Locrine, Cromwell, Puritan), frequently reprinted plays and so on. Shakespeare's bibliographic history, which includes the reception of Shakespeare by early modern readers, can thus be reconstructed in a number of different ways according to the research interests of the compiler, creating a "complete" Shakespeare that operates within a strictly-limited, but empirically defined, framework.

The plurality of potential canons is perhaps better realised in multi-volume series than in a single-volume "Complete Works". As noted, the RSC Complete Works shares its title with all other major single volume editions, despite its very different remit. Where the RSC Shakespeare aims to recover a textual moment, the Oxford Complete Works aims to recover a performative moment, the text in the form staged by the company. ${ }^{14}$ The Arden Complete Works simply compiles the most recent texts from the single-volume series, creating a composite and eclectic compendium of editorial

\footnotetext{
${ }^{14}$ See Bevington for a judicious and useful summary of the conflicts between editorial agency and the moment of re-creation in the Oxford edition ("Determining the Indeterminate", esp. 502-03 on Bevington's own dispute with the editors over the renaming of Falstaff as "Oldcastle").
} 
work conducted over half a century by scholars working in a variety of fields with different agendas and approaches. ${ }^{15}$ It is perhaps Arden that best illustrates the fallacy of a "Complete" works; its mixture of second and third series texts has already been updated once to take into account more recent texts, and until the third series is itself brought to its conclusion, the "Complete" volume remains a compromised patchwork; a complete works, but an incomplete project.

It is the attempt to fix a moment of completeness that necessitates this compromise. Publishing constraints and deadlines impose the need for selectivity even as an edition strives towards completeness. Wells and Taylor ("Re-viewed") discuss the role of publishers in deciding to omit the unpopular Edward III from the first edition of the Oxford Shakespeare, a decision that was overturned twenty years later by a shift in the critical climate towards the acceptance of the play. The sceptic may note, however, that the inclusion of a new play was of no small weight in persuading readers to purchase the edition again (see Jansohn, "Reconsideration" 323-25). The Arden Complete Works will similarly update itself, with a third edition in 2011 bringing together the most recent texts including Double Falsehood. In comparison, the edition-based single volume model maintains stability by preserving an historical moment of textual completeness.

Multi-volume series are, however, far more flexible to the kind of dynamic canonising and book-based editing that the paradigm requires. Importantly, here, the titles of individual series no longer promise completeness. "The Arden Shakespeare", "The New Cambridge Shakespeare" and "The Oxford Shakespeare" are still in direct competition but have distinct identities, allowing them to pursue different approaches to Shakespeare. This is most obvious in constitution, with each series made up of

\footnotetext{
${ }^{15}$ At the extremes, and located consecutively within the volume, are Gordon McMullan's text of Henry VIII (2000) and E.A.J. Honigmann's King John (1951).
} 
different works. ${ }^{16}$ The choice of texts also varies: Oxford's Pericles includes the "reconstructed" text of Jackson and Taylor, Gossett edits a conservative version of the first quarto for Arden, and the Cambridge editors, in a spirit of increasingly isolated defiance, claim the whole play for Shakespeare alone and edit it prudently. ${ }^{17}$ Lear is produced in a conflated text for Arden, Cambridge print two separate editions based on folio and quarto, Oxford compromises its two-text practice in the Complete Works and produces a single text based on the quarto, and the RSC Shakespeare single edition copies the parent volume in following folio. The Arden Hamlet appears in no fewer than three texts, as opposed to the single-text editions of the other series. Each series has an identity, a governing remit and the potential for expansion within that remit, hence Cambridge's pioneering Early Quartos series and the extra plays introduced by Arden.

Proudfoot, one of Arden's general editors, oddly suggests that it is a multivolume series that is most likely to be reluctant to expand its remit:

Publishers of multi-volume editions, whose stake in Shakespeare might suffer little if Titus and Henry VI were to vanish from their lists, may view with concern any move to promote yet another early history to canonic rank. Even outside the canon, [Edward III] has been separately published only four times in our century. It is harder to see why single-volume complete works should continue to exclude what has become, by the process of elimination I have just outlined, the sole remaining 'doubtful play.' ("Edward the Third" 185)

He is referring here to commercial considerations, the tendency of publishers concerned with bottom lines to focus on the plays that will sell. Edward III, he suggests, can be

\footnotetext{
${ }^{16}$ As of August 2011, Cambridge is the only series to include Edward III, but also the only series to lack The Two Noble Kinsmen. Double Falsehood and Thomas More are uniquely included in the Arden Shakespeare.

${ }^{17}$ See Vickers for discussion of the Cambridge edition ("Incomplete Shakespeare" 347).
} 
conveniently "piggybacked" within the pages of a Complete Works, requiring little additional investment and serving as an extra enticement for prospective purchasers. However, Wells and Taylor argue against this.

From the publisher's point of view, any edition of The Complete Works has to compete financially with the many other available editions of The Complete Works; adding yet another early history play [Edward III] to the several early history plays which usually go unread in existing editions will add to the bulk and cost of the edition without necessarily adding to its attractiveness. ("Re-viewed" 18)

Proudfoot's example hinges on a notion of completeness as exhaustiveness, assuming that publishers will only produce a volume because they have to in order to bring a series to completion. However, in the case of Oxford, the play is too like unmarketable Shakespeare to justify inclusion: it does not contribute to the commercial appeal of Shakespeare.

Decisions such as that of Oxford remind us that a series is never complete, only temporarily fixed. As Marino points out, "the editorial tradition maintains Shakespeare's authority and the publishers' proprietary claims, by issuing a succession of changing texts each of which is the newly 'authoritative' version" (Owning 11). Shakespeare's authority is maintained by his continual updating in new editions and new constitutions. The open-ended and unstable nature of the multi-volume format, and the ability to conveniently add and withdraw volumes, physically realises this partial and alwaysincomplete Shakespeare.

The furore over Arden's publication of Double Falsehood demonstrates the potential of the multi-volume series to expand definitions of completeness and make 
new claims. Since the play's publication in 1728 , it has only ever borne Shakespeare's name, and within strict bibliographic principles its author therefore is and always has been William Shakespeare. As was customary, the venue of performance (Drury Lane) is granted the most space, followed by "W. SHAKESPEARE" with the qualification "Written Originally by". Theobald, meanwhile, takes up the following two lines: "And now Revised and Adapted to the Stage By Mr. THEOBALD, the Author of Shakespeare Restor'd" (title page). The assertion of levels of authority in this authorial attribution is circular: Shakespeare wrote the original, which is adapted by Theobald, who in turn derives his authority from having "restored" Shakespeare, the term evoking Vickers's favoured term for the resituation of textual fragments with their originating author. ${ }^{18}$ Theobald's dual role here as adaptor and restorer of Shakespeare enacts a dispersal of authority that prioritises Shakespeare but qualifies him as incomplete, giving Theobald the responsibility of re-presenting Shakespeare on the page and on the stage. This strategy is rendered performative by the play's living paratext, its Prologue, "Written by Philip Frowde, Esq. and spoken by Mr Wilks" (181; my emphases). Within the text, Shakespeare is authenticated by the modern age, "Transcending his Eliza's golden days!" (Prologue 32). ${ }^{19}$ While the age does honours to "his shade" (30), Shakespeare in turn does honours to "this auspicious era" $(40) .{ }^{20}$ The temporary loss of his last masterpiece is recast as an advantage, as it is better suited to the modern era: "well for the birth it stay'd" (39). Shakespeare and the Augustine period therefore mutually complete one

\footnotetext{
${ }^{18}$ It should be noted, of course, that the qualification of both Shakespeare and Theobald's contributions means that the play lacks a definitive "author": Shakespeare wrote an original version rather than the present text, while Theobald's own role is imagined to be that of a reviser (though on Theobald's strategies for avoiding authorial responsibility in the event of failure, see Kahan 1.171). In either case, the primary authorising body listed on the title page is the Drury Lane Theatre, building on the play's theatrical success.

${ }^{19}$ Unless stated otherwise, quotations from Double Falsehood are taken from Hammond.

${ }^{20}$ The "resurrection" of the "shade" or "ghost" of Shakespeare was a key authenticating strategy utilised for adaptations of Shakespeare on the Restoration and eighteenth-century stages. See Dobson 113-23, particularly his discussion of Granville's 1701 The Jew of Venice which offers a useful comparison, and 172-75.
} 
another: Shakespeare authorises Theobald's play, while the "auspicious era" in turn completes and authorises Shakespeare. The Epilogue takes this a step further, distancing itself from Shakespeare's own period ("heaven defend us from these ancient plays", 1), and appealing to the "modern wits" (5) of the audience with their more sophisticated taste and morality. The apology for "old stories" (8) is as necessary an element of fitting Shakespeare to his new spiritual home as Theobald's textual adaptation. In this form, he is available for his final appropriation and consolidation as a national Augustine hero. "Tis yours to crown the Bard, whose magic strain / Could charm the heroes of that glorious reign / Which humbled to the dust the pride of Spain" (Epilogue 34-36). As Hammond notes, this is a reference to contemporary politics rather than to Shakespeare's own period (Prologue 36n). Shakespeare is at last crowned the "Bard" by Double Falsehood in text and performance, and within two lines is put to work (anachronistically) against the Spanish, with whom Britain had just completed a brief war. The play's original publishing context is thus inseparable from the use of Shakespeare, in this peculiarly eighteenth-century guise, to present and frame the drama. Shakespeare is constructed and understood as the play's author regardless of the presence of Theobald or other authorial contributions, and play and Bard become symbiotic.

Arguments over the play's authorship continue to rage. Hammond's edition strengthens the case for the play being an adaptation of Shakespeare and Fletcher's Cardenio on bibliographic and historical grounds, and attribution scholarship on the play over the last few decades has largely supported a growing consensus that the play is Shakespeare's. ${ }^{21}$ However, the publication of the play in the Arden Shakespeare has

\footnotetext{
${ }^{21}$ Bradford Jr initiated the modern debate by arguing that the play's structure and themes were authentically Jacobean in 1910. Important interventions include Muir, who uses parallels to suggest the possibility of Shakespearean and Fletcherian authorship (Shakespeare as Collaborator); Freehafer, who provides a full survey and answers immediate doubts; Kukowski,
} 
prompted a backlash, supported by the publication some years previously of Kahan's edition of the play in Shakespeare Imitations, Parodies and Forgeries (2004). He casts doubt on Theobald's story and, based on analysis of Theobald's own emending practices, argues that the range of classical and Shakespearean references in the play indicate the work of an editor saturated in Shakespeare's work rather than Shakespeare himself. Kahan's argument has weaknesses, but they provide the groundwork for Tiffany Stern's more thorough rebuttal of the case ("Forgery"). ${ }^{22}$ She points out that Theobald was not only editing Shakespeare at the time but also the works of Beaumont and Fletcher, explaining the likenesses to both canons. Further, she demonstrates that Theobald had a particular interest in Don Quixote, especially the Cardenio episodes, making that story an obvious choice for his forgery regardless of whether or not he knew of the Shakespeare-Fletcher play.

The argument will doubtless continue to run, as both believers and sceptics of the play's Cardenio connection rely on equally possible narratives of textual genealogy. However, my contention is that the play's inclusion in the Arden Shakespeare acts as a productive stimulus for debate, rather than as a final statement. Importantly, the play is presented as Double Falsehood, a play first performed a century after Shakespeare's death, rather than as Cardenio. Within a strict bibliographic principle that understands a work printed as Shakespeare's to be, in some sense, "by Shakespeare", there is a case

who finds parallels with Fletcher's work; and Pujante, who pursues the connection with Shelton. Committed stylometric work on the play has been less helpful, but the possibility of a genuinely Fletcherian play is mooted by both Merriam ("Linguistic Computing") and Hope. New internal evidence will be set forth by Jackson, Proudfoot, Taylor and David Carnegie in The Quest for Shakespeare's Cardenio (forthcoming, 2012). Finally, Hammond's excellent Arden edition summarises all important scholarship on both sides of the debate.

${ }_{22}$ Kahan's parallels of plot and dramaturgy, attempting to show Theobald copying elements of Shakespeare, are often so vague as to be meaningless ("Camillo's misanthropy suggests the broad plot of Timon of Athens", 1.167); there are basic errors of fact and understanding (he dismisses the theory that Mary Davenant could be the "natural daughter" because he believes that Mary was Charles Davenant's daughter, rather than wife, 1.175n); and he fails to address the question of Fletcherian parallels. All of these errors are addressed by Stern. 
for inclusion. ${ }^{23}$ Its inclusion is justified by the general editors on the grounds that it "reflects the unique interest of this avowedly thorough eighteenth century adaptation as containing what may be the sole surviving textual evidence for a lost ShakespeareFletcher collaboration" (xvi), thus establishing the qualified basis on which the play is included. Notably, Hammond makes no attempt to "disintegrate" the play within the body of the text, relying primarily on the general historical narrative as the basis for inclusion.

Double Falsehood's canonical uncertainty, as with several apocryphal plays, has for centuries served to exclude it from publication and performance, either in Shakespearean contexts or elsewhere. This position is increasingly unviable given the significance of the evidence presented in the play. Proudfoot outlines the rationale behind the commissioning of the edition:

That Double Falsehood should enter the Shakespeare canon may seem an unlikely proposition - if we continue subconsciously to regard canonic status as a reflection of literary merit rather than of historical fact ... Double Falsehood's interest lies in its relation to the other Shakespeare/Fletcher collaborations, and it therefore belongs beside them in its own corner of the Shakespeare and Fletcher canons, or in the Jacobean repertoire of the King's Men. Only when it is duly placed there will the further study that may reveal more of its chequered history become possible. (“Canon" 81)

\footnotetext{
${ }^{23}$ A similar theoretical case could be made along these lines for manifest forgeries such as Vortigern and Rowena, and Kahan's grouping of these plays together perhaps makes this point. While there is a separate case to be made for the construction of deliberately false Shakespeare (which could take into account conjectural reconstructions such as M. Egan's Richard II Part 1 and the performed versions of Cardenio by Stephen Greenblatt, Gary Taylor and Bernard Richards), this is beyond the scope of this study. For the purposes of a credible Shakespeare canon, the strength of Double Falsehood's claim is its engagement with multiple authorial paradigms, rather than just the bibliographic.
} 
Proudfoot recognises that canonicity is not an end, but a useful starting place for discussing the connections between related works. The multiple hands and agencies of Double Falsehood are incorporated into "Shakespeare", while at the same time connecting Shakespeare inextricably to the wider social networks of authorship that remain usefully conversant with the traditional canon. The canon remains authorial, but that no longer needs to be a limiting factor. Following Proudfoot's observations, Arden's Double Falsehood finally allows the play to be considered within the Shakespearean contexts that determine its meanings. This is productive even if in provoking the kind of sustained and considered counter-argument that Stern offers, as well as prompting productions that allow the disputed play to be evaluated in performance.

As the argument over the play's authorship advances with new impetus, so too are the play's internal connections to the Shakespeare canon made freshly available for consideration. Whether authentically Shakespeare or posthumously constructed to appear Shakespearean, the play offers striking support to recent arguments surrounding Shakespeare's plays of the early 1610s. Throughout his commentary, Hammond draws out the play's intertextual connections with Pericles, Winter's Tale, Cymbeline and The Two Noble Kinsmen, but he also finds that the play has strong links with The Two Gentlemen of Verona, a play that William C. Carroll suggests was also revisited in the contemporaneous Two Noble Kinsmen (Hammond 7-8, Carroll 32-35). Following Hammond's suggestion, it is worth noting the close proximities of plotting between the two plays: Valentine/Julio is called away to court. Proteus/Henriquez loves Julia/Violante, but subsequently falls in love with Silvia/Leonora, the requited object of his friend's affections. Proteus/Henriquez betrays Valentine/Julio, forcing the latter's flight to a rural environment while the former woos Silvia/Leonora. Meanwhile, the 
rejected Julia/Violante disguises herself as a boy to follow her churlish lover. ${ }^{24}$ The comic, musical wooing scene of Silvia by Proteus is also revisited in Henriquez wooing Violante. While the sketch of these aspects of Double Falsehood's plot derives from Cervantes, they are only reported months after the event; the dramatic emphasis is unique to the drama.

Mowat has argued for the more appropriate use of "family resemblance theory" in attempting to define the genre of plays, and discusses in particular the problems of attempting to categorise Shakespeare's later plays in any definitive sense ("What's In a Name?" 138). ${ }^{25}$ She argues, however, that the plays (especially Cymbeline, Winter's Tale, Pericles and The Tempest) self-consciously refer back to older forms of dramatic romance including Mucedorus. Double Falsehood contains both of the shared elements that Mowat identifies Shakespeare as drawing from the older form (136-40): a cycle of loss and redemption culminating in the recovery of royal children (based on the Eustace legend/motif), and cross-rank wooing, which in Double Falsehood performs a central plot function. In taking as its direct source a novel which is itself a self-consciously parody of the romance, Double Falsehood goes even further in what Mowat refers to as the "deliberately old-fashioned" shaping of tragicomic and romantic elements into a distinctly Shakespearean form (140).

Double Falsehood thus interacts with the plays contemporaneous with Cardenio's original moment of production, but also with the broader generic shifts

\footnotetext{
${ }^{24}$ The renaming of characters from Cardenio has caused some comment, and an unpublished essay by Richard Proudfoot ("A Julio for Cardenio") argues that the superfluous words occurring in lines when Julio's name is mentioned suggest that the text originally used the longer "Cardenio". Although the derivation of the names of Double Falsehood may be random, it is perhaps no coincidence that the names of two corollating sets of characters are near-anagrams of one another: Julia and Valentine become Violante and Julio.

${ }^{25}$ McMullan's work on the late plays draws attention to the implications of the word "late" as applied to the plays of the Shakespeare canon otherwise described as "romances" or "tragicomedies" (Late Writing). The word is tied in to biographical notions of genius and selfawareness that McMullan argues are anachronistic and perpetuate an outdated perception of Shakespeare's literary career. The term is used advisedly here.
} 
identified by Mowat that characterise the work of the Shakespearean repertory at this particular moment. ${ }^{26}$ The King's Men's play is lost, along with Shakespeare's words, but the partial reconstruction of its themes, motifs, structures and images may be possible. Even if the play is a forgery, it is a forgery remarkably resonant with critical discussion of genre theory and Shakespeare's late writing, and its increased availability usefully brings these issues to the fore. This argument is not to deny the importance of scepticism in approaching authorial ascriptions. However, by interrogating the relation of a bibliographic ascription to a sense of what Shakespeare meant at a given time allows us to reflect on the very nature of what we consider to be Shakespearean.

As the multi-volume Arden Shakespeare does not claim completeness, it is able to forge its own identity. Similarly, there is no theoretical pressure for other series to also include the play as, without the notion of completeness, there is no need for homogeneity. It is only the requirements of a competitive market that push towards the "complete", and therefore homogeneous, Shakespeare. Issues of authenticity are less urgent in the case of an independent edition such as R.J. Stewart's 1989 The Birth of Merlin, which retains the bibliographically accurate statement "Attributed to William Shakespeare \& William Rowley" (title page). It is the apparently institutional authorising of attributions by respected imprints such as The Arden Shakespeare or The New Cambridge Shakespeare that causes objections. Implicitly, the concern is with the packaging and organising principles of the texts rather than the texts themselves. Yet it is the early modern packaging that defines study of the plays' original print circulation. To rewrite this packaging owing to its "falsehood" is to prioritise modern standards of correctness over important aspects of the plays' original publication. The materialist

\footnotetext{
${ }^{26}$ Cardenio is usually dated to 1613 on the basis of records of court performances, placing it chronologically with the other Shakespeare/Fletcher collaborations immediately following the "late" plays. Stern argues that the early evidence is far more ambiguous and that there may, in fact, have never been a Cardenio play ("Forgery").
} 
paradigm allows the historical and legitimate ambiguity of authorial attributions to be foregrounded in discussion.

The RSC Shakespeare's reassertion of the 1623 folio as the basis of a Complete Works offers a new configuration of canon that recaptures an aspect of the materiality of the book and offers an empirical justification for excluding the apocryphal plays, even if this exclusion is not fully carried out in practice. The advent of hypertext editions and online databases such as Early English Books Online, Eighteenth Century Collections Online and Literature Online, meanwhile, offers to democratise the availability of texts and allow "canons" to be constructed by readers. By adopting similarly objective theoretical principles of collection/collation, a plurality of Shakespeare canons might be established that highlight important bibliographic differences, with the only sacrifice being the word "Complete".

\section{The [Authorial] Works of William Shakespeare [and Thomas Middleton]}

An explicit concern for "completeness" has already been abandoned in the recent canonisation of Shakespeare's contemporary Thomas Middleton, in Taylor and Lavagnino's 2007 Thomas Middleton: The Collected Works. This major new edition "brings together for the first time in a single volume all the works currently attributed to Middleton" (2); a wording which carefully implies completeness ("all the works") while qualifying that claim temporally ("currently attributed"). The implication is that attribution is, to an important extent, a transitory and changeable phenomenon.

Many of Middleton's works were printed anonymously, and there is no early authoritative collection of his writings available as a model, as for the RSC Shakespeare. The edition therefore operates under an authorial rather than a bibliographic paradigm. Plays are included or excluded based on interrogation of internal and external evidence, with a prioritisation of internal evidence: as Jackson points out, "although the quality of 
the external evidence for Middleton's authorship even of these twelve [core] plays is variable, the complete consistency of the internal features linking them to one another and differentiating them from other dramatists' plays has ensured their all-but-universal acceptance as solely his" ("Early Modern Authorship" 83). The twelve plays which provide the "universal" core canon for Middleton are: A Game at Chess, Your Five Gallants, A Trick to Catch the Old One, A Mad World, My Masters, The Witch, A Chaste Maid in Cheapside, More Dissemblers Besides Women, Women Beware Women, No Wit/Help Like a Woman, Hengist, King of Kent, Michaelmas Term and The Phoenix. For all of these there is external evidence, though the last two are only attributed to Middleton in Archer and Kirkman's notoriously unreliable book lists. It is worthy of note that Jackson accepts the attributions of these two based on their company association with the Children of Paul's; the same argument would, of course, support the attribution of The London Prodigal, Thomas Lord Cromwell and, most pertinently for this edition, A Yorkshire Tragedy to Shakespeare. It is, therefore, internal evidence that dictates the quality of the external evidence; a slightly problematic, if not insurmountable, complication when establishing a secure base sample.

By prioritising internal evidence, it is the specific authorial contribution that is sought. Jackson largely avoids using embodied language such as "hands", although he does suggest that the "highly idiosyncratic linguistic and orthographical profile" is "almost as reliable a guide to identification as actual physiognomy - or as fingerprinting" (84), aligning internal evidence with the certainty of physical embodiment and drawing attention to the fact that an authorial manuscript of $A$ Game at Chess is extant. In addition, the format of the edition is itself based on that of the Oxford Shakespeare, featuring two prestige volumes: the text of the plays and a textual companion, Thomas Middleton and Early Modern Culture. In adopting the format of the Shakespeare edition, and through Taylor's persistent descriptions of Middleton as "our other Shakespeare", 
the edition deliberately appropriates Shakespeare's cultural authority. ${ }^{27}$ It attempts to bolster the cultural value of Middleton through an association with Shakespeare that justifies the prestige presentation of Middleton's authorial canon. The effect of this, however, is to consolidate Shakespeare's cultural exceptionalism. He remains the standard by which other dramatists must be measured, and Taylor's formulation inadvertently moves Middleton into a position of dependence on Shakespeare's reputation as Middleton's "other", his negative.

In this sense, the Oxford Middleton is entirely orthodox, elevating the figure of the author and using the cultural authority of the authorial paradigm itself to justify a major capital investment in these plays. Shakespeare grants Middleton value by association as his "other"; and Middleton in turn confers value on the plays to which he is linked. Shakespeare and Middleton are bound in a mutually authorising relationship that ignores the other major dramatists of the period, implying a similarly exceptional status for Middleton.

However, as the title of the companion volume indicates, at the same time as the author is apotheosised he is also resituated in a much wider discursive textual culture. This is, as Engle and Rasmussen write, "an edition that recognizes, more clearly than any other [we are] aware of, the contingencies of authorship, editing and canonical status" (247-48). ${ }^{28}$ The author is discovered in plays, pageants, royal entertainments, masques, poems and pamphlets, and the presentation of the edition itself contests the homogeneity of the authorial paradigm by employing a range of editorial strategies to

\footnotetext{
${ }^{27}$ As well as appearing in the first line of text in both volumes, "Middleton: Our Other Shakespeare" was the title of Taylor's publicity talk for the volume given at the National Theatre on 3 June 2008 and elsewhere.

${ }^{28}$ Engle and Rasmussen playfully acknowledge the discursivity and multivocality of the edition by reviewing it as a conversation between two fictional characters, "Sven" and "Leif". As they suggest, "A federal edition deserves a responses that does not repress its dialogic tendencies" (247).
} 
evoke the materiality and discursiveness of the texts. ${ }^{29}$ Further, the edition prominently foregrounds the work of collaborators in the general and individual introductions, arguing for multiple agents in about a third of the edition's inclusions. ${ }^{30}$ Shakespeare has a significant presence in the volume: full texts of Timon of Athens, Macbeth, Measure for Measure, Yorkshire Tragedy, The Puritan and The Lady's Tragedy, equally weighting Middleton's "Shakespeare" between canonical and apocryphal. ${ }^{31}$

It is in the edition's liberal inclusion of texts normally considered Shakespearean that the authorial paradigm becomes most provocative. By incorporating a play such as Macbeth under the aegis of Middleton, even with Shakespeare's contribution highlighted in the introduction to that play, the edition gives the impression of reclaiming it for Middleton, taking it away from Shakespeare. This is less contentious in the case of the apocryphal plays, here restored to their rightful author. However, the language of restitution is highly polemic. Vickers's attack on the Oxford Middleton in the Times Literary Supplement accuses Taylor of abusing the "vulnerability" of Macbeth, recast as "helpless" and in need of protection "like some World Heritage site" (“Disintegrated"). Vickers's vitriolic and personal attack on Taylor places him in an awkward theoretical position, given that Vickers's own work on "co-authorship" does

\footnotetext{
${ }^{29}$ This is particularly the case in An/The Old Law (edited by Masten), which randomly moves the position of the commentary on each page to margins, foot or even the head of the page; The Lady's Tragedy (ed. Julia Briggs), which presents parallel texts; A Game at Chess (ed. Taylor), which offers a transcript of Middleton's holograph as well as an edited text; and the running titles throughout the edition, which represent the variant titles of the work in facsimiles of their early typographical manifestations.

${ }^{30}$ News from Gravesend, The Meeting of Gallants, The Patient Man, The Roaring Girl, The Bloody Banquet (Middleton-Dekker); Wit at Several Weapons, The Fair Quarrel, The World Tossed at Tennis, The Changeling (Middleton-Rowley); Timon of Athens, Macbeth, Measure for Measure (Middleton-Shakespeare); Anything for a Quiet Life (Middleton-Webster); The Whole Royal and Magnificent Entertainment (Middleton-Dekker-Jonson-Harrison); The Old Law (RowleyMiddleton-Heywood); The Spanish Gypsy (Ford-Dekker-Middleton-Rowley); and Sherley's Entertainment (Loeaechius, translated and adapted by Middleton).

${ }^{31}$ The Birth of Merlin is discussed in the "Works Excluded From This Edition" section, primarily on the basis of Rowley's probable authorship, but the editors find no case for inclusion (Early Modern Textual Culture 444). The London Prodigal, despite its date and subject matter, is not even considered.
} 
not accord the texts this "protection". This suggests that the same process can be reclassified as either invasive "disintegration" or merciful "restitution" depending not on methodological grounds but on whether or not Vickers agrees with the results.

The argument over Macbeth is ongoing and is likely to remain unresolved for some time. Of more immediate interest is the occasion of Vickers's assault. Like Stern, he is attacking a longstanding theory of attribution that has recently been canonised in a major instance of publication. As Vickers himself notes, the theory that the folio text of Macbeth is a posthumous adaptation by Middleton is an old one, and one that the Oxford Shakespeare promoted in 1986. While Vickers protested the decision at that time, it is the removal/resituation of the play into the Middleton canon that has prompted his full-scale rebuttal: as he states in his review of the second edition of the Oxford Shakespeare, "Taylor has included both Shakespeare plays in the forthcoming Oxford Middleton, an enormous boost to that dramatist's oeuvre" ("Are All of Them by Shakespeare?"). Despite Vickers's promotion of collaboration in the early modern drama, his theory of restitution is rooted in notions of individual authorial responsibility and ownership. The single-author model of the Oxford Middleton, despite the edition's claims that Macbeth is "by WILLIAM SHAKESPEARE, adapted by THOMAS MIDDLETON" (1170), enacts a visual and contextual reclamation of the play, "restoring" it to Middleton's canon. As with Stern's attack on the Arden Double Falsehood, the reaction is prompted by the material assertion of a problematic attribution, published under an authorial imprint in a respected academic publication. ${ }^{32}$ Yet both attributions are in fact far more complex than a simple attribution to Middleton or Shakespeare, recognising

\footnotetext{
${ }^{32}$ Taylor himself plays into this, boasting of how the "new textual revolutionaries" had "succeeded in hijacking the international resources and the cultural authority of Oxford University Press, not only the most respectable but commercially the most powerful of all academic publishers" (qtd. in Vickers, "Disintegrated"). Taylor's deliberately confrontational language, which admits to appropriating cultural authority for an avowedly "revolutionary" agenda, in some ways explains the personal nature of Vickers's attack. See also Rosenbaum, Shakespeare Wars 36-40.
} 
the plays' participation in a network of agency and contingency that renders them usefully conversant with the Middleton and Shakespeare canons.

The key to interpreting the Oxford Middleton's inclusion of Macbeth and other plays is partially concealed by the author-centred marketing and the attempts to elevate Middleton's cultural status. The true achievement of this Middleton canon is, in fact, the decentring of Middleton within his own volume, to a point where even the text of an auditor's response to a Middleton pageant can be included. ${ }^{33}$ Middleton here is not "complete" and is barely even "collected". Instead, Middleton's authorial presence is dispersed, the author disappearing into wider networks of pageantry, collaboration and textual ephemera. Middleton becomes a motif or meme in his own book, acting as a link rather than a tyrannical bordering presence. This is most obviously represented in Masten's editorial apparatus for The Old Law which "insists on the multiple interventions the editorial process makes in the text in order to produce such an experience for the reader" (1335). Authorial authority acts as a marketable selling point in the edition's publicity materials and unifying paratexts but, within the texts themselves, this authority is dispersed amongst competing, contradictory and (usefully) inconsistent paradigms of textual possession.

As such, several of the plays of the Shakespeare Apocrypha are successfully rehoused, "restored" to Middleton but continuing to exist within an avowedly transitory and discursive textual culture. This is particularly important for The Puritan Widow. ${ }^{34}$ Bibliographically, the original quarto belongs to "W.S." (Title page), whose identity is necessarily ambiguous. Organised by company, it is part of the repertory of the Children of Paul's, a company strongly represented within the Middleton volume. Authorially, the

\footnotetext{
${ }^{33}$ A fully edited and annotated version of Aleksei Ziuzin's account of The Triumphs of Truth is printed on 977-79.

${ }^{34}$ The play has historically been known by several different titles. While I use The Puritan elsewhere for its more general familiarity, I here acknowledge the Oxford edition's choice of title.
} 
play is Middleton's, as has been convincingly argued by attribution specialists. ${ }^{35}$ These conflicting authorising bodies have left the play largely untouched by editors since Brooke's Apocrypha. The Oxford team's inclusion of it therefore reclaims the play not only for Middleton, but also for the networks of textual culture which the edition prioritises. Here, The Puritan can be seen in a context of other Paul's plays, other Middleton plays and other satirical comedies featuring city rakes, witty tricksters and rich widows.

The inclusion of The Puritan Widow does not only act to provide the play with a useful context, however, but also serves to shape Middleton himself and his canon. As Donna B. Hamilton notes, the religious issues raised by the play "are full of implication, not just for assessing the satire of The Puritan Widow, but also for identifying Middleton ideologically, and even for developing a secure sense of the Middleton canon" (Taylor and Lavagnino, Collected Works 509). The association of Middleton himself with Puritanism has had significant implications for determining the constitution of the canon, with Margot Heinemann among those who found the satire of moderate Puritans "inconceivable for Middleton" (Taylor and Lavagnino, Collected Works 509). Within a context of other Middletonian plays satirising Puritans, however, Hamilton is able to argue along with N.W. Bawcutt that The Puritan Widow offers one of the clearest indicators that "Puritan" is an inappropriate label for the author. This anonymous play, with its strong ideological and satirical focus, offers to construct or disrupt the authorial canon into which it is inserted, changing the meaning of the works surrounding it. In her important re-examination of the play's textual context, Hamilton demonstrates that the play was a key participant in the flurry of literary activity that followed the Gunpowder

\footnotetext{
${ }^{35}$ Although Brooke himself thought the play was by Marston, an Oxford man, he acknowledged that Fleay, Bullen, Hopkinson and Ward all favoured Middleton's authorship (Apocrypha xxxi). The studies of Lake and Jackson were formative in establishing the current consensus. See Jackson, Studies in Attribution 41-53, and Taylor and Lavagnino, Textual Culture 358-60.
} 
Plot and James's enforcement of the oath of allegiance for Catholics. This activity also included the publication of an account of Henry Garnet's 1606 trial, strongly evoked in Macbeth. The presence of these two plays in the same volume, both under Middleton's aegis but with longstanding Shakespeare connections, points to the limitations of individual authorial paradigms unless they are fully contextualised by the intertextual connections that authored the discourses in which the plays participated.

The presence of an author licenses the resurrection and publication of neglected plays. This is problematic, however, as it continues to prioritise the author as a governing principle and reinforces anxieties over canonical boundaries and the preservation of authorial property. It is also a problem insofar as it continues to prejudice against anonymous plays. The least published of the Apocrypha, Thomas Lord Cromwell and Fair Em, are also the plays with the least certain attribution claims.

However, to deny completely the role of the individual author in the creation of a text is to work against historical evidence and the practical realities of writing. By offering a practical and commercially viable opportunity to make more obscure drama available in print, the authorial model proves its utility in imbuing texts with the necessary cultural capital to compete in the marketplace.

This careful utilisation of authorial canons poses another problem, potentially acting to reinforce a hierarchy of canonical authors where some have greater or lesser cultural value than others. This can only be avoided by loosening the institutional investment in certain canons and making other canons and texts more widely available. Politicised anti-canonical arguments attack the canon of the classroom and academy, treating it as an institutionally controlled body of works allied with "a spectrum of vested interests that include male dominance, Anglo-Catholic orthodoxy, national selfdefinition, and professional aggrandizement" to the exclusion of minority works (Gorak 
3). These problems are implicit in "integrationist" authorship research that assumes more value in Shakespeare than in other writers and seeks to enhance his canon accordingly. The attributions of Thomas of Woodstock and Edmond Ironside to Shakespeare by Michael Egan and Eric Sams are examples of this, aiming to bolster both canonical author and the disputed text (always presented as a neglected artistic masterpiece) through their mutual (re)association. ${ }^{36}$

The presence of The Lady's Tragedy in the Oxford Middleton consolidates a longstanding attribution consensus that the play is by Middleton, rather than by Chapman, Goff or Shakespeare, as George Buc guessed. ${ }^{37}$ The play has never been included in a collected Apocrypha, and it sits comfortably in a Middletonian context of religiously inflected "Jacobean sex tragedy." ${ }^{38}$ Yet the edition betrays some anxiety over its institutional reclamation of the play for Middleton in its choice of title: The Lady's Tragedy is a new editorial name for a play that critical tradition usually refers to as The Second Maiden's Tragedy. The more familiar title is based on Buc's note that "This second Maydens tragedy (for it hath no name inscribed) may with the reformations bee acted publikely" (qtd. in Collected Works 833). The "second" refers to the fact that the King's Men had submitted Beaumont and Fletcher's The Maid's Tragedy for approval earlier that year. By retitling the play in accordance with the central female protagonist's only designation, the Oxford editors deliberately break away from the connection with

\footnotetext{
${ }^{36}$ The methodologies of both Sams and Egan have been roundly refuted. Both rely heavily on the accumulation of unchecked parallels between Shakespeare's canon and the play in question; both deny the possibility of collaboration; and both adopt a preemptively defensive tone throughout their books. Jackson counters Egan's arguments with a particular emphasis on the play's date as well as answering his individual arguments ("Shakespeare's Richard II" and "Date and Authorship"). For sample positions on Ironside, see M.W.A. Smith ("Ironside") and Philip Palmer.

${ }^{37}$ Briggs provides a useful summary of the attribution history in Early Modern Textual Culture 371-73. Swinburne was the first to advance Middleton's authorship in 1908, and the pioneering studies of Lake and Jackson found that the play "represented Middleton at his most characteristic" (372).

${ }^{38}$ The phrase is borrowed from Wiggins, who includes it in his Four Jacobean Sex Tragedies under the title The Maiden's Tragedy, along with The Maid's Tragedy, The Insatiate Countess and Valentinian.
} 
Beaumont and Fletcher. Further to this, in 1994 Charles Hamilton published his influential edition of Cardenio: or, The Second Maiden's Tragedy; and it is from this sensational attribution that the Middleton edition seeks to distance itself. ${ }^{39}$

Hamilton's edition is representative of much amateur integrationist practice. His theory, based on weak parallels and an overreliance on palaeographic evidence, bolsters the play ("a splendid Shakespearean drama" 2) through appeal to the play's role in the Shakespeare canon. Cardenio is variously "the Golden Fleece of literature" (1), and "the Holy Grail of world literature" (inside cover), and his assertions of Shakespeare's authorship appeal to the idea of Shakespeare as a pure moral genius. 1.2.257-63 "seems to bear the magic touch of the wizard of Stratford" (10), and "almost every page bears at least a fingertip touch of Shakespeare's genius" (7). ${ }^{40}$ Most importantly,

The Lady in Cardenio is one of the most subtle creations of Shakespeare's wondrous imagination. To some she might appear static and no more fleshly than a marble Aphrodite by Praxiteles. In short, a character whom the dramatist looked upon as a mere foil for the protagonist. But I believe Shakespeare created The Lady as the embodiment of the perfect woman; beautiful and innocent, strong and brave, faithful to her lover and her ideals. (6)

It is this interpretation of the Lady's character that, for Hamilton, offers the most powerful argument against Middleton's authorship, for “Middleton is regarded by literary historians as a woman hater" and thus he could not have created "an idealistic woman who spurned wealth and power and, pure of heart and body, laid down her life

\footnotetext{
${ }^{39}$ Briggs, the Oxford editor, incorrectly accuses Hamilton of "renaming the characters from the 'Cardenio' plot of Cervantes's Don Quixote" (835). Hamilton's edition is in fact remarkably diplomatic in its presentation of the text, although the Dramatis Personae list (14) does note the Cervantian corollaries for the major characters' names.

${ }^{40}$ Line references refer to Hamilton's edition.
} 
on the alter [sic] of chastity" (243). Instead, "in my opinion, both The Lady and The Tyrant are characters of Shakespearean stature, molded by the Stratford dramatist and far beyond the comprehension or creative powers of Middleton" (244).

Hamilton's own partiality for the character of The Lady interprets her in an unambiguously positive light, which does not fit with his interpretation of Middleton's treatment of women. This is a difference in quality as well as kind: the characters are of a nature "far beyond the comprehension or creative powers of Middleton" (244). Fascinatingly, Hamilton even provides a hierarchy of early modern dramatists that explicitly casts the play's move from Middleton to Shakespeare as a promotion. ${ }^{41}$ Conversely, one of the key projects of the Oxford Middleton is to rehabilitate Middleton's reputation, placing him in the top tier of Hamilton's ranking. For the Oxford editors, Middleton's "frank sexuality" (54) is a result of his lively involvement in the theatrical world of early modern London rather than of a dissolute mind as implied by Hamilton. The play's resituation alongside Middleton's religious pamphlets and plays such as The Yorkshire Tragedy, with its chaste and patient Wife, greatly expands our understanding of what was within Middleton's "comprehension."

Although Hamilton's attribution has been refuted by scholars, its commercial appeal persists: in 2010 and 2011, the play was once more staged in London and Stratford-upon-Avon by Aporia Theatre as Cardenio, now "by William Shakespeare and John Fletcher or Thomas Middleton" ("Shakespeare's Lost Play Cardenio"). The production's awkwardly ambiguous and self-contradicting attribution attempted to balance commercial imperative with academic consensus, a balance made more difficult

\footnotetext{
${ }^{41}$ "According to their position in the hierarchy of genius", Hamilton lists the greatest as Shakespeare, Jonson, Tourneur (an anomalous and unexplained inclusion), Beaumont and Fletcher. "In the second group, a few rungs below: Middleton, Dekker, Webster, Chapman, Ford, Massinger, Marston, and Heywood" (12). Field, Rowley and Munday occupy a lower position on the ladder.
} 
by the enormous publicity drive for Arden's Double Falsehood earlier in 2010. The awkwardness of the attribution was admitted at the Stratford performances by the company, who explained to audiences that it was a very different play to the RSC's Cardenio, then playing at the Swan. Despite the difficulties, however, the cultural capital wielded by the authorial name, fixed in print to the disputed text, was sufficient to prompt performative investment in the attribution. Despite the best efforts of the Oxford Middleton to assert a Shakespearean prestige for its texts, a dubious Shakespeare continues to exert more fascination than an authentic Middleton. The elevation of specific authors within the established parameters of a canon-based field does not offer the level of corrective intervention needed to rehabilitate the apocryphal plays. As an alternative, we must turn to the authority of performance.

\section{The [Performative] Complete Works of Shakespeare}

Whenever an early modern play is newly attributed, it is paramount to consolidate the attribution in performance; for a play to be saved, the word must be made flesh. Hamilton's Cardenio "was launched with a play-reading by the Allied Theatre Group" (Briggs 835); the RSC staged The Two Noble Kinsmen at the Swan in 1986 and Thomas More in 2005, both of which coincided with the plays' first inclusion in the Oxford Shakespeare; and Arden's publication of Double Falsehood in 2010 prompted several revivals. As W.B. Worthen's pioneering work has shown, the interface between stage and page is key to a consolidation of what is considered to be authentic.

“'Shakespeare' - sometimes coded as the 'text,' its 'genre,' or the 'theatre' itself remains an apparently indispensable category for preparing, interpreting, and evaluating theatrical performance, at least as much for practitioners as for scholars and critics" (3). He goes on to consider "how both scholars and performers take the stage to be authorized in this way, as a place for authentically Shakespearean meaning" (3). What is staged as Shakespearean defines what is considered to be authentically Shakespearean. 
Decisions over the meaning and constitution of Shakespeare are brought into the public sphere through their enactment on the stage, especially the stages of institutional theatres such as the National Theatre or the Royal Shakespeare Company. This performed canon therefore offers the most flexible and responsive manifestation of the Shakespeare canon, offering a version of Shakespeare that is by definition unfixed and socially produced.

The use of performance to consolidate attribution is standard practice. This has recently been the case with Middleton. The National Theatre's staging of The Revenger's Tragedy (dir. Melly Still, 2008) coincided with the publication of the Oxford Middleton, and two years later the reissue of the volume in paperback was accompanied by Marianne Elliott's production of Women Beware Women (2010). Taylor delivered platform talks to accompany both productions, appropriating the institutional weight of the National Theatre and Oxford UP simultaneously to consolidate Middleton's cultural capital in print and on stage. In doing so, Middleton was turned into a desirable, vendible and valuable commodity. Yet even as this process was underway in 2008 , a competing production of The Revenger's Tragedy at Manchester's Royal Exchange offered a very different approach to authorship. Director Jonathan Moore, after admitting the strength of the internal evidence for Middleton's authorship, refuses to be swayed:

Most of the theatre writers I know - and actors and writers - have this hunch that it was by this guy called Tourneur. I think the reason they say that is that it is a very different play to the other plays that Middleton wrote. It seems to be this stand-alone piece of genius- this mad 
flowering. And there are quite a few similarities with the play that is indisputably Tourneur's, THE ATHEIST's TRAGEDY. (Programme) ${ }^{42}$

For Moore, the advantage of attribution is not in canonical contextualisation, but in its individualisation of the play. As a "stand-alone piece of genius", this de-canonised play can be staged as a "mad flowering" (reflected in Moore's kinetic and irreverent production) rather than conforming to an established Middletonian production style. Conversely, the National's Revenger's Tragedy and Women Beware Women, despite having different directors, shared a strikingly similar use of a revolving stage, contemporary jazz soundtrack, mute physical theatre sequences and spectacular conclusions. In doing so, the National created its own specific performance language for Middleton. Moore's appeal is rather to the instinctive feeling of creative artists, finding value in spontaneity and uniqueness rather than in the institutional categorisation.

Shakespeare has a longstanding history of institutionalisation in performance. Kahan notes that, even in the case of Vortigern and Rowena, "it made good sense to have Shakespeare actors play in Shakespeare imitations ... It is likely that their Shakespearean typecasting added to the legitimacy of a new Shakespeare" (1.xxxv). Although the twenty-first century continues to employ a stable of recognisably "Shakespearean" actors, the pervasiveness of other media has reduced the possibility for the kinds of association that Kemble and Siddons brought to their pseudoShakespearean roles. However, a similar function is performed by the major theatrical institutions, especially the RSC, where the presentation of non-Shakespeare drama is inevitably seen and interpreted by comparison with the company's primary programme of canonical Shakespeare.

\footnotetext{
${ }^{42}$ In his 2008 talk, Taylor accused the Royal Exchange of editing the play's page on Wikipedia in order to make the case for Middleton more ambiguous ("Middleton, Our Other Shakespeare"). Regardless of the truth of this accusation, it points to a fundamental anxiety over the fluidity of authorial attributions according to the medium through which they are asserted.
} 
The company's staging of a "Complete Works Festival" in 2006-07 provides a unique opportunity to evaluate the presentation of the Shakespeare canon as a complete body in a performative context. Across fifty-four productions, as well as numerous fringe events, the company offered "The Greatest Dramatist. The Essential Year" (RSC, Festival Guide front cover). The year-long event attracted massive publicity at a transitional time for the company, ending with the closing of the Royal Shakespeare Theatre for its largest ever refurbishment. ${ }^{43}$

The promise of a "Complete Works" raised immediate questions. At one level, the very ephemerality of stage performance means that no one performance can ever be a "complete" rendition of a work. Cuts, errors, interpolations, adaptation and interpretation all turn the theatrical experience into a performative engagement with the text, defying and rejecting the possibility of completion. The problems noted by Orgel of reaching a complete textual Shakespeare are even more apparent on stage, where a choice has to be made between textual variants: there is no performative equivalent of the "Textual Variants" appendix. On a more immediately obvious level, however, several reviewers raised complaints about the constitution of the Festival. Although the promise of fifty-four productions appeared to offer a heavily supplemented Shakespeare canon, no apocryphal or dubious plays were in fact included. This was particularly incongruous in light of the fact that, only the previous year, the RSC had produced Thomas More under the attribution "Anthony Munday, William Shakespeare and Others" (Programme), yet excluded the play here. In interview, festival organiser Deborah Shaw stated that she would rather arrange two interestingly different productions of Richard III in tandem than repeat ground covered so recently by

\footnotetext{
${ }^{43}$ Academic responses to the Festival include a special issue of Cahiers Elisabethains with reviews of most productions and several contributory essays (P. Smith, Valls-Russell and Bradley), Carol Rutter "Watching Ourselves" (which focuses particularly on Münchner Kammerspiele's Othello), Duncan-Jones, "Complete Works, Essential Year?" and Kirwan, The Bardathon, which includes reviews of all fifty-four productions.
} 
reviving Thomas More ("Complete Works"); a statement of artistic independence that appears to run counter to the assumed mandate of a "Complete" Works Festival. ${ }^{44}$ The other Shakespeare plays mounted in the same season as More (Dream, Twelfth Night, As You Like It, Errors) were all performed during the Festival by visiting companies, demonstrating that different standards applied to fringe Shakespeare, despite the claims of the 2005 season.

Aside from the exclusion of the Apocrypha, the festival treated the canon in what Duncan-Jones criticised as "no discernable or systematic sequence . . . an artistic free-for-all" (354). The Two Noble Kinsmen was staged as a one-off rehearsed reading by the actors then touring in The Canterbury Tales, cross-casting the play with their version of The Knight's Tale in a fascinating event that, however, "fell short of being a staged performance" (354). In productions such as this, the Festival preserved an implicit hierarchy of representation according to authenticity: of the non-folio plays and poems usually ascribed to the canon, only Pericles was accorded a full run. ${ }^{45}$ However, normative hierarchies were destabilised in other ways: Othello was only performed in a heavily adapted German translation by Münchner Kammerspiele, for instance, while Macbeth took the form of a fragmented series of work-in-progress scenes combining the music of lost Polish communities with devised physical theatre. Several other plays, including Richard II, Titus Andronicus and Henry V, were only performed in foreign languages. Cymbeline, to the disgust of many critics, was performed by Cornish company

\footnotetext{
${ }^{44}$ In fact, the Festival included three productions of Richard III: the RSC's own (dir. Michael Boyd); Richard III: An Arab Tragedy by the Al-Bassam Theatre (dir. Sulayman Al-Bassam); and a heavily cut version performed by students from RADA (dir. Jennie Buchanan). A plan to stage rehearsed readings of all the plays in Brooke's Apocrypha was mooted and abandoned at an early stage of development (Bate, private communication).

${ }^{45}$ Selected sonnets were performed as part of the concert Nothing Like the Sun, and A Lover's Complaint was omitted. The Rape of Lucrece received a rehearsed reading by members of the RSC ensemble, and Venus and Adonis was presented in a puppet show by the Little Angel theatre. The Phoenix and the Turtle was given more attention, presented in a costumed reading at Holy Trinity Church along with the other poems appended to Lover's Martyr, interspersed with Renaissance music.
} 
Kneehigh in an adaptation mostly consisting of contemporary English, and theatre school students performed a heavily cut edit of All's Well That Ends Well. ${ }^{46}$

The promise of "completeness" implies unity, the presentation of a disparate group of works according to a shared purpose and design. Duncan-Jones, writing about the Festival, voiced the same expectation and her subsequent frustration with the "artistic free-for-all". "It was impossible during the opening months to identify any coherent overview, narrative, or larger concept of Shakespeare's complete works underpinning the astonishing theatrical marathon of the RSC, and this made decisions about what to see, and when, extremely perplexing" (355). As a reviewer, Duncan-Jones searches for the overriding authoritative voice of performance, the institutionalised and overarching "meaning" of Shakespeare that she expects from a "complete" Festival performed under the authority of the RSC. Her assumptions are rooted in a New Critical desire for thematic unity, and thus she reads the post-modern eclecticism of the Festival as incoherence. This is linked with her assumption of a pedagogical function for the Festival: an inclusive schedule "would also have offered that year's school and college students a unique opportunity to see productions of any play or plays, however minor, that they happened to be studying" (353). However, "perverse" (355) or only "loosely Shakespearean" (361) productions like Cymbeline and Othello frustrated the pedagogic purpose. "Any student who had naively hoped that a 'Complete Works' season would offer opportunities to see strong, text-based productions of all of Shakespeare's mature tragedies was to be sorely disappointed" (361). Speaking of the Ninagawa Company's Japanese production of Titus Andronicus, she is more explicit:

For English speakers, the Japanese language inevitably reduced its value as a rendition of one of Shakespeare's most poetic and rhetorically

\footnotetext{
${ }^{46}$ For Kneehigh's Cymbeline and the responses to it, see Stephen Purcell 126-32.
} 
realized tragedies. For those new to Titus - or, indeed, anyone who wanted to hear the play in English - Shakespeare's Globe's terrifically lively and spectacular production ... had much more to offer. (360)

For Duncan-Jones, completeness is a resolutely text-based promise that even a twoweek run of a fully staged Titus Andronicus cannot deliver on if it is not in English. The Festival's responsibility is expected to be one of conservative textual fidelity and respectful mediation of Shakespeare's words for first-time visitors.

This is a function that the Festival itself did not offer to fulfil. The arrangement of the Festival as a series of short runs, events and adaptations does not indicate the Festival's failure to meet the needs of an education market, but suggests rather that it was not aimed at school audiences (for whom the much cheaper Globe arguably offers a far more appropriate resource). Instead, Duncan-Jones's attention to what the Festival didn't offer prevents her, until much later in her article, comprehending that the Festival's variety and diversity was a deliberate artistic choice rather than an undesirable side effect. She discusses Boyd's preference for new drama over classical revivals with disapproval, and suggests that the method in the "summer madness" (363) lies in the displacement of canonical plays in favour of the new writing and adaptation that Boyd champions.

The triumph of the Complete Works Festival was in fact in its destabilisation of what might be considered authentically "Shakespearean", and in the important debates it provoked. As well as the variants on Shakespeare mentioned above, the Festival also included a series of "responses", new plays that reshaped aspects of Shakespeare according to a twenty-first-century writerly perspective. ${ }^{47}$ Translations, adaptations,

\footnotetext{
${ }^{47}$ Days of Significance by Roy Williams, One of These Days by Leo Butler, The Indian Boy by Rona Munro, Rough Magyck devised by Forkbeard Fantasy, and Regime Change by Peter Strachan.
} 
new writing, poems, readings, discussions and musical arrangements all sat alongside more traditional productions as part of a celebration of the diversity of Shakespeare.

The Festival deliberately defied Duncan-Jones's expectations for textual authority, playing instead with the authorising potential of Shakespeare as a generator of theatrical possibility. By opening up the discursive field of what might be considered authentically Shakespearean, the Festival argued that the purpose of stage playing is to remake Shakespeare for the times, provoking fresh artistic responses that were sometimes anchored to the "authoritative" text and sometimes broke away from it. This was particularly apparent in the use of surtitles during the foreign language productions, which used Shakespearean lines whenever possible following controversy surrounding Othello. ${ }^{48}$ The disjunct between experimental productions such as Pippo Delbono's Henry $V$ and the overhead Shakespearean text served to emphasise the fluency of the physical language of Shakespeare in comparison to the two-dimensional text.

This is the purpose of the canon as repertoire: to authorise the new through juxtaposition with the established. The dichotomy between the canon and the "perverse" productions (a "new Apocrypha", we might say) was elided through varied levels of capital investment: thus, Roy Williams's Days of Significance received a fullscale RSC production in the Swan Theatre, while The Comedy of Errors appeared only in a shoestring student production. In the repertoire, value is conferred by a combination of authorial authority, theatrical and institutional authority, capital investment and critical response, creating a "work" rooted in its specific historical moment and dependent on collaborative forces.

In the repertoire, theatrical authority resists completeness in favour of temporal

\footnotetext{
${ }^{48}$ See C. Rutter for analysis of the impact of the non-Shakespearean surtitles (54-55, 62-63). Rutter suspects that the negative reaction to the production's profanity so early in the Festival (it was the third production to open) prompted the RSC to impose a policy of Shakespearean surtitles on subsequent visiting productions.
} 
contingency. As Worthen puts it, authority is "a function of the rhetorical structure of each textual event, how the event - production and reception - generates its own version of the authoritative experience of the work" (14). As such, performance becomes the venue in which the apocryphal plays are offered the greatest potential both to become "Shakespearean" and to dissociate themselves from Shakespeare. With the author and the written text both invisible on stage, the decision on whether or not the performed text is to be constructed as "Shakespearean" becomes that of theatremakers, theatre-sellers and theatre-goers. Shakespeare offers a context for the plays that is inescapable in a commercial theatre where Shakespeare is inevitably more familiar than his contemporaries, limiting the range of comparative associations. Thus, Barrie Addenbrooke, directing Double Falsehood for KDC Theatre in 2010, "always ... approached Double Falsehood as a Shakespeare play" ("Double Falsehood"). This decision is partly a result of the production's stated intention to be the first production of the play since the publication of Hammond's Arden edition. However, despite the edition prioritising Shakespeare, Fletcher and Theobald as contributors, Addenbrooke's theatrical familiarity is with Shakespeare. "We did not spend any time in rehearsal discussing which bits we thought were Shakespeare and which not; we simply approached the text as a body of work in the same way I did with Macbeth and The Merchant of Venice" (Programme). By avoiding consideration of authorship issues, but approaching the text without a wider knowledge of Theobald's or Fletcher's work, he inadvertently accepts the entire play within a Shakespearean context, a decision which shapes his interpretation. The production, staged at the Union Theatre, read Double Falsehood through Shakespeare's most familiar plays. Don Bernard and Leonora's relationship was played as that of Capulet and Juliet, with Richard Williams's performance in 2.3 drawing on Capulet's anger in Romeo 3.5 as he angrily threw his daughter to the ground following her reluctance to marry Henriquez. The similarity was 
further emphasised through turning Leonora's Maid into an elderly Duenna who adopted a motherly attitude towards Leonora that gave way to enforcement of Don Bernard's instructions, echoing Juliet's Nurse. ${ }^{49}$ Later, the working male shepherds of Act 4 of Double Falsehood were reorganised as a group of holidaying country-folk in the spirit of the sheep-shearing festival of The Winter's Tale, and the appearance of Julio was treated with merriment rather than with fear. These readings are playable without substantially altering the text, but directly emerge from the production's engagement with an attribution and the director's experience with a specific playwright. Whether or not Double Falsehood has its roots in a Shakespeare and Fletcher play, KDC's Double Falsehood was certainly "Shakespearean" in terms of the agencies that authored the performed text.

2010 was a rich year for productions of Double Falsehood. Several companies attempted to consolidate the canonical claim of the Arden Shakespeare in performance much as Hamilton's Cardenio had been supported some sixteen years earlier. A rehearsed reading at the University of Warwick explored the play's dramaturgical connections with Shakespeare as outlined in the Arden edition. ${ }^{50}$ The Arden editor was himself visibly involved both in the full KDC production, writing programme notes, and in an extremely poor staged reading at Nottingham Playhouse, where he introduced the play. This reading took its indebtedness to Arden's authorisation to an extreme by providing its cast with cumbersome photocopies of the Arden edition, impractical for coherent reading. The heavy presence of the Arden text in both productions spoke to the authority of the material attribution, and the intention of the productions to stage this attribution. In all three of these versions, textual fidelity was not to Shakespeare or

\footnotetext{
${ }^{49}$ Doran's Spanish-set production of Cardenio for the RSC also included a Duenna to similar effect.

${ }^{50} \mathrm{~A}$ report of this staging is forthcoming in Research Opportunities in Medieval and Renaissance Drama (2011).
} 
even to Theobald, but to Hammond: it was a particular material manifestation of the text that was being authorised in performance.

The KDC production took things further in its one major creative intervention, which replaced Fabian and Lopez with pantomimic versions of Don Quixote and Sancho Panza, who provided comic relief by riding around the stage on hobby horses and quoting Shakespearean dialogue. The production utilised undeniably Shakespearean quotations in order to heighten a sense of overall likeness to Shakespeare and instil a sense of recognition in the audience that could be unconsciously applied to the whole production. ${ }^{51} \mathrm{~A}$ similar strategy was used by Michael Egan in his edition of Woodstock as 1 Richard II. Egan offered "probably the longest conjectural emendation in dramatic literature" (1.525) by writing a conclusion for the unfinished play, in order to promote future stagings of the play. As with KDC, though, he made extensive use of quotations in an attempt to subliminally impose a sense of Shakespeare on auditors.

Because I believe 1 Richard II comes from the master's hand, and also because he himself evidently drew upon it for 2 Richard II . . I have taken as much as possible from Shakespeare's own treatment of the investigation into Woodstock's death. Secondly, where it seemed appropriate, I used, or transfused, lines drawn from earlier scenes in 1 Richard II. Thirdly, I borrowed ideas and phrases from Macbeth, Hamlet and other works, believing that this was justified because the play itself seems to anticipate these dramas in some important ways. (M. Egan 1.525)

This results in him completing the play with speeches that awkwardly rework common

\footnotetext{
${ }^{51}$ The use of deliberately recognisable Shakespearean dialogue in these scenes unintentionally served to highlight the lack of recognisable Shakespeare in the main text of Double Falsehood. For further discussion, see Kirwan, "Chasing Windmills" (forthcoming).
} 
Shakespearean quotations, as in:

Not so, my lords, at Callice was our watch

Decei'vd by murd'rers that his Majesty did send,

Who chok'd the goodly kind old man. Yet still

I do repent that in my rage I slew

The villains both and cast their bloody limbs

From off the battlements into the sea. $(5.6 .57-62)^{52}$

While KDC's approach is deliberately parodic and Egan's is serious, both work on the assumption of authorial homogeneity and self-quotation. Yet, as Heather James points out, the purpose of this kind of quotation is to be recognised and, as such, "the citation is there to help the reader retrieve the maxim, not reflect on the work as a whole" (8081). Rather than create a dramatic whole with its own authority, the excerption and insertion of recognisable Shakespeare here serves to disperse authority and maintain difference between Shakespeare and the disputed text.

Authorial attribution in a theatrical context serves a dual purpose. It informs company interpretation and audience response, in the same way as a print attribution associates the play with a recognisable canon of work which engenders expectations and encourages comparison. It also, especially in the case of Shakespeare, fulfils an important marketing function by promising a Shakespearean experience. Thus, while Shakespeare and Fletcher both appeared in KDC's publicity materials, Shakespeare was heavily prioritised throughout the programme and particularly in Addenbrooke's interpretive introduction. The lure of the Shakespeare attribution could also be seen in

\footnotetext{
${ }^{52}$ Act and scene references are taken from Egan. The references are, of course, to Hamlet ("the unseen good old man" 3.4.218) and more pointedly to Macbeth, where Lapoole substantially repeats Macbeth's faux-lament "O, yet I do repent me of my fury, / That I did kill them" (2.3.10910). This borrowing echoes not only the words, but the entire situation of a lying murderer killing two other suspects to deflect inquiry.
} 
the RSC's 2002 Edward III, attributed unambiguously in publicity materials to "William Shakespeare" with no discussion of the possibility of collaboration (programme), and the same company's 2005 Thomas More, attributed to "Anthony Munday, William Shakespeare, and Others" (programme). Despite Shakespeare's relatively minor contribution to the latter, his importance to the RSC as a "house dramatist" and guarantor of interest/authority promotes him to equal status with Munday. ${ }^{53}$

A similar appropriation of authorial capital informed Tough Theatre's 2010 production entitled $A$ Yorkshire Tragedy: Not So New as Lamentable and True at the White Bear Theatre Pub, which entirely ignored the modern attribution to Middleton and, in its place, declared the play to be "Part of the Shakespeare Apocrypha" (Programme). Fascinatingly, although presumably unconsciously, the use of an attribution based in late nineteenth- and early twentieth-century editorial practices was reflected in Victorian performance choices. Director Andy Brunskill insisted on scene breaks and blackouts between each (editorially imposed) scene, resulting in a production that fatally enforced pauses on a play that Wells argues "from Scene 2 onwards, reads as if it were written at white heat" (Taylor and Lavagnino, Collected Works 454). The Husband, in this version, became a sane, sober and calculating killer, who paused for a long while before sliding a dagger into the baby he cradled in his arms, rendering the play's violence chilling but inappropriately premeditated. ${ }^{54}$ Here, by clinging onto a Shakespeare attribution for purely commercial reasons, the company restricted itself to a respectfully traditional and formal "Shakespearean" format that diminished the production's dramatic potential.

\footnotetext{
${ }^{53}$ The attribution is interestingly reminiscent of that for The Witch of Edmonton, whose title page reads "A known true story Composed into A Tragi-Comedy by divers well-esteemed poets; William Rowley, Thomas Dekker, John Ford, \&c." (title page). As Vickers drily notes, "scholars could have done without the 'etc.'" (Co-Author 15).

${ }^{54}$ See Kirwan, "If The Law" for a full review.
} 
Two productions of Arden of Faversham in 2010 offered more productive interactions with the Shakespeare canon as a repertoire. ${ }^{55}$ Terry Hands brought the play to Theatr Clwyd Cymru in his second full production of the play, the first being a studio production at The Other Place in Stratford-upon-Avon in 1982. In the earlier production, the play was simply “Anon” (Programme). In 2010, however, the cover of the Clwyd programme emphatically stated "Arden of Faversham. By Anonymous" (Programme). The subtle but important reorientation of the authorial attribution interacts interestingly with Masten's assertion that the modern sense of the word "Anonymous", emerging c. 1676 , "begins to signal the author-ization of a text, the importance of someone, anyone, speaking. The author's emergence is marked by the notice of its absence" (Textual Intercourse 12). Where the 1982 production rendered the text "anon", the 2010 production uses the older sense of the word to refer to "a person whose name is not given, or is unknown" (12). In the former, it is the text that is ambiguous, unknown; in the latter, the text has an identity of its own and it is the authorial space that is made newly ambiguous. ${ }^{56}$ Authorial attribution is not discussed within the programme, and the play's anonymity is foregrounded in a spirit of celebration, as had been earlier articulated in John Barber's review of the 1982 production:

The drama season at Stratford-upon-Avon opens, excitingly and refreshingly, with an Elizabethan play at The Other Place that is not by Shakespeare, the ananymous [sic] "Arden of Faversham" (1590). It achieves something the great dramatist never did, being the first

\footnotetext{
${ }^{55}$ Jansohn's Zweifelhafter Shakespeare devotes its entire second half to a discussion of stage productions of Arden of Faversham, recognising the unusual popularity of this anonymous play in performance as an important focus for exploring the range of meanings of authorship in a performative context.

${ }^{56}$ The notion that a play can be advertised as "by Anonymous" will be affected, however, by the title of Roland Emmerich's forthcoming motion picture Anonymous (2011), which reclaims the word as pseudonymous for the "true" author of the works of William Shakespeare. The close association of the word with a specific authorial identity inevitably affects the ways in which the word can be used.
} 
domestic and contemporary tragedy in the language and one, moreover, based on truth. ("Refreshing")

The dissociation of play from canon becomes here "refreshing", holding up its unShakespearean status as something to be praised. Barber is expressing a similar attitude to that of Jonathan Moore in placing text before author, allowing it to break free from the interpretative constraints imposed by wider canonical associations and become defiantly "not-Shakespeare". In the theatre, despite potential individual and collective memorial associations informing interpretation, the performed text stands ultimately alone as its own authorising agent.

Peter Darney's production of Arden for the Rose Theatre on Bankside was simply "Anon", although "Kidd [sic], Marlowe and Shakespeare [are] all championed by various academics as possible authors ... and the work endures as a comic thriller which in many respects is worthy of any of those great authors" (Programme). This production located the play within an alternative canon: plays that may have been performed the original incarnation of the Rose. In 2010-11, the Rose produced Arden, Titus Andronicus, 1 Henry VI, The Spanish Tragedy, Soliman and Perseda and more. ${ }^{57}$ The unifying authorising aspect for these productions was not authorship or even company, but the social and physical conditions of the play's imagined original performances. This was embodied by the Rose itself, a cavern-like space filled with water and lit in red light, which offers a striking backdrop to the amateur productions performed on its viewing gallery and unavoidably unifies them in the eyes of the audience. By reclaiming the space as a governing concept, and evoking reportorial identity, a different set of connections was engendered. Each of these productions was performed by a different company, but the shared constraints of the playing space, the acoustics and the

\footnotetext{
${ }^{57}$ However, it should be noted that Vickers's work on the Kyd canon would argue for a shared authorial identity linking four of these plays.
} 
available resources imposed a shared identity on the plays. The hellish Ferryman of Scene 12 of Arden appeared from the void of the Rose itself, into which Joan descended in 1 Henry $\mathrm{VI}$ and from which the figures of Love, Fortune and Death arose to introduce Soliman. Comedy was foregrounded by the close proximity of actors and audience, rendering both Arden and Spanish Tragedy surprisingly amusing as would-be murderers concealed themselves between audience members' legs. In a less tangible sense, the historical connotations of the space, coupled with the hollow acoustics that are a result of being effectively underground, engendered a shared atmosphere of reverence between company and audience. Regardless of their authorial provenance, the "return" of these texts to their original home meant that each play was treated as a uniquely important revival in a full, textually faithful production.

Individual authorial identity is subsumed into performance, as Satiromastix argues. Authorship is reconstructed as a collaborative and moment-specific phenomenon, according to a shared understanding between production and audience of what the "Shakespearean" is. This can result in an experience of living disintegration if authorial identity is prioritised: at the rehearsed reading of The Two Noble Kinsmen during the Complete Works Festival, a closing question-and-answer session was dominated by audience attempts to pick out the Shakespearean sections from what they had just witnessed. However, as Worthen points out, "the meanings of the play emerge on the stage, regardless of how performers and audiences have been conditioned to produce and see them" (4-5). Prior conceptions of the Shakespearean are always reworked, rethought, appropriated or directly opposed in performance, and it is this dynamic that constitutes performed Shakespeare. It is the conflict between prior and reworked conceptions of Shakespeare that Benedict Nightingale articulates in two articles on the RSC's 2002 Edward III. Before attending, he argued that "It's up to your and my ears to judge whether Edward III should be added to the canon ... We'll have to 
wait until the RSC opens the play on April 25 for the evidence that really counts: live performance" ("The Plays What They All Wrote"). In his review of the performance, however, he postponed judgement:

The argument continues, and won't be settled until someone finds a copy of the text, inscribed "I Wille Shaksper did writte thisse," inside some antique Stratford thatch. But Anthony Clark's production of the disputed history-play, the first major one in modern England, proves it modestly gripping in its own right ... Finally, one must rely on the testimony of one's ear, and that gives a mixed report . . . But I don't think anyone could have done more to clinch the important point; never mind the author, never mind the apprentice verse, Edward III merits a place in the classical repertoire. ("A Classic of Uncertain Provenance") $)^{58}$

Nightingale's requirements for authenticity, of course, would not be met by any of the extant plays. Despite the RSC's unambiguous presentation of the play as "By William Shakespeare", here the authorial attribution was ultimately marginalised in favour of the performance. It is reconstituted as part of the "classical repertoire" despite the ambiguity of its classic author. In performance, finally, the dichotomy of Canon and Apocrypha is reversed, the work serving to exclude the author rather than the author the work. In a performance of Edward III, Edward III itself is canonical.

The modern Shakespearean repertory offers a model for a Shakespeare canon that resists notions of completeness. Instead, the cultural authority of Shakespeare is used to authorise a company's output to be more discursive, exchanging the canonical paradigm of selection and exclusion for porous notions of adaptability and recyclability.

\footnotetext{
${ }^{58}$ The "testimony of one's ear" giving "a mixed report" is a useful reminder of the cautions that need to be applied to Elliott and Valenza's "Golden Ear" test. However, despite its name, this test is an assessment of visual rather than aural impressions, asking participants to read rather than listen to extracts of text.
} 
The authority of Shakespeare, as in the Complete Works Festival, is used as a presentational framework that supports new writing, adaptation and cultural exploration. In this, the canon as repertoire is in keeping with Edward Said's notion of the "open canon" that Gorak suggests "ultimately proposes not so much the abandonment of the canon as a kind of canon in transience, a flexible arrangement of valued texts that will shift its shape according to the changing contours of the cultural scene" (220). These changing contours continue to shift the meanings and resonances of the "Shakespeare" signifier to respond to the needs of the time; and these are the processes that, as I argued in Chapter One, shaped the canon itself. The "Shakespeare repertoire" reminds us that Shakespeare is always in transience. Within this, it is not the apocryphal plays that are excluded, but notions of completeness and finality themselves.

\section{Conclusions}

Speaking of the biblical canon, Ross points out that the word "canon" previously "designated a catalogue of authors and not a rule or measure" (23). As such, he suggests,

It may therefore be useful to consider literary canons as lists as much as standards of excellence. Among the earliest forms of writings, lists are the simplest of texts, held together by the most arbitrary of syntaxes, the page they are written on ... Canons are similarly the products and signs of literate cultures, texts of texts in effect ... [and] are wholly arbitrary as syntactical units. (23)

Conceiving of canons in this way speaks to an older ethos behind the grouping of works that allows for plurality and contingency. In a Shakespearean context, the notion of canons as lists foregrounds the compiler's role in canonisation. The ethos behind the list 
- whether it is to collate the bibliographical works of Shakespeare, the authorial works of Shakespeare or the performed works of Shakespeare - is contingent, and each list speaks to its own specific purpose rather than to a single overarching paradigm.

The Shakespeare repertoire-canon continues to expand and adapt. In 2011, the RSC premiered a new version of Cardenio subtitled "Shakespeare's 'Lost Play' ReImagined" (Doran, Cardenio title page). Taking Double Falsehood as its basis, but supplementing Theobald with material both old (versified scenes from Shelton's 1613 translation of Don Quixote) and new (contributions from a contemporary Spanish dramaturge), director Gregory Doran produced a "new" Shakespeare play from a compilation of sources and authorial agents. The print canonisation of Double Falsehood by the Arden Shakespeare thus led to an institutional performative canonisation of a Cardenio the following year, and the significant textual differences between the two pointed clearly towards the transient nature of the dramatic canon as it chooses its form according to the cultural moment. The very indeterminacy and ephemerality of stage performance, both theoretically and practically resisting a notion of completeness, offers the best possible canonical space within which to understand canon as plural and inclusive. The repertoire moves in waves, meaning that plays are "rarely", rather than "never", staged. The project at Shakespeare's Globe to semi-stage every extant play from the early modern period in its "Read Not Dead" series of rehearsed readings continues to move towards a point of completion that simultaneously recedes as the series broadens its scope according to year, genre and reinterpretation. ${ }^{59}$

Said "signifies his reluctance to expel from the canon the acknowledged masterpieces already housed within it. He wants to change, rather, the mode of apprehension of those masterpieces, to open up the field of interpretation" (Gorak 195).

\footnotetext{
${ }^{59}$ On February $13^{\text {th }} 2011$, the series included for the first time the UK premiere of a new play, Wittenberg by David Davales.
} 
The resituation of plays such as Cardenio, Edward III and Thomas More in the Swan Theatre does not mean that they replace the RSC's work on the established canon of Shakespeare, but rather extend the interpretive context for those plays, as well as establishing the disputed plays in their own right. Similarly, the presentation of The Puritan alongside Macbeth in the Oxford Middleton, or of Double Falsehood alongside other volumes in the Arden Shakespeare, seeks to open up new aspects of all the plays. The practical paradigms discussed in this chapter redefine the meanings of both "Shakespeare" and "complete" in a bid to offer multiple configurations of canon that resist the exhaustion and limitation that Said is concerned with. As Werstine argues,

Now that the desire for scholarly consensus that inspired visions of definitive scholarly old-spelling authored-centred critical editions has disappeared into acceptance of mutually exclusive interpretive communities, any editor who attempted to establish once and for all "what Shakespeare wrote" as the basis for all subsequent criticism would be sure to hear about not only the futility but also the intellectual tyranny of such an aspiration. ("Editing" 51)

As textual scholarship begins to reject the fixed, idealised text and move towards the hyperlinked e-text, transcending the physical canonical boundaries imposed by the material book, so too is the fixity of the bound canon giving way to the fluidity of the printed and performed repertoire. The intention is to provide options instead of answers, foregrounding the subjectivity of editorial-directorial decisions. In both, the end user - the reader or the audience member - becomes part of the act of completion, bringing their own participation in discourses of the Shakespearean to bear on interpretation of the text and canon. 
In these discursive and collaborative canons, the point of division between "Shakespeare" and "not-Shakespeare" becomes fluid. While the New Textualism has laid the theoretical groundwork for transcending authorial boundaries and reintegrating the Apocrypha, it will take capital investment in the plays, in print and on stage, for them to re-enter the commercial and public discourses that tend towards more conservative canonical groupings. The investment in Cardenio/Double Falsehood has prompted widespread acknowledgement of the instability of canon and of the contingency of publishing and directorial decisions. Whether the play will remain a prominent part of the theatrical repertoire, or enter more edited canons, remains to be seen. Paradoxically, despite being omitted from all recent productions apart from that at Warwick, the epilogue to Double Falsehood is the text that most clearly points to the process of accommodation in canonisation. Speaking of Violante's actions after her rape, the Epilogue tells us "Had this been written to the modern stage / Her manners had been copied from the age" (Epilogue 12-13). The role of "this reforming Age" (26) in reshaping the work of Shakespeare and his contemporaries remains vital, canonising Shakespeare according to an always-shifting and redefinable set of cultural values. The new commercial availability of Double Falsehood has revived it for this reforming age and, in doing so, has demonstrated that canonical fluidity does not equate to critical or commercial unviability. Alongside the reconfigurations of canon offered in the RSC Shakespeare, the Oxford Middleton and the contemporary theatrical repertoire, the play has created space for the like revival of the remaining apocryphal plays. 


\section{Epilogue: An Apocryphal Identity}

Why ... do those who criticize canonical authority so often turn to Shakespeare to ratify the authority of their critique?

- $\quad$ Garber, Ghost Writers 235.

The remainder, like many martyrs, await canonization.

- Berger, "Shakespeare Writ Small" 62.

Where does the idea of a Shakespeare Apocrypha end? For Thomas Berger, the implication is in an eventual canonisation that, until realised, leaves the plays in a notional limbo. Yet this canonisation is implicitly never to arrive; for, as Berger believes, the plays are only "associated in one way or another with Shakespeare, often more in fancy than in fact" (62). As this thesis has already demonstrated, the associations of most of the plays with the Shakespeare canon are factual, not fanciful, but the diversity and fluidity of those connections problematises their canonical position. They do not meet the standard author-based conditions for publication in a Shakespearean collection, and few of the individual plays have the level of recognition necessary to prompt a commercial edition or production.

If the plays are not to be canonised, however, this does not mean that they need to remain unread. Returning to the biblical Apocrypha, Metzger usefully reminds us that a division in kind between Canon and Apocrypha need not mean an occlusion of the other. "In Luther's German translation of the Bible (1534) the Apocrypha stand between the Old Testament and the New Testament, with the title: "Apocrypha, that is, books which are not held equal to the sacred Scriptures, and nevertheless are useful and good to read" (vi). The qualification Luther's Bible added to the biblical Apocrypha 
offers, to a modern society that equates religious doctrine with absolute canonical sanctity, a surprisingly relaxed attitude towards authority within its pages. Divine inspiration, the equivalent here of authorial intent, does not determine constitution. Instead, a difference is noted in paratextual detail and the reader is allowed to choose what is read. Carroll and Prickett offer a similar assessment. "Such stories, for instance, as Susanna and the Elders - arguably the first piece of detective fiction - have been so popular with later writers and artists that to leave them out would have unnecessarily mutilated what is probably the world's most longstanding best-seller (xxv). The apocryphal books have their own qualities, and are both readable and popular. From a literary point of view, their absence is detrimental to the book. The sanctity of the book is here not dependent on its authorisation by a single governing source, but by its ongoing ratification in discourse. Carroll and Prickett's edition - in the Oxford World's Classics series, rather than sponsored by a religious group - reclaims an earlier state of canonicity in deliberate opposition to the dominant sixty-six-book biblical model, arguing for the prioritisation of a different kind of value.

While this thesis has has argued for the destabilisation of the Apocrypha, and for the fluidity of canonical boundaries, there may still be something to be said for the shared identity of the group. The discourses that have bound them together have also served to inflect the experience of encountering them. They are implicitly transgressive, both in the texts themselves (the dangerous politics of More, the bloody slaughter of Yorkshire Tragedy, the class erosion of Mucedorus) and in their destabilising potential on the stage. Productions of apocryphal plays cause a stir, and new editions prompt outrage. This need not be an entirely negative thing. As Rosenbaum's comments at the start of Chapter Four demonstrate, the debates open up the possibility for re-evaluation of established ways of thinking. The status of the plays also offers potential for rediscovery, as in Stodder's three reviews of the Los Angeles Globe's season of 
apocryphal plays. "The plays ... do possess considerable merit in performance and are quite capable of standing by themselves as worthy examples of Elizabethan and Jacobean Theatre" ("Three Apocryphal Plays" 248). Speaking of the audience experience, he claimed that "for most [the thrill] was mainly the experience of seeing these plays, so long neglected, brought to life again on the stage" ("Review: Continued" 238). ${ }^{1}$ The group identity of these plays is historical, and continues to make these kinds of collective discovery possible.

In addition, it is only through prioritising the history of the plays as Apocrypha that the idea of Apocrypha can be challenged. The suggestions of Jowett ("Supplemented") and Proudfoot ("Is There?") offer to disperse the plays, whether into the canons of other authors or into a wider textual-historical-performative culture. While this rehabilitates the standing of individual plays, it disregards the historical biases that have impacted on the reception and criticism of those plays. One cannot break down a category by moving specific plays out of it, as this continues to tacitly accept the need for the category. The acknowledgement of a shared identity for the apocryphal plays allows for a critique of that identity, as offered in this thesis.

However, while there is a need to reassert the position of the apocryphal plays en masse alongside the Shakespeare canon, this does not mean that the group needs to be treated as homogeneous. While several of the plays are importantly linked (the 1664 folio additions to one another; the King's Men's plays to the rest of their repertory), the overriding feature of the apocryphal plays is their diversity. This is occluded in discussions of the plays as a group which elide their important differences.

\footnotetext{
${ }^{1}$ The productions Stodder reviews for Shakespeare Quarterly include: Arden of Feversham, The Puritan, The Raigne of King Edward III ("Three Apocryphal Plays"), The London Prodigal, Thomas Lord Cromwell, Sir John Oldcastle (Part One), The Yorkshire Tragedy ("Review: Continued"), Mucedorus and The Birth of Merlin ("Mucedorus").
} 
Lene Petersen, creator of KEMPE (Korpus of Early Modern Playtexts in English) divides her 287 texts into thirty-eight "author/canon groups" (164). Most of these are single authors, some collaborative (Fletcher/Massinger, Middleton/Rowley etc.). She also includes a grouping for "ANONYMOUS" and, finally, one for "APOCRYPHA," which includes the fourteen plays in Brooke's Apocrypha with the addition of The Taming of a Shrew. Despite her recognition that "the group remains internally inconsistent and semigeneric", she justifies her grouping because it "is believed to be inspired by 'the school of Shakespeare'" (213), which Petersen interprets literally as "inspired by him" (216). This, of course, makes no allowance for the different kinds and quality of attribution, which range from the purely internal (Edward III, Arden) to the purely external (Oldcastle, Merlin) to plays written far too early to be "inspired" by Shakespeare in a linguistic sense (Locrine, Mucedorus). She continues to treat the group as having a shared identity as she reapportions texts according to her principal component analysis - the quartos of Merry Wives, Two Noble Kinsmen and Pericles are categorised under APOCRYPHA, Yorkshire Tragedy moves from APOCRYPHA to the "Shakespeare Folio" group; Edward III goes to Kyd, Locrine to Marlowe and so forth (214-16). Regardless of the validity of Petersen's investigations in other contexts, she fails to address the fundamental problem here: the tests impose a homogeneous identity onto the hugely diverse apocryphal plays, muting their individual characteristics in a way that prevents fair comparison with plays in single-authored canons.

Is this the inherent risk of repeatedly publishing the plays in concert with one another? Can any amount of paratexts and theoretical justification counter the overriding impression that a group of plays, bound and edited together, share a homogeneous identity? As Petersen herself notes, "once added, works can be hard to subtract from putative author groupings" (161), which would seem to include the APOCRYPHA category. The New Textualism, however, gives us the opportunity to re- 
group these plays with attention to ambiguity. Jowett, discussing his planned two-text editorial treatments of Measure for Measure and Sir Thomas More, argues that

Both editions are playing initiatory roles in redefining canons ... the fact that these texts are being deliberately and conspicuously moved into a new context correlates meaningfully with the textual mobility that will be seen within these editions... To this extent, the two-text editing of these plays is a mark of the problematic nature of authorial canons. Two-text editing says that these plays can be securely placed neither within nor without authorial canons as they are usually conceptualized. It defines an authorial penumbra. It suggests a practical, concretized image of authoriality not as a set of sealed containers but as an intercanonical network. Paradoxically, in order to sustain this image that erodes the authorial boundaries, the local markers of authorship within the text, as far as they are understood by scholars, must always be clear to the play's readers. ("Addressing Adaptation" 75) ${ }^{2}$

Jowett's remarks are particularly relevant to editors of any putative collection of disputed Shakespeare plays. If the idea of an Apocrypha is to be rethought for the twenty-first century, the plays must be edited with attention to their differences and ambiguities, their textual complexities and the variety of forms of authorship embedded within them.

One approach will be offered in 2013, when the RSC Shakespeare is supplemented by a new volume entitled Collaborative Plays by Shakespeare and Others. Edited by Bate and Rasmussen, this companion volume to their Complete Works will

\footnotetext{
${ }^{2}$ In the event, Jowett did not adapt a parallel-text layout for sections of the Arden Thomas More, although the edition stays true to his project of drawing attention to the layers of textuality and adaptation in the manuscript.
} 
offer the first completely new edition of the disputed plays as a group in over a century. Its constitution is partly determined by commercial considerations: Pericles and The Two Noble Kinsmen, included in the Complete Works volume, have no place here. Instead, the edition will include those plays for which the strongest case for a Shakespearean involvement can be made. Thomas More, Edward III, Arden of Faversham and Double Falsehood are included according to attribution studies that assign sections of the play to Shakespeare. Mucedorus, Locrine and the additions to The Spanish Tragedy are included as examples of possible revisory work. The London Prodigal, Thomas Lord Cromwell and The Merry Devil of Edmonton are all anonymous Chamberlain's-King's Men's plays associated with Shakespeare, and are included for their connections to his repertory. Finally, A Yorkshire Tragedy, despite the play's current association with Middleton, is included owing to its still-ambiguous role as one of "Four Plays in One", with which Shakespeare may have been involved. The grouping of the plays and the editing under one remit will, for better or worse, continue to associate them as a group, presented with a measure of uniformity and under a single institutionalised remit. ${ }^{3}$

The edition remains compromised, in thrall to the spectre of a governing author who continues to legitimise the commercial packaging of plays by appealing to the notion that they may contain Shakespeare's presence. However, as Marcus notes, "Poststructuralist iconoclasm preserves the icon, if only as a continuing ground for its own energies of defacement and dispersal” (Puzzling 213). By foregrounding collaboration as the priority, rather than a subsidiary element of the edition, authorial authority is instantly dispersed. This helps avoid many of the problems which Gossett

\footnotetext{
${ }^{3}$ Gossett discusses the specific problems of standardising presentation when editing collaborative drama. "Modernising tends to mask or remove precisely the evidence employed to determine authorship and/or collaboration" ("Editing Collaborative Drama" 215). While this might, from a post-structuralist point of view, do the necessary work of prioritising the collaborative text as an object of interest in its own right, from a materialist perspective it elides important idiosyncracies of the material text.
} 
argues are endemic to the editing of collaboration, such as the implicit relegation of "inferior" collaborations to the back of a volume ("Editing Collaborative Drama" 214). With collaboration presented as the subject, rather than a distraction from the authorial canon, the plays' ambiguities become an object of interest rather than a negative. The disparity of the models of authorship included in the volume will also be foregrounded in the presentation of the plays: the additions to Mucedorus, for example, will be printed in a different typeface, and the excerpted additions to The Spanish Tragedy will be edited independently of the rest of the play and presented as an example of (possible) individual revisionary work. ${ }^{4}$ While Masten, Werstine and others have disputed the validity of this strategy in the case of Hand D of Thomas More (see Chapter Three), in the context of a Collaborative Plays volume the presentation will draw attention to the eclecticism both of the edition and of early modern dramatic authorship. The incompleteness of these fragments, one might argue, serves the same purpose as the empty brackets that conclude Sonnet 126, which Orgel argues "stand as emblematic of the whole ... as if to say that the one more couplet that might really do the trick, finally provide some sense of closure, is missing" ("Desire and Pursuit" 293). The incompleteness of the text, and thus of the canon, is implicit. Importantly, while the title of the edition may be misleading (if the volume is of "collaborative plays", whither 1 Henry VI, Timon of Athens, Macbeth?), the deliberate change of title from “Disputed Plays" or "Apocrypha" is important. There is no definite article; this is not "The" Apocrypha, or "All of" the disputed plays. In a modern critical climate influenced by post-structuralism and textual materialism, the edition gestures towards an open-ended canon that overlaps with, supplements and contradicts its companion volume. In doing so, the plays may regain something of their ever-present, contentious function, reengaging with the canon and transcending simple authorial boundaries.

\footnotetext{
${ }^{4}$ Jackson's argument of 1964 that the 1610 additions to Mucedorus are Shakespeare's has not since been revisited ("Archer's Ascription").
} 
The impact of that edition remains to be seen. Elsewhere, with the third edition of the Oxford Shakespeare in preparation and new "Complete Works" events being mounted to coincide with the 2012 Cultural Olympiad, the group identity of the plays continues to underpin their inclusion or exclusion from projects. As this thesis has shown, however, their shared identity can be historicised, re-theorised and used to effect a reconsideration of the processes of canonisation that still require an Apocrypha. Marcus tells us that "Any closed-off space inhabited for too long is likely to become confining" (Puzzling 31). Her call for historically localised reading is one of the ways by which she suggests we can move towards Shakespeare as an "ongoing cultural activity" or "set of related, often competing, activities which need to remain open in order to retain their vitality" (218-19). The formalisation of the canon is the most fundamental means by which "Shakespeare" becomes "closed off". The category of the Apocrypha may be seen as a useful corrective to this, drawing attention to the artificiality of the boundaries imposed on Shakespeare. By confronting rather than ignoring the issues the disputed plays raise, the Shakespeare canon can remain a vital field of inquiry. 


\section{Appendix}

\section{"The First Collected 'Shakespeare Apocrypha'"}

[This is a reprint of a note accepted for publication in a future issue of Shakespeare Quarterly, and is included here for reference.]

The disparate group of early modern plays still referred to by many critics as the "Shakespeare Apocrypha" take their dubious attributions to Shakespeare from a variety of sources. Many of these attributions are external, such as the explicit references on the title pages of The London Prodigal (1605), A Yorkshire Tragedy (1608), 1 Sir John Oldcastle (1619), The Troublesome Raigne of King John (1622) The Birth of Merlin (1662), and, more ambiguously, the initials on the title pages of Locrine (1595), Thomas Lord Cromwell (1602) and The Puritan (1607). Others, including Edward III, Arden of Faversham, Sir Thomas More and many more, have been attributed much later on the basis of internal evidence.

The first collection of disputed plays under Shakespeare's name is usually understood to be the second impression of the third folio in 1664, which "added seven Playes, never before Printed in Folio" (Title page). Yet there is some evidence of an interest in dubitanda before the Restoration. The case of the Pavier quartos, which included Oldcastle and Yorkshire Tragedy among authentic plays and variant quartos in 1619 , has been amply discussed elsewhere as an early attempt to create a canon of texts that readers would have understood as "Shakespeare's", despite later critical division of these plays into categories of "authentic" and "spurious," which was then supplanted by the canon presented in the 1623 folio. ${ }^{1}$ I would like to attend, however,

\footnotetext{
${ }^{1}$ For excellent recent discussions see: Murphy (Shakespeare in Print 36-41); Massai (Rise of the Editor 106-35) and Jowett (Shakespeare and Text 69-72).
} 
to a much more rarely examined early collection of plays. Mucedorus, Fair Em and The Merry Devil of Edmonton, all included in C.F. Tucker Brooke's seminal The Shakespeare Apocrypha (1908), derive their original attribution from their inclusion in an early binding of plays inscribed with the title "Shakespeare, Vol. 1.", that originally belonged to the Royal Library. The attribution of Mucedorus and Merry Devil to Shakespeare is supported by the book catalogues of Edward Archer (1656) and Francis Kirkman (1661). Quartos of both of these plays additionally confirm that they were owned by the King's Men. The attribution of Fair Em, however, rests solely on inclusion in "Shakespeare, Vol. 1." It is this volume that concerns this essay.

\section{Redating the volume}

Despite the volume's obvious importance to the history of these plays, and its ubiquitous appearance in the footnotes of papers on Mucedorus, Fair Em and Merry Devil, critics have been content merely to repeat information about the volume without cross-checking its provenance and constitution, which has led to two important features of the volume being overlooked. The volume passed into the collection of David Garrick, and it is his testimony, supported by Edward Capell, who catalogued Garrick's collection, that affirms the volume's original provenance. The volume in turn passed into the British Museum, and was broken up in the 1840s on the orders of Anthony Panizzi. Regrettably, the volume binding is no longer extant.

All twentieth-century references to the volume state that it belonged to the library of Charles II, a belief continued in articles as recent as John Jowett "Shakespeare Supplemented" (2007), Richard Preiss, "A Play Finally Anonymous" (2007) and Pavel Drábek, "Shakespeare's Influence on Mucedorus" (2008). However, the earliest references to the volume all concur that it in fact belonged to the library of Charles the First. Capell, who rebound it as Garr.I.VIII, unequivocally refers to Charles the First in his 
mention of the volume in his $1768 \mathrm{Mr}$. William Shakespeare his comedies, histories, and tragedies (1.“Table of his Editions"). He is followed by George Steevens in his 1778 The Plays of William Shakspeare, whose footnotes report that Merry Devil was "Bound up in a volume of plays attributed to Shakspeare, and once belonging to King Charles I, but now in Mr. Garrick's collection" and that Mucedorus was "Bound up in a volume of plays attributed to Shakspeare, and once belonging to King Charles the First. See Mr. Garrick's Collection" (1.260n). These footnotes are in turn quoted by Edmond Malone in 1790 in The Plays and Poems of William Shakspeare, in ten volumes (1.257n, 259n).

The error appears for the first time in the 1793 "First Variorum", in three footnote references to the volume by Steevens $(1.432 n, 433 n, 453 n)$. All three references note "a volume" belonging to Garrick, which is respectively attributed to the library of "King Charles II", "King Charles the Second" and "King Charles II". There is no stated reason for the change, and the fact that the footnotes are otherwise repeated verbatim from the 1778 edition suggests there has been no fresh examination of the material. The third footnote, which is repeated in the 1821 Malone-Boswell Variorum reads "In Mr. Garrick's collection is a volume, formerly belonging to King Charles II, which is lettered on the back 'Shakespeare, Vol. I'. This volume consists of Fair Em, The Merry Devil \&C., Mucedorus, \&c. There is no other authority for ascribing Fair Em to our author" (2.682n). Where Malone followed Steevens's authority in 1790, the MaloneBoswell volume consistently follows Steevens's most recent footnotes and provides no independent evidence. Responsibility for the change thus rests solely with Steevens, whose original reference to the volume was based entirely on Capell's report, suggesting that the change is a simple mistake. George M. Kahrl, the most recent bibliographer of the Garrick collection (1982), comes to the same conclusion and silently emends the 1821 footnote to read "Charles I" (139). 
However, the prominence of the 1821 variorum acted to preserve the mistake in critical discourse for future generations, particularly influencing scholars at the turn of the century. It was Simpson's source in School of Shakespeare (1878), on which basis he asserted that the attribution was a "tradition current in the time of Charles II" (2.339). Both E.K. Chambers (The Elizabethan Stage 4.12, 30, 36, and Facts and Problems 1.538) and Sir Sidney Lee (264) explicitly take their references to the volume from the 1821 edition, and it appears also to have been the basis for Brooke, who refers to "Charles the Second" throughout The Shakespeare Apocrypha, and who had certainly read Simpson. With these books acting as standard reference sources for all scholars subsequently working on the apocryphal plays, the error was passed on without cross-checking. A useful corollary is found in Preiss's article which, in using Jupin's edition of the play as its basis, compounds an error in Jupin (22) by retitling the volume "Shakespeare, Vol. II" (121); an immediately relevant example of how easily such mistakes are made and sustained.

The attribution of the volume to the library of either Charles I or Charles II cannot, unfortunately, be firmly substantiated by independent evidence: the extant quartos themselves are unannotated except for Capell's catalogue numbers. We do not know at what point the volume left the Royal Library, but it was not part of the (Old) Royal Library gifted to the British Museum in 1757. However, the well-documented history of Charles I's annotated copy of the 1632 folio may provide some guidance. Sir Thomas Herbert, Charles's jailor from 1647, claimed to have been given several books including the folio - as a gift by Charles. T.A. Birrell reports that the volume "belonged to Herbert, and then via Dr Richard Mead and Antony Askew, to George Steevens," before being bought back by George III" (45). As Birrell points out, the dispersal of royal property in the aftermath of the war, and the treatment of Charles's possessions as "relic[s] of a martyr" means that it is difficult to separate forged claims from genuinely 
dispersed volumes; however, that an authentic volume from Charles I's library made its way to Steevens affirms the possibility of his contemporary, Garrick, receiving another "Shakespeare" volume by a similar route. Charles II, by contrast, was more interested in retaining and recovering the books belonging to his father (Birrell 47). In the absence of confirmatory evidence, our only authoritative source is Capell, and his ascription to the library of Charles I must cautiously stand.

\section{The constitution of the volume}

A more significant error occasioned by critical oversight concerns the constitution of Garr.I.VIII. All references to the volume from Capell onwards mention only three plays - Mucedorus, Fair Em and Merry Devil - and the implication has increasingly been that this is exhaustive, as in Simpson's note that "The volume contained also [in addition to Mucedorus] Fair Em, and another" ("On Some Plays Attributed to Shakespeare" 157), and Roslyn Knutson's suggestion that, as the two other plays in the volume belonged to Shakespeare's company, so also may Fair Em have come from the same company (Repertory 184). However, as noted by George Kahrl and Dorothy Anderson in their catalogue of the Garrick collection, the volume in fact contained no fewer than eight plays, bound in the following order:

The Puritan (1607)

Thomas Lord Cromwell (1613)

The Merry Devil of Edmonton (1631)

The London Prodigal (1605)

Mucedorus and Amadine (1598) 
Fair Em (1631)

Love's Labour's Lost $(1631)^{2}$

The eighth play was a copy of 1 Sir John Oldcastle (1600), as noted on Capell's flyleaf for Garr.I.VIII, but apparently sold as a duplicate following the break-up of the volume in the British Museum (Kahrl and Anderson 128). Capell's footnote to the volume reads "it is worth remarking, that this volume, bound as it is, belong' $\mathrm{d}$ to $\mathrm{K}$. Charles the first, and is titl'd upon the back, Shakespeare. Vol. I." (Catalogue; qtd. in Kahrl and Anderson 199). Kahrl confirms that "Capell appears to have left this volume in its original binding, or at least did not break up and disperse the contents; he listed the eight items, which included one Shakespeare play and others ascribed to him, consecutively; the Capell flyleaf is of a different paper from that used for the other flyleaves, indicating that the volume was not rebound" (199). Kahrl thus supports Capell's claim that, while most of the plays from the Garrick collection had originated from the Harleian library via Robert Dodsley, this volume from a different source had already been bound separately, and that the plays already bound together continued to be grouped until divided by Panizzi in the nineteenth century. ${ }^{3}$

How, then, have 350 years of scholarship on the apocryphal plays failed to notice that the volume contained five other plays? I would like to suggest that this is in no small part due to Capell's tortuous referencing mechanism in the original notes on the plays in his "Table of Editions of plays ascribed to Shakespeare."

The seven, with single aster-isks, are publish'd with his other plays in a folio edition printed in 1664, and in some editions since. O.C. signified, old catalogues; in some of which, these two plays are scrib'd to

\footnotetext{
${ }^{2}$ As listed on Capell's flyleaf for the volume, preserved in the British Library (A Catalogue of Plays).

${ }^{3}$ A useful summary is provided by Moelwyn I. Williams 110-11.
} 
Shakespeare: and the remaining three, distinguish'd by crosses, are in a volume, now in Mr. Garrick's possession, that did belong to king Charles the first, which is titl'd upon the back, "SHAKESPEAR Vol. 1:" and these likewise are given to him by old catalogues, "Fair Em" excepted, which is Therefore differenc'd by having but one cross-bar. (1: Introduction)

Capell's system of categorisation is based on a hierarchy of strength of attribution to Shakespeare. Love's Labour's Lost is treated as authentic, and not discussed by him in this section. The London Prodigal, The Puritan, Sir John Oldcastle and Thomas Lord Cromwell were all included in the second impression of the 1664 third Shakespeare folio, and are thus marked with single asterisks. Mucedorus, Fair Em and Merry Devil are the only plays remaining whose attribution to Shakespeare needs to be supported by inclusion in the Charles I volume, and the crosses serve to distinguish them from the other two plays whose evidence for attribution is based solely on old catalogues: Edward III (1595) and The Arraignment of Paris (1584). The plays are "in a volume" (my emphasis); they do not constitute the entire volume, as has subsequently been assumed.

The implications of this are to alter significantly our understanding of the nature of these early attributions. The size of this volume, and the inclusion of four non-folio plays with an explicit or implied Shakespearean attribution, shows that the binder of the collection was attempting to compile a collection of Shakespeareana. It is, in fact, the first attempt to create a "Shakespeare Apocrypha" in the sense that, with the odd exception of Love's Labour's Lost, it compiles non-canonical plays under a single heading. Further, the volume responds immediately to the bookselling market of the day. Three of the quartos are dated 1631, which becomes the earliest possible date for the compilation. This goes some way to supporting the ascription to Charles I's library, 
and may also suggest that the reason for the inclusion of the canonical Love's Labour's Lost and the previously unassigned Merry Devil and Fair Em was their recent publication, making them available to pad out the compilation.

\section{Implications}

The correct date and constitution for the volume have some further interesting implications. A basic one is to weaken the volume's support for Knutson's proposed attribution of Fair Em to the Chamberlain's-King's Men's ownership. Where its presence in a three-play volume with two other company plays seemed promising, its inclusion instead in an eight-play volume incorporating plays belonging to the Children of Paul's (The Puritan) and the Admiral's Men (Oldcastle) reminds us that the plays do not have a homogeneous origin, and that the volume provides no evidence for company attribution.

The second, and much more significant, implication is that the collection provides evidence of a much earlier association of several of these plays with Shakespeare than previously thought. Of the eight, only three (Oldcastle, London Prodigal, Love's Labour's Lost) had been explicitly attributed to Shakespeare by 1623. Two more (Cromwell, The Puritan) were attributed to "W.S.". The 1664 folio is usually understood to be the first authority to expand these initials to infer Shakespeare, along with Locrine, in 1664. The earliest alternative ascription of Mucedorus and Merry Devil, meanwhile, are the booksellers' catalogues of 1656 and 1661.

The re-dating of the Charles I volume to the years immediately following 1631 thus allows us to back-date the association of Shakespeare's name with Cromwell, Puritan, Mucedorus, Fair Em and Merry Devil by some thirty years. This has significant implications for an understanding of the formation of the Shakespeare Canon and 
Apocrypha. The spate of attributions in the 1650 s and 1660 s can be explained by the rupture in professional playing and the distance from the plays' original circumstances of production, but the Charles I volume suggests that the notion of a Shakespearean "supplement" or "Apocrypha" already existed in the Caroline period, taking shape as early as a decade after the publication of the 1623 folio and suggesting that the "canon" established by that volume was already unstable in discourse.

While the Charles I volume was a unique "nonce" collection, and would therefore have only a limited readership and impact, the importance of such collections should not be underestimated. Sonia Massai's recent groundbreaking work on early modern readers of Shakespeare has made a compelling case for the importance of nonce collections and annotating readers both in shaping Shakespeare's works and in providing an insight into how Shakespeare was read and interpreted by successive generations, and goes so far as to suggest that the Pavier collection was deliberately designed to resemble a nonce collection in order to whet appetites for the folio (Rise of the Editor 115-19). In a manner not dissimilar to the Pavier project, the Charles I volume acts as an authority, not on what Shakespeare wrote, but what could legitimately be read as Shakespearean; and, as a one-off compilation for an individual library rather than a publishing project, the volume's attribution to Shakespeare has readerly rather than commercial implications.

Eric Rasmussen and Richard Proudfoot have recently suggested that the proliferation of quartos of disputed plays in the mid-1630s may have been a response to the publication of the second Shakespeare folio in 1632:

The considerable number of extant copies [of The Two Noble Kinsmen] suggests a sizeable print run. Perhaps the 1634 quarto was intended as a supplementary volume to be sold in association with the Shakespeare 
Second Folio, which was published by Cotes in 1632 and apparently reissued by Cotes and his brother, Richard, throughout the decade. The sixth quarto of Pericles, printed by Cotes in 1635 , may also have been published to supplement F2. (Analogously, Humphrey Moseley published The Wilde-Goose Chase in folio in 1652 as a companion to his 1647 Beaumont and Fletcher Folio with which it is sometimes bound.). (The Two Noble Kinsmen vii)

This suggestion imagines a vogue for Shakespeare in the years following the publication of the 1632 folio that prompted the gathering and republication of non-folio plays that could be presented and read as Shakespeare's. The compilation of the Charles I volume at this time may thus be seen as a further symptom of this trend: an early attempt to gather together plays with a potentially Shakespearean attribution, similar in kind to that carried out by Chetwind in the early 1660s.

We should not infer from this that the Charles I volume has any unique authority on questions of attribution, or that its inclusions/exclusions have implications for continuous associations of Shakespeare's name with these plays. However, through correcting some long-held bibliographical assumptions, we can see an earlier state of instability in the creation of the Shakespeare canon, with the notion of an "Apocrypha" emerging almost as soon as the "canon" was consolidated in 1623. While we may never be fully able to comprehend the entirety of what early modern readers and audiences perceived to be "Shakespeare's", the Charles I volume suggests that, even before the closure of the theatres, there were already several potential answers to that question. 


\section{Works Cited}

In order to best suit the theoretical rationale and structure of this thesis, this Works Cited list is divided into four sections. The first lists sixteenth- and seventeenth-century works according to chronology, with putative authors removed in favour of a more neutral approach to early modern authorship. The second section lists later editions, anthologies and quotation books of early modern plays according to editor for convenience, as my citations primarily refer to paratextual and editorial matter. The third section, the critical bibliography, is presented in alphabetical order according to author/editor as per standard formatting systems. The final section gives details of selected theatrical performances I attended which bear on my discussion in Chapter Four.

\section{(a) Sixteenth- and seventeenth-century texts (chronological)}

Comoedia A worke in ryme, containing an enterlude of myndes, witnessing the mans fall from God and Christ. Set forth by HN, and by him newly perused and amended. Translated out of Base-almayne, into English. Cologne, 1574. Early English Books Online. Web. 25 July 2011.

The Psalmes of Dauid truly opened and explaned by paraphrasis, according to the right sense of euerie Psalme. With large and ample arguments before euerie Psalme, declaring the true vse thereof. To the which is added a briefe table, shewing wherevnto euery Psalme is particularly to be applied, according to the direction of M. Beza and Tremellius. Set foorth in Latine by that excellent learned man Theodore Beza. And faithfully translated into English, by Anthonie Gilbie, and by him newlie purged from sundrie faultes escaped in the first print, and supplied with the principal pointes of euerie Psalme, summarilie set downe in a table at 
the end of the booke. London, 1590. Early English Books Online. Web. 25 July 2011.

Greenes, groats-vvorth of witte, bought with a million of repentance Describing the follie of youth, the falshoode of makeshifte flatterers, the miserie of the negligent, and mischiefes of deceiuing courtezans. Written before his death, and published at his dyeing request. London, 1592. Early English Books Online. Web. 25 July 2011.

The lamentable tragedie of Locrine, the eldest sonne of King Brutus discoursing the warres of the Britaines, and Hunnes, with their discomfiture: the Britaines victorie with their accidents, and the death of Albanact. No lesse pleasant then profitable. Newly set foorth, ouerseene and corrected, by VV.S. London, 1595. Early English Books Online. Web. 25 July 2011.

A rich store-house or treasury for the diseased Wherein, are many approued medicines for diuers and sundry diseases, which haue been long hidden, and not come to light before this time. Now set foorth for the great benefit and comfort of the poorer sort of people that are not of abilitie to go to the physitions. By A.T. London, 1596. Early English Books Online. Web. 25 July 2011.

A most pleasant comedie of Mucedorus the kings sonne of Valentia and Amadine the Kings daughter of Arragon with the merie conceites of Mouse. Newly set foorth, as it hath bin sundrie times plaide in the honorable cittie of London. Very delectable and full of mirth. London, 1598. Early English Books Online. Web. 25 July 2011.

The true chronicle historie of the whole life and death of Thomas Lord Cromwell As it hath beene sundrie times publikely acted by the right honorable the Lord 
Chamberlaine his seruants. Written by W.S. London, 1602. Early English Books Online. Web. 25 July 2011.

The London prodigall As it was plaide by the Kings Maiesties seruants. By VVilliam Shakespeare. London, 1605. Early English Books Online. Web. 25 July 2011.

Two most vnnaturall and bloodie murthers the one by Maister Cauerley, a Yorkeshire gentleman, practised vpon his wife, and committed vppon his two children, the three and twentie of Aprill 1605. The other, by Mistris Browne, and her seruant Peter, vpon her husband, who were executed in Lent last past at Bury in Suffolke. 1605. London, 1605. Early English Books Online. Web. 25 July 2011.

A most pleasant comedie of Mucedorus, the kings sonne of Valentia, and Amadine the kinges daughter of Arragon, with the merry conceits of Mouse. Newly set foorth, as it hath bin sundry times playde in the honorable cittie of London. Very delectable, and full of mirth. London, 1606. Early English Books Online. Web. 25 July 2011.

A Yorkshire tragedy Not so new as lamentable and true. Acted by his Maiesties Players at the Globe. VVritten by VV. Shakspeare. London, 1608. Early English Books Online. Web. 25 July 2011.

The merry deuill of Edmonton. As it hath beene sundry times acted, by his Maiesties Seruants, at the Globe, on the banke-side. London, 1608. Early English Books Online. Web. 25 July 2011.

A nest of ninnies Simply of themselues without compound. Stultorum plena sunt omnia. London, 1608. Early English Books Online. Web. 25 July 2011. 
A most pleasant comedie of Mucedorus the Kings sonne of Valentia, and Amadine the Kinges daughter of Aragon With the merry conceites of Mouse. Amplified with new additions, as it was acted before the Kings Maiestie at White-hall on Shroue-sunday night. By his Highnes Seruantes vsually playing at the Globe. Very delectable, and full of coneeited [sic] mirth. London, 1610. Early English Books Online. Web. 25 July 2011.

The true chronicle historie of the whole life and death of Thomas Lord Cromwell As it hath beene sundry times publikely acted by the Kings Maiesties Seruants. Written by VV.S. London, 1613. Early English Books Online. Web. 4 August 2011.

The first part of the true \& honorable history, of the life of Sir lohn Old-castle, the good Lord Cobham As it hath bene lately acted by the Right honorable the Earle of Notingham Lord High Admirall of England, his seruants. Written by William Shakespeare. London, 1619. [Misdated 1600]. Early English Books Online. Web. 25 July 2011.

Villiam Shakespeares comedies, histories, \& tragedies Published according to the true originall copies. London, 1623. Early English Books Online. Web. 25 July 2011.

The life and death of the merry deuill of Edmonton With the pleasant prancks of Smug the smith, Sir lohn, and mine host of the George, about the stealing of venison. By T.B. London, 1631. Early English Books Online. Web. 25 July 2011.

The two noble kinsmen presented at the Blackfriers by the Kings Maiesties servants, with great applause: written by the memorable worthies of their time; Mr. Iohn Fletcher, and Mr. William Shakspeare. Gent. London, 1634. Early English Books Online. Web. 10 August 2011. 
The witch of Edmonton a known true story composed into a tragi-comedy by divers wellesteemed poets, William Rowley, Thomas Dekker, John Ford, \&c. London, 1658. Early English Books Online. Web. 11 August 2011.

A true, perfect, and exact catalogue of all the comedies, tragedies, tragi-comedies, pastorals, masques and interludes, that were ever yet printed and published, till this present year 1661 all which you may either buy or sell at the several shops of Nath. Brook at the Angel in Cornhil, Francis Kirkman at the John Fletchers Head, on the back-side of St. Clements, Tho. Johnson at the Golden Key in St. Pauls Churchyard, and Henry Marsh at the Princes Arms in Chancery-lane near Fleetstreet. London, 1661. Early English Books Online. Web. 25 July 2011.

Mr. William Shakespear's comedies, histories and tragedies published according to the true original copies : and unto this impression is added seven playes never before printed in folio, viz. Pericles Prince of Tyre, The London prodigall, The history of Thomas Ld. Cromwell, Sir John Oldcastle Lord Cobham, The Puritan widow, A York-shire tragedy, The tragedy of Locrine. London, 1664. Early English Books Online. Web. 25 July 2011.

"An Epilogue". Miscellany poems containing a new translation of Virgills eclogues, Ovid's love elegies, odes of Horace, and other authors : with several original poems by the most eminent hands. London, 1684. 291-92. Early English Books Online. Web. 25 July 2011.

Titus Andronicus, or, The rape of Lavinia, acted at the Theatre Royall: a tragedy, alter'd from Mr. Shakespears works. London, 1687. Early English Books Online. Web. 25 July 2011. 


\section{(b) Later editions of playtexts (alphabetical by editor)}

Abrams, William Amos, ed. The Merry Devil of Edmonton. Durham: Duke UP, 1942. Print.

Alexander, Peter, ed. The Complete Works of William Shakespeare. London and Glasgow: Collins, 1951. Print.

Armstrong, Jane, ed. The Arden Dictionary of Shakespeare Quotations. Walton-onThames: The Arden Shakespeare, 1999. Print. The Arden Shakespeare.

Ayers, Philip J., ed. Sejanus his Fall. Manchester: Manchester UP, 1990. Print. The Revels Plays.

Bang, W., ed. The Tragical Reign of Selimus: 1594. London: Chiswick Press, 1908. Print. Malone Society Reprints.

Bate, Jonathan, ed. Titus Andronicus. London and New York: Routledge, 1995. Print. The Arden Shakespeare.

Bate, Jonathan, and Eric Rasmussen, eds. William Shakespeare: The Complete Works. New York: Modern Library, 2007. Print. The RSC Shakespeare.

Bate, Jonathan, and Eric Rasmussen, eds. King Lear. Basingstoke: Macmillan, 2009. Print. The RSC Shakespeare.

Bennett, Nicola, ed. The Merry Devil of Edmonton. London: Nick Hern Books, 2000. Print. Globe Quartos.

Bevington, David, ed. Troilus and Cressida. Walton-on-Thames: Nelson, 1998. Print. The Arden Shakespeare.

Bevington, David, and Eric Rasmussen, eds. Doctor Faustus. Manchester: Manchester UP, 1993. Print. The Revels Plays. 
Blayney, Glenn H.,ed. The Miseries of Enforced Marriage. Oxford: Oxford UP, 1964. Print. Malone Society Reprints.

Boswell, James, ed. The Plays and Poems of William Shakspeare with the corrections and illustrations of various commentators: comprehending a life of the poet and an enlarged history of the stage by the late E. Malone, with a new glossarial index. 21 vols. London, 1821. Print.

Bowers, Fredson, ed. The Dramatic Works of Thomas Dekker. Vol. 1. Cambridge: Cambridge UP, 1953. Print.

Bowers, Fredson, ed. The Dramatic Works in the Beaumont and Fletcher Canon. 9 vols. Cambridge: Cambridge UP, 1966-94. Print.

Brooke, C.F. Tucker, ed. The Shakespeare Apocrypha: Being a Collection of Fourteen Plays Which Have Been Ascribed to Shakespeare. Oxford: Clarendon Press, 1908. Print.

Capell, Edward, ed. Prolusions; or, Select Pieces of Antient Poetry,- compil'd with great care from their several originals, and offer'd to the publick as specimens of the integrity that should be found in the editions of worthy authors. London, 1760. Eighteenth Century Collections Online. Web. 25 July 2011.

Capell, Edward, ed. Mr William Shakespeare his comedies, histories, and tragedies, set out by himself in quarto, or by the players his fellows in folio, and now faithfully republish'd from those editions in ten volumes octavo; with an introduction. 10 vols. London, 1768. Eighteenth Century Collections Online. Web. 25 July 2011.

Carroll, William C., ed. The Two Gentlemen of Verona. London: Arden Shakespeare, 2004. Print. The Arden Shakespeare. 
Cawley, A.C., and Barry Gaines, eds. A Yorkshire Tragedy. Manchester: Manchester UP, 1986. Print. The Revels Plays.

Child, Harold H., ed. The Arraignment of Paris. Oxford: Oxford UP, 1910. Print. The Malone Society Reprints.

Corbin, Peter, and Douglas Sedge, eds. The Oldcastle Controversy: Sir John Oldcastle, Part 1, and the Famous Victories of Henry V. Manchester and New York: Manchester UP, 1991. Print. The Revels Plays Companion Library.

Crane, David, ed. The Merry Wives of Windsor. Cambridge and New York: Cambridge UP, 1997. Print. The New Cambridge Shakespeare.

Del Vecchio, Doreen, and Anthony Hammond, eds. Pericles, Prince of Tyre. Cambridge and New York: Cambridge UP, 1998. Print. The New Cambridge Shakespeare.

Dodd, William, ed. The beauties of Shakespear: regularly selected from each play. With a general index, digesting them under proper heads. Illustrated with explanatory notes, and similar passages from ancient and modern authors. 2 vols. London, 1752. Eighteenth Century Collections Online. Web. 25 July 2011.

Dodsley, Robert, ed. A Select Collection of Old Plays. 12 vols. London, 1744. Eighteenth Century Collections Online. Web. 25 July 2011.

Doran, Gregory, ed. Cardenio: Shakespeare's 'Lost Play' Reimagined. London: Nick Hern Books, 2011. Print.

Edmondson, Paul Matthew, ed. "A Critical Edition of The London Prodigal." Diss. U of Birmingham, 2000. Print.

Edwards, Philip, ed. The Spanish Tragedy. Manchester: Manchester UP, 1959. Print. The Revels Plays. 
Egan, Michael, ed. The Tragedy of Richard II Part One: A Newly Authenticated Play by William Shakespeare. 3 vols. Lampeter: Mellen, 2006. Print.

Evans, G. Blakemore, ed. The Riverside Shakespeare. Boston: Houghton Mifflin, 1974. Print.

Evans, G. Blakemore, and J.J.M. Tobin, eds. The Riverside Shakespeare. $2^{\text {nd }}$ ed. Boston: Houghton Mifflin, 1997. Print.

Foakes, R.A., ed. King Lear. Walton-on-Thames: Nelson, 1997. Print. The Arden Shakespeare.

Forker, Charles R., ed. The Troublesome Reign of John, King of England. Manchester: Manchester UP, 2011. Print. The Revels Plays.

Fraser, Russell A., and Norman Rabkin, eds. Drama of the English Renaissance 1: The Tudor Period. New York: MacMillan, 1976. Print.

Gabrieli, Vittorio, and Giorgio Melchiori, eds. Sir Thomas More. Manchester: Manchester UP, 1990. Print. The Revels Plays.

Gair, W. Reavley, ed. Antonio's Revenge. Manchester: Manchester UP, 1978. Print. The Revels Plays.

Gossett, Suzanne, ed. Pericles. London: Arden Shakespeare, 2004. Print. The Arden Shakespeare.

Gossett, Suzanne, ed. Philaster. London: Methuen Drama, 2009. Print. Arden Early Modern Drama.

Greg, W.W., ed. The Book of Sir Thomas More. Oxford: Oxford UP, 1911. Print. Malone Society Reprints. 
Halio, Jay L., ed. The Tragedy of King Lear. Rev. ed. Cambridge and New York: Cambridge UP, 2005. Print. The New Cambridge Shakespeare.

Halio, Jay L., ed. The First Quarto of King Lear. Cambridge and New York: Cambridge UP, 1994. Print. The New Cambridge Shakespeare: The Early Quartos.

Hamilton, Charles, ed. Cardenio; Or, The Second Maiden's Tragedy. Lakewood: Glenbridge, 1994. Print.

Hammond, Brean, ed. Double Falsehood. London: Arden Shakespeare, 2010. Print. The Arden Shakespeare.

Happé, Peter, ed. The Magnetic Lady. Manchester: Manchester UP, 2000. Print. The Revels Plays.

Hayward, Thomas, ed. The British muse, or, a collection of thoughts moral, natural, and sublime, of our English poets: who flourished in the sixteenth and seventeenth centuries. With several curious Topicks, and beautiful Passages, never before extracted, from Shakespear, Johnson, Beaumont, Fletcher, and above a Hundred More. 3 vols. London, 1738. Eighteenth Century Collections Online. Web. 25 July 2011.

Hazlitt, William, ed. The Supplementary Works of William Shakespeare. London, 1852. Print.

Hazlitt, William, ed. The Doubtful Plays of William Shakspeare. London, 1887. Print.

Hinman, Charlton, ed. The First Folio of Shakespeare. London and New York: Norton, 1968. Print.

Hodgdon, Barbara, ed. The Taming of the Shrew. London: Arden Shakespeare, 2010. Print. The Arden Shakespeare. 
Hopkinson, A.F., ed. A Yorkshire Tragedy. London: M.E. Sims \& Co., 1910. Print. Shakespeare's Doubtful Plays.

Hughes, Alan, ed. Titus Andronicus. Cambridge and New York: Cambridge UP, 2006. Print. The New Cambridge Shakespeare.

Inchbald, Elizabeth, ed. The British theatre: or, A collection of plays, which are acted at the Theatres Royal, Drury Lane, Covent Garden, Haymarket, and Lyceum: printed under the authority of the managers from the prompt books with biographical and critical remarks by Mrs. Inchbald . . . 25 vols. London, 1806-09. Print.

Jacob, Edward, ed. The lamentable and true tragedie of M. Arden of Feversham ... With a Preface; in which some Reasons are offered, in favour of its being the earliest dramatic Work of Shakespear now remaining; and a genuine Account given of the Murder from authentic Papers of the Time. Feversham, 1770. Eighteenth Century Collections Online. Web. 25 July 2011.

Johnson, Samuel, ed. The plays of William Shakespeare, in eight volumes, with the corrections and illustrations of various commentators; to which are added notes by Sam. Johnson. 8 vols. London, 1765. Eighteenth Century Collections Online. Web. 25 July 2011.

Jowett, John, ed. Sir Thomas More. London: Arden Shakespeare, 2011. Print. The Arden Shakespeare.

Jupin, Arvin H., ed. A Contextual Study and Modern-Spelling Edition of Mucedorus. New York and London: Garland Publishing, 1987. Print. The Renaissance Imagination 29. 
Kahan, Jeffrey, ed. Shakespearean Imitations, Parodies and Forgeries: 1710-1820. 3 vols. Abingdon: Routledge, 2004. Print.

Kirk, Florence Ada, ed. The Faithful Shepherdess. New York and London: Garland, 1980. Print. Renaissance Drama.

Knight, Charles, ed. The Pictorial Edition of the Works of Shakspere: Doubtful Plays \&c. London: 1841. Print.

Kozlenko, William, ed. Disputed Plays of William Shakespeare. New York: Hawthorn Books, 1974. Print.

Lamb, Charles, ed. Specimens of English Dramatic Poets, Who Lived About the Time of Shakespeare. London, 1808. Print.

Leishman, J.B., ed. The Three Parnassus Plays. London: Ivor Nicholson \& Watson, 1949. Print.

Malone, Edmond, ed. Supplement to the edition of Shakspeare's plays published in 1778 by Samuel Johnson and George Steevens. In two volumes. Containing additional observations ... to which are subjoined the genuine poems of the same author, and seven plays that have been ascribed to him; with notes by the editor and others. 2 vols. London, 1780. Eighteenth Century Collections Online. Web. 25 July 2011.

Malone, Edmond, ed. The plays and poems of William Shakspeare, in ten volumes; collated verbatim with the most authentick copies, and revised: with the corrections and illustrations of various commentators; to which are added, an essay on the chronological order of his play; an essay relative to Shakspeare and Jonson; a dissertation on The Three Parts of King Henry VI.; an historical account 
Of The English Stage; And Notes. 10 vols. London, 1790. Eighteenth Century Collections Online. Web. 25 July 2011.

McLuskie, Kathleen E., and David Bevington, eds. Plays on Women. Manchester: Manchester UP, 1999. Print. Revels Student Editions.

McMullan, Gordon, ed. Henry VIII (All is True). London: Arden Shakespeare, 2000. Print. The Arden Shakespeare.

Melchiori, Giorgio, ed. King Edward III. Cambridge and New York: Cambridge UP, 1998. Print. The New Cambridge Shakespeare.

Moltke, Max, ed. The Doubtful Plays of William Shakespeare. Leipzig, 1869. Print.

Muir, Kenneth, and F.P. Wilson, eds. The Life and Death of Jack Straw 1594. Oxford: Oxford UP, 1957. Print. Malone Society Reprints.

Pope, Alexander, ed. The works of Shakespear. In six volumes. Collated and corrected by the former editions, By Mr. Pope. 6 vols. London, 1725. Eighteenth Century Collections Online. Web. 25 July 2011.

Pope, Alexander, and George Sewell, eds. The works of Mr. William Shakespear. In ten volumes. Publish'd by Mr. Pope and Dr. Sewell. 10 vols. London, 1728. Eighteenth Century Collections Online. Web. 25 July 2011.

Potter, Lois, ed. The Two Noble Kinsmen. Walton-on-Thames: Nelson, 1997. Print. The Arden Shakespeare.

Proudfoot, Richard, Ann Thompson and David Scott Kastan, eds. Complete Works. $2^{\text {nd }}$ ed. London: Arden Shakespeare, 2002. Print. The Arden Shakespeare. 
Proudfoot, G.R., and Eric Rasmussen, eds. The Two Noble Kinsmen: 1634. Oxford: Oxford UP, 2005. Print. Malone Society Reprints.

Richards, Bernard, ed. Cardenio. Oxford: Oxford Print Centre, 2009. Print.

Rowe, Nicholas, ed. The works of Mr. William Shakespear; in six volumes. Adorn'd with cuts. Revis'd and corrected, with an account of the life and writings of the author. 6 vols. London: Jacob Tonson, 1709. Eighteenth Century Collections Online. Web. 25 July 2011.

Sams, Eric, ed. Shakespeare's Edmund Ironside: The Lost Play. 1985. Aldershot: Wildwood House, 1986. Print.

Sams, Eric, ed. Shakespeare's Edward III. New Haven and London: Yale UP, 1996. Print.

Schlegel, A.W., and Ludwig Tieck, eds. Shakespeares dramatiscehe Werke. Berlin, 182533. Print.

Siemon, James R., ed. Richard III. London: Arden Shakespeare, 2009. Print. The Arden Shakespeare.

Spencer, Christopher, ed. Five Restoration Adaptations of Shakespeare. Urbana: $U$ of Illinois $P, 1965$. Print.

Steevens, George, ed. The Plays of William Shakespeare. In ten volumes. With the corrections and illustrations of various commentators; to which are added notes by Samuel Johnson and George Steevens. $2^{\text {nd }}$ ed. 10 vols. London, 1778. Eighteenth Century Collections Online. Web. 25 July 2011.

Steevens, George, and Isaac Reed, eds. The plays of William Shakspeare. In fifteen volumes. With the corrections and illustrations of various commentators. To which are added, notes by Samuel Johnson and George Steevens. The fourth 
edition. Revised and augmented (with a glossarial index) by the editor of Dodsley's collection of old plays. 15 vols. London, 1793. Eighteenth Century Collections Online. Web. 25 July 2011.

Stewart, R.J., ed. The Birth of Merlin; or, The Childe Hath Found His Father. Longmead: Element, 1989. Print.

Sturgess, Keith, ed. Three Elizabethan Domestic Tragedies. Harmondsworth: Penguin, 1969. Print. Penguin Classics.

Taylor, Gary, and John Lavagnino, eds. Thomas Middleton: The Collected Works. Oxford: Clarendon Press, 2007. Print.

Theobald, Lewis, ed. The works of Shakespeare: in seven volumes. Collated with the oldest copies and corrected; with notes, explanatory, and critical. 7 vols. London, 1733. Eighteenth Century Collections Online. Web. 25 July 2011.

Thompson, Ann, and Neil Taylor, eds. Hamlet. London: Arden Shakespeare, 2006. Print. The Arden Shakespeare.

Thompson, Ann, and Neil Taylor, eds. Hamlet: The Texts of 1603 and 1623. London: Arden Shakespeare, 2006. Print. The Arden Shakespeare.

Tieck, Ludwig, ed. Altenglisches Theater. Oder Supplemente zum Shakspear. Übersezt und herausgegeben von L. Tieck. 2 vols. Berlin, 1811. Print.

Tieck, Ludwig, ed. Shakespeare's Vorschule. Hrsg. und mit Vorreden begleitet von Ludwig Tieck. 2 vols. Leipzig, 1823-29. Print.

Tonson, J., ed. The tragedy of Locrine, the eldest son of King Brutus. London, 1734. Eighteenth Century Collections Online. Web. 25 July 2011. 
Tyrrell, Henry, ed. The Doubtful Plays of William Shakspere; Being all the Dramas attributed to the Muse of the World's Great Poet. London, 1853[?]. Open Library. Web. 25 July 2011.

Waith, Eugene M., ed. Titus Andronicus. Oxford: Clarendon Press, 1984. Print. The Oxford Shakespeare.

Waith, Eugene M., ed. The Two Noble Kinsmen. Oxford: Clarendon Press, 1989. Print. The Oxford Shakespeare.

Walker, R., ed. The puritan: or, the widow of Watling-Street. A Comedy. London, 1734. Eighteenth Century Collections Online. Web. 25 July 2011.

Walker, R., ed. The tragedy of Locrine, the eldest son of King Brutus. London, 1734. Eighteenth Century Collections Online. Web. 25 July 2011.

Walker, R., ed. The dramatick works of William Shakespear. 7 vols. London, 1734-35. Eighteenth Century Collections Online. Web. 25 July 2011.

Warburton, William, ed. The works of Shakespear in eight volumes. The genuine text (collated with all the former editions, and then corrected and emended) is here settled: Being restored from the blunders of the first editors, and the interpolations of the two last: With a comment and notes, critical and explanatory. By Mr. Pope and Mr. Warburton. 8 vols. London, 1747. Eighteenth Century Collections Online. Web. 25 July 2011.

Warnke, Karl, and Ludwig Proeschoedt, eds. Pseudo-Shakespearian Plays. 5 vols. Halle, 1883-88. Print.

Wells, Stanley, ed. The History of King Lear. Oxford: Clarendon Press, 2000. Print. The Oxford Shakespeare. 
Wells, Stanley, and Gary Taylor, eds. William Shakespeare: Complete Works. Oxford: Clarendon Press, 1986. Print. The Oxford Shakespeare.

Wells, Stanley, and Gary Taylor, eds. William Shakespeare: Complete Works. $2^{\text {nd }}$ ed. Oxford: Clarendon Press, 2005. Print. The Oxford Shakespeare.

White, Martin, ed. Arden of Faversham. 1982. $2^{\text {nd }}$ ed. New Mermaids. London: A \& C Black, 2007. Print.

Wiggins, Martin, ed. Four Jacobean Sex Tragedies. Oxford: Oxford UP, 1998. Print. Oxford World's Classics.

Wiggins, Martin, ed. A Woman Killed with Kindness and Other Domestic Plays. Oxford: Oxford UP, 2008. Print. Oxford World's Classics.

Wilson, F.P., ed. When You See Me, You Know Me 1605. Oxford: Oxford UP, 1952. The Malone Society Reprints.

Wine, M.L., ed. The Tragedy of Master Arden of Faversham. London: Methuen, 1973. Print. The Revels Plays.

Wright, William Aldis, ed. The Works of William Shakespeare. 9 vols. London and New York, 1863-93. Print. The Cambridge Shakespeare.

\section{(c) Critical bibliography (alphabetical by author/editor)}

Adams, Henry Hitch. English Domestic Or, Homiletic Tragedy, 1575 to 1642. New York: Columbia UP, 1943. Print.

Addenbrooke, Barrie. "Double Falsehood." Double Falsehood. Theatre Programme, 2010. Print. 
The Adventurer. 2 vols. London, 1753. Eighteenth Century Collections Online. Web. 25 July 2011.

Altholz, Josef Lewis. Anatomy of a Controversy: the Debate over Essays and Reviews, 1860-1864. Aldershot: Scolar, 1994. Print.

“Apocrypha, n." Def. 1a. The Oxford English Dictionary. Online version. Oxford UP, June 2011. Web. 25 July 2011.

Austen, Jane. Mansfield Park. 1814. Ed. John Wiltshire. Cambridge: Cambridge UP, 2005. Print.

Austin, Warren B. A Computer-Aided Technique for Stylistic Discrimination: The Authorship of Greene's Groatsworth of Wit. Washington: U.S. Office of Education, 1969. Print.

“Author, v." Def. 1. The Oxford English Dictionary. Online version. Oxford UP, June 2011. Web. 25 July 2011.

Bald, R.C. "The Booke of Sir Thomas More and its Problems." Shakespeare Survey 2 (1949): 44-61. Print.

Barber, John. "Refreshing, this witch with murder in mind." Rev. of Arden of Faversham, dir. Terry Hands. Daily Telegraph. Daily Telegraph, $31^{\text {st }}$ March 1982. Web. 25 July 2011.

Bate, Jonathan. Shakespearean Constitutions: Politics, Theatre, Criticism, 1730-1830. Oxford: Clarendon Press, 1989. Print.

Bate, Jonathan. The Genius of Shakespeare. 1997. $2^{\text {nd }}$ ed. Basingstoke: Picador, 2008. Print. 
Bate, Jonathan. "The Case for the Folio." The RSC Shakespeare. Web. 25 July 2011.

Bate, Jonathan. A Very Short Introduction to English Literature. Oxford: Oxford UP, 2010. Print.

Beck, Ervin. "Terence Improved: The Paradigm of the Prodigal Son in English Renaissance Comedy." Renaissance Drama 6 (1973): 107-22. Print.

Beckerman, Bernard. Shakespeare at the Globe 1599-1609. London: Collier Books, 1962. Print.

Bednarz, James P. “Canonizing Shakespeare: The Passionate Pilgrim, England's Helicon and the Question of Authenticity." Shakespeare Survey 60 (2007): 252-67. Print.

Berek, Peter. "Locrine Revised, Selimus, and Early Responses to Tamburlaine." Research Opportunities in Renaissance Drama 23 (1980): 33-54. Print.

Berek, Peter. "Tamburlaine's Weak Sons: Imitation as Interpretation Before 1593." Renaissance Drama 13 (1982): 55-82. Print.

Berger, Thomas L. "Shakespeare Writ Small: Early Single Editions of Shakespeare's Plays." Murphy, Concise Companion 57-70.

Bevington, David. "Review: Determining the Indeterminate: The Oxford Shakespeare." Shakespeare Quarterly 38.4 (1987): 501-19. Print.

Birrell, T.A. English monarchs and their books: from Henry VII to Charles II. London: British Library, 1986. Print. The Panizzi Lectures.

Blayney, Glenn H. "Wilkins's Revision in The Miseries of Inforst Mariage." Journal of English and Germanic Philology 56.1 (1957): 23-41. Print. 
Blayney, Peter W.M. “'The Booke of Sir Thomas Moore' Re-Examined." Studies in Philology 69.2 (1972): 167-91. JSTOR. Web. 9 August 2011.

Blayney, Peter W.M. The First Folio of Shakespeare. Washington D.C.: Folger Library Publications, 1991. Print.

Borgerson, Jess, Adam Long and Daniel Singer. The Reduced Shakespeare Co. presents The Compleat Works of WIIm Shakspr (abridged). Ed. J.M. Winfield. New York: Applause, 1994. Print.

Boris, Edna Zwick. Shakespeare's English Kings, the People and the Law: A Study in the Relationship between the Tudor Constitution and the English History Plays. Rutherford: Fairleigh Dickinson UP, 1978. Print.

Bowsher, Julian M.C. "Marlowe and the Rose." Downie and Parnell 30-40.

Boyd, Brian, ed. Words that Count: Essays on Early Modern Authorship in Honor of Macdonald P. Jackson. Newark: U of Delaware P, 2004. Print.

Boyd, Brian. "Kind and Unkindness: Aaron in Titus Andronicus." Boyd 51-77.

Bradford, Jr, Gamaliel. "The History of Cardenio by Mr. Fletcher and Shakespeare." Modern Language Notes 25.2 (1910): 51-58. JSTOR. Web. 25 July 2011.

Bristol, Michael D. "Shakespeare Is an Author: An Essentialist View." Shakespeare Studies 36(2008): 122-31. Print.

Britten, Nick, and Richard Alleyne. “William Shakespeare's lost $18^{\text {th }}$ Century play Double Falsehood 'not a hoax'." Daily Telegraph. Daily Telegraph, 16 March 2010. Web. 25 July 2011. 
Brooke, Tucker. "Elizabethan 'Nocturnal' and 'Infernal' Plays." Modern Language Notes 35.2 (1920): 120-21. JSTOR. Web. 25 July 2011.

Brooke, Tucker. "The Marlowe Canon." PMLA 37.3 (1922): 367-417. JSTOR. Web. 16 August 2011.

Brooks, Douglas A. From Playhouse to Printing House: Drama and Authorship in Early Modern England. Cambridge and New York: Cambridge UP, 2000. Print. Cambridge Studies in Renaissance Literature and Culture.

Brooks, Douglas A., ed. The Shakespeare Apocrypha. Lampeter: Edwin Mellen Press, 2007. Print. Shakespeare Yearbook 16.

Campbell, Lily B. Shakespeare's "Histories": Mirrors of Elizabethan Policy. London: Methuen \& Co., 1947. Print.

Capell, Edward. A Catalogue of Plays; the Collection of David Garrick Esq. 2 vols. N.d. MS. British Lib., London.

Cardwell, M. John. "John Duncombe." Oxford Dictionary of National Biography. Online ed. Oxford UP. October 2008. Web. 25 July 2011.

Carnegie, David, and Gary Taylor, eds. The Quest for Cardenio: Shakespeare, Fletcher, and the Lost Play. Oxford: Oxford UP, forthcoming. TS.

Carrell, J.L. The Shakespeare Secret. London: Sphere, 2007. Print.

Carroll, Robert, and Stephen Prickett, eds. The Bible: Authorized King James Version with Apocrypha. Oxford: Oxford UP, 1997. Print. Oxford World's Classics.

Cauthen Jr, I.B. “Review.” College English 18.5 (1957): 290-93. JSTOR. Web. 25 July 2011. 
Cawley, A.C. English Domestic Drama: A Yorkshire Tragedy: An Inaugural Lecture. Cambridge: Leeds UP, 1966. Print.

Cawley, A.C. "A Yorkshire Tragedy and Two Most Vnnaturall and Bloodie Murthers." The Morality of Art. Ed. D.W. Jefferson. London: Routledge and Kegan Paul, 1969. 102-18. Print.

Chalmers, George. A supplemental apology for the believers in the Shakspeare-Papers: being a reply to Mr. Malone's answer, which was early announced, but never published. London, 1799. Eighteenth Century Collections Online. Web. 25 July 2011.

Chambers, R.W. "The Expression of Ideas - Particularly Political Ideas - in the Three Pages and in Shakespeare." Pollard 142-187.

Chambers, E.K. The Elizabethan Stage. 4 vols. Oxford: Clarendon Press, 1923. Print.

Chambers, E.K. "The Disintegration of Shakespeare." 1924. Aspects of Shakespeare: Being British Academy Lectures. Oxford: Oxford UP, 1933. 23-48. Print.

Chambers, E.K. William Shakespeare: A Study of Facts and Problems. 2 vols. Oxford: Oxford UP, 1930. Print.

Cheney, Patrick. Shakespeare's Literary Authorship. Cambridge and New York: Cambridge UP, 2008. Print.

Cheney, Patrick. "Introduction: Forum: The Return of the Author." Shakespeare Studies 36 (2008): 19-25. Print.

Chillington, Carol A. “Playwrights at Work: Henslowe's, Not Shakespeare's Book of Sir Thomas More." English Literary Renaissance 10 (1980): 439-79. Print. 
Clwyd Theatr Cymru. Arden of Faversham. Theatre Programme. Clwyd: 2010. Print.

Comensoli, Vivana. 'Household Business': Domestic Plays of Early Modern England. Toronto: U of Toronto P, 1996. Print.

Cooper, Helen. "Pursued by Bearists." London Review of Books. London Review of Books, 6 January 2005. Web. 25 July 2011.

Craig, Hugh. "The 1602 Additions to The Spanish Tragedy." Craig and Kinney 162-80.

Craig, Hugh, and Arthur F. Kinney, eds. Shakespeare, Computers, and the Mystery of Authorship. Cambridge and New York: Cambridge UP, 2009. Print.

Crinkley, Richmond. "New Perspectives on the Authorship Question." Shakespeare Quarterly. 36.4 (1985): 515-22. Print.

Dawson, Anthony B. "What do Editors Do and Why Does it Matter?" How to Do Things with Shakespeare: New Approaches, New Essays. Ed. Laurie Maguire. Malden and Oxford: Blackwell, 2008. 160-80. Print.

De Grazia, Margreta. Shakespeare Verbatim: The Reproduction of Authenticity and the 1790 Apparatus. Oxford: Clarendon Press, 1991. Print.

De Grazia, Margreta. "Shakespeare in Quotation Marks." Marsden 57-71.

De Grazia, Margreta, and Peter Stallybrass. "The Materiality of the Shakespearean Text." Shakespeare Quarterly 44.3 (1993): 255-83. Print.

Derrida, Jaques. Of Grammatology. Trans. Gayatri Chakravorty Spivak. Baltimore and London: Johns Hopkins UP, 1976. Print.

DiPietro, Cary. "The Shakespeare Edition in Industrial Capitalism." Shakespeare Survey 59 (2006): 147-56. Print. 
Dobson, Michael. The Making of the National Poet: Shakespeare, Adaptation, and Authorship, 1660-1769. Oxford: Clarendon Press, 1992. Print.

Dominik, Mark. William Shakespeare and The Birth of Merlin. Beaverton: Alioth Press, 1985. Print.

Dominik, Mark. Shakespeare-Middleton Collaborations. Beaverton: Alioth Press, 1988. Print.

Dominik, Mark. A Shakespearean Anomaly: Shakespeare's Hand in Sir John Oldcastle. Beaverton: Alioth Press, 1991. Print.

Doran, Gregory. "The First Folio." The RSC Shakespeare. Macmillan, 2008. Web Video Presentation. 25 July 2011.

Downie, J.A., and J.T. Parnell, eds. Constructing Christopher Marlowe. Cambridge: Cambridge UP, 2000. Print.

Downs, Gerald. "A Question (not) to Be Askt: Is Hand D a Copy?" Brooks, Apocrypha 24166.

Drábek, Pavel. "Shakespeare's Influence on Mucedorus." Shakespeare and His Collaborators over the Centuries. Eds. Pavel Drábek, Klára Kolinská, and Matthew Nicholls. Newcastle upon Tyne: Cambridge Scholars Publishing, 2008. 45-53. Print.

Draper, Matthew. The spend-Thrift; a comedy: as it is acted at the New Theatre in the Hay-Market. London, 1731. Eighteenth Century Collections Online. Web. 25 July 2011.

Duncan-Jones, Katherine. “Complete Works, Essential Year? (All of) Shakespeare Performed." Shakespeare Quarterly 58.3 (2007): 353-66. Print. 
Dutton, Richard. Mastering the Revels: The Regulation and Censorship of English Renaissance Drama. lowa City: U of lowa P, 1991. Print.

Dutton, Richard. Licensing, Censorship and Authorship in Early Modern England: Buggeswords. Basingstoke and New York: Palsgrave, 2000. Print.

Dutton, Richard, and Jean E. Howard, eds. A Companion to Shakespeare's Works Vol. IV: The Poems, Problem Comedies, Late Plays. Malden and Oxford: Blackwell, 2003. Print.

Edmond, Mary. Rare Sir William Davenant. Manchester: Manchester UP, 1987. Print. The Revels Plays Companion Library.

Edmondson, Paul. “'Beyond the Fringe'? Receiving, Adapting, and Performing The London Prodigal." Brooks, Apocrypha 195-221.

Edmondson, Paul, and Stanley Wells. "The Limitations of the First Folio." Without Boundaries: Essays in Honor of Dieter Mehl. Eds. Christa Jansohn, Lena Cowen Orlin and Stanley Wells. Newark: U of Delaware P, 2011. 23-34. Print.

Egan, Gabriel. "Review of Andrew Gurr The Shakespeare Company, 1594-1642 (Cambridge: Cambridge University Press, 2004)." The Sixteenth Century Journal 37 (2006): 155-57. Print.

Eliot, T.S. What is a Classic?: An Address Delivered Before the Virgil Society on the $16^{\text {th }}$ October 1944. London: Faber and Faber, 1945. Print.

Elliott, Ward E.Y. “Language: Key to Authorship." Cambridge World Shakespeare Encyclopedia. Forthcoming. TS. 
Elliot, Ward E.Y., and Robert J. Valenza. "And Then There Were None: Winnowing the Shakespeare Claimants." Computers and the Humanities 30.3 (1996): 191-245. Print.

Elliott, Ward E.Y., and Robert J. Valenza. "Glass Slippers and Seven-League Boots: CPrompted Doubts about Ascribing A Funeral Elegy and A Lover's Complaint to Shakespeare." Shakespeare Quarterly 48.2 (1997): 177-207. Print.

Elliott, Ward E.Y., and Robert J. Valenza. "The Professor Doth Protest Too Much, Methinks: Problems with the Foster 'Response.'" Computers and the Humanities 32.6 (1998): 425-90. Print.

Elliott, Ward E.Y., and Robert J. Valenza. "So Many Hardballs, So Few Over the Plate: Conclusions from our 'Debate' with Donald Foster." Computers and the Humanities 36.4 (2002): 455-60. Print.

Elliott, Ward E.Y., and Robert J. Valenza. "Shakespeare Golden Ear Text: Do You Have a Golden Ear?" Claremont McKenna College. N.d. Web. 25 July 2011.

Elliott, Ward E.Y., and Robert J. Valenza. "Two Tough Nuts to Crack: Did Shakespeare Write the 'Shakespeare' Portions of Sir Thomas More and Edward III?" Ward Elliott's Home Page. Claremont McKenna College. 2010. Web. 28 May 2010.

Elliott, Ward E.Y., and Robert J. Valenza. "Two Tough Nuts To Crack: Did Shakespeare Write the 'Shakespeare' Portions of Sir Thomas More and Edward III?" Rev. version. Literary and Linguistic Computing 25.1 (2010): 67-83; 25.2 (2010): 16577. Print.

Em-Lou Productions. Arden of Faversham. Theatre Programme. London: 2010. Print. 
Engle, Lars, and Eric Rasmussen. "The Oxford Middleton." Shakespeare Quarterly 61.2 (2010): 246-61. Print.

Erne, Lukas. "The Popularity of Shakespeare in Print." Shakespeare Survey 62 (2009): 1229. Print.

Erne, Lukas. Shakespeare as Literary Dramatist. Cambridge and New York: Cambridge UP, 2003. Print.

Erne, Lukas. "Reconsidering Shakespearean Authorship." Shakespeare Studies 36 (2008): 26-36. Print.

Erne, Lukas, and Margaret Jane Kidnie, eds. Textual Performances: The Modern Reproduction of Shakespeare's Drama. Cambridge: Cambridge UP, 2004. Print.

Felperin, Howard. "Bardolatry Then and Now." Marsden 129-44.

Fiehler, Rudolph. "II Serve the Good Duke of Norfolk'”. Modern Language Quarterly. 10.3 (1949): 364-67. Duke University Press. Web. 25 July 2011.

Fleay, Frederick Gard. A Biographical Chronicle of the English Drama 1559-1642. Vol. II. London: Reeves and Turner, 1891. Print.

Foakes, R.A., ed. Coleridge on Shakespeare: the text of the lectures of 1811-12. London: Routledge \& Kegan Paul, 1971. Print.

Ford, H.L. Shakespeare 1700-1740: A Collation of the Editions and Separate Plays with Some Account of T. Johnson and R. Walker. Oxford: Oxford UP, 1935. Print.

Forker, Charles R. "Webster or Shakespeare? Style, Idiom, Vocabulary and Spelling in the Additions to Sir Thomas More." Howard-Hill 151-70. 
Forni, Kathleen. The Chaucerian Apocrypha: A Counterfeit Canon. Gainesville: UP of Florida, 2001. Print.

Forni, Kathleen. The Chaucerian Apocrypha: A Selection. Kalamazoo: Medieval Institute Publications, 2005. Print. Middle English Texts.

Fortier, Paul A. "Introduction." Computers and the Humanities 27.5/6 (1993/4): 305-07. Print.

Foster, Donald W. "Response to Elliot and Valenza, 'And Then There Were None.'” Computers and the Humanities 30.3 (1996): 247-55. Print.

Foster, Donald W. "The Claremont Shakespeare Authorship Clinic: How Severe Are The Problems?" Computers and the Humanities 32.6 (1998): 491-510. Print.

Foucault, Michel. "What Is An Author?” 1969. Trans. Josué V. Harari. The Foucault Reader. Ed. Paul Rabinow. London: Penguin, 1984. 101-20. Print.

Frazier, Harriet C. A Babble of Ancestral Voices: Shakespeare, Cervantes, and Theobald. The Hague and Paris: Mouton, 1974. Print. Studies in English Literature 73.

Freehafer, John. "Cardenio, by Shakespeare and Fletcher." Publication of the Modern Language Association of America 84 (1969): 501-13. JSTOR. Web. 25 July 2011.

Friedlaender, Marc. "Some Problems of A Yorkshire Tragedy." Studies in Philology 35.2 (1938): 238-53. JSTOR. Web. 25 July 2011.

Frost, David L. “'Mouldy Tales': The Context of Shakespeare's Cymbeline." Essays and Studies 39 (1986): 19-38. Print.

Furnivall, F.J. “Opening Meeting at University College.” The New Shakspere Society's Transactions 1874. London: Trübner \& Co., 1874. v-xi. Print. 
Garber, Marjorie. Shakespeare's Ghost Writers: Literature as Uncanny Causality. 1987. $2^{\text {nd }}$ ed. New York and Abingdon: Routledge, 2010. Print. Routledge Classics.

Garrick, David. An ode upon dedicating a building, and erecting a statue, to Shakespeare, at Stratford upon Avon. London, 1769. Eighteenth Century Collections Online. Web. 25 July 2011.

Garrick, David. The Stratford Jubilee. A new Comedy of two acts, as it has been lately exhibited at Stratford upon Avon, with great applause. To which is prefixed Scrub's trip to the jubilee. London, 1769. Eighteenth Century Collections Online. Web. 25 July 2011.

Gaud, W.S. "The Authorship of Locrine." Modern Philology 1.3 (1904): 409-22. JSTOR. Web. 25 July 2011.

"Globe to Globe". Shakespeare's Globe. Shakespeare's Globe, 2011. Web. 4 August 2011.

Gorak, Jan. The Making of the Modern Canon: Genesis and Crisis of a Literary Idea. London \& Atlantic Highlands: Athlone, 1991. Print.

Gossett, Suzanne. “Editing Collaborative Drama." Shakespeare Survey 59 (2006): 213-24. Print.

Grady, Hugh. "Disintegration and its Reverberations." Marsden 111-27.

Grant, Teresa. "White Bears in Mucedorus, The Winter's Tale and Oberon, The Fairy Prince." Notes and Queries 48.3 (2001). 311-13. Print.

Grant, Teresa. "Pursued by Bearists." London Review of Books. London Review of Books, 3 January 2005. Web. 25 July 2011. 
Greg, Walter W. "On Certain False Dates in Shakespearian Quartos." The Library 9

(1908): 113-31, 381-409. Oxford Journals Archive. Web. 25 July 2011.

Greg, W.W. "Three Manuscript Notes by Sir George Buc." The Library 12 (1931-32): 307-

21. $4^{\text {th }}$ series. Oxford Journals Archive. Web. 25 July 2011.

Greg, W.W. A Bibliography of the English Printed Drama to the Restoration. Vol. 1: Stationer's Records, Plays to 1616: Nos. 1-349. London: The Bibliographical Society at Oxford UP, 1962. Print.

Greg, W.W. The Shakespeare First Folio: Its Bibliographical and Textual History. Oxford: Clarendon Press, 1955. Print.

Guillory, John. Cultural Capital. Chicago: U of Chicago P, 1993. Print.

Gurr, Andrew. The Shakespearian Playing Companies. Oxford: Clarendon Press, 1996. Print.

Gurr, Andrew. "Maximal and Minimal Texts: Shakespeare v. the Globe." Shakespeare Survey 52 (1999): 68-87. Print.

Gurr, Andrew. The Shakespeare Company 1594-1642. Cambridge: Cambridge UP, 2004. Print.

Gurr, Andrew. "The Work of Elizabethan Plotters, and 2 The Seven Deadly Sins." Early Theatre 10.1 (2007): 67-87. Print.

Gurr, Andrew. Shakespeare's Opposites: The Admiral's Company 1594-1625. Cambridge: Cambridge UP, 2009. Print.

Hammond, Brean, Richard Proudfoot and Stanley Wells. "Double Falsehood." Shakespeare Centre, Stratford-upon-Avon. 16 July 2010. Panel discussion. 
Haney, John Louis. “Review: Shakespeare." Modern Language Notes 24.6 (1909), 18486. JSTOR. Web. 25 July 2011.

Harbage, Alfred. Shakespeare and the Rival Traditions. New York: The Macmilllan Company, 1952. Print.

Hattaway, Michael. Elizabethan Popular Theatre: Plays in Performance. London: Routledge \& Kegan Paul, 1982. Print.

Hattaway, Michael. "The Shakespearean History Play." The Cambridge Companion to Shakespeare's History Plays. Eds. Michael Hattaway and New York. Cambridge: Cambridge UP, 2002. 3-24. Print.

Hayne, Victoria. "Performing Social Practice: The Example of Measure for Measure." Shakespeare Quarterly 44.1 (1993): 1-29. Print.

Hays, Michael L. "Shakespeare's Hand in Sir Thomas More: Some Aspects of the Palaeographic Argument." Shakespeare Studies 8 (1975): 241-54. Print.

Hazlitt, William. Lectures on the Dramatic Literature of the Age of Elizabeth. 1817. $2^{\text {nd }}$ ed. London, 1821. Print.

Hazlitt, William. Characters of Shakespeare's Plays. 1817. London: J.M. Dent \& Sons, 1906. Print.

Helgerson, Richard. The Elizabethan Prodigals. Berkeley: U of California P, 1976. Print.

Hill, Leslie. The Cambridge Introduction to Jacques Derrida. Cambridge: Cambridge UP, 2007. Print.

Hinman, Charlton. The Printing and Proofreading of the First Folio of Shakespeare. London and New York: Oxford UP, 1963. Print. 
Holderness, Graham. Shakespeare: The Histories. Basingstoke: Macmillan, 1999. Print.

Holderness, Graham. Cultural Shakespeare: Essays in the Shakespeare Myth. Hatfield: U of Hertfordshire P, 2001. Print.

Holderness, Graham, and Bryan Loughrey. "Shakespeare Misconstrued: The True Chronicle Historie of Shakespearean Originals." Textus 9 (1996): 393-418. Print.

Holland, Bernard. "Review/Music; Adding a Shakespearean Tone to a Folk Melody." New York Times. New York Times, 30 March 1993. Web. 25 July 2011.

Holland, Peter, and Stephen Orgel, eds. From Performance to Print in Shakespeare's England. Basingstoke and New York: Palgrave Macmillan, 2006. Print. Redefining British History.

Holmes, David I. “Authorship Attribution." Computers and the Humanities 28.2 (1994): 87-106. Print.

Holtcamp, Victor. "A Fear of 'Ould' Plays: How Mucedorus Brought Down the House and Fought for Charles II in 1652." Brooks, Apocrypha 141-66.

Hope, Jonathan. The Authorship of Shakespeare's Plays: A Socio-Linguistic Study.

Cambridge and New York: Cambridge UP, 1994. Print.

Horrell, Joseph. "Peter Fabell and Dr. Faustus." Notes and Queries 183.2 (1942): 35-36. Print.

Howard-Hill, T.H., ed. Shakespeare and Sir Thomas More: Essays on the Play and Its Shakespearian Interest. Cambridge and New York: Cambridge UP, 1989. Print. New Cambridge Shakespeare Studies and Supplementary Texts. 
Hoy, Cyrus. "Critical and Aesthetic Problems of Collaboration in Renaissance Drama." Research Opportunities in Renaissance Drama 19 (1976): 3-6. Print.

Hubbard, F.G. "Repetition and Parallelism in the Earlier Elizabethan Drama." Publications of the Modern Language Association of America 20.2 (1905): 360-79. JSTOR. Web. 25 July 2011.

Hubbard, Frank G. "Locrine and Selimus." Shakespeare Studies by Members of the Department of English of the University of Wisconsin. Madison: $U$ of Wisconsin, 1916. 17-35. Print.

Hubbell, Lindley Williams. A Note on the Shakespeare Apocrypha. $4^{\text {th }}$ edition. Kobe: Ikuta, 1977. Print.

Hunter, G. K. “Review.” Modern Language Review 52.4 (1957): 587-88. Print.

Hunter, G.K. "Italian Tragicomedy on the English Stage." Renaissance Drama 6 (1973): 123-48. Print.

Ioppolo, Grace. Revising Shaksepeare. Cambridge and London: Harvard UP, 1991. Print. Isaac, Megan Lynn. "Legitimizing Magic in The Birth of Merlin." Early Theatre 9.1 (2006): 109-21. Print.

Jackson, MacD. P. “Edward Archer's Ascription of Mucedorus to Shakespeare." Journal of the Australasian Universities Language and Literature Association 22 (1964): 233-48. Print.

Jackson, MacDonald P. Studies in Attribution: Shakespeare and Middleton. Salzburg: Institute für Anglistik und Amerikanistik, Universität Salzburg, 1979. Print. Jacobean Drama Studies 79. 
Jackson, MacD. P. "Shakespeare's Richard II and the Anonymous Thomas of Woodstock." Medieval and Renaissance Drama in England 14 (2001): 17-65. Print.

Jackson, MacDonald P. "Shakespeare and the Quarrel Scene in Arden of Faversham." Shakespeare Quarterly 57.3 (2006): 249-93. Print.

Jackson, MacDonald P. Defining Shakespeare: Pericles as Test Case. Oxford and New York: Oxford UP, 2003. Print.

Jackson, MacDonald P. "Early Modern Authorship: Canons and Chronologies." Taylor and Lavagnino, Early Modern Textual Culture 80-97.

Jackson, MacD. P. "The Date and Authorship of Thomas of Woodstock: Evidence and its Interpretation." Research Opportunities in Medieval and Renaissance Drama 46 (2007): 67-100. Print.

Jackson, MacD. P. "New Research on the Dramatic Canon of Thomas Kyd." Research Opportunities in Medieval and Renaissance Drama 47 (2008): 107-27. Print.

James, Heather. "Shakespeare, the Classics, and the Forms of Authorship." Shakespeare Studies 36 (2008): 80-89. Print.

Jansohn, Christa. "Ludwig Tieck as the Champion of Shakespeare's Apocrypha in Germany." Cahiers Élisabéthains 48 (1995): 45-51. Print.

Jansohn, Christa. Zweifelhafter Shakespeare: Zu den Shakespeare-Apokryphen und ihrer Rezeption von der Renaissance bix zum 20. Jahrhundert. Münster: Lit, 2000. Print. Studien zur englischen Literatur 11.

Jansohn, Christa. "The Shakespeare Apocrypha: A Reconsideration." English Studies 84 (2003): 318-29. Print. 
Jarvis, Simon. Scholars and Gentlemen: Shakespearian Textual Criticism and Representations of Scholarly Labour, 1725-1765. Oxford and New York: Clarendon Press, 1995. Print.

“John." Def. 3. The Oxford English Dictionary. Online version. Oxford UP, June 2011. Web. 25 July 2011.

Johnson, Samuel. Johnson on Shakespeare. Ed. Arthur Sherbo. New Haven and London: Yale UP, 1968. Print.

Jones, Richard Foster. Lewis Theobald: His Contribution to English Scholarship with Some Unpublished Letters. New York: AMS Press, 1966. Print.

Jowett, John. "Johannes Factotum: Henry Chettle and Greene's Groatsworth of Wit." Papers of the Bibliographical Society of America 87 (1993): 453-86. Print.

Jowett, John. "The Pattern of Collaboration in Timon of Athens." Boyd 181-205.

Jowett, John. "Addressing Adaptation: Measure for Measure and Sir Thomas More." Textual Performances: The Modern Reproduction of Shakespeare's Drama. Eds. Lukas Erne and Margaret Jane Kidnie. Cambridge and New York: Cambridge UP, 2004. 63-76. Print.

Jowett, John. "Editing Shakespeare in the Twentieth Century." Shakespeare Survey 50 (2006): 1-19. Print.

Jowett, John. "Shakespeare Supplemented." Brooks, Apocrypha 39-73.

Jowett, John. Shakespeare and Text. Oxford: Oxford UP, 2007. Print. Oxford Shakespeare Topics. 
Jowett, John. "Editions and Textual Studies: The RSC Complete Works." Shakespeare Survey 61 (2008): 394-403. Print.

Jowett, John. "Shakespeare". Times Literary Supplement. Times Literary Supplement, 4 June 2010. Web. 25 July 2011.

Joyce, James. Ulysses. 1922. London: Penguin, 1992. Print. Penguin Classics.

Kahrl, George M., and Dorothy Anderson. The Garrick Collection of Old English Plays. London: The British Library, 1982. Print.

Karpinska, Monika. "Bawdily Manipulations: Spheres of Female Power in The Birth of Merlin." Early Theatre 9.1 (2006): 123-30. Print.

Kastan, David Scott. "The Mechanics of Culture: Editing Shakespeare Today." Shakespeare Studies 24 (1996): 30-37. Print.

Kastan, David Scott. Shakespeare After Theory. London and New York: Routledge, 1999. Print.

Kastan, David Scott. Shakespeare and the Book. Cambridge and New York: Cambridge UP, 2001. Print.

Kathman, David. “Reconsidering The Seven Deadly Sins." Early Theatre 7.1 (2004): 13-44. Print.

Kermode, Frank. The Classic. London: Faber and Faber, 1975. Print.

King, Edmund G.C. "Cardenio and the Eighteenth-Century Shakespeare Canon." Carnegie and Taylor, forthcoming. TS.

King, Edmund G.C. “Fragmenting Authorship in the Eighteenth-Century Shakespeare Edition." Shakespeare 6.1 (2010): 1-19. Print. 
Kinney, Arthur F. "Transforming King Lear." Craig and Kinney 181-201.

Kirschbaum, Leo. "The Texts of Mucedorus." Modern Language Review 50 (1955): 1-5. Print.

Kirwan, Peter. The Bardathon. University of Warwick. 2006-present. Web. 11 August 2011.

Kirwan, Peter. "If the law could forgive as soon as I': A Review of A Yorkshire Tragedy at the White Bear Theatre Pub, London, January 2010." Law and Humanities 4.1 (2010): 162-68. Print.

Kirwan, Peter. "Review of Shakespeare, Computers, and the Mystery of Authorship, ed. Hugh Craig and Arthur F. Kinney." Early Theatre 13.1 (2010): 159-63. Print.

Kirwan, Peter. "The First Collected 'Shakespeare Apocrypha.'” Shakespeare Quarterly, forthcoming. Reprinted in Appendix 266-75.

Kirwan, Peter. "Chasing Windmills: An Identity Crisis in Double Falsehood at the Union Theatre, Southwark." Shakespeare. Forthcoming. TS.

Knapp, Jeffrey. "Shakespeare as Coauthor." Shakespeare Studies 36 (2008): 49-59. Print.

Knapp, Jeffrey. Shakespeare Only. Chicago and London: U of Chicago P, 2009. Print.

Knutson, Roslyn L. "Evidence for the Assignment of Plays to the Repertory of Shakespeare's Company." Medieval and Renaissance Drama in England 4 (1989): 63-89. Print.

Knutson, Roslyn L. The Repertory of Shakespeare's Company, 1594-1613. Fayetteville: U of Arkansas P, 1991. Print. 
Knutson, Roslyn L. Playing Companies and Commerce in Shakespeare's Time. Cambridge and New York: Cambridge UP, 2001. Print.

Kukowski, Stephan. "The Hand of John Fletcher in Double Falsehood." Shakespeare Survey 43 (1991): 81-89. Print.

Leahy, William, ed. Shakespeare and His Authors: Critical Perspectives on the Authorship Question. London and New York: Continuum, 2010. Print.

Lee, Sidney. Notes and Additions to the Census of Copies of the Shakespeare First Folio. London: Henry Frowde, 1906. Print.

Lee, Sidney. A Life of William Shakespeare. $2^{\text {nd }}$ edition. London: John Murray, 1916. Print.

Leggatt, Alexander. "Arden of Faversham." Shakespeare Survey 36 (1983): 121-33. Print.

Lockwood, Tom. "Manuscript, Print and the Authentic Shakespeare: The Ireland Forgeries Again." Shakespeare Survey 59 (2006): 108-23. Print.

Lockwood, Tom. "Introduction." Arden of Faversham. Ed. Martin White. Rev. ed. London: A \& C Black, 2007. Print. New Mermaids.

Loewenstein, Joseph. Ben Jonson and Possessive Authorship. Cambridge: Cambridge UP, 2002. Print. Cambridge Studies in Renaissance Literature and Culture.

Logan, Terence P., and Denzell S. Smith, eds. The Predecessors of Shakespeare. Lincoln: U of Nebraska P, 1973. Print.

Love, Harold. Attributing Authorship: An Introduction. Cambridge: Cambridge UP, 2002. Print. 
Lyons, Tara L. "The Pavier Quartos and Selling 'Shakespeare' in Serial." Shakespeare Association of America Annual Meeting. Hyatt Regency, Bellevue. Shakespeare Association of America. Bellevue: 9 April 2011. Seminar paper.

Maguire, Laurie. Shakespearean Suspect Texts: The "Bad" Quartos and Their Contexts. Cambridge and New York: Cambridge UP, 1996. Print.

Maguire, Laurie E. “Introduction." Maguire and Berger 11-18.

Maguire, Laurie E. “Composition/Decomposition: Singular Shakespeare and the Death of the Author." The Renaissance Text: Theory, Editing, Textuality. Ed. Andrew Murphy. Manchester: Manchester UP, 2000. 135-53. Print.

Maguire, Laurie E., and Thomas L. Berger, eds. Textual Formations and Reformations. Newark: U of Delaware P, 1998. Print.

Maley, Willy. "Malfolio: Foul Papers on the Shakespeare Authorship Question." Leahy 23-40.

Malone, Edmond. A dissertation on the three parts of King Henry VI, tending to shew that those plays were not written originally by Shakspeare. London, 1787. Eighteenth Century Collections Online. Web. 25 July 2011.

Malone, Edmond. An inquiry into the authenticity of certain miscellaneous papers and legal instruments, published Dec. 24, MDCCXCV. And attributed to Shakspeare, Queen Elizabeth, and Henry, Earl of Southampton ... London, 1796. Eighteenth Century Collections Online. Web. 25 July 2011.

Marino, James J. "William Shakespeare's Sir John Oldcastle." Renaissance Drama 30 (2001): 93-114. Print. 
Marino, James J. Owning William Shakespeare: The King's Men and Their Intellectual Property. Philadelphia: U of Pennsylvania P, 2011. Print. Material Texts.

Marcus, Leah S. Puzzling Shakespeare: Local Reading and Its Discontents. Berkeley: U of California P, 1988. Print.

Marcus, Leah S. Unediting the Renaissance: Shakespeare, Marlowe, Milton. London and New York: Routledge, 1996. Print.

Marsden, Jean I., ed. The Appropriation of Shakespeare: Post-Renaissance Reconstructions of the Works and the Myth. London: Harvester Wheatsheaf, 1991. Print.

Massai, Sonia. Shakespeare and the Rise of the Editor. Cambridge and New York: Cambridge UP, 2007. Print.

Massai, Sonia. "Shakespeare, Text and Paratext." Shakespeare Survey 62 (2009): 1-11. Print.

Masten, Jeffrey. "Playwrighting: Authorship and Collaboration." A New History of Early English Drama. Eds. John D. Cox and David Scott Kastan. New York: Columbia UP, 1997. 357-82. Print.

Masten, Jeffrey. Textual Intercourse: Collaboration, Authorship, and Sexualities in Renaissance Drama. Cambridge: Cambridge UP, 1997. Print. Cambridge Studies in Renaissance Literature and Culture.

Masten, Jeffrey. "More or Less: Editing the Collaborative." Shakespeare Studies 29 (2001): 109-31. Print.

Maxwell, Baldwin. Studies in the Shakespeare Apocrypha. New York: Greenwood Press, 1956. Print. 
McDonald, Russ. "Fear of Farce." "Bad" Shakespeare. Ed. Maurice Charney. London and Toronto: Associated UPs, 1988. 77-90. Print.

McMillin, Scott. "Building Stories: Greg, Fleay, and the Plot of 2 Seven Deadly Sins." Medieval and Renaissance Drama in England 4 (1989): 53-62. Print.

McMillin, Scott. "The Book of Sir Thomas More: Dates and Acting Companies." HowardHill 57-76.

McMillin, Scott. The Elizabethan Theatre and the Book of Sir Thomas More. Ithaca and London: Cornell UP, 1987. Print.

McMillin Scott, and Sally-Beth Maclean. The Queen's Men and Their Plays. Cambridge: Cambridge UP, 1998. Print.

McMullan, Gordon. The Politics of Unease in the Plays of John Fletcher. Amherst: $U$ of Massachusetts P, 1994. Print.

McMullan, Gordon. “'Our Whole Life is Like a Play': Collaboration and the Problem of Editing." Textus 9 (1996): 437-59. Print.

McMullan, Gordon. Shakespeare and the Idea of Late Writing: Authorship in the Proximity of Death. Cambridge: Cambridge UP, 2007. Print.

Mehl, Dieter. The Elizabethan Dumb Show: The History of a Dramatic Convention. London: Methuen \& Co., 1965. Print.

Mehl, Dieter. "The London Prodigal as Jacobean City Comedy." Plotting Early Modern London: New Essays on Jacobean City Comedy. Eds. Dieter Mehl, Angela Stock and Anne-Julia Zwierlein. Aldershot and Bulington: Ashgate, 2004. 165-76. Print. Studies in Performance and Early Modern Drama. 
Melchiori, Giorgio. “What Did Shakespeare Write?” Textus 9 (1996): 339-56. Print.

Merriam, Thomas. "Marlowe's Hand in Edward III." Literary and Linguistic Computing 8.2 (1993): 59-72. Print.

Merriam, Thomas. "Heterogeneous Authorship in Early Shakespeare and the Problem of Henry V." Literary and Linguistic Computing 13.1 (1998): 15-28. Print.

Merriam, Thomas. "Marlowe's Hand in Edward III Revisited." Literary and Linguistic Computing 11.1 (1996): 19-22. Print.

Merriam, Thomas. "Linguistic Computing in the Shadow of Postmodernism." Literary and Linguistic Computing 17.2 (2002): 181-92. Print.

Merriam, Thomas. "Marlowe versus Kyd as Author of Edward III I.i, III and V". Notes and Queries 56.4 (2009): 549-51. Print.

Merriam, Thomas, and Robert A.J. Matthews. "Neural Computation in Stylometry II: An Application to the Works of Shakespeare and Marlowe." Literary and Linguistic Computing 9.1 (1994): 1-6. Print.

Metz, G. Harold, ed. Sources of Four Plays Ascribed to Shakespeare. Columbia: U of Missouri Press, 1989. Print.

Metz, G. Harold. " 'Voice and credyt': The Scholars and Sir Thomas More". Howard-Hill 11-44.

Metzger, Bruce M., ed. The Apocrypha of the Old Testament: Revised Standard Version. New York: Oxford UP, 1965. Print.

Mincoff, Marco. "The Faithful Shepherdess: A Fletcherian Experiment." Renaissance Drama 9 (1966): 163-77. Print. 
Moore, Jonathan. "Author! Author!" The Revenger's Tragedy. Theatre Programme. Manchester, 2008. Print.

Moorman, F. W. “Review.” Modern Language Review 5.1 (1910): 119-20. Print.

Mowat, Barbara A. "Constructing the Author". Parker and Zitner 93-110.

Mowat, Barbara A. "'What's in a Name?' Tragicomedy, Romance, or Late Comedy." Dutton and Howard 129-49.

Muir, Kenneth. "A Reconsideration of Edward III." Shakespeare Survey 6 (1953): 39-48. Print.

Muir, Kenneth. Shakespeare as Collaborator. London: Methuen, 1960. Print.

Munro, Lucy. Children of the Queen's Revels: A Jacobean Theatre Repertory. Cambridge: Cambridge UP, 2005. Print.

Murphy, Andrew. Shakespeare in Print: A History and Chronology of Shakespeare Publishing. Cambridge. Cambridge UP, 2003. Print.

Murphy, Andrew, ed. A Concise Companion to Shakespeare and the Text. Oxford and Malden: Blackwell, 2007. Print.

“Natural, adj." Def. 15. The Oxford English Dictionary. Online version. Oxford UP, June 2011. Web. 25 July 2011.

Nightingale, Benedict. "The plays what they all wrote." The Times. The Times, 10 April 2002. Web. 25 July 2011.

Nightingale, Benedict. "A classic of uncertain provenance." Rev. of Edward III, dir. Anthony Clark. Times, 26 April 2002. Web. 25 July 2011. 
Orgel, Stephen. "What is a Text?" Research Opportunities in Renaissance Drama 24 (1981): 3-6. Print.

Orgel, Stephen. The Authentic Shakespeare and Other Problems of the Early Modern Stage. New York and London: Routledge, 2002. Print.

Orgel, Stephen. "The Desire and Pursuit of the Whole." Shakespeare Quarterly 58.3 (2007): 290-310. Print.

Orlin, Lena Cowen. "Man's House as His Castle in Arden of Faversham." Medieval and Renaissance Drama in England 2 (1985): 57-89. Print.

Ousby, lan, and Heather Dubrow Ousby. "Art and Language in Arden of Faversham." Durham University Journal 68 (New Series 37) (1975-76): 47-54. Print.

Palmer, Philip. "Edmond Ironside and the Question of Shakespearean Authorship." Craig and Kinney 100-15.

Parker, R.B. and S.P. Zitner, eds. Elizabethan Theater: Essays in Honor of S. Schoenbaum. Newark: U of Delaware P, 1996. Print.

Parnell, J.T. "Introduction." Downie and Parnell 1-12.

Patterson, Annabel. "All is True: Negotiating the Past in Henry VIII." Parker and Zitner 147-66.

Paulin, Roger. Ludwig Tieck: A Literary Biography. Oxford: Clarendon Press, 1985. Print.

Petersen, Lene B. Shakespeare's Errant Texts: Textual Form and Linguistic Style in Shakespearean "Bad" Quartos and Co-authored Plays. Cambridge and New York: Cambridge UP, 2010. Print.

Pollard, Alfred W. Shakespeare Folios and Quartos. London: Methuen, 1909. Print. 
Pollard, A.W., ed. Shakespeare's Hand in the Play of Sir Thomas More. Cambridge: Cambridge UP, 1923. Print. Shakespeare Problems.

Pope, Alexander. The Poems of Alexander Pope Volume III: The Dunciad (1728) \& The Dunciad Variorum (1729). Ed. Valerie Rumbold. Harlow: Pearson Education, 2007. Print.

Pope, Elizabeth Marie. "The Renaissance Background of Measure for Measure." Shakespeare Survey 2 (1949): 66-82. Print.

Preiss, Richard. "A Play Finally Anonymous." Brooks, Apocrypha 117-39.

Proudfoot, Richard. "The Reign of King Edward the Third (1596) and Shakespeare." Proceedings of the British Academy 71 (1985): 159-85. Print.

Proudfoot, Richard. "Shakespeare's Most Neglected Play." Maguire and Berger 149-57.

Proudfoot, Richard. "Canon." Shakespeare: Text, Stage and Canon. London: The Arden Shakespeare, 2001. 61-96. Print.

Proudfoot, Richard. "'Modernising' the Printed Play-Text in Jacobean London: Some Early Reprints of Mucedorus." "A Certain Text": Close Readings and Textual Studies on Shakespeare and Others. Eds. Linda Anderson and Janis Lull. Newark: U of Delaware P, 2002. 18-28. Print.

Proudfoot, Richard. "Is There, and Should There Be, a Shakespeare Apocrypha?" In The Footsteps of William Shakespeare. Ed. Christa Jansohn. Münster: Lit, 2005. 4971. Print. Studien zur englischen Literatur 20.

Proudfoot, Richard. “A Julio for Cardenio.” 2011. TS. 
Pujante, Luis A. "Double Falsehood and the Verbal Parallels with Shelton's Don Quixote." Shakespeare Survey 51 (1998): 95-105. Print.

Purcell, Stephen. Popular Shakespeare: Simulation and Subversion on the Modern Stage. Basingstoke: Palgrave Macmillan, 2009. Print. Palgrave Shakespeare Studies.

Rabkin, Norman. "Problems in the Study of Collaboration." Research Opportunities in Renaissance Drama 19 (1976): 7-13. Print.

Raddadi, Mongi. Davenant's Adaptations of Shakespeare. Uppsala: Almqvist and Wiksell, 1979. Print.

Reynolds, George F. "Mucedorus, Most Popular Elizabethan Play?" Studies in the English Renaissance Drama. Eds. Josephine W. Bennett, Oscar Cargill and Vernon Hall Jr. London: Peter Owen and Vision Press, 1961. 248-68. Print.

Ribner, Irving. The English History Play in the Age of Shakespeare. 1957. Revised edition. London: Methuen \& Co., 1965. Print.

Robertson, John M. Did Shakespeare Write "Titus Andronicus"?: A Study in Elizabethan Literature. London: Watts and Co., 1905. Print.

Robinson, Ian. "The Case for Shakespeare as Author." M. Egan 262-78.

Rosenbaum, Ron. The Shakespeare Wars: Clashing Scholars, Public Fiascoes, Palace Coups. New York: Random House, 2006. Print.

Rosenbaum, Ron. "The Double Falsehood of Double Falsehood." Slate. The Spectator. 13 May 2010. Web. 17 August 2011.

Ross, Trevor. The Making of the English Literary Canon from the Middle Ages to the Late Eighteenth Century. Montreal and Kingston: McGill-Queen's UP, 1998. Print. 
Royal Shakespeare Company. Arden of Faversham. Theatre programme. Stratford-uponAvon, 1982. Print.

Royal Shakespeare Company. Edward III. Theatre Programme. Stratford-upon-Avon, 2002. Print.

Royal Shakespeare Company. Thomas More. Theatre Programme. Stratford-upon-Avon, 2005. Print.

Royal Shakespeare Company. The Complete Works Festival Guide. Brochure. Leicester, 2006. Print.

The RSC Shakespeare. Macmillan, 2008. Web. 25 July 2011.

Rubinstein, William D. "The Authorship Question: An Historian's Perspective." Leahy 4157.

Rudman, Joseph. "The State of Authorship Attribution Studies: Some Problems and Solutions." Computers and the Humanities 31.4 (1997/8): 351-65. Print.

Rutter, Carol Chillington. "Watching Ourselves Watching Shakespeare - Or - How Am I Supposed to Look?" Shakespeare Bulletin 25.4 (2007): 47-68. Project Muse. Web. 10 August 2011.

Rutter, Tom. "Introduction: The Repertory-Based Approach." Early Theatre 13.2 (2010): 12132. Print.

Sabor, Peter, and Paul Yachnin, eds. Shakespeare and the Eighteenth Century. Aldershot and Burlington: Ashgate, 2008. Print.

Sams, Eric. The Real Shakespeare: Retrieving the Early Years, 1564-1594. New Haven and London: Yale UP, 1995. Print. 
Sauer, Thomas G. A.W. Schlegel's Shakespearean Criticism in England, 1811-1846. Bonn: Bouvier Verlag Herbert Grundmann, 1981. Print.

Scherer, Abigail. “Mucedorus's Wild Man: Disorderly Acts on the Early Modern Stage.” Renaissance Papers 1999. Eds. T.H. Howard-Hill and Philip Rollinson. Rochester: Camden House, 1999. 55-65. Print.

Schneider Jr, Ben Ross. Index to the London Stage 1660-1800. Carbondale: Southern Illinois UP, 1979. Print.

Schoenbaum, S. Shakespeare's Lives. 1970. New edition. Oxford: Clarendon Press, 1991. Print.

Schoenbaum, S. Internal Evidence and Elizabethan Dramatic Authorship: An Essay in Literary History and Method. Evanston: Northwestern UP, 1966. Print.

“Shakespeare's Lost Play Cardenio." Warehouse Theatre. N.p. n.d. Web. 25 July 2011.

Shapiro, James. Contested Will: Who Wrote Shakespeare? New York: Simon and Schuster, 2010. Print.

Shaw, Deborah. "The Complete Works Festival." Royal Shakespeare Company Open Day. Stratford-upon-Avon. 29 April 2007. Panel Discussion.

Shaw, Bernard. Three Plays for Puritans. Ed. Dan H. Laurence. London: Penguin, 1946. Print.

Sherman, William H. "From the Editor: All the Workes." Shakespeare Quarterly 58.3 (2007): 285-89. Print.

Sherman, William H. Used Books: Marking Readers in Renaissance England. Philadelphia: U of Pennsylvania P, 2008. Print. 
Shirley, William. Edward the Black Prince; or, The battle of poictiers: An historical tragedy. Attempted after the manner of Shakespear. As it is acted at the Theatre-Royal in Drury-Lane, by His Majesty's servants. London, 1750. Eighteenth Century Collections Online. Web. 25 July 2011.

Simpson, Richard. "Are There Any Extant MSS in Shakespeare's Handwriting?" Notes and Queries 183 (1871): 1-3. Print.

Simpson, R. "On Some Plays Attributed to Shakespeare." The New Shakspere Society's Transactions, 1875-6. London: Trubner \& Co., 1876. 155-80. Print.

Simpson, R. The School of Shakespeare. 2 vols. London: Chatto \& Windus, 1878. Print.

Slater, Eliot. The Problem of the Reign of King Edward III: A Statistical Approach. Cambridge and New York: Cambridge UP, 1988. Print. New Cambridge Shakespeare Studies and Supplementary Texts.

Smith, Emma. "Studying Shakespeare and His Contemporaries." Talking Shakespeare: Shakespeare into the Millennium. Eds. Deborah Cartmell and Michael Scott. Basingstoke and New York: Palgrave, 2001. 55-69. Print.

Smith, Emma. "'Such Readers we Wish Him': Reading the Shakespeare First Folio." London Shakespeare Seminar, Institute of English Studies. 31 January 2011. Lecture.

Smith, M.W.A. "The Authorship of The Raigne of King Edward the Third." Literary and Linguistic Computing 6 (1991): 166-74. Print.

Smith, M.W.A. "Edmund Ironside." Notes and Queries. 40.2 (1993): 202-05. Print. 
Smith, Peter J., and Janice Valls-Russell, with Kath Bradley, eds. The Royal Shakespeare Company Complete Works Festival 2006-07, Stratford-upon-Avon. Spec. issue of Cahiers Élisabéthains (2007). Print.

Smout, Clare. "Actor, Poet, Playwright, Sharer... Rival? Shakespeare and Heywood, 1603-4." Early Theatre 13.2 (2010): 175-89. Print.

Spedding, James. "Shakespeare's Handwriting." Notes and Queries 247 (1872): 227-28. Print.

Spencer, T.J.B. "Shakespeare v. The Rest: The Old Controversy." Shakespeare Survey 14 (1961): 76-89. Print.

Stallybrass, Peter, and Roger Chartier. "Reading and Authorship: The Circulation of Shakespeare 1590-1619." Murphy, Concise Companion 35-56.

Stern, Tiffany. Rehearsal from Shakespeare to Sheridan. Oxford: Clarendon Press, 2000. Print.

Stern, Tiffany. "'The Forgery of some Modern Author'?: Theobald's Shakespeare and Cardenio's Double Falsehood." Shakespeare Quarterly. Forthcoming. TS.

Stevenson, Warren. Shakespeare's Additions to Thomas Kyd's The Spanish Tragedy: A Fresh Look at the Evidence Regarding the 1602 Additions. Lewiston, Queenston, and Lampeter: Mellen, 2008. Print.

Stodder, Joseph H. "Review: Three Apocryphal Plays in Los Angeles." Shakespeare Quarterly 38.2 (1987): 243-48. Print.

Stodder, Joseph H. "Review: Apocryphal Plays in Los Angeles: Continued." Shakespeare Quarterly 39.2 (1988): 232-38. Print. 
Stodder, Joseph H. "Mucedorus and The Birth of Merlin at the Los Angeles Globe." Shakespeare Quarterly 41.3 (1990): 368-72. Print.

Swift, Jonathan. Miscellanies in prose and verse. The first volume. London, 1728. Eighteenth Century Collections Online. Web. 25 July 2011.

Sykes, H. Dugdale. Sidelights on Shakespeare. Stratford-upon-Avon: Shakespeare Head Press, 1919. Print.

Taylor, Gary. Reinventing Shakespeare: A Cultural History from the Restoration to the Present. New York: Weidenfeld and Nicolson, 1989. Print.

Taylor, Gary. "The Date and Auspices of the Additions to Sir Thomas More." Howard-Hill 101-29.

Taylor, Gary. "Thomas Middleton, The Spanish Gypsy, and Collaborative Authorship." Boyd 241-73.

Taylor, Gary. “Making Meaning Marketing Shakespeare 1623.” Holland and Orgel 55-72.

Taylor, Gary. “Middleton: Our Other Shakespeare.” Cottesloe Theatre, London. 3 June 2008. Lecture.

Taylor, Gary, and John Lavagnino, eds. Thomas Middleton and Early Modern Textual Culture: A Companion to the Collected Works. Oxford: Clarendon Press, 2007. Print.

Taylor, Gary, and Michael Warren, eds. The Division of the Kingdoms: Shakespeare's Two Versions of King Lear. Oxford: Clarendon Press, 1983. Print. 
Teetgen, Alexander. Shakespeare's "King Edward the Third," Absurdly Called, and Scandalously Treated as, a "Doubtful Play:" An Indignation Pamphlet. London, 1875. Print.

Theobald, Lewis. Shakespeare restored; or, a specimen of the many errors, as well committed, as unamended, by Mr. Pope in his late edition of this poet. Designed Not only to correct the said Edition, but to restore the True Reading of Shakespeare in all the Editions ever yet publish'd. London, 1726. Eighteenth Century Collections Online. Web. 25 July 2011.

Theobald, Lewis. Double falshood; or, the distrest lovers. A play, as it is acted at the Theatre-Royal in Drury-Lane. Written originally by W. Shakespeare; and now revised and adapted to the stage by Mr. Theobald, the Author of Shakespeare Restor'd. London, 1728. Eighteenth Century Collections Online. Web. 25 July 2011.

Theobald, Lewis. Double falshood; or, the distrest lovers. A play, as it is acted at the Theatre-Royal in Drury-Lane. Written originally by W. Shakespeare; and now revised and adapted to the stage by Mr. Theobald, the Author of Shakespeare Restor'd. $2^{\text {nd }}$ edition. London, 1728. Eighteenth Century Collections Online. Web. 25 July 2011.

Thompson, Sir Edward Maunde. Shakespeare's Handwriting. Oxford: Clarendon Press, 1916. Print.

Thompson, E. Maunde. "The Handwriting of the Three Pages Attributed to Shakespeare Compared with his Signatures." Pollard 57-112.

Thornberry, Richard T. "A Seventeenth-Century Revival of Mucedorus in London before 1610." Shakespeare Quarterly 28.3 (1977): 362-64. Print. 
Tillyard, E.M.W. Shakespeare's History Plays. 1944. London: Chatto \& Windus, 1994. Print.

Tough Theatre. A Yorkshire Tragedy: Not so New as Lamentable and True. Theatre Programme. London, 2010. Print.

Vickers, Brian. Shakespeare, Co-Author: A Historical Study of Five Collaborative Plays. Oxford and New York: Oxford UP, 2002. Print.

Vickers, Brian. "Are All of Them By Shakespeare?" Times Literary Supplement. Times Literary Supplement, 9 August 2006. Web. 25 July 2011.

Vickers, Brian. "Incomplete Shakespeare: Or, Denying Coauthorship in 1 Henry VI." Shakespeare Quarterly 58.3 (2007): 311-52. Print.

Vickers, Brian. "Thomas Kyd, Secret Sharer." Times Literary Supplement. Times Literary Supplement, 18 April 2008. Web. 25 July 2011.

Vickers, Brian. “Coauthors and Closed Minds." Shakespeare Studies 36 (2008): 101-13. Print.

Vickers, Brian. "Disintegrated: Did Thomas Middleton Really Adapt Macbeth?" Times Literary Supplement. Times Literary Supplement, 28 May 2010. Web. 25 July 2011.

Vickers, Brian. "Disintegrating Shakespeare." Times Literary Supplement. Times Literary Supplement, 25 June 2010. Web. 25 July 2011.

Vickers, Brian. "The Canon of Thomas Kyd." London Forum for Authorship Studies. School of Advanced Study, University of London. 18 July 2010. Web. 25 July 2011. 
Vickers, Brian. "Shakespeare and Authorship Studies in the Twenty-First Century." Shakespeare Quarterly 62.1 (2011): 106-42. Print.

Walker, Alice. "Edward Capell and his Edition of Shakespeare." Studies in Shakespeare: British Academy Lectures. Ed. Peter Alexander. London: Oxford UP, 1964. 13248. Print.

Watt, Timothy Irish. "The Authorship of the Hand-D Addition to The Book of Sir Thomas More." Craig and Kinney 134-61.

Watt, Timothy Irish. "The Authorship of The Raigne of Edward the third." Craig and Kinney 116-33.

Weimann, Robert. Author's Pen and Actor's Voice: Playing and Writing in Shakespeare's Theatre. Cambridge and New York: Cambridge UP, 2000. Print.

Wells, Stanley. "Multiple Texts and the Oxford Shakespeare." Textus 9 (1996): 375-92. Print.

Wells, Stanley, and Gary Taylor. "The Oxford Shakespeare Re-viewed by the General Editors." Analytical \& Enumerative Bibliography new series 4 (1990): 6-20. Print.

Wells, Stanley, and Gary Taylor, with John Jowett and William Montgomery. William Shakespeare: A Textual Companion. Oxford: Clarendon Press, 1987. Print.

Werstine, Paul. “McKerrow's 'Suggestion' and Twentieth-Century Shakespeare Textual Criticism." Renaissance Drama new series 19 (1988): 149-73. Print.

Werstine, Paul. "Narratives About Printed Shakespeare Texts: 'Foul Papers' and 'Bad' Quartos." Shakespeare Quarterly 41.1 (1990): 65-86. Print. 
Werstine, Paul. "Editing after the End of Editing." Shakespeare Studies 24 (1996): 47-54. Print.

Werstine, Paul. “A Century of 'Bad' Quartos." Shakespeare Quarterly 50.3 (1999): 31033. Print.

Werstine, Paul. "Shakespeare, More or Less: A.W. Pollard and Twentieth-Century Shakespeare Editing." Florilegium 16 (1999): 125-45. Print.

West, Anthony James. "The Life of the First Folio in the Seventeenth and Eighteenth Centuries." Murphy, Concise Companion 71-90.

Westley, Richard. "Computing Error: Reassessing Austin's Study of Groatsworth of Wit." Literary and Linguistic Computing 21.3 (2006): 363-78. Print.

Wiggins, Martin. Shakespeare and the Drama of his Time. Oxford and New York: Oxford UP, 2000. Print. Oxford Shakespeare Topics.

Wiles, David. Shakespeare's Clown: Actor and Text in the Elizabethan Playhouse. Cambridge and New York: Cambridge UP, 1987. Print.

Williams, Moelwyn I., ed. A Directory of Rare Books and Special Collections in the United Kingdom and the Republic of Ireland. London: Library Association Publishing, 1985. Print.

Wilson, J. Dover. "Bibliographical Links Between the Three Pages and the Good Quartos." Pollard 113-41.

Worthen, William B. Shakespeare and the Authority of Performance. Cambridge and New York: Cambridge UP, 1997. Print. 
Yachnin, Paul. "Shakespeare's Problem Plays and the Drama of His Time: Troilus and Cressida, All's Well That Ends Well, Measure for Measure." Dutton and Howard 46-68.

\section{(d) Productions (alphabetical by title)}

Arden of Faversham. Dir. Terry Hands. Theatr Clwyd Cymru. Emlyn Williams Theatre, Clwyd. 20 February 2010. Performance.

Arden of Faversham. Dir. Peter Darney. Em-Lou Productions. Rose Theatre Bankside, London. 22 June 2010. Performance.

Cardenio. Dir. Gregory Doran. Royal Shakespeare Company. Swan Theatre, Stratfordupon-Avon. 23 April 2011. Performance.

Cardenio. Dir. Jonathan Busby. Aporia Theatre. The Dell, Stratford-upon-Avon. 31 July 2011. Performance.

Cymbeline. Dir. Emma Rice. Kneehigh. Swan Theatre, Stratford-upon-Avon. 20 September 2006. Performance.

Double Falsehood. Dir. Sophie Gilpin. University of Warwick Shakespeare Society. Warwick Arts Centre, Coventry. 27 June 2010. Performance.

Double Falsehood. Dir. Barrie Addenbrooke. KDC Theatre. Union Theatre, London. 17 August 2010. Performance.

Double Falsehood. Dir. Michael Fentiman. Nottingham Playhouse, Nottingham. 11 October 2010. Performance. 
Henry V. Dir. Pippo Delbono. Compagnia Pippo Delbono. Swan Theatre, Stratford-uponAvon. 3 February 2007. Performance.

Henry VI Part One. Dir. Bronagh Lagan. Rose Theatre Bankside, London. 15 May 2011. Performance.

Macbeth (Work-In-Progress). Dir. Grzegorz Bral. Teatr Piesn Kozla. Swan Theatre, Stratford-upon-Avon. 21 February 2007. Performance.

Nothing Like the Sun: The Sonnet Project. Curated by Gavin Bryars. Royal Shakespeare Company/ Opera North. Courtyard Theatre, Stratford-upon-Avon. 24 February 2007. Performance.

Othello. Dir. Luk Perceval. Münchner Kammerspiele. Royal Shaksespeare Theatre, Stratford-upon-Avon. 29 April 2006. Performance.

The Phoenix and the Turtle. Dir. Deborah Shaw. Royal Shakespeare Company. Holy Trinity Church, Stratford-upon-Avon. 5 November 2006. Performance.

The Revenger's Tragedy. Dir. Melly Still. National Theatre. Olivier, London. 3 June 2008. Performance.

The Revenger's Tragedy. Dir. Jonathan Moore. Royal Exchange, Manchester. 11 June 2008. Performance.

Soliman and Perseda. Dir. Sophie Hickman. Trifle Productions. Rose Theatre Bankside, London. 28 April 2010. Performance.

The Spanish Tragedy. Dir. Adrian Brown. Planet Theatre Productions. Rose Theatre Bankside, London. 10 September 2010. Performance. 
Thomas More. Dir. Robert Delamere. Royal Shakespeare Company. Swan Theatre, Stratford-upon-Avon. 5 October 2005. Performance.

The Two Noble Kinsmen and A Knight's Tale. Dir. William Oldroyd and Gregory Doran. Royal Shakespeare Company. Swan Theatre, Stratford-upon-Avon. 21 May 2006. Performance.

Women Beware Women. Dir. Marianne Elliott. National Theatre. Olivier, London. 8 June 2010. Performance.

A Yorkshire Tragedy: Not so New as Lamentable and True. Dir. Andy Brunskill. Tough Theatre. White Bear Theatre Pub, London. 10 January 2010. Performance. 